\title{
Cultura Laica
}

\section{Nuevos retos y perspectivas de la laicidad}

Pauline Capdevielle COORDINADORA

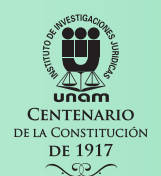


NUEVOS RETOS Y PERSPECTIVAS DE LA LAICIDAD 


\section{INSTITUTO DE INVESTIGACIONES JURÍDICAS}

Colecaión Gultura Laica, Núm. I

\section{COORDINACIÓN EDITORIAL}

Lic. Raúl Márquez Romero

Secretario Técnico

Lic. Wendy Vanesa Rocha Cacho

Jefa del Departamento de Publicaciones

Iván Escoto Mora

Cuidado de la edición

y formación en computadora

Mauricio Ortega Garduño

Elaboración de portada 


\title{
NUEVOS RETOS Y PERSPECTIVAS DE LA LAICIDAD
}

\author{
Pauline Capdevielle
}

Coordinadora
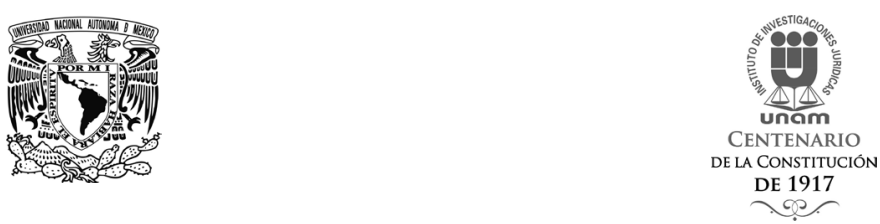

UNIVERSIDAD NAGIONAL AUTÓNOMA DE MÉXICO INSTITUTO DE INVESTIGACIONES JURÍDICAS 
Primera edición: 5 de diciembre de 2017

DR (C) 2017. Universidad Nacional Autónoma de México

INSTITUTO DE INVESTIGACIONES JURÍDICAS

Circuito Maestro Mario de la Cueva s/n

Ciudad de la Investigación en Humanidades

Ciudad Universitaria, 04510 Ciudad de México

Impreso y hecho en México

ISBN 978-607-02-9741-0 


\title{
GONTENIDO
}

Presentación ......................... IX Pauline Gapdevielle

Diana Alejandra AviLA Pérez

Estudio introductorio. La laicidad del Estado mexicano . . . . . . . . . 1 Olga SÁnchez Cordero

Preámbulo. Miedo y laicidad. . . . . . . . . . . . . . 23

René GonZÁLEz DE LA VEGA

\author{
CAPÍtULlO PRIMERO \\ REFLEXIONES EN TORNO A LA SECULARIZACIÓN \\ Y PLURALISMO
}

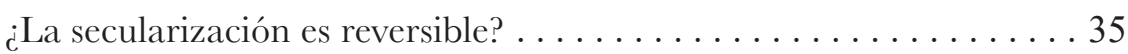

Liz Hamui SutTon

Modelos de Estado secular/laico: laicización en Turquía entre 1923

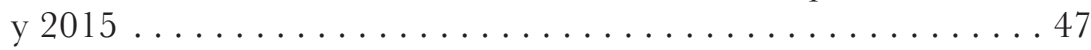

Bahattin AKsIT

Laicidad, secularización y pluralismo. Reflexiones desde el caso

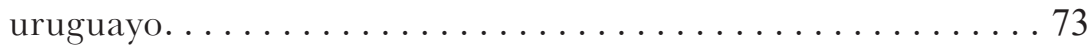

Néstor DA Costa 


\title{
CapÍtulo Segundo \\ LAICIDAD Y LIBERTADES LAICAS
}

Religión, secularización y matrimonio entre personas del mismo sexo . . 89 Fernando ARLETTAZ

Laicidad francesa y los derechos de las mujeres: ¿existe alguna relación entre el secularismo francés y la igualdad para las mujeres? . . . . . 123 Blandine GHELINI-PONT

Derechos de la niñez: educación laica y vida en familia. . . . . . . . . 143 Rodolfo VÁzQUEz

\author{
Gapítulo TERCERO \\ LAICIDAD Y POLÍTICAS PÚBLICAS
}

Las políticas educativas en Brasil: entre el confesionalismo y la laicidad . . 163 Luiz Antônio GuNHA

Laicidad y políticas públicas en Argentina: derecho, religión y cultura

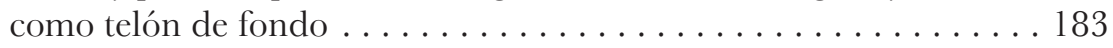
Juan Cruz ESQUIVEL

Laicidad y políticas públicas en la Europa actual: el rol estratégico de la esfera local . . . . . . . . . . . . . . . . . . 203 Mar GRIERA

Conclusiones. Laicidad y cultura laica . . . . . . . . . . . 231 Jean BAUBÉROT 


\section{PRESENTACIÓN}

Desde el año de su creación en 2012, la Cátedra Extraordinaria "Benito Juárez" de la UNAM y del Instituto Iberoamericano de Derecho Constitucional se ha dado a la tarea de impulsar una reflexión crítica en torno a la laicidad y a las interacciones entre Estados, instituciones religiosas, sociedades y personas. En este contexto se llevó a cabo la "Semana Internacional de la Cultura Laica. Nuevos Retos y Perspectivas" en el Instituto de Investigaciones Jurídicas de la UNAM y en El Colegio de México, los días 23, 24 y 25 de marzo de 2015. Para su segunda edición, este evento convocó a un conjunto de expertos provenientes de diferentes culturas políticas y jurídicas para reflexionar y debatir sobre los nuevos desafíos y perspectivas de la laicidad en el siglo XXI.

Las intervenciones de los especialistas estuvieron a la altura de la propuesta: más allá de la calidad de cada una de las exposiciones, se desarrolló una reflexión fructífera en condiciones de interdisciplinariedad, la cual resulta indispensable para llegar a un entendimiento cabal del complejo andamiaje político, jurídico, social, histórico y cultural que implica la convivencia en el Estado laico.

La presente obra es el resultado de tres días intensos de debate, durante los cuales se hizo patente la creciente preocupación de la academia en torno al tema de las relaciones entre lo político y lo religioso, lo público y lo privado. Hace apenas unas décadas esta discusión habría sin duda parecido obsoleta, frente a la convicción generalizada según la cual la historia arrastraba a las sociedades hacia una pérdida de lo religioso, en el mejor de los casos replegado a la esfera de lo íntimo. La actualidad no podría ser más alejada de esta predicción. En muchas partes del mundo, lo religioso se ha vuelto a manifestar creando desequilibrios en los consensos anteriormente alcanzados, y planteando nuevos desafios tanto a nivel nacional, internacional como local.

Frente a este fenómeno, los trabajos aquí reunidos hacen hincapié en la necesidad de reflexionar de manera crítica sobre el paradigma de la secularización y sobre la modernidad, ambos estrechamente vinculados con la laicidad. Más que conceptos y paradigmas comprobables, son usa- 
Esta obra forma parte del acervo de la Biblioteca Jurídica Virtual del Instituto de Investigaciones Jurídicas de la UNAM

dos como herramientas analíticas que permiten sentar las bases para el análisis de la diversidad, tanto entre diferentes modelos de Estados como dentro de ellos.

Asimismo, los textos presentados permiten definir la "laicidad" como un concepto atravesado por un núcleo duro de preocupaciones, y a la vez, dinámico en sus desarrollos y adaptaciones nacionales y locales. Desde la primera perspectiva, la laicidad aparece siempre como una exigencia de autonomía de lo político y de lo religioso, en aras de la defensa de la libertad e igualdad de los individuos. Sin embargo, se hace también patente que la laicidad no es un modelo predefinido, sino una estructura adaptable a un tiempo y lugar que atiende a las necesidades políticas, jurídicas, sociales, culturales e incluso económicas de cada sociedad.

Como consecuencia, el lector encontrará en los diferentes textos un esfuerzo de reconstrucción histórica que hace patentes las inercias en la aplicación de la laicidad como principio de las relaciones entre personas, Estado e instituciones religiosas. Así, desde una perspectiva sociológica, debemos atrevernos a hablar de laicidades en plural, a fin de generar mayor inclusión de los diversos panoramas, incluso cuando no exista como tal un reconocimiento formal del Estado laico a nivel jurídico. De esta manera, se observa la construcción y reconocimiento de los derechos de las personas a partir de la concepción laica, de tal suerte que su ámbito de aplicación, aunque similar o igual, no arroja el mismo resultado.

El abordaje de políticas públicas - aportación fundamental de esta obra - ilustra bien la idea anteriormente expuesta. Si bien existe un consenso en la mayoría de los ordenamientos constitucionales descritos en este libro en torno a principios, valores y derechos, la definición y ejecución de las políticas públicas muestran los diversos matices con los que la sociedad vive la laicidad, así como el grado de implementación y recepción que se tiene de esta estructura. Los programas y acciones diseñados desde arriba por los Estados en materia de laicidad visibilizan las relaciones de fuerza a distintos niveles, haciendo patentes las tensiones entre la legitimidad estatal, las dinámicas de actuación de las poblaciones y los operadores políticos y sociales a nivel local. De tal suerte, la laicidad, dentro de los mismos Estados, se desarrolla como un principio de geometría variable en sus condiciones prácticas de aplicación.

La cuestión de las políticas públicas es, sin duda, imprescindible cuando recordamos que la laicidad debe ser entendida como principio al servicio de las libertades de los seres humanos. En este sentido, la autonomía entre esfera política y religiosa postulada por ella garantiza precisamente a cada individuo el desarrollo libre de sus convicciones, así como de sus proyectos 
y planes de vida. Desde esta perspectiva, varios trabajos abordan el tema de la libertad, ya sea de religión of frente a la religión. Una primera aproximación al tema es la cuestión de las libertades de las personas que no comparten la visión religiosa históricamente arraigada en una determinada sociedad. En este caso, la laicidad estatal impide que la religión de la mayoría imponga sus pautas de moralidad a todos los individuos. Este fenómeno es particularmente visible en materia de derechos sexuales y reproductivos, o respecto de los derechos de los grupos de diversidad sexual. La laicidad del Estado exige aquí una nítida separación entre las normas religiosas que valen para los creyentes, y las normas civiles que se aplican a toda una comunidad. Otro enfoque es la igualdad de las minorías religiosas en las sociedades donde existe una religión dominante. Aquí, el eje de reflexión se desplaza de la libertad hacia la gestión de la pluralidad, en aras de permitir que todos los grupos puedan gozar de sus libertades en las mismas condiciones que los demás y que no sufran discriminación alguna. Respecto a este escenario, algunos ajustes podrán ser necesarios, para que la imparcialidad del Estado no consista en una simple abstención, sino que implique acciones positivas para restablecer las condiciones de igualdad. Inclusive las sociedades más laicas y secularizadas se han percatado de la exigencia de equidad de todos los grupos religiosos para garantizar la cohesión y paz social. Finalmente, un tercer acercamiento es posible, cuando las condiciones de neutralidad laica son tan estrictas que juegan en detrimento de las personas que consideran a la religión como parte integrante de su identidad. En este sentido, la emancipación reclamada por el ideal laico puede entrar en conflicto con las libertades religiosas reivindicadas por los propios individuos y grupos.

Ahora bien, para amenizar la lectura y subrayar los puentes entre los trabajos de los diferentes autores, hemos organizado la obra en tres capítulos: "Reflexiones en torno a la secularización y pluralismo"; "Laicidad y libertades laicas", y "Laicidad y políticas públicas". Pero antes de adentrarse en sus contenidos, dos trabajos despertarán el interés del lector. El trabajo de Olga Sánchez Cordero constituye una valiosa aportación al tema, al hacer un recorrido histórico de las relaciones entre el Estado mexicano y la Iglesia católica, insistiendo en la pugna entre conservadores y liberales respecto del proyecto de nación: para los primeros, un Estado cimentado sobre bases católicas; para los segundos, un Estado plenamente soberano, tanto a nivel institucional como económico y axiológico, con normas civiles por encima de las religiosas. A partir de esta reflexión histórica, la autora nos guía a través del marco constitucional laico mexicano actual, enriquecido e interpretado por algunos fragmentos de la jurisprudencia de la Suprema Corte mexicana, en particular respecto del 
Esta obra forma parte del acervo de la Biblioteca Jurídica Virtual del Instituto de Investigaciones Jurídicas de la UNAM

régimen "histórico" de separación, la libertad de conciencia y de religión. Reconstrucción histórica que nos permite entender la laicidad mexicana como un andamiaje político-jurídico que busca garantizar la convivencia respetuosa y pacífica de la sociedad, con base en un concepto robusto de libertad e igualdad.

Por su lado, el trabajo de René González de la Vega introduce el tema de la laicidad a partir de un enfoque original, al entenderla como un punto de vista intermedio, un especie de "Hermes conciliador" entre lo terrenal y lo divino. La laicidad, nos dice el autor, es el antídoto a un miedo político que comparten tanto "dogmáticos como anti-dogmáticos": para los primeros, el miedo reside en el desajuste entre las normas civiles y las prescripciones divinas con la consecuente perdición eterna; mientras los segundos, temen la imposición de una visión única del mundo, obstáculo al libre desarrollo de las personalidades y proyectos de vida. Desde la perspectiva del miedo, la laicidad se inserta en una tradición de pesimismo antropológico de la naturaleza humana, pero ¿cómo pensar distinto ante las atrocidades cometidas en nombre de una sola verdad? Así, este trabajo se presenta como una propuesta filosófica innovadora, lúcida y sin concesiones.

Así mismo, el primer capítulo de la obra, titulado "Reflexiones en torno a la secularización y pluralismo", reúne los trabajos de Liz Hamui, Bahattin Aksit y Néstor Da Costa. El primero consiste en una reflexión sólida y crítica en torno al concepto de secularización, modernidad, racionalidad y privatización de lo religioso, especialmente, ante las profundas transformaciones que ha conocido el mundo durante las últimas décadas. Sirve para recordarnos que el proceso de secularización y laicización no es lineal ni natural, sino que se produce en ciertos espacios y temporalidades, y que siempre es susceptible de retrocesos. Por su lado, la visión sociológica de Bahattin Aksit retoma la discusión teórica sobre la secularización, a partir de sus diferentes significados y enfoques, confrontándola con distintos modelos de relaciones Estado-Iglesias, y aterrizándola en los avatares del Estado turco desde 1923 y hasta 2015. Se trata de un texto de gran relevancia para entender las relaciones entre periferia y centro a nivel de la ciudadanía y de la creencia, herramientas de comprensión para descifrar las mutaciones políticas que vive el Estado turco en la actualidad. Néstor Da Costa, por su parte, propone una reflexión sociológica, a la vez que teórica y "aterrizada" sobre la laicidad, secularización y pluralismo, haciendo hincapié en la historia y cultura uruguaya. Es pues, sin duda, un texto fundamental para pensar la laicidad a partir de tiempos y espacios concretos, es decir, desde un posicionamiento crítico respecto de su pre- 
Esta obra forma parte del acervo de la Biblioteca Jurídica Virtual del Instituto de Investigaciones Jurídicas de la UNAM

tendido universalismo. Ilustra, además, la pluralidad de modelos relaciones Estado-Iglesias en Latinoamérica, especialmente respecto a la idea de espacio público, de política y de educación.

El segundo capítulo de esta obra reúne diferentes trabajos que se enfocan en el tema de la libertad y de la igualdad, valores claves del constitucionalismo contemporáneo. En primer lugar, el texto de Fernando Arlettaz analiza el tema del matrimonio desde la perspectiva de la laicidad y de la secularización, haciendo hincapié en las relaciones - muchas veces complejas y polémicas - entre lo político, lo jurídico y lo sexual. El caso del matrimonio igualitario es paradigmático al respecto, al ser parte, de acuerdo con el autor, de una evolución secularizadora del derecho, frente a una posición de reticencia de las Iglesias mayoritarias, las cuales siguen abogando por un matrimonio vinculado a un enfoque heterosexual y procreativo. En una línea similar que conecta a la laicidad y las libertades, el texto de Blandine Chelini-Pont ofrece una reflexión comprometida en torno al binomio laicidad e igualdad de género, apoyándose en el caso francés. Asimismo, muestra que, más allá de un simple dispositivo jurídico, la laicidad - especialmente en el marco del republicanismo francés - se presenta como un proyecto político e intelectual con gran carga axiológica, como lo ilustran los dilemas existentes en el país respecto de los signos religiosos, tal como el velo islámico y el velo integral. Para concluir este capítulo, Rodolfo Vázquez plantea de manera sólida y sugerente la cuestión de los derechos y libertades laicas desde la perspectiva de la infancia, pugnado a favor de una educación laica en aras de una protección robusta de la conciencia de las niñas, niños y adolescentes. Se trata de un trabajo orientado hacia la defensa de la familia, entendida desde una perspectiva incluyente, que busca abrir un abanico de oportunidades, a partir de lo diverso, en condiciones de igual respeto para todos los planes de vida.

El tercer capítulo, titulado "Laicidad y políticas públicas", permite visualizar los nuevos retos y problemáticas vinculados con la implementación en la vida diaria de los principios, valores y derechos defendidos por el Estado laico. A partir de la problemática de la educación laica en Brasil, Luiz Antônio Cunha aborda de manera profunda la cuestión del proceso de diversificación religiosa que experimenta el país, los nuevos arreglos institucionales que generó, y finalmente, las tensiones que surgen entre el terreno político-jurídico y su aplicación a nivel local. Asimismo, muestra cómo el ámbito educativo es clave en la disputa entre el Estado y las instituciones religiosas respecto del control de las conciencias y del espacio público, especialmente en el contexto de poblaciones marginalizadas. El atractivo trabajo de Juan Cruz Esquivel dialoga con el anterior, al problematizar tam- 
Esta obra forma parte del acervo de la Biblioteca Jurídica Virtual del Instituto de Investigaciones Jurídicas de la UNAM

bién las interacciones y tensiones entre lo nacional y lo local respecto de la aplicación de políticas públicas con sustratos laicos en la Argentina contemporánea; así, se aborda un tema imprescindible para la agenda laica: el reconocimiento y protección de los derechos sexuales y reproductivos - en particular, el tema fundamental de la educación religiosa-, y la cuestión de sus límites en sociedades donde la religión permea la cultura popular. Mar Griera finaliza este capítulo con una reflexión original sobre el protagonismo de los grupos de la sociedad civil, y especialmente las minorías religiosas en la ejecución de políticas públicas laicas en Europa. Hace hincapié en la necesidad de crear nuevos marcos de convivencia a nivel local, en los cuales todos los grupos puedan beneficiarse de sus libertades en las mismas condiciones que las confesiones dominantes. Un eje de reflexión sin duda imprescindible ante los desafíos de la radicalización religiosa que conoce Europa en la actualidad.

Finalmente, esta obra concluye con el extraordinario ensayo de síntesis de Jean Baubérot, enfocado a los significados de la cultura laica, los vínculos entre laicidad y secularización, la idea de progreso y modernidad, y los elementos que conforman el núcleo duro de la laicidad, entre ellos la exigencia de libertad como pilar de las sociedades democráticas. El gran desafío cultural de la laicidad en el siglo XXI, señala el catedrático, será repensar las relaciones entre lo político y lo religioso desde los nuevos procesos de globalización. Esperemos que esta obra, que busca subrayar la diversidad y riqueza del tema en sus múltiples dimensiones y latitudes, pueda, modestamente, colaborar a esta tarea.

\author{
Pauline CAPDEVIELLE* \\ Diana Alejandra Avila PÉREZ**
}

* Coordinadora de la Cátedra Extraordinaria "BenitoJuárez" de la UNAM sobre Laicidad.

** Becaria de la Cátedra Extraordinaria "Benito Juárez" de la UNAM sobre Laicidad. 


\title{
ESTUDIO INTRODUGTORIO. LA LAICIDAD DEL ESTADO MEXICANO
}

\begin{abstract}
Pero si el principio religioso se convierte en un poder político, y, saliendo de las vías de la convicción que les son propias, pretende ejercer sobre los ciudadanos una fuerza coercitiva, tener rentas, imponer contribuciones, gozar de un fuero exterior, y aplicar penas temporales, su degeneración es completa y, en lugar de auxiliar al Poder soberano en el orden directivo, se convierte en su rival en la parte administrativa.
\end{abstract}

José María Luis MORA

\section{LA SEPARACIÓN IGLESIA Y ESTADO EN MÉXICO}

El principio histórico de la separación del Estado y la Iglesia, previsto en los artículos 24 y 130 de la Constitución Política de los Estados Unidos Mexicanos, es el resultado de los hechos históricos acontecidos durante el siglo XIX entre liberales y conservadores, ${ }^{1}$ y el movimiento cristero de 1926-1929, ${ }^{2}$ durante los cuales la Iglesia y el Estado mexicano tuvieron profundas diferencias de índole ideológica y política que les llevaron a enfrentarse y recurrir a las armas.

Estos conflictos provocaron el rompimiento de relaciones diplomáticas con el Vaticano, mismas que permanecieron así por más de un siglo, siendo restablecidas hasta el 21 de septiembre de 1992, durante el gobierno del presidente Carlos Salinas de Gortari, con lo que se cerró este polémico capítulo de la historia del país.

1 Hale, Charles A., El liberalismo mexicano en la época de Mora (1821-1853), 8a. ed., México, Siglo XXI, 1987, pp. 14-73.

2 Meyer, Jean, La cristiada, 4a. ed., México, Siglo XXI, 1976, t. 2: El conflicto entre la Iglesia y el Estado. En esta obra el autor estudia los avatares del conflicto religioso durante el gobierno de Plutarco Elías Calles y del llamado periodo del "maximato". 
En la primera mitad del siglo XIX las divergencias que le dieron vida a México se adaptaron al tiempo, así, en unos momentos eran liberales contra conservadores, en otros, federalistas y centralistas, republicanos y monárquicos, criollos y peninsulares, pugnas que eran en esencia iguales.

Con el Plan de Iguala el país conquistó la independencia, esto es, la separación de España; sin embargo el esfuerzo de unos por conservar el legado de Iguala, y el de otros por destruirlo, empeñó al país en una lucha de un tercio de siglo.

En los inicios del México independiente la influencia del clero en la sociedad mexicana era extraordinaria debido a su gran poderío económico. Ningún otro grupo, ninguna otra clase social disfrutaba a este respecto de semejante preponderancia social y política, mayor inclusive a su poder económico. "Los miembros del clero no estaban aislados, convivían con el resto de la población y en la difusión y dispersión de su organización en todo el país, en su cercanía a los núcleos de población, se encontraba una causa de la amplitud de su poder social". ${ }^{3}$

En el campo esta influencia se ejercía activamente gracias al sistema de la aparcería, utilizada por el clero en sus tierras, y también por los préstamos de dinero que otorgaba a los cultivadores. En las ciudades, la influencia del clero no era menos grande: el arriendo de sus numerosas propiedades le permitía controlar directamente a un gran número de personas, al tiempo que el monopolio del comercio de dinero aumentaba la masa de sus deudores, incluso entre las clases más pobres de la sociedad urbana.

Pero la influencia social del clero provenía también de su ascendiente moral sobre un pueblo que permanecía profundamente católico. En este dominio, el clero era "todopoderoso" y defendía celosamente la autoridad espiritual que ejercía sobre la gran mayoría de la población.

De allí provenía la animadversión del clero mexicano hacia los extranjeros, los cuales, a sus ojos, representaban la introducción al país de ideas opuestas al espíritu católico; y ello explica también la vigilancia extrema que ejercía mediante numerosas corporaciones religiosas diseminadas por todo el país.

Desde el punto de vista económico, hay que recordar que la guerra de Independencia (1810-1821) provocó un auténtico desastre financiero para el tesoro público de la joven nación mexicana. A partir de 1824, en el país comenzó a percibirse la escasez de capitales, la cual se agravó todavía más por el hecho de que la gran mayoría de los fondos particulares buscaban

3 Reyes Heroles, Jesús, El liberalismo mexicano, 2a. ed., México, Fondo de Cultura Económica, 1974, t. II, p. 92. 
provecho más elevados y más seguros en la especulación y el agiotismo. Estas operaciones financieras fueron nefastas para toda la economía del país. No sólo habían hecho de los gobiernos mexicanos su víctima tradicional, sino que también alejaban a los capitales de la industria y de la agricultura, lo mismo cabría decir de la especulación financiera, que aprovechaba igualmente la pobreza crónica de los gobiernos.

El principal agiotista del país era el clero, cuyas enormes riquezas le permitían prestar a tasas inferiores que las que exigían los otros capitalistas mexicanos. Estos, en efecto, rehusaban suscribir préstamos cuya tasa fuese inferior al $12 \%, 18 \%$ o $24 \%$; la tasa legal del $6 \%$ no se aplicaba sino a los préstamos hipotecarios.

Ahora bien, el clero era el único capitalista que podía otorgar créditos a tasas inferiores a la legal. Ello le daba el monopolio casi absoluto del agiotismo, permitiéndole también ejercer una influencia directa sobre el gran número de sus deudores.

Si el agiotismo era practicado casi exclusivamente por el clero y el Monte de Piedad, la especulación financiera con los gobiernos mexicanos había llegado a ser monopolio de los comerciantes extranjeros y de algunos capitalistas mexicanos. Dicha especulación asumía diversas formas, pero el procedimiento más ventajoso consistía en prestar dinero al gobierno mexicano, obligándolo a aceptar una rebaja sobre los derechos de aduana.

Estos préstamos, que no eran nunca completamente pagados, constituían una buena parte de la deuda exterior de México. Todo ello explica por qué tanto los capitalistas mexicanos como los extranjeros tenían siempre interés en mantener al país en una anarquía que les resultaba sumamente productiva. El problema de los capitales se debatía así en un círculo vicioso difícil de romper.

Por tanto, México no podía contar con los capitales privados, ya fuesen extranjeros o nacionales. Con mayor razón aún, no podía confiar tampoco en los fondos del tesoro público, puesto que todos los gobiernos que se habían sucedido desde la consumación de la Independencia habían padecido siempre la misma escasez financiera. Además, éstos no sólo habían sido incapaces de hacer la menor inversión económica, sino incluso llegaban al poder en tan graves condiciones financieras que su existencia se encontraba en todo momento amenazada por la falta de recursos.

Las grandes riquezas del clero no constituían una fortuna de la que pudiesen disfrutar todos sus miembros, sino al contrario, era solamente una minoría la que monopolizaba el disfrute de los grandes ingresos eclesiásticos, creando así una división profunda en los rangos de la Iglesia mexicana, en la cual no cesaban de manifestarse graves disputas interiores. 
Esta obra forma parte del acervo de la Biblioteca Jurídica Virtual del Instituto de Investigaciones Jurídicas de la UNAM

Ocurría lo mismo en los conventos y monasterios en donde se encontraba también un igual contraste entre la situación personal de las diferentes categorías jerárquicas.

Y, sin embargo, la gran influencia del clero sobre la masa de la población la aseguraba la presencia de los monjes, cuya actividad se extendía a todas las capas de la sociedad. ${ }^{4}$ Los abusos y privilegios introducidos en los conventos por los superiores y mayordomos preocuparon a tal grado a las autoridades eclesiásticas de México y del Vaticano, que en 1855 un delegado de la Santa Sede llegó a México con la misión específica de asegurar la reforma interior de las corporaciones religiosas.

Por otra parte, la corrupción del bajo clero llegó a ser casi proverbial ante los ojos extranjeros de la época. Más que la ociosidad y la voracidad del alto clero, estos testigos subrayan frecuentemente la corrupción y la mundanidad del bajo clero.

Es preciso recordar, a este respecto, que el clero gozaba en sus actividades de la protección que le aseguraba su fuero. Este estatuto privilegiado lo ponía al abrigo de toda intervención civil, lo que estimulaba grandemente su irresponsabilidad eclesiástica.

Por su parte, los liberales luchaban por una reforma económica y política que limitara la fuerza de los grupos que se mantenían al margen de la vida constitucional; se oponían a la existencia de las pequeñas sociedades dentro de la general, con pretensiones de independencia respecto de ella, y a que los poderes sociales destinados al ejercicio de la soberanía se hiciesen derivar de los cuerpos y clases existentes, sino, por el contrario, buscaban que los cuerpos creados o por crear derivasen su existencia y atribuciones del poder soberano preexistente y no pudiesen, como los ciudadanos particulares, alegar ni tener derecho contra él.

Cuatro eran los puntos principales del programa liberal en 1833: 1) secularización de la enseñanza; 2) adopción del Patronato por el Estado mexicano; 3) reforma de las órdenes religiosas y 4) incautación de los bienes eclesiásticos.

4 Véase Ambroy, Carta al MAE de 12 de mayo de 1855, III, f. 334. Las grandes riquezas de los conventos y su influencia sobre la población hacían a estas corporaciones extremadamente poderosas en el país y en el interior de la propia Iglesia. En 1854 y 1855, decidida la jerarquía eclesiástica a ejercer su control sobre los conventos, trató de introducir en ellos ciertas reformas. El fracaso de semejante tentativa no hizo sino mostrar claramente la solidez y la resistencia de las comunidades religiosa. "Esta inexpugnable posición de los conventos - comentó entonces Gavriac - debe ser un tema de estudios tan curiosos como importantes. La cuestión de su mantenimiento o de su supresión, de su disminución o de su reforma, está quizás estrechamente ligada a la existencia misma de la nación... Me parece que la organización de las comunidades religiosas domina toda la cuestión en las antiguas colonias españolas de América" (Carta al MAE, 3 de marzo de 1855, III, f. 277). 
El clero era uno de los principales obstáculos al triunfo liberal - decía Mora - contribuía a perpetuar la deuda nacional y la miseria pública, impidiendo el pago de la primera y la cesación de la segunda, asimismo, era insuficiente para atender las necesidades de los fieles; se acumulaba en las capitales donde no hacía falta y escaseaba en los pueblos, aldeas y campos donde se le necesitaba. Tenía estancado un capital de casi 180 millones de pesos y una renta de 7.5 millones. Diez obispos y 177 canónigos consumían las dos terceras partes de las rentas eclesiásticas, cuyos bienes se componían de propiedades territoriales y capitales impuestos sobre ellas, diezmos y derechos parroquiales.

La Iglesia católica novohispana vivió sujeta al rey de España durante la Colonia por medio del Regio Patronato. Sin embargo, al realizarse la Independencia la Iglesia rechazó las pretensiones del novel gobierno mexicano de suceder a la Corona española en esas prerrogativas.

En cuanto a este punto, los liberales de 1833 se dividían en dos bandos, uno encabezado por el vicepresidente Gómez Farías, quien se inclinaba por la separación absoluta del Estado y de la Iglesia o para decirlo con las palabras del propio Mora querían "la independencia absoluta entre el poder civil coactivo y el espiritual de conciencia y de convicción”, que según Blas José Gutiérrez, éste fue un pensamiento iniciado por las Cortes españolas de 1812, el cual se estableció en México hasta mucho tiempo después. ${ }^{5}$

El otro grupo, dominante en ambas cámaras, lo encabezaban el diputado Espinosa de los Monteros y el senador Manuel Crescencio Rejón, este último pretendía que el gobierno mexicano recobrase el derecho del Patronato. Precisamente cuando las cámaras ejercitaron el Patronato, mediante la Ley de provisión de curatos, la lucha llegó a su punto álgido. Como se puede advertir, la separación de la Iglesia y el Estado tiene un carácter trascendente en la historia nacional.

Más adelante, la administración de Gómez Farías, partícipe de la primera reforma laboral, también intentó una desamortización general, según la cual los bienes quedarían en poder de los usufructuarios; los religiosos y religiosas dejarían de serlo y recibirían, en cambio, 3 o 4 mil pesos y el gobierno sostendría una catedral en cada estado.

Por otra parte, para Mora el diezmo era una contribución tan viciosa en su naturaleza y exacción, como mal e inútilmente distribuida. La Iglesia sólo tenía potestad para ejercer coacción en orden a su objeto espiritual y por los medios a él conducentes; no era éste el caso de los diezmos, y por

5 Gutiérrez Flores Alatorre, Blas José, Leyes de Reforma. Colección de las disposiciones que se conocen con este nombre, publicadas desde el año de 1855 al de 1868, México, Imprenta de "El Constitucional", 1868-1870, t. I, p. 611. 
esta razón se quitó la coacción civil al pago de éstos el 27 de octubre de 1833.

Santa Anna, presionado por las sublevaciones de "religión y fueros", acabó por desautorizar a su vicepresidente Gómez Farías y derogó estas reformas. Trece años después, siendo Mariano Salas presidente y Rejón secretario de Relaciones Exteriores, se pronunciaron muchos discursos en pro de la tolerancia de cultos (al parecer fue Rejón el primer funcionario público que propugnó públicamente la libertad de cultos, cuando se discutía el proyecto de la Constitución de 1824, idea que llevaría a la práctica en la Constitución Yucateca de 1840), el matrimonio civil, la supresión de la confesión, la clausura de los noviciados, y la ocupación de los bienes eclesiásticos.

A fines de 1846 se repitió el binomio Santa Anna-Gómez Farías, y éste aprovechó la ausencia de Santa Anna para decretar la Ley del 11 de enero de 1847, en la cual se estableció que el gobierno recibiría autorización para obtener hasta 15 millones de pesos mediante la hipoteca o venta de bienes del clero, con el objeto de destinarlos al sostenimiento del ejército. Como en la primera ocasión, Gómez Farías fue separado de su cargo y Santa Anna reasumió el poder.

Posteriormente, en 1854 se inició la Revolución de Ayutla, un movimiento rebelde que desconocía a Santa Anna como presidente, con presencia de los jóvenes en el campo liberal y de los viejos en el conservador, en el que por primera ocasión se percibió un cambio profundo en la vida política del país. En efecto, el triunfo de la Revolución de Ayutla deslindó claramente los bandos que se disputaban en el poder, en dónde Antonio López de Santa Anna fue finalmente derrocado, exiliado y arrojado a los infiernos de la historia. Esa juventud vio en la Revolución de Ayutla, y subsecuentemente en la Reforma liberal de 1857-1860, la victoria de la democracia.

Al triunfo de la Revolución de Ayutla, el gobierno del general Juan Álvarez promulgó la Ley sobre administración de justicia y orgánica de los tribunales de la nación, del Distrito y territorios federales, conocida como "Ley Juárez", del 23 de noviembre de 1855. Sin duda alguna con esta disposición se daba un duro golpe al estatus de privilegio o "fuero" de que gozaba el clero mexicano.

Las nuevas generaciones de mexicanos buscaban volver a fundar el país y fiel a la tradición originada por el Primer Emperador de México Agustín de Iturbide, se dio a la tarea de elaborar un marco legal que sustentara al nuevo Estado mexicano. El triunfo de la Revolución de Ayutla sirvió como campo fértil para el nacimiento de una nueva estructura política del país.

La inestabilidad política en el país había ocasionado que la Constitución de 1824 fuera un documento meramente simbólico, obsoleto a la rea- 
Esta obra forma parte del acervo de la Biblioteca Jurídica Virtual del Instituto de Investigaciones Jurídicas de la UNAM

lidad en la que vivía le país; así, el 5 de febrero de 1857 se creó una nueva Constitución, que fue un catalizador de las diferencias entre partidos, lo cual anunció un nuevo conflicto ideológico, siendo así el documento más polémico en la historia de nuestro país.

Este texto constitucional era enteramente liberal, moderno y apegado a las ideas vanguardistas de las naciones más avanzadas, entre las que se encontraban libertades de trazo progresista como la libertad de expresión, de asamblea y había uno que por su trascendencia en ese periodo supuso el mayor obstáculo que habría de sortear para justificar su éxito: la libertad de culto, un golpe al poder de la Iglesia católica en México; el inconveniente fue que la sociedad y clase política mexicanas no estaban preparadas para esto.

La libertad de culto para México fue un parteaguas en su historia, pues recordemos que México era católico antes de nacer, el primer símbolo nacional que logró reunir a miles de personas sin importar diferencias económicas, políticas o sociales fue el estandarte de la Virgen de Guadalupe que acompañó a Hidalgo durante su campaña militar. Los documentos más importantes creados durante la insurgencia, pilares del constitucionalismo mexicano tales como Elementos Constitucionales de López Rayón (1811), Los Sentimientos de la nación de José María Morelos (1813) y la Constitución de Apatzingán (1814), establecían que la religión oficial y la única que debía profesar el Estado era la católica, así como que los herejes y apóstatas perderían la ciudadanía. En 1824, México ya siendo independiente, la primera Constitución Federal se hizo en "nombre de Dios todo poderosos, autor y supremo legislador de la sociedad...".

De esto podemos advertir que la independencia de México no hubiera sido posible, en su tiempo, sin la Iglesia católica, la única conspiración exitosa se forjó frente a la imagen de Cristo agonizante en el templo de la Profesa.

Los tres principios de la recién creada nación mexicana en Iguala fueron "religión, independencia y unión", que fueron plasmados en los tres colores de la bandera que representa los tres pilares sobre los que se basó el proyecto del Estado nacional mexicano.

Es por esto que cuando en la Constitución de 1857 se dio el golpe contra el pilar religioso, el país tambaleó.

La Ley sobre Bienes Eclesiásticos, promulgada en 1847 por Valentín Gómez Farías, es el antecedente de la Ley Juárez de 1885, de la Ley Lerdo de (1856) y la Ley Iglesias de 1857, que en su conjunto son conocidas como las "Leyes de Reforma", mismas que establecieron la línea religiosa que predominaría en el Congreso constituyente de 1856-1857. En el Congreso 
constituyente de 1856-1857, se exaltó la democracia y se ponderaron las ideas liberales con entusiasmo delirante.

La Constitución de 1857 dejó atrás la disposición en la que se establecía a la religión católica como la única del Estado; fue la primera Constitución en la que se reconoció la enseñanza libre sin injerencia de la doctrina católica; asimismo, eliminó el ataque a la religión y el dogma como limitantes de la libertad de expresión, prohibió fueros y tribunales especiales y limitó la propiedad de la Iglesia. Los liberales "puros" la convirtieron en una religión y se declararon sus apóstoles.

En represalia, la Iglesia católica, para defender sus intereses, decretó excomunión para todo aquel que jurara la Constitución; el grupo conservador se opuso tajantemente al nuevo documento constitucional. La Revolución de Tacubaya es la consecuencia armada de esto, y su objetivo fue, precisamente, derogar la Constitución y convocar a un congreso para redactar un nuevo texto constitucional.

El presidente Ignacio Comonfort, frente a las presiones de la Iglesia, del partido conservador, y también ante el clamor popular, cede ante sus pretensiones y anula la Constitución, el partido liberal no se quedó cruzado de brazos y contraatacó, con lo que se inició "La Guerra de Reforma".

Desde el aspecto político, se puede decir que la Reforma liberal respondía a la necesidad de poner de manifiesto, de una vez y para siempre, el principio de separación entre la Iglesia y el Estado en México.

El triunfo liberal dio aplicación a la Constitución de 1857. En 1860 Juárez promulgó la Ley sobre Libertad de Cultos, que protegía la libertad religiosa como un derecho natural del hombre y reconocía expresamente la independencia entre el Estado y las creencias y prácticas religiosas.

En el corto periodo de Maximiliano de Habsburgo como emperador, se reconoció la libertad religiosa, pero con protección especial a la religión católica, haciendo de la Iglesia un órgano favorecido del Estado.

Tan importante como la forma de gobierno, y en parte mezclada con él, fue la lucha por el poder civil y el eclesiástico. La tímida victoria que los liberales moderados alcanzaron con la Constitución de 1857 se afianzó con las "Leyes de Reforma", obra de los liberales "puros".

Fue necesario el triunfo definitivo de la reforma liberal para liquidar no solamente el poderío material del clero mexicano, sino, también, el privilegio de inmunidad del que se había hecho una prerrogativa tradicional de casta, inconciliable con una estructura social que exigía cambios profundos.

La reforma iniciada por Valentín Gómez Farías y José María Luis Mora en 1833 llegó a su culminación un cuarto de siglo después con el establecimiento de un "poder civil laico" superior a la Iglesia. 
Hubo coincidencias en la política que la República y el Imperio adoptaron frente a la Iglesia. En el primer caso, la base ideológica es la separación de la Iglesia y el Estado, en el segundo el regalismo. Pero en ambos opera el interés de los adjudicatarios de los bienes eclesiásticos. Juárez decretó la nacionalización de los bienes del clero el 12 de julio de 1859, y Maximiliano confirmó esta disposición el 26 de febrero de 1865. En octubre de ese mismo año el Imperio confirmó la existencia del Registro Civil establecido por Juárez el 28 de julio de 1859. El propio Juárez decretó la secularización de los cementerios el 31 de julio de 1859, lo cual confirmó Maximiliano el 12 de marzo de 1865. Por último, Juárez decretó la libertad de cultos el 4 de diciembre de 1860, y Maximiliano la confirmó el 26 de febrero de 1865 .

Además, los liberales intentaron resolver el problema agrario primero con la desamortización de los bienes de las comunidades, y después, ante la resistencia del clero, por medio de la nacionalización de los bienes eclesiásticos. En ambos casos se trató de crear la pequeña propiedad. Sin embargo, el Constituyente de 1856-1857 se conformó con decretar la "Ley de desamortización" el 25 de junio de 1856.

Una vez restaurada la República en 1873, Sebastián Lerdo de Tejada restituyó la independencia entre el Estado y la Iglesia, prohibiendo al Congreso dictar leyes que establecieran una religión oficial. El problema "político" fundamental resuelto en este periodo es el de la forma de gobierno. Desde luego, la antinomia República versus Monarquía, se resuelve definitivamente por la solución republicana. La lucha, en este aspecto, coincidió con el conflicto de intereses de Europa (representada principalmente por Francia) y los Estados Unidos. El fracaso del Imperio determinó que México quedara dentro de la zona de influencia de los Estados Unidos.

Ya en el porfiriato, conforme avanzaban los años, las relaciones entre el Estado y la Iglesia se hicieron menos tensas, la Constitución de 1857 de corte liberal y anticlerical estuvo en aplicación.

La Revolución mexicana implicó un nuevo sobresalto en la relaciones del Estado con la Iglesia, las generaciones de mexicanos que participaron en la lucha armada eran de tendencia radical, lo cual quedó plasmado tanto en los campos de batalla como en los documentos políticos.

El Congreso Constituyente de 1916-1917 estableció en la Constitución la educación laica, a partir de lo cual, las corporaciones religiosas y ministros de culto tenían prohibido impartir educación y adquirir bienes inmuebles. 
En su artículo 24 se reconoció la libertad de creencia religiosa, se estableció que el culto se celebrara exclusivamente en los domicilios particulares, y solamente en los templos el de carácter público. De esta manera, quedó prohibido el llamado culto externo.

El artículo antes referido de la Constitución Política de los Estados Unidos Mexicanos ordena: "Todo hombre es libre para profesar la creencia religiosa que más le agrade y para practicar las ceremonias, devociones o actos del culto respectivo, siempre que no constituyan un delito o falta penados por la ley...”.

Pero, ¿qué se entiende por libertad religiosa y cómo se distingue de la tolerancia religiosa? La tolerancia religiosa se practica por quienes pertenecen a una religión dominante en relación con los miembros de otros cultos o prácticas religiosas de la minoría, mientras que la libertad religiosa tiene como presupuesto la separación de las Iglesias y el Estado.

De acuerdo con la Suprema Corte de Justicia de la Nación, la libertad religiosa es un derecho del cual goza cada individuo que vive en sociedad y que protege a éste contra cualquier acto del Estado que viole este derecho. La religión o creencia de cada individuo se convierte, así, en un asunto estrictamente privado y es de algún modo ilimitada puesto que el Estado no tiene los medios directos para cambiar o imponer lo que el individuo desarrolle en su intimidad y en su pensamiento.

La dimensión o faceta interna de la libertad religiosa se relaciona íntimamente con la libertad ideológica y, aunque es difícil de definir de un modo que sea general y a la vez útil, atiende a la capacidad de los individuos para desarrollar y actuar de conformidad con una particular visión del mundo en la que quede definida la relación del hombre con lo divino. Esta libertad de sostener y cultivar las creencias religiosas que cada uno considere incluye también la de cambiar de creencias religiosas, lo cual, por otro lado, viene asegurado por la prohibición de discriminación.

La dimensión o proyección externa de la libertad de religión es múltiple y se entrelaza de modo estrecho, en muchas ocasiones, con el ejercicio de otros derechos individuales, como la libertad de expresión, la libertad de reunión, o la libertad de enseñanza. Una proyección típica y específica a la que la Constitución se refiere expresamente es la libertad de culto, que alude a la libertad para practicar las ceremonias, ritos y reuniones que se asocian con el cultivo de determinadas creencias religiosas. Las manifestaciones externas de la libertad religiosa pueden ser, por otro lado, individuales o colectivas. Las dos son abarcadas y protegidas por el primer párrafo del artículo 24. 
Llevar la kipá o una cadena con una medalla de la virgen en el cuello, es símbolo y expresión de la filiación religiosa judía o católica, respectivamente, de la persona que los lleva, y en esa medida son una manifestación externa de la libertad religiosa, pero no, evidentemente, un acto de "culto público".

Análogamente, el hecho de que sean varias las personas que llevan dichos símbolos conjuntamente no convierte a esa coincidencia en un acto de "culto público", como tampoco lo serían otras expresiones o vivencias colectivas de ciertas creencias religiosas, como fundar una escuela privada con orientación religiosa u organizar una excursión privada a un lugar sagrado.

Los actos de "culto público", en resumen, son aquellos actos específicamente orientados a desarrollar de manera colectiva los ritos, ceremonias y conductas que las diferentes religiones reconocen como manifestaciones institucionalizadas o formalizadas de su fe religiosa, definidas y gobernadas por reglas pre-establecidas por ellas.

El segundo párrafo del artículo 24 también consagra el llamado principio de separación entre las Iglesias y el Estado, pues insta al Estado a no "establecer", pero tampoco "prohibir", religión alguna; esto es, a no respaldar como propia del Estado a una religión en particular, manteniéndose al tiempo imparcial y respetuoso con una de las manifestaciones más importantes del pluralismo en las sociedades actuales: el pluralismo religioso propio de la ciudadanía en una democracia contemporánea.

Así, la libertad religiosa plasmada en las Constituciones de los Estados modernos, trajo consigo, incluido el caso de México, que la Iglesia católica deba competir con otras religiones o creencias para conseguir y mantener el número de sus adeptos. Este nuevo contexto se desarrolló en el siglo pasado lo que podría denominarse un mercado religioso.

Actualmente el artículo 24, reformado en 2013, a la letra establece lo siguiente:

Toda persona tiene derecho a la libertad de convicciones éticas, de conciencia y de religión, y a tener o adoptar, en su caso, la de su agrado. Esta libertad incluye el derecho de participar, individual o colectivamente, tanto en público como en privado, en las ceremonias, devociones o actos del culto respectivo, siempre que no constituyan un delito o falta penados por la ley. Nadie podrá utilizar los actos públicos de expresión de esta libertad con fines políticos, de proselitismo o de propaganda política.

El Congreso no puede dictar leyes que establezcan o prohíban religión alguna.

Los actos religiosos de culto público se celebrarán ordinariamente en los templos. Los que extraordinariamente se celebren fuera de éstos se sujetarán a la ley reglamentaria. 
Asimismo, el artículo 130 aprobado unánimemente por los constituyentes, en el que también se establece el principio de separación del Estado-Iglesia, fue la obra cumbre del radicalismo de 1917, pues otorgó a los poderes federales las facultades para intervenir en materia de culto religioso, estableció el matrimonio como un contrato civil y desconoció la personalidad jurídica de las agrupaciones religiosas denominadas Iglesias.

El artículo 130 de la Constitución Política de los Estados Unidos Mexicanos de 1917, desde la expedición de ésta y hasta la reforma publicada en el Diario Oficial de la Federación el 28 de enero de 1992, establecía lo siguiente:

Corresponde a los Poderes Federales ejercer en materia de culto religioso y disciplina externa, la intervención que designen las leyes. Las demás autoridades obrarán como auxiliares de la Federación.

El Congreso no puede dictar leyes estableciendo o prohibiendo religión cualquiera.

El matrimonio es un contrato civil. Este y los demás actos del estado civil de las personas, son de la exclusiva competencia de los funcionarios y autoridades del orden civil, en los términos prevenidos por las leyes, y tendrán la fuerza y validez que las mismas les atribuyan.

La simple promesa de decir verdad y de cumplir las obligaciones que se contraen, sujeta al que la hace, en caso de que faltare a ella, a las penas que con tal motivo establece la ley.

La ley no reconoce personalidad alguna a las agrupaciones religiosas denominadas iglesias.

Los ministros de los cultos serán considerados como personas que ejercen una profesión y estarán directamente sujetos a las leyes que sobre la materia se dicten.

Las Legislaturas de los Estados únicamente tendrán facultad de determinar, según las necesidades locales, el número máximo de ministros de los cultos.

Para ejercer en México el ministerio de cualquier culto, se necesita ser mexicano por nacimiento.

Los ministros de los cultos nunca podrán, en reunión pública o privada constituida en junta, ni en actos del culto o de propaganda religiosa, hacer crítica de las leyes fundamentales del país, de las autoridades en particular, o en general del Gobierno; no tendrán voto activo ni pasivo, ni derecho para asociarse con fines políticos.

Para dedicar al culto nuevos locales abiertos al público se necesita permiso de la Secretaría de Gobernación, oyendo previamente al Gobierno del Estado. Debe haber en todo templo un encargado de él, responsable ante la autoridad del cumplimiento de las leyes sobre disciplina religiosa, en dicho templo, y de los objetos pertenecientes al culto. 
El encargado de cada templo, en unión de diez vecinos más, avisará desde luego a la autoridad municipal, quién es la persona que esté a cargo del referido templo. Todo cambio se avisará por el ministro que cese, acompañado del entrante y diez vecinos más. La autoridad municipal, bajo pena de destitución y multa hasta de mil pesos por cada caso, cuidará del cumplimiento de esta disposición; bajo la misma pena llevará un libro de registro de los templos, y otro de los encargados. De todo permiso para abrir al público un nuevo templo, o del relativo a cambio de un encargado, la autoridad municipal dará noticia a la Secretaría de Gobernación, por conducto del Gobernador del Estado. En el interior de los templos podrán recaudarse donativos en objetos muebles.

Por ningún motivo se revalidará, otorgará dispensa o se determinará cualquier otro trámite que tenga por fin dar validez en los cursos oficiales, a estudios hechos en los establecimientos destinados a la enseñanza profesional de los ministros de los cultos. La autoridad que infrinja esta disposición será penalmente responsable, y la dispensa o trámite referidos, será nulo y traerá consigo la nulidad del título profesional para cuya obtención haya sido parte la infracción de este precepto.

Las publicaciones periódicas de carácter confesional, ya sea por su programa, por su título o simplemente por sus tendencias ordinarias, no podrán comentar asuntos políticos nacionales ni informar sobre actos de las autoridades del país, o de particulares, que se relacionen directamente con el funcionamiento de las instituciones públicas.

Queda estrictamente prohibida la formación de toda clase de agrupaciones políticas cuyo título tenga alguna palabra o indicación cualquiera que la relacione con alguna confesión religiosa. No podrán celebrarse en los templos reuniones de carácter político.

No podrá heredar por sí ni por interpósita persona ni recibir por ningún título un ministro de cualquiera culto, un 'inmueble', ocupado por cualquiera asociación de propaganda religiosa o de fines religiosos o de beneficencia. Los ministros de los cultos tienen incapacidad legal para ser herederos, por testamento, de los ministros del mismo culto o de un particular con quien no tengan parentesco dentro del cuarto grado.

Los bienes muebles o inmuebles del clero o de asociaciones religiosas, se regirán, para su adquisición, por particulares, conforme al artículo 27 de esta Constitución.

Los procesos por infracción a las anteriores bases, nunca serán vistos en jurado.

Como se advierte, en el precepto constitucional transcrito se garantizaba la libertad de cultos, pero no se reconocía personalidad alguna a las agrupaciones religiosas denominadas Iglesias, mientras que a los ministros 
de los cultos se les consideraba como personas que ejercían una profesión y estarían directamente sujetas a las leyes que sobre la materia se dictaran.

En dicho precepto constitucional se establecía también la prohibición para heredar, por sí o por interpósita persona, de un ministro de cualquier culto, un inmueble ocupado por cualquier asociación de propaganda religiosa, de fines religiosos o de beneficencia.

Asimismo, se prohibía a los ministros de culto heredar, por testamento, de los ministros del mismo culto o de un particular con quien no tuvieran parentesco dentro del cuarto grado.

En ese sentido, los ministros de los cultos podían heredar por sucesión legítima de los ministros del mismo culto o de los particulares a pesar de que tuvieran una relación de parentesco de cualquier grado, pues la prohibición sólo alcanzaba a la sucesión testamentaria. Asimismo, los ministros del culto podían heredar de parte de ministros de otro culto o de particulares con quienes tuvieran una relación de parentesco dentro del cuarto grado.

Por virtud de la reforma constitucional publicada en el Diario Oficial de la Federación el 28 de enero de 1992, se modificó el citado artículo 130 para quedar de la manera siguiente:

El principio histórico de la separación del Estado y las iglesias orienta las normas contenidas en el presente artículo. Las iglesias y demás agrupaciones religiosas se sujetarán a la ley.

Corresponde exclusivamente al Congreso de la Unión legislar en materia de culto público y de iglesias y agrupaciones religiosas. La ley reglamentaria respectiva, que será de orden público, desarrollará y concretará las disposiciones siguientes:

a) Las iglesias y las agrupaciones religiosas tendrán personalidad jurídica como asociaciones religiosas una vez que obtengan su correspondiente registro. La ley regulará dichas asociaciones y determinará las condiciones y requisitos para el registro constitutivo de las mismas;

b) Las autoridades no intervendrán en la vida interna de las asociaciones religiosas;

c) Los mexicanos podrán ejercer el ministerio de cualquier culto. Los mexicanos así como los extranjeros deberán, para ello, satisfacer los requisitos que señale la ley;

d) En los términos de la ley reglamentaria, los ministros de cultos no podrán desempeñar cargos públicos. Como ciudadanos tendrán derecho a votar, pero no a ser votados. Quienes hubieren dejado de ser ministros de cultos con la anticipación y en la forma que establezca la ley, podrán ser votados;

e) Los ministros no podrán asociarse con fines políticos ni realizar proselitismo a favor o en contra de candidato, partido o asociación política alguna. Tampoco podrán en reunión pública, en actos del culto o de propaganda 
religiosa, ni en publicaciones de carácter religioso, oponerse a las leyes del país o a sus instituciones, ni agraviar, de cualquier forma, los símbolos patrios.

Queda estrictamente prohibida la formación de toda clase de agrupaciones políticas cuyo título tenga alguna palabra o indicación cualquiera que la relacione con alguna confesión religiosa. No podrán celebrarse en los templos reuniones de carácter político.

La simple promesa de decir verdad y de cumplir las obligaciones que se contraen, sujeta al que la hace, en caso de que faltare a ella, a las penas que con tal motivo establece la ley.

Los ministros de cultos, sus ascendientes, descendientes, hermanos y cónyuges, así como las asociaciones religiosas a que aquellos pertenezcan, serán incapaces para heredar por testamento, de las personas a quienes los propios ministros hayan dirigido o auxiliado espiritualmente y no tengan parentesco dentro del cuarto grado.

Los actos del estado civil de las personas son de la exclusiva competencia de las autoridades administrativas en los términos que establezcan las leyes, y tendrán la fuerza y validez que las mismas les atribuyan.

Las autoridades federales, de los estados y de los municipios tendrán en esta materia las facultades y responsabilidades que determine la ley.

En relación con esta disposición de la Constitución federal, la Primera Sala de la Suprema Corte de Justicia de la Nación ha resuelto asuntos al respecto, en uno de ellos se estudió el tema de si una asociación civil al estar constituida por sacerdotes que practican el culto público, podía o no heredar por testamento de una persona que éstos hubieran auxiliado espiritualmente y con la que no tengan parentesco dentro del cuarto grado, por estar sujetos estos últimos a la prohibición constitucional prevista en el artículo 130. En esta resolución que es relativamente reciente se señalaron aspectos importantes que se expondrán a continuación:

El artículo 130, párrafo quinto, de la Constitución, establece una prohibición consistente en que los ministros de culto, sus ascendientes, descendientes, hermanos y cónyuges, así como las asociaciones religiosas a las que pertenezcan serán incapaces para heredar, por testamento, de las personas a quienes los propios ministros hayan dirigido o auxiliado espiritualmente y no tengan parentesco dentro del cuarto grado.

La prohibición está dirigida a los ministros de culto religioso, sus ascendientes, descendientes, hermanos y cónyuges, así como la asociación religiosa a la que el ministro pertenezca.

$\mathrm{Al}$ respecto, de conformidad con el artículo 12 de la Ley de Asociaciones Religiosas y Culto Público, se considerará como ministro de culto religioso a 
“...aquellas personas mayores de edad a quienes las asociaciones religiosas a que pertenezcan confieran ese carácter”.

Las asociaciones religiosas respectivas deben notificar dicha determinación a la Secretaría de Gobernación, y, cuando no se notifique, se podrá reputar la calidad de ministro de culto a aquellas personas que siendo mayores de edad ejerzan en dichas asociaciones como ocupación principal, funciones de dirección, representación u organización.

Una vez que se determine si un individuo tiene la calidad de ministro de culto religioso podrán identificarse los demás sujetos de la prohibición: los ascendientes, descendientes, hermanos y cónyuge del ministro de culto, así como la asociación religiosa a la que pertenezca, de acuerdo con las previsiones normativas respectivas.

En lo que respecta a la interpretación de los conceptos "auxilio" o "dirección" espiritual, ésta debe hacerse a la luz del principio de laicidad o, como se señala en la propia norma, a partir del principio histórico de separación entre Estado e Iglesias.

Así, existe auxilio o dirección espiritual cuando se actualizan dos condiciones: 1) que el ministro de culto religioso realice las actividades inherentes a su función, y 2) que la persona pertenezca a la comunidad religiosa respecto de la cual el ministro de culto religioso realiza sus funciones.

Del análisis de la prohibición contenida en el artículo 130 de la Constitución federal, se pone de manifiesto que la reforma constitucional no introdujo una garantía o derecho fundamental a favor del ciudadano, sino que modalizó una prohibición ya prevista - la capacidad para heredar de los ministros de culto religioso-.

Como es fácil de advertir, en el antepenúltimo párrafo del artículo 130 constitucional se estableció que los ministros de culto, sus ascendientes, descendientes, hermanos y cónyuges, así como las asociaciones religiosas a que aquellos pertenezcan, serán incapaces para heredar por testamento, de las personas a quienes los propios ministros hayan dirigido o auxiliado espiritualmente y no tengan parentesco dentro del cuarto grado.

Entonces, claramente la norma en cuestión tiene como finalidad impedir que los sujetos enunciados hereden en ciertas condiciones.

También es menester tener en cuenta lo dispuesto en la exposición de motivos de la reforma al artículo 130 de la Constitución general de la República, publicada en el Diario Oficial de la Federación el 28 de enero de 1992.

Se evidencia que el Constituyente, consciente de los cambios que la sociedad había sufrido desde 1917, decidió modificar el régimen jurídico de la relación Iglesias-Estado, uno de los principales cambios fue el que se dotara a las Iglesias de personalidad jurídica, pues en su opinión la existencia de las 
Iglesias es una realidad social; insoslayable en todas las sociedades de nuestro tiempo, indistintamente del signo ideológico de su organización estatal, aclarando que no se debe confundir, por eso, Estado laico con la carencia de personalidad jurídica de las Iglesias; ni la regulación de las organizaciones sociales llamadas Iglesias con limitar las libertades de creencias religiosas y su práctica.

Por tanto, fue clara la intención del legislador en dotar de personalidad jurídica a las Iglesias, sujetándolas así a un régimen administrativo y fiscal, para lo cual creó la figura jurídica de la asociación religiosa, cuya reglamentación remitió a una legislación secundaria.

En consecuencia, se otorgó a las Iglesias la capacidad de propiedad, limitada únicamente a que los bienes que adquieran sean indispensables para la realización de su objeto, para lo cual se modificó la fracción II del artículo 27 de la Constitución.

Asimismo, se eliminó la prohibición que dichos entes tenían para dirigir, administrar instituciones de asistencia privada, pues no era justificado impedir a los ministros de los cultos o a las corporaciones religiosas formar parte de instituciones de beneficencia que tengan por objeto el auxilio de los necesitados o cualquier otro objeto lícito, siempre y cuando se ajusten a los objetivos asistenciales que les dan origen.

Por último, en cuanto a la imposibilidad que para heredar tenían los ministros de culto, el Constituyente consideró que esa imposibilidad jurídica que tienen los ministros de los cultos para heredar debe asumir algunas características que, de manera específica, ya contiene el Código Civil con respecto a los tutores, médicos, notarios y sus testigos. El propósito de la prohibición es la misma: que en los momentos de agonía, el poder que ejercen los ministros como el de otras profesiones y funciones, puede generar influencias indebidas a los que dichas persona, por su condición, no podría oponerse.

Por tales consideraciones se propuso que el párrafo relativo en el artículo 130 se modificara para precisar este caso y eliminar la prohibición general a heredar de otro ministro o de cualquier particular. Igualmente, se elimina la prohibición de recibir por cualquier título un inmueble ocupado por cualquier asociación de propaganda religiosa, o de fines religiosos, o de beneficencia.

Así, acorde con la posibilidad que se otorgaba a las asociaciones religiosas de contar con personalidad jurídica y patrimonio propio, el Constituyente consideró necesario reconocer el derecho tanto de los ministros de culto como de las asociaciones religiosas de heredar por testamento. 
Por lo que resulta patente que la intención del legislador al modificar el antepenúltimo párrafo del artículo 130 constitucional fue la de matizar la prohibición ahí prevista, de tal forma que tales sujetos pudieran heredar por testamento, libremente de aquellos con quienes tuvieran una relación de parentesco dentro del cuarto grado, y de cualesquier otro particular, no emparentado dentro de dicho grado, pero con la salvedad de que no fuera de las personas a quienes hayan prestado auxilio espiritual, acotando la prohibición a los momentos de agonía, con el fin de que no se pudieran generar influencias indebidas a las que dichas personas, por condición, no podría oponerse.

Esa prohibición se extendió a los ascendientes, descendientes, hermanos y cónyuges, así como a las asociaciones religiosas a que pertenezcan los ministros de culto que hayan prestado el referido auxilio espiritual.

Por otra parte, debe señalarse que la conducta prohibida es la de heredar por testamento, y nada más. Entonces, los destinatarios de la norma, esto es, aquellos a quienes está impedido heredar son los siguientes:

El que $i$ ) fuera ministro de culto y ii) sus ascendientes, iii descendientes, $i v)$ hermanos y $v$ ) cónyuge, siempre y cuando el autor del testamento: $a$ ) haya sido dirigido o auxiliado espiritualmente por dicho ministro, y $b$ ) no tenga parentesco con el mismo ministro dentro del cuarto grado.

Las asociaciones religiosas a las que pertenezca tal ministro, es decir, aquel que hubiera dirigido o auxiliado espiritualmente al autor de la sucesión y que no tenga con él parentesco dentro del cuarto grado.

Ahora bien, cabe precisar que por ministro de culto debe entenderse aquella persona a quien su propia Iglesia o asociación le confiere las atribuciones de dirección y auxilio religioso a los fieles, y las ejerce respecto de la persona del testador; y no a quien dirija o represente - jurídicamente hablando - a una Iglesia o agrupación religiosa o a quien realice otras funciones religiosas. Ya que quien dirige o representa jurídicamente a una Iglesia o asociación religiosa no necesariamente es quien presta auxilio espiritual ni quien dirige espiritualmente a una persona, según se desprende del artículo 12 de la Ley de Asociaciones Religiosas y Culto Público, que a continuación se cita.

Para los efectos de esta Ley, se consideran ministros de culto a todas aquellas personas mayores de edad a quienes las asociaciones religiosas a que pertenezcan confieran ese carácter. Las asociaciones religiosas deberán notificar a la Secretaría de Gobernación su decisión al respecto. En caso de que las asociaciones religiosas omitan esa notificación, o en tratándose de iglesias o 
agrupaciones religiosas, se tendrán como ministros de culto a quienes ejerzan en ellas como principal ocupación, funciones de dirección, representación u organización.

En cuanto a la interpretación de "dirección y auxilio espiritual", debe buscarse asidero en lo que de antaño recoge el actual Código Civil Federal. En el artículo 1325 se dispone, desde la emisión del Código de 1928, lo siguiente:

Los ministros de los cultos no pueden ser herederos por testamento de los ministros del mismo culto o de un particular con quien no tengan parentesco dentro del cuarto grado. La misma incapacidad tienen los ascendientes, descendientes, cónyuges y hermanos de los ministros, respecto de las personas a quienes éstos hayan prestado cualquiera clase de auxilios espirituales, durante la enfermedad de que hubieren fallecido o de quienes hayan sido directores espirituales los mismos ministros.

Por otra parte, por "asociación religiosa", debe acudirse a lo que dispone el mismo artículo 130 constitucional en su inciso $a$; de dicho enunciado normativo resulta que son asociaciones religiosas - un tipo especial de persona moral - única y exclusivamente las Iglesias y agrupaciones religiosas que obtengan su registro como tales en términos de la ley reglamentaria, y cuyo objeto y finalidad sea justamente la propagación de su fe y la ministración de los ritos relativos: "Las iglesias y las agrupaciones religiosas tendrán personalidad jurídica como asociaciones religiosas una vez que obtengan su correspondiente registro. La ley regulará dichas asociaciones y determinará las condiciones y requisitos para el registro constitutivo de las mismas".

En otro aspecto, una asociación civil es una persona jurídica con patrimonio y personalidad jurídica propia, cuyo origen es el contrato por el que varios individuos consienten en reunirse de forma no transitoria para conseguir un fin común no prohibido por la ley y no preponderantemente económico.

Lo anterior se desprende de lo dispuesto en el artículo 1996 del Código Civil para el estado de Tamaulipas, a precisar: "Cuando varios individuos convinieren en reunirse, de manera que no sea enteramente transitoria, para realizar un fin común que no está prohibido por la ley y que no tenga carácter preponderantemente económico, constituyen una asociación civil con patrimonio y personalidad jurídica propia”.

De lo hasta ahora reseñado se puede arribar a las subsecuentes conclusiones: 
Esta obra forma parte del acervo de la Biblioteca Jurídica Virtual del Instituto de Investigaciones Jurídicas de la UNAM

1) Las asociaciones religiosas tienen personalidad jurídica y patrimonio propios.

2) Las asociaciones civiles tienen patrimonio y personalidad jurídica propios independiente de la de sus socios.

3) $\mathrm{Al}$ reformar el artículo 27 constitucional, en la exposición de motivos el Constituyente permitió que los ministros de culto o las corporaciones religiosas formen parte de instituciones de beneficencia.

4) La expresión "dirigido o auxiliado espiritualmente" debe entenderse acotada y no en sentido amplio.

En tal contexto significativo, acorde a la interpretación de dicho precepto constitucional, un ministro de culto sí puede heredar de un particular con quien no guarde algún parentesco, siempre y cuando no haya prestado auxilio espiritual al autor del testamento, entendido esto último en los términos ya referidos, esto es, acotado al momento de la muerte.

Dados estos elementos, también es evidente que, conforme a lo dispuesto en el antepenúltimo párrafo del artículo 130 de la Constitución Política de los Estados Unidos Mexicanos, una asociación civil creada con arreglo a las leyes civiles que establecen un tipo especial de persona moral puede heredar en la medida en que se ciña a la norma; para el caso de las personas jurídicas la prohibición sólo incumbe a las asociaciones religiosas, un tipo de persona moral diferente de la civil, quien, además, acorde con la interpretación del referido precepto constitucional, sí puede heredar siempre y cuando uno de sus miembros no haya prestado auxilio espiritual al autor del testamento, entendido esto último en los términos ya referidos, esto es, acotado al momento de la muerte, y, por otra parte, tenga relación de parentesco dentro del cuarto grado con el autor de la herencia.

De este modo, se llega a la conclusión de que el objeto del Estado laico es permitir la convivencia respetuosa y pacífica dentro de una misma organización política, de diferentes grupos religiosos. Así, el Estado laico sin libertad religiosa implicaría una contradicción y una contravención a los derechos fundamentales de las personas.

\section{BIBLIOGRAFÍA}

Hale, Charles A., El liberalismo mexicano en la época de Mora (1821-1853), 8a. ed., México, Siglo XXI, 1987. 
Meyer, Jean, La cristiada, 4a. ed., México, Siglo XXI, 1976, t. 2: El conflicto entre la Iglesia y el Estado.

Reyes Heroles, Jesús, El liberalismo mexicano, 2a. ed., México, Fondo de Cultura Económica, 1974.

Olga SÁnchez CORDERO

Ex ministra de la Suprema Corte de Justicia de la Nación 


\section{PREÁMBULO. MIEDO Y LAICIDAD}

En el siglo IV el filósofo Sópatro de Apamea fue ejecutado por orden de Constantino, después de haberse negado a purificarlo por asesinar a su hijo; fue acusado de trivializar la fe cristiana. En el 415 o 416, Hipatia de Alejandría, la famosa mujer filósofa, quien se opuso al abuso del poder religioso, fue rasgada en pedazos con fragmentos de vidrio y piedra por una turba histérica de cristianos guiados por Pedro, y llevada hasta la puerta de la Catedral para ser mostrada como trofeo. Carlomagno, en el 782, mandó a decapitar a 4,500 sajones por no haberse convertido al cristianismo. Cerca del año 1456, en las guerras otomano-húngaras, se aniquilaron a más de 80,000 turcos en nombre de Dios. En 1542, Paulo III declaró jurisdicción sobre todos los creyentes y ordenó la persecución, condena y ejecución de todos los herejes.

De esta forma, podríamos recorrer muchas de nuestras etapas históricas, citando tragedias como éstas que se encuentran en ese tejido de la humanidad y la religión. Podríamos, incluso, y sin sorpresa, llegar hasta los siglos XX y XXI encontrando sucesos como éstos. Sería posible recordar nombres como el del capellán del ejército argentino de seudónimo Marcial Castro Castillo, quien en 1972, en su libro Fuerzas armadas, ética y represión, decía:

Nuestra civilización no es contradictoria como la estupidez democrática liberal... Podemos aniquilar la subversión sin dejar de ser buenos cristianos; es más: la condición de triunfo es que sepamos ser mejores cristianos a través de la pelea, mediante la guerra victoriosa, cumpliendo nuestra misión de soldados de Cristo y de la Patria... ${ }^{1}$

Los que se nieguen a esos fines y principios provenientes de nuestra espléndida tradición católica, directamente se enrolan en el enemigo; vale decir, se definen revolucionarios rebeldes al orden natural y al magisterio de la Iglesia. ${ }^{2}$

Podríamos recordar también el nombre del ex presidente de Estados Unidos, George W. Bush, quien se decía cristiano y rezaba a diario. Éste lle-

1 Castro Castillo, Marcial, Fuerzas armadas, ética y represión, Buenos Aires, Nuevo Orden, 1979, p. 32 .

2 Ibidem, p. 31. 
vaba su fe hasta la vida pública y decía que la libertad era el "plan del Cielo para la humanidad". El presidente que defendió el "poder de la fe" e hizo que en la Casa Blanca fuera obligatorio asistir a las sesiones de lectura bíblica. ${ }^{3}$ Pero, como se sabe, fue con base en esa fe con la que trató de ayudar al mundo, sobre todo, quiso salvar a Iraq de la perdición eterna; y por ello aniquiló a 600,000 personas en 2006, y se contaban casi un millón en 2007, según el estudio del Opinion Research Business.

En el siglo XXI, como en los anteriores, la laicidad se encuentra encerrada en medio de un juego perverso guiado por el miedo. Como celador de una prisión que aún sin haber sido condenado vive en el infierno, la laicidad se encuentra encerrada en un mundo de temor: el temor de aquellos que no creen en un "ser superior" y se resisten a ser gobernados por una idea fundamentada en su existencia, y el temor de quienes consideran que, cuando el Estado no se basa en sus creencias sobre el destino divino, nos está guiando hacia la perdición eterna.

Para el pensamiento laico, el miedo llega por partida doble: el dogmático teme al antidogmático y el antidogmático al dogmático. Y en medio de ellos el pensamiento laico se convierte, como el Hermes de la era moderna, en conciliador entre estos dos bandos que se temen mutuamente en términos políticos. La laicidad, como pensamiento mediador del liberalismo, no puede favorecer ni a la antirreligiosidad, como tampoco a la religiosidad; debe mantenerse incólume entre dos reclamos que difieren sobre los fundamentos de la autoridad política. Dos bandos irreconciliables en tanto que uno procura su libertad y autonomía en el mundo terrenal, y el otro continúa angustiado por su destino divino.

Esta angustia que refiero es traducida en la Biblia con la palabra "miedo". La primera emoción experimentada por los personajes de la Biblia. Guando Adán come del árbol del conocimiento, descubre que está desnudo y se esconde. Se esconde de Dios, quien lo está viendo, y le confiesa: "Tenía miedo porque estaba desnudo". La historia de la Iglesia católica ha estado construida sobre esta misma base. Sobre la base del temor, el temor a Dios, el temor al pecado y el temor al infierno. Moisés insta a los judíos a que abandonen su miedo a los enemigos y teman a Dios. El miedo fue la causa y la herramienta de la Santa Inquisición; momento de la historia en el que las leyes positivas equivalían a las leyes de la Iglesia. Hay que temer para salvarse en el más allá. De ahí el miedo que genera en los creyentes (los más fundamentalistas) que el Estado no esté guiado por las enseñanzas

3 Singer, Peter, El presidente del bien y el mal. Las contradicciones éticas de George W. Bush, Barcelona, TusQuetes, 2004, p. 135. 
del libro sagrado. Pues para ellos debe existir una relación intrínseca entre el pecado y la ley. Entonces, ¿qué sucede cuando lo que está plasmado en la ley positiva, en la ley creada por el ser humano, contradice las enseñanzas divinas?, ¿qué sucede cuando la ley no corresponde con el pecado o con la ley de Dios?

Es por ello que la laicidad, como figura central del liberalismo y enseñanza que heredamos de la Ilustración, siempre está presente cuando tratamos de responder preguntas centrales de la filosofía política, como: ¿debe estar la autoridad política fundamentada en la razón o en la revelación?, ¿Jerusalén o Atenas?, ¿la autoridad política radica en el reconocimiento democrático o en el reconocimiento divino?, ¿las leyes son buenas porque las hemos elegido nosotros, o son buenas porque reflejan la voluntad de un Dios?

Esa calidad de Hermes conciliador que le confiero a la laicidad, moderador entre lo terrenal y lo divino, es lo que en la literatura especializada se le suele atribuir cuando la relacionan con otros conceptos distintos como la neutralidad y la tolerancia. La reconocen como un punto intermedio que concilia entre nuestra libertad de creer y la prohibición de imponer.

Indudablemente, estos conceptos están, hasta cierto grado, relacionados e intrincados con una misma clase de doctrina filosófica - el liberalismo-, pero debemos notar que son de distinto calado y que requieren, normativamente hablando, cosas distintas. Empero, y a pesar de estas diferencias conceptuales que son importantes, lo relevante de esta relación es que el liberalismo le ha conferido a la laicidad el papel de mediador ilustrado entre polos radicalmente distintos que surgen por el miedo, y la considera como el antídoto del temor, calificándolo de infundado.

El miedo por quién ocupará el poder político e imponga su visión del mundo sirve como válvula de escape de los valores políticos liberales. El miedo al fundamentalismo, el miedo al totalitarismo, apoyan la idea de la tolerancia, del pluralismo y, por supuesto, del pensamiento laico.

Las sociedades modernas, temerosas de contraer enfermedades ideológicas como el dogmatismo religioso o el nihilismo moral, encuentran sustento para el liberalismo en el pensamiento laico; éste se convierte en la penicilina que cura estas enfermedades endémicas de las sociedades plurales. Por ello, el liberalismo construye su pensamiento con diferentes clases de antídotos: el imperio de la ley, la democracia liberal, y los derechos humanos.

Es decir, el miedo no es únicamente una preocupación de los religiosos sino también de los seglares. En la época premoderna ambos, religiosos y seglares, cultivaban deliberadamente el miedo como apoyo a una especie de conocimiento moral sobre cómo debían conducirse los hombres y las muje- 
Esta obra forma parte del acervo de la Biblioteca Jurídica Virtual del Instituto de Investigaciones Jurídicas de la UNAM

res en tanto seres éticos. Es muy conocido que uno de los fundamentos del pensamiento hobbesiano, en el que radica la fundamentación del Estado, es el miedo.

Pero también encontramos la misma preocupación dentro del pensamiento liberal. Autores como Locke consideran al miedo como un estado de intranquilidad mental; el filósofo inglés estima que "el principal acicate de la laboriosidad y las acciones humanas, si no es que el único, es la intranquilidad", es decir, el miedo. ${ }^{4}$ Para Rousseau, el fundamento del contrato social deriva de la depravación del hombre. Rousseau tiene que esperar a la corrupción del alma, debe esperar a que el bon sauvage se convierta en "animal degenerado", para encontrar los fundamentos del contrato social y justificar el paso a la República; momento en el que ya no existe la imposición unilateral del poder, sino que éste ya pertenece a todos.

El liberalismo moderno, desde Rawls a la fecha, se ha configurado como una doctrina que pretende construir una moral independiente de cualquier concepción comprehensiva del bien; basada en la idea de un "consenso traslapado" que logre aglomerar las preocupaciones generales y compartidas de todos los individuos con el fin de lograr una estabilidad social. Lo importante acá es la distancia que toma el liberalismo frente a cualquier concepción del bien.

Así, el liberalismo político también está relacionado con el mismo miedo en el que está inmiscuida la laicidad. Un miedo ante el dogmatismo y el fundamentalismo ideológicos. El liberalismo político trató, desde la aparición de $A$ Theory of Justice, de encontrar una fórmula que evitara el maniqueísmo político de la época. De ese maniqueísmo político entre izquierda y derecha, entre comunismo y capitalismo, entre creyentes y agnósticos, que Rawls veía como la imposición política de distintas concepciones del bien, contradictorias e inconmensurables, las cuales no necesariamente son correctas o razonables.

Fue el espíritu que antes también guió a Hannah Arendt cuando analizó el páramo moral en que resultó la Segunda Guerra Mundial. Para Arendt, los axiomas del pasado ya no servían, eran inoperantes, y lo que quedó fue el miedo de los horrores generados durante la guerra, pero en ese miedo yacía el instrumento de un nuevo consenso moral y político. ${ }^{5}$ Era, de nueva cuenta, el miedo lo que movía la maquinaria del pensamiento liberal.

En temas directamente relacionados con la laicidad, es el miedo al imperio de una religión como mecanismo de fundamentación de los criterios

4 Locke, John, An Essay Concerning Human Understanding, Campell Fraser, Alexander (ed.), Nueva York, Dover, 1959, p. 334.

5 Arendt, Hannah, Los orígenes del totalitarismo, México, Taurus, 2004, p. 537. 
de justicia en general, y de las normas jurídicas en particular, que da auspicio a la idea misma de un pensamiento secular. Como he dicho, la laicidad se encuentra encerrada entre dos clases de miedos: 1) el miedo de que sea una religión en particular la que se apodere del espacio público, eliminando así el diálogo plural y democrático, e imponiendo una cosmovisión única del mundo a individuos libres e iguales, y 2) el miedo que experimentan creyentes y religiosos al ver que las leyes del Estado no coinciden con las leyes divinas y pensar que esto nos llevará a la perdición eterna.

De ahí que una de las implicaciones prácticas que se le atribuyen al pensamiento laico sea la neutralidad estatal. Pues funciona como el antídoto que evita intestinas pugnas por el poder entre distintas concepciones del bien, y logra garantizar una justicia imparcial y universal.

Efectivamente, está el problema, de por sí interesante, sobre cuál es la clase de neutralidad de que se trata cuando hablamos de laicidad. Sin embargo, lo que me interesa subrayar aquí son los motivos por los que se discute y acepta esta relación entre laicidad y neutralidad; es decir, los criterios que han motivado el reclamo secular por la neutralidad estatal. No busco la fundamentación de la neutralidad, sino las razones que se tuvieron para comenzar a discutirla. Esos criterios, como vengo diciendo, los encuentro bajo el argumento del miedo.

Desde la perspectiva laica, el Estado neutral no se sostiente en bases morales (como lo fundamentan filósofos como Rawls o Dworkin) sino en consideraciones de corte prudencial. Siendo así, el principio de neutralidad se toma como un mecanismo de protección y no como un reclamo moralmente cimentado en la autonomía de las personas.

Esta forma de comprender la neutralidad estatal considera necesario restringir las acciones del Estado para que éste no se convierta en represivo, abusivo o tiránico. Riesgos que son en los que se cimienta la neutralidad prudencial que - digo - defiende el pensamiento laico.

George Sher ha distinguido tres clases de razones que apoyan el argumento a favor de la neutralidad del Estado: la opresión, la inestabilidad y el error. Cuando habla de la "opresión"6 se refiere específicamente al tipo de presión que el poder del Estado puede infundir a ciertos individuos o grupos sociales y que elimina cualquier posibilidad de libertad. Sher describe esta postura de la siguiente manera:

Para mantener el orden, proteger a los ciudadanos frente a amenazas externas y para proporcionar servicios esenciales y los bienes públicos, el gobierno

6 Sher, George, Beyond Neutrality. Perfectionism and Politics, Cambridge, Cambridge University Press, 1997, pp. 107-111. 
debe tener tanto el monopolio de la fuerza, como el acceso a la riqueza. Pero, obviamente, estos recursos también se pueden utilizar de maneras menos saludables: para suprimir a los disidentes, para consolidar y mantener el poder personal, y para crear y mantener criterios injustos de ventaja y privilegio. ${ }^{7}$

Esta perspectiva sobre las autoridades estatales y gubernamentales es arquetípica del pensamiento liberal. Ciertamente, por sus rasgos esenciales se puede confundir con el argumento moral de la "defensa de la autonomía personal". Sin embargo, el punto de vista es bastante diferente a éste. Sus orígenes se remontan a la obra de Benjamin Constant (entre otros, como Montesquieu); en la filosofía contemporánea se ha defendido a través del "liberalismo del miedo" de Judith Shklar. ${ }^{8}$

Tanto Shklar como Constant creen que los grandes poderes conferidos al Estado, si no están lo suficientemente controlados, pueden dar lugar a las formas más eficaces de represión y tiranía. El liberalismo de Shklar, específicamente, toma distancia frente a cualquiera de las versiones "utópicas" del liberalismo que, según ella, están representadas fundamentalmente por el liberalismo de los derechos naturales y por el liberalismo de la autonomía personal. "El liberalismo de los derechos naturales prevé una sociedad justa compuesta de ciudadanos políticamente robustos, cada uno capaz y dispuesto a ponerse de pie por sí mismo y frente a los demás". 9

El liberalismo de la autonomía personal sostiene que la "libertad, es tan necesaria para el progreso personal como para el social... y la moral es imposible a menos que tengamos la oportunidad de elegir nuestros propios cursos de acción". ${ }^{10}$

Ubicándonos en el liberalismo del miedo, la perspectiva cambia. Estas formas de comprender a la neutralidad y la relación entre el Estado y los individuos son erróneas - según Shklar - por dos razones fundamentalmente: i) por pensar que los derechos individuales, por sí solos, servirán como un mecanismo de protección eficaz y, ii) por pensar que un gobierno "corrupto" tenga la voluntad para detenerse en nombre del progreso social y la autonomía personal.

Esta perspectiva, a diferencia del liberalismo de la autonomía, defiende la idea de la neutralidad estatal desde un punto de vista "negativo" en vez de uno "positivo". Esta última perspectiva comprende el gobierno y el po-

7 Ibidem, p. 106.

8 Shklar, Judith N., "The Liberalism of Fear", en Rosenblum, Nancy L. (ed.), Liberalism and the Moral Life, Cambridge, Harvard University Press, 1989, pp. 21-38.

$9 \quad$ Ibidem, pp. 26 y 27.

$10 \quad$ Ibidem, p. 27. 
Esta obra forma parte del acervo de la Biblioteca Jurídica Virtual del Instituto de Investigaciones Jurídicas de la UNAM

der político como una forma de alcanzar la libertad y la autonomía personal. Por lo tanto, el Estado es neutral para no afectar la autonomía personal y la libertad.

El Estado se toma como un aliado, incapaz de conferir ningún mal. $\mathrm{Al}$ contrario del liberalismo del miedo, que entiende la neutralidad como un reclamo necesario frente a un poder en el que ve una amenaza latente hacia la libertad y tiende a oprimir diferentes concepciones del bien que difieren de las jurídicamente aceptadas. Se entiende al gobierno y al poder político como una amenaza constante para los individuos. Aquí el Estado se toma como un enemigo latente.

Antes dije que Sher consideraba tres clases de razones, la segunda de ellas es la inestabilidad. El poder del Estado puede ser utilizado por ciertos grupos sociales para defender una concepción particular del bien que conduce a una supresión inevitable y al debilitamiento de concepciones del bien antagónicas. El resultado más obvio, y que trata de evitar un pensamiento laico, es el de un panorama político-social básicamente regido por una relación de resistencia-imposición. Acá, el pensamiento laico juega un papel predominante, pues según éste "para evitar este tipo de conflictos es necesario poner cualquier concepción del bien estrictamente fuera de los límites del Estado". ${ }^{11}$

La idea básica de este argumento es que concibe a la neutralidad como un modus vivendi. La neutralidad es vista como un acuerdo de carácter instrumental según la vieja leyenda vive y deja vivir, como una forma de acomodar a los individuos que mantienen concepciones divergentes sobre la vida buena.

La tercera y última razón discutida por Sher se refiere a la posibilidad del error: ¿qué sucedería si la idea sobre lo "bueno" que es defendida por el gobierno, e impuesta a sus ciudadanos, no resulta ser "buena" en absoluto?

Decía que el pensamiento laico es un punto medio, entre el dogmatismo y el nihilismo, pero esto no implica que los defensores del argumento del miedo ante el error sean escépticos en materia moral. Por el contrario, lo que sostiene este punto de vista "no es que no podamos conocer el bien, sino que no importa qué tan bien lo conozcamos, éste no tiene porqué guardar una relación y tener influencia en el poder político". ${ }^{12}$ Sher lo explica de una manera más clara:

Aquellos que tienen ideas correctas o profundas sobre la bondad puede ser que carezcan de la habilidad para afectar la retórica pública o para influir en aquellos que tienen el poder, ya sea porque su público potencial está sesgado,

11 Sher, George, op. cit., p. 107.

12 Ibidem, p. 108. 
preocupado, o le falta interés. Y a la inversa, los que poseen una autoridad pueden tener opiniones sobre lo bueno que son superficiales, incompletas o simplemente erróneas. ${ }^{13}$

Con esto en la cabeza, volvamos al liberalismo del miedo de Shklar. Ella insiste en que las bases "instrumentalistas" (que he llamado antes "prudenciales") que defiende en estos casos no responden a ningún vicio, sino que son una virtud. El sentido de la razón instrumental defendido por el liberalismo del miedo pretende resaltar los esfuerzos de todos aquellos que no quieren pagar el precio de las empresas utópicas. Los motivos de esta clase de liberalismo, que defiende la neutralidad secular del Estado, son negarse a tomar riesgos a expensas de los demás en la búsqueda de un ideal, la perspectiva entera se apoya en la idea del miedo a la opresión, a la inestabilidad o al error; para los partidarios de esta perspectiva los derechos individuales son una buena manera de mantener al "león" enjaulado, en lugar de tenerlo liberado y olfateando nuestra piel.

Para Shklar, el liberalismo del miedo sin duda no ofrece un summum bonum hacia el cual deben derivar todos los agentes políticos, pero ciertamente empieza con un summum malum que todos nosotros conocemos y que evitaríamos si pudiéramos. Ese mal es la crueldad a la que tarde o temprano lleva todo dogmatismo impuesto políticamente hablando, el temor que inspira la ausencia de libertad, y como diría Michel de Montaigne "el temor al miedo mismo" que inspira la imposición de una forma de pensar, por correcta que está parezca. Como lo ha expresado el intelectual-político Michael Ignatieff:

En el siglo XX, la idea de la universalidad humana no se basa tanto en la esperanza como en el temor, no tanto en el optimismo que despierta la capacidad humana para el bien como en el pánico que produce su capacidad para el mal, no tanto en el hombre creador de su propia historia como en el enemigo que resulta para su propia especie. ${ }^{14}$

El argumento de Ignatieff continúa diciendo que quizá no sepamos quiénes somos ni tampoco qué es verdaderamente bueno o justo, pero sí sabemos a qué tener miedo.

Un conocimiento casi instintivo estructura nuestra vida pública y ánima nuestros esfuerzos, el miedo es la energía disonante de nuestra fe cívica, el irritante necesario de un objetivo en común. Energía e irritación que no

\footnotetext{
13 Idem.

14 Ignatieff, Michael, El honor del guerrero. Guerra étnica y conciencia moderna, Madrid, Santillana, 1999, p. 24.
} 
Esta obra forma parte del acervo de la Biblioteca Jurídica Virtual del Instituto de Investigaciones Jurídicas de la UNAM

cesarán hasta que las distintas fracciones religiosas no consigan aceptar que el bien común se construye con base en una moral de aceptación universal y, en consecuencia, dejen de perseguir el poder estatal; hasta entonces, la única salida que tenemos está marcada por el mecanismo liberal que llamamos laicidad.

\section{BIBLIOGRAFÍA}

ARendt, Hannah, Los orígenes del totalitarismo, México, Taurus, 2004.

Castro Castillo, Marcial, Fuerzas armadas, ética y represión, Buenos Aires, Nuevo Orden, 1979.

IGNATIEFF, Michael, El honor del guerrero. Guerra étnica y conciencia moderna, Madrid, Santillana, 1999.

LOCKE, John, An Essay Concerning Human Understanding, Campell Fraser, Alexander (ed.), Nueva York, Dover, 1959.

SHER, George, Beyond Neutrality. Perfectionism and Politics, Cambridge, Cambridge University Press, 1997.

ShKLAR, Judith N., "The Liberalism of Fear", en Rosenblum, Nancy L. (ed.), Liberalism and the Moral Life, Massachusetts, Harvard University Press, 1989.

SINGER, Peter, El presidente del bien y el mal. Las contradicciones éticas de George W. Bush, Barcelona, TusQuetes, 2004.

René GONZÁLEZ DE LA VEGA Facultad de Derecho de la UNAM 
Esta obra forma parte del acervo de la Biblioteca Jurídica Virtual del Instituto de Investigaciones Jurídicas de la UNAM www.juridicas.unam.mx

CAPÍTULO PRIMERO

REFLEXIONES EN TORNO A LA SEGULARIZACIÓN Y PLURICULTURALISMO 


\title{
¿LA SEGULARIZACIÓN ES REVERSIBLE?
}

\section{Liz HaMui SUTTON*}

\begin{abstract}
Sumario: I. Introducción. II. La modernidad y el paradigma de la secularización. III. Limites al paradigma de la secularización. IV. Relación entre secularización, laicidad y pluralismo. V. Conclusiones. VI. Bibliografia.
\end{abstract}

\section{INTRODUCGIÓN}

La secularización ha acompañado el proceso de modernización de las sociedades occidentales y de aquellas que han adoptado, aunque sea de manera parcial, el modelo democrático y liberal. Históricamente, la secularización se ha asociado a la liberación de las determinaciones religiosas en el ordenamiento político y por lo tanto se inscribe en la lógica de la emancipación y la Ilustración, donde la razón adquiere primacía sobre la fe. La palabra "secularización" viene del latín saeculum (generación), y en su acepción canónica, saecularizatio se refería a la autorización que se concedía a un religioso para dejar el convento y el hábito con el fin de vivir en el mundo, en el tiempo prolongado del siglo.

De acuerdo con los postulados de la modernidad europea de los siglos XVIII y XIX, cada ámbito de la vida social está normado por sus propias reglas en las que tiene sentido el juego entre sus elementos: por ejemplo, las reglas del mercado en la economía, las prácticas democráticas en lo político, el método experimental en las ciencias, los contratos sociales en lo jurídicopolítico, etcétera. De la misma manera, lo religioso - en sus dimensiones institucional, doctrinal, ritual, espiritual y social - constituía otra esfera de la vida de las personas que decidían participar voluntariamente.

De esta manera, la libertad de creencias y la posibilidad de elegir la adscripción religiosa constituyeron las premisas ontológicas, epistemológicas

* Coordinación de Investigación Educativa, División de Estudios de Posgrado, Facultad de Medicina, UNAM. 
y morales para sostener el paradigma de la secularización. El avance del racionalismo fue acompañado de un proceso de individuación y subjetivación de lo religioso en el ámbito de la vida privada. La expresión pública de los actos y símbolos religiosos se limitó a los espacios y recintos donde se congregaban los creyentes, y la identidad de los sujetos dejó de estar marcada por su adscripción religiosa para definirse en torno a la cualidad de su ciudadanía nacional. A medida que lo religioso se reguló, uno de sus efectos fue que las prácticas de sus miembros fueron desatendidas, lo que se manifestó en el descenso de los indicadores de creencias y prácticas religiosas, por ejemplo, en el número de personas que acudían a los templos, personas que no recibían sacramentos, la disminución de quienes seguían la vocación religiosa, en el desacato de los preceptos transmitidos por las autoridades religiosas, etcétera. En palabras de Luckmann, la religión tendió a volverse invisible y a confinarse en el ámbito de la vida privada del sujeto. ${ }^{1}$

No obstante, tanto el descenso como las tesis de privatización han sufrido numerosas críticas y revisiones en los últimos quince años. Pero el núcleo de la teoría - la comprensión de la secularización como un solo proceso de diferenciación de las distintas esferas institucionales o subsistemas de las sociedades modernas, entendida como la característica paradigmática y definición de los procesos de modernización - sigue siendo relativamente indiscutible en las ciencias sociales, particularmente dentro de la sociología europea.

Es importante abrir el debate para explorar y reconocer la historicidad particular de los desarrollos religiosos europeos occidentales, así como los múltiples y muy diferentes patrones históricos de secularización y diferenciación en otros contextos. Este reconocimiento permitirá a su vez un análisis comparativo menos eurocéntrico de los modelos de diferenciación y la secularización en otras civilizaciones y religiones del mundo. El punto de partida supone el reconocimiento de que el proceso histórico de la globalización, iniciado por la expansión colonial europea, conlleva transformaciones dinámicamente interrelacionadas y mutuamente constituidas, donde el paradigma de la secularización tiene más o menos sentido.

\section{LA MODERNIDAD Y EL PARADIGMA DE LA SEGULARIZACIÓN}

Según Casanova, la secularización conlleva un cambio en el modo de ver, ser y creer, y está marcada por tres dimensiones: la emancipación, el declive de las creencias religiosas y la marginalización de lo religioso a lo privado. ${ }^{2}$ Es

\section{Luckmann, Thomas, The Invisible Religion, Nueva York, McMillan, 1967.}

2 Casanova, José, “The Secular, Secularizations and Secularism”, en Calhoun, Craig et al. (eds.), Rethinking Secularism, Nueva York, Oxford University Press, 2011. 
importante partir de algunas distinciones analíticas básicas de los conceptos: lo "secular" se entiende como categoría epistémica moderna central; "secularización" como una conceptualización analítica de procesos modernos histórico-mundiales y "secularismo" como una visión del mundo. Los tres conceptos están relacionados pero se usan de manera diferente en diversos contextos académico-disciplinares, sociopolíticos y culturales.

La reconfiguración de la religión en la posmodernidad, según Mardones, atraviesa los siguientes ámbitos que podemos entender como polarmente constituidos: individuo-comunidad, emocionalidad-racionalidad, libre agrupación-institución, inmanencia-trascendencia, globalidad-localismo, consumismo-producción, sapiencial-mesiánica. ${ }^{3}$ Por lo tanto el mapa siempre cambiante de la religión presenta, por un lado, una religiosidad institucionalizada que experimenta fuertemente la desinstitucionalización y la pérdida del monopolio de lo religioso, y, por otro, una religiosidad poco institucionalizada, flexible, organizativamente cambiante, con un carácter difuso desde el punto de vista doctrinal, ecléctica, con énfasis en la experiencia, basada en un holismo místico-esotérico, con un gran pragmatismo en la concepción de la salvación y que discurre extramuros de las instituciones religiosas.

La religiosidad institucionalizada reacciona de varias maneras frente a lo que percibe como la descomposición de la religión. Primero, mediante un movimiento de defensa ante la creciente libertad interpretativa de sus miembros, la cual se juzga peligrosa y degenerativa. Esta amenaza conduce a convocar agrupamientos internos para apelar a la sana doctrina. Este tipo de reacción se encuentra en fenómenos como el neotradicionalismo o el fundamentalismo. La segunda reacción es la de la adaptación y actualización crítica de las doctrinas, que conlleva un ejercicio de confrontación y asimilación del espíritu ilustrado que trata de colocar a la religión a la altura de la modernidad crítica. Finalmente, la tercera reacción procede de las capas más populares que se oponen al elitismo de la religiosidad moderna y sofisticada, la cual no ofrece respuestas a las necesidades de los más oprimidos. Ésta es la religiosidad popular que vuelve a recuperarse y a tener múltiples seguidores que expresan su cercanía con la tradición e incluso cierta libertad frente a la religión institucionalizada. Los movimientos religiosos populares pueden o no ser de corte fundamentalista. El surgimiento de los nuevos movimientos religiosos pueden leerse como una reacción ante el agotamiento de las promesas de la modernidad, de ahí que muchos de ellos sean etiquetados como antimodernos o posmodernos.

3 Mardones, José María (dir.), Diez palabras clave sobre fundamentalismos, Navarra, Verbo Divino, 1999, p. 31. 
Esta obra forma parte del acervo de la Biblioteca Jurídica Virtual del Instituto de Investigaciones Jurídicas de la UNAM

Lo cierto es que estamos frente a un fenómeno espiritual inusitado que requiere de nuevas claves de interpretación, de nuevos paradigmas y marcos de referencia para su comprensión, y el paradigma de la secularización resulta insuficiente.

\section{LÍMITES AL PARADIGMA DE LA SEGULARIZACIÓN}

La modernidad ha desempeñado ciertas funciones ideológicas en las sociedades que creen en el progreso, la ciencia y la razón, lo que conlleva a una lectura teleológica que es compartida por el paradigma de la secularización. Esta conciencia histórica moderna plantea una evolución por etapas, que hace que lo secular implique lo moderno. Mientras que la permanencia de lo religioso conlleva una modernidad inconclusa. Esta premisa fue cierta sobre todo en la cultura occidental europea ante el catolicismo, no así en la modernidad norteamericana o en las sociedades poscoloniales de orígenes diversos al occidental.

El auge del paradigma de la secularización se sitúa en la década de los sesenta del siglo pasado, cuando la religión se hizo casi "invisible". Las críticas surgieron en los ochenta cuando las promesas de la modernidad se vieron cuestionadas con la aparición de movimientos políticos y nacionalistas de inspiración religiosa, por lo que la modernidad también ha producido sus propias expresiones de contra-secularización.

Tomando en cuenta las tres premisas de la secularización que menciona Casanova: ${ }^{4}$ 1) la emancipación de la esfera secular de las instituciones y normas religiosas; 2) el declive de las creencias; y 3) la marginalización de lo religioso en la esfera privada, las últimas dos pueden considerarse como fenómenos reversibles. El declive de las creencias religiosas no es una tendencia estructural y existen religiones públicas compatibles con las libertades "liberales" así como con la diferenciación moderna entre ambas esferas. Además, dentro de la reversibilidad de dichas tesis, los movimientos religiosos de las últimas décadas desmienten la tendencia hacia la privatización en la modernidad, lo que pone en duda ciertos fundamentos del paradigma de la secularización.

Según Gauchet, el concepto weberiano de "desencantamiento del mundo" no llevaría a la desaparición de los fieles, o de las creencias religiosas, sino al acotamiento de la capacidad de las religiones para estructurar el espacio

4 Casanova, José, Public Religions in the Modern World, Chicago, University of Chicago Press, 1994. 
Esta obra forma parte del acervo de la Biblioteca Jurídica Virtual del Instituto de Investigaciones Jurídicas de la UNAM

social. ${ }^{5}$ No obstante, en el proceso quedan residuos del mundo previo a la modernidad y la religión sigue presente y ausente en la ordenación del mundo. Esta visión es criticada por Hans Blumenberg, para quien la modernidad no tiene fundamentos religiosos. ${ }^{6}$ La secularización no es una transposición de contenidos, sino una ocupación de determinadas posiciones vacantes.

En contraste, autores como Oliver Roy consideran que la reformulación militante de lo religioso en la actualidad se da en contextos que han avanzado en el proceso de secularización y son consecuencia de ello, ahí encuentran espacios de autonomía y las condiciones para su expansión. ${ }^{7}$ No habría entonces una vuelta a lo religioso, sino una evolución de religiones tradicionales hacia nuevas y recientes formas religiosas más fundamentalistas y carismáticas como el evangelismo, salafismo, haredismo, pentecostalismo, entre otras. En este sentido, el retorno de lo religioso es una ilusión, sería más adecuado hablar de mutación, donde las religiones son cada vez más visibles, pero al mismo tiempo están en declive.

Por su parte para el filósofo canadiense Charles Taylor, lo que caracteriza la era secular no es la división de esferas o el declive de las prácticas religiosas, sino el paso de una sociedad, en la que la creencia en Dios no era desafiada ni problemática, a otra en la que es una opción entre otras, y en ocasiones, difícil de sostener. De esta forma, hay un cambio en el modo de creer y la secularización aparece como el contexto comprensivo (surgimiento del individualismo moderno y desencantamiento del mundo) en el que se enmarca la experiencia moral, espiritual o religiosa. ${ }^{8}$

Un estudio destacado que pone en duda el paradigma de la secularización es el de Talal Asad, desde un análisis genealógico de inspiración foucaultiana. El antropólogo de Stanford, de origen saudí, critica la premisa de la división de esferas que subyace a la tesis de la secularización. Para Asad, el espacio público está necesariamente (no sólo contingentemente) articulado por el poder y no es neutral. La experiencia religiosa del espacio privado, en la casa y la escuela, es importante para los sujetos que pueblan una particular cultura pública, condicionando los principios políticos que la rigen. Los lugares, prácticas, palabras y representaciones de los creyentes no pueden ser confinados dentro del espacio exclusivo de lo que los secula-

5 Gauchet, Marcel, El desencantamiento del mundo, una historia política de la religión, Madrid, Trotta-Universidad de Granada, 2005.

6 Blumenberg, Hans, La legitimación de la edad moderna, Valencia, Pre-Textos, 2008.

7 Roy, Oliver, La sainte ignorance. Le temps de la religion sans culture, París, Seuil, 2008.

8 Taylor, Charles, A Secular Age, Cambridge, The Belknap Press, Harvard University Press, 2007. 
Esta obra forma parte del acervo de la Biblioteca Jurídica Virtual del Instituto de Investigaciones Jurídicas de la UNAM

ristas llaman religión, ya que lo rebasan, abarcando prácticamente todos los aspectos de la vida social. La distinción de esferas y sus límites están siendo continuamente reformulados, sobre todo si las religiones desempeñan un papel relevante en la sociedad, están articuladas a las esferas políticas y ejercen el poder. Asad también cuestiona el carácter eurocéntrico de la secularización y su dificultad para dar cuenta de otras modernidades como la de los países poscoloniales. ${ }^{9}$

Hoy estamos ante lo religioso en movimiento, no es un retorno, sino un proceso que Hervieu-Léger describe como "desestructuración y restructuración, descomposición y recomposición, desorganización pero también redisposición y reutilización de los elementos surgidos del orden antiguo en el dispositivo móvil de la sociedad moderna". ${ }^{10}$ En todo caso, como refiere Ramón Solans, la modernidad religiosa está sujeta a una doble tensión: entre racionalidad moderna y emoción religiosa, por un lado; y, entre la aculturación a la modernidad y la exaltación de la tradición como continuidad, por otro. ${ }^{11}$

Así, influenciados por la teoría de la secularización, el análisis de lo religioso en su diversidad (instituciones eclesiásticas, cultos, mitos, tradiciones, etcétera) se tiene una cierta ilusión de inmovilismo, la religión se considera como un resto atávico condenado a la extinción por no ser capaz de adaptarse a la modernidad. Lejos de esta visión ideológica, en la actualidad la religión se ha manifestado como algo más complejo, difícil de asirse con las categorías de dicha teoría.

\section{RELACIÓN ENTRE SECULARIZAGIÓN, LAICIDAD Y PLURALISMO}

La laicidad también es un proceso ligado a la modernidad y alude a la independización del ámbito político-jurídico de lo religioso, lo que coloca al Estado como un ente imparcial ante la diversidad de credos. Arlettaz refiere que mientras la secularización parte de los cambios sociales a las configuraciones político-legales (países protestantes), la laicización instituye los cambios político-legales y los traslada a los procesos sociales (países católicos). ${ }^{12} \mathrm{La}$

9 Asad, Talal, Formations of the Secular. Christianity, Islam, Modernity, California, Stanford University Press, 2003.

10 Hervieu-Léger, Danièle, Religión, hilo de memoria, Barcelona, Herder, 2005.

11 Ramón Solans, Francisco Javier, La virgen del Pilar dice... usos políticos y nacionales de un culto mariano en la España contemporánea, Zaragoza, Universidad de Zaragoza, 2014.

12 Arlettaz, Fernando, "La laicidad vista desde el paradigma de la secularización", en Pele, Antonio et al., (eds.), La laicidad, Madrid, Dykinson, 2010, colección Debates del Instituto Bartolomé de las Casas, Universidad Carlos III de Madrid. 
separación de la Iglesia del Estado no significa la eliminación de la religión en el debate de lo público, Eleonora Ceccherini tiene razón al argumentar que en ocasiones el criterio de los jueces resulta más importante que la misma ley, pues son ellos quienes están en contacto con la complejidad social. ${ }^{13} \mathrm{El}$ pluralismo jurídico no siempre corresponde al pluralismo cultural y quienes median son los jueces. La laicidad favorece el mercado religioso porque parte de la premisa de la libertad de creencia y de culto, así como de la existencia de la oferta de múltiples agrupaciones y por lo tanto se justifica en el pluralismo religioso. La laicidad es la herramienta política que busca hacer valer reglas de convivencia pacífica en contextos de pluralismo cultural y diversidad religiosa.

Karel Dobbelaere, en su escrito "Secularización: un concepto multidimensional", ${ }^{14}$ hace dos señalamientos: en primer lugar distingue entre la participación religiosa, el cambio religioso y la secularización como un proceso de laicización; y en segundo, que la laicización no es un proceso mecánico evolutivo, sino uno que depende del contexto cultural en el que se desarrolla, así como de las personas y los grupos involucrados. Tal perspectiva de la laicización se sostiene al reconocer que los procesos de diferenciación, de racionalización funcional y de societalización son reversibles. Son activados por personas o grupos que - manifiesta o latentemente-, laicizan o sacralizan instituciones sociales. Con estas consideraciones Dobbelaere cuestiona las bases en que se sustenta el paradigma de la secularización, pues no se trata de un proceso evolutivo inexorable, intrínseco a la modernidad, sino de uno que tiene que ver con el contexto histórico específico.

También rompe la relación supuesta entre el grado de participación religiosa y la laicización, según la cual entre mayor modernización social, menor participación personal, destacando que las ligas entre las instituciones religiosas y el mundo laico son complejas y multidimensionales. En cuanto al cambio social, el autor se pregunta si las organizaciones cambian su doctrina, su ética y sus ritos en respuesta a la laicización del mundo o a la noparticipación de sus miembros, y vuelve a responder que depende de los casos concretos y específicos, en los cuales se analizan los distintos sistemas de significado en competencia, estilos de vida y antecedentes religiosos, de tal suerte que podamos ampliar nuestra comprensión de la relación entre lai-

13 Ceccherini, Eleonora, Pluralismo religioso y pluralismo legal: un compromiso posible, México, UNAM, Instituto de Investigaciones Jurídicas, 2015, disponible en: http://biblio.juridicas.unam. $m x /$ libros/8/3864/11.pdf.

14 Dobbelaere, Karel, Secularización: un concepto multi-dimensional, México, Universidad Iberoamericana, 1994. 
Esta obra forma parte del acervo de la Biblioteca Jurídica Virtual del Instituto de Investigaciones Jurídicas de la UNAM

cización y sistemas de significado funcionales, incluyendo la religión. Tanto Hervieu-Léger como Dobbelaere, elaboran una reflexión crítica que apunta hacia la desacralización del concepto de secularización, y junto con Jeffrey Hadden, ${ }^{15}$ consideran que la secularización no ha sido sujeta suficientemente a un escrutinio sistemático.

\section{Gonclusiones}

Surge la pregunta de si puede haber una modernidad no secular, no occidental, o necesariamente la secularización está ligada a la modernidad y a la universalización de la experiencia europea. Lo cierto es que el proceso de secularización no es lineal ni radical, se produce en ciertos niveles, se liga con modalidades variadas a aspectos públicos y privados, se expresa en conductas sociales y requiere de un análisis estratificado y multidimensional. La teoría de la secularización no es un paradigma generalizable, sirve para explicar algunas realidades pero no todas, es un constructo conceptual que se desarrolla en condiciones de posibilidad diacrónica y sincrónica, y su estudio debe situarse en las configuraciones discursivas en las que interviene. La religión lejos de invisibilizarse en su adaptación a la modernidad, muestra su complejidad y no se deja reducir al paradigma de la secularización, cada sociedad encuentra sus formas históricas para establecer articulaciones y límites entre lo político y lo religioso que se expresan en configuraciones de poder dinámicas. En lugar del romanticismo de la convivencia y la armonía, se requiere de la negociación y el diálogo que tome en cuenta los valores, las creencias y los intereses de los involucrados, es decir una secularización múltiple que considere acomodos diversos y esté sustentada en la realidad, no en nociones teórico-conceptuales. ${ }^{16}$

La religión se articula y se tensa con otros discursos económicos, políticos, sociales, educativos, de salud, y genera respuestas inéditas múltiples ligadas a los intereses de quienes ejercen su influencia en el entramado social donde tienen lugar juegos entre los sujetos posicionados, que se expresan en ideas, decisiones y en actos performativos que constituyen el objeto de

15 Hadden, Jeffrey K., "Desacralizing Secularization Theory", en Hadden, Jeffrey K. y Shupe, Anson (eds.), Secularization and Fundamentalism Reconsidered, Nueva York, Paragon House, 1989.

16 Bhatia, Mohita, "Secularism and Secularization. A Bibliographical Essay", Economic and Political Weekly, India, vol. XLVIII, núm. 50, diciembre 2013, disponible en: http://wrwe. academia.edu/5387073/Revisiting_Secularism_Secularism_and_Secularisation-A_Bibliographical_Essay. 
Esta obra forma parte del acervo de la Biblioteca Jurídica Virtual del Instituto de Investigaciones Jurídicas de la UNAM

los acontecimientos discursivos. ${ }^{17}$ A la pregunta que titula este trabajo, ¿la secularización es reversible?, la respuesta es que puede serlo dependiendo de las disposiciones histórico-sociales por las que transiten los fenómenos religiosos.

La secularización como proceso multidimensional está vigente, con sus alcances y limitaciones respecto a su capacidad interpretativa, lo que se puede desafiar es la idea del secularismo, ya que diferentes sociedades desarrollan diferentes tipos de modernidad donde la religión se articula con modalidades particulares. Lo que sí resulta insostenible es la narrativa de la secularización como proceso natural, ${ }^{18}$ que podría ser sustituido por el estudio de la reorganización continua de los sistemas de creencias en la pluralización del espectro religioso. ${ }^{19}$

\section{BIBLIOGRAFÍA}

Arlettaz, Fernando, "La laicidad vista desde el paradigma de la secularización", en PeLe, Antonio et al. (eds.), La laicidad, Madrid, Dykinson, 2010, colección Debates del Instituto Bartolomé de las Casas, Universidad Carlos III de Madrid.

ASAD, Talal, Formations of the Secular. Christianity, Islam, Modernity, California, Stanford University Press, 2003.

BHATiA, Mohita, "Secularism and Secularization. A Bibliographical Essay", Economic and Political Weekly, India, vol. XLVIII, núm. 50, diciembre 2013, disponible en: http://wrere.academia.edu/5387073/Revisiting_Secularism_Secularism_and_Secularisation-A_Bibliographical_Essay.

Blumenberg, Hans, La legitimación de la edad moderna, Valencia, Pre-Textos, 2008.

Casanova, José, Public Religions in the Modern World, Chicago, University of Chicago Press, 1994.

, "The Secular, Secularizations and Secularism", en CalHoun, Craig et al. (eds.), Rethinking Secularism, Nueva York, Oxford University Press, 2011.

17 Foucault, Michel, La arqueología del saber, México, Siglo XXI, 1970.

18 Esteban, Valeriano, "Más allá de la secularización”, en López, Ana y Colom, Francisco (coords.), ¿Hacia una sociedad post-secular?: la gestión pública de la nueva diversidad religiosa, Zaragoza, Fundación Manuel Giménez Abad, 2011.

19 Mora Duro, Carlos Nazario, "Secularización y reconfiguración en el mapa religioso de México: el caso de la población «sin religión»", ponencia presentada en el XVII Encuentro de la Red de Investigadores del Fenómeno Religioso en México, México, 2014. 
Esta obra forma parte del acervo de la Biblioteca Jurídica Virtual del Instituto de Investigaciones Jurídicas de la UNAM

CECaherini, Eleonora, Pluralismo religioso y pluralismo legal: un compromiso posible, México, UNAM, Instituto de Investigaciones Jurídicas, 2015, disponible en: http://biblio.juridicas.unam.mx/libros/8/3864/11.pdf.

Dobbelere, Karel, Secularización: un concepto multi-dimensional, México, Universidad Iberoamericana, 1994.

Esteban, Valeriano, "Más allá de la secularización", en LóPEz, Ana y CoLOM, Francisco (coords.), ¿Hacia una sociedad post-secular?: la gestión pública de la nueva diversidad religiosa, Zaragoza, Fundación Manuel Giménez Abad, 2011.

FOUCAUlt, Michel, La arqueología del saber, México, Siglo XXI, 1970.

GAUCHET, Marcel, El desencantamiento del mundo, una historia política de la religión, Madrid, Trotta-Universidad de Granada, 2005.

HADDEN, Jeffrey K., "Desacralizing Secularization Theory", en HadDEN, Jeffrey K. y SHUPE, Anson (eds.), Secularization and Fundamentalism Reconsidered, Nueva York, Paragon House, 1989.

Hervieu-LÉGer, Danièle, Religión, hilo de memoria, Barcelona, Herder, 2005.

Luckmann, Thomas, The Invisible Religion, Nueva York, McMillan, 1967.

Mardones, José María (dir.), Diez palabras clave sobre fundamentalismos, Navarra, Verbo Divino, 1999.

MORA DURO, Carlos Nazario, "Secularización y reconfiguración en el mapa religioso de México: el caso de la población «sin religión»", ponencia presentada en el XVII Encuentro de la Red de Investigadores del Fenómeno Religioso en México, México, 2014.

Ramón Solans, Francisco Javier, La virgen del Pilar dice... usos políticos y nacionales de un culto mariano en la España contemporánea, Zaragoza, Universidad de Zaragoza, 2014.

ROY, Oliver, La sainte ignorance. Le temps de la religion sans culture, París, Seuil, 2008.

TAYlor, Charles, A Secular Age, Cambridge, The Belknap Press of Harvard University Press, 2007. 
Esta obra forma parte del acervo de la Biblioteca Jurídica Virtual del Instituto de Investigaciones Jurídicas de la UNAM

\title{
MODELOS DE ESTADO SEGULAR/LAICO: LAICIZAGIÓN EN TURQUÍA ENTRE 1923 Y 2015*
}

Bahattin AKSIT ${ }^{* *}$

\begin{abstract}
SUMARIO: I. Introducción. II. Modelos de Estado laico en países musulmanes y cristianos. III. Relaciones de economia, Estado, instituciones educativas y religión: hallazgos de una investigación en Turquía. IV. Conclusión.

V. Bibliografia.
\end{abstract}

\section{INTRODUCGIÓN}

El año 2015 será crucial para el futuro del Estado laico en Turquía. En junio de este año se llevarán a cabo elecciones generales, donde los partidos más importantes estarán contendiendo. Tres partidos de oposición son de orientación laica dentro del marco parlamentario plasmado en las Constituciones desde 1924, mientras que el partido en el poder y el presidente recientemente electo se han vuelto abiertamente en contra del régimen parlamentario y

* Una primera versión de este ensayo fue presentada en la Conferencia organizada por la Oficina de Instituciones Democráticas y Derechos Humanos (OSCE), y el Comité Estatal para Relaciones religiosas de la República de Kyrgyz, Osh, Kirguistán, el 3 y 4 de diciembre del 2003. La segunda versión fue presentada con motivo del taller organizado por el Instituto Goethe y el Departamento de Filosofía de METU de Identidad Islámica y Cambio Social Ankara, el 24 y 25 de mayo. La versión actual incluye algunas ideas de las versiones anteriores pero se aparta en otras, especialmente, al incluir hallazgos de investigaciones recientes. Aksit, B. et al., Turkiye'de Dindarlk: Sosyal Gerilimler Ekseninde İnanc ve Yasam Bicimleri (Religiosity in Turkey: Modes of Life and Belief in the Context of Social Tensions), Estambul, Iletisim Publications, 2012.

La versión publicada por la Cátedra Extraordinaria "Benito Juárez" del Instituto de Investigaciones Jurídicas de la UNAM fue traducida por Diana Alejandra Avila Pérez.

** Profesor en el Departamento de Sociología de la Universidad de Maltepe, Estambul. 
Esta obra forma parte del acervo de la Biblioteca Jurídica Virtual del Instituto de Investigaciones Jurídicas de la UNAM

están optando por una nueva Constitución, la cual será esencialmente presidencial, autoritaria, conservadora y orientada religiosamente. Si el partido que está actualmente en el poder, y que lo fue durante los últimos trece años, gana las próximas elecciones, estará en el poder hasta el 2019, a sólo cuatro años del centenario del establecimiento de la República secular turca.

Éste es el enigma que ha mantenido mi mente comprometida y ocupada por la última década. El Estado secular turco ha estado vigente por más de noventa y un años con sus altibajos: empezó con una alta dosis de secularización entre 1924 y 1946, y continuó con una dosis moderara, después de la transición hacia un sistema multipartidista en 1946, hasta finales de los años noventa. Sin embargo, esta tendencia parece revertirse en dirección de una islamización de la sociedad, con la llegada al poder de un partido de islam político, el Partido Justicia y Desarrollo (PJD/AKP) que ganó las elecciones en 2002, 2007 y 201 1. Estas victorias electorales fueron consolidadas en 2014 con la elección de Recep Tayyip Erdogan como el primer presidente electo popularmente. ${ }^{1}$

Un desarrollo paradójico se dio de la siguiente forma: durante el periodo secular de noventa y un años, se aplicaron las normas seculares a la sociedad, las cuales fueron criticadas como mecanismo de ingeniería social por los actuales dirigentes del partido y otros grupos religiosos de oposición, mientras que buena parte de la sociedad resistió a la secularización, siendo islámicos en su esfera privada e insistiendo en la presencia de símbolos y prácticas islámicas en la esfera pública. Sin embargo, a partir de la llegada al poder del Partido Justicia y Desarrollo, parece que sucedió lo contrario: mientras el Estado hace cumplir las normas religiosas a la sociedad mediante el sistema educativo y la movilización del partido, ha habido una resistencia secular de una parte sustancial de la sociedad, como por ejemplo el movimiento Taksim Gezi en Estambul. ${ }^{2}$

Asimismo, mientras en el pasado la secularización impuesta por el Estado y las instituciones educativas y el incremento de los niveles de educación y bienestar dieron lugar a una tendencia en dirección de una islamización

1 Recep Tayyip Erdogan es fundador y líder del Partido Justicia y Desarrollo (JDP/ AKP); fue primer ministro de 2003 a 2014, y desde agosto de 2014 es el primer presidente de la República electo de forma popular. Su elección con base popular le dio mayor poder que sus predecesores electos por el parlamento, con excepción de los presidentes fundadores y los presidentes con una intervención militar. Con las elecciones de junio de 2015, busca una mayoría que reforme la Constitución hacia un mayor presidencialismo. Los sectores seculares de la sociedad temen un estilo de gobierno autoritario, conservador y antisecular.

2 Entre mayo y julio de 2013 se organizó una resistencia social y política en el parque Taksim Gezi en el centro de Estambul, cuando el municipio inició un proyecto de renovación urbana de construcción de un centro comercial en el centro del área verde. La resistencia se extendió al resto de la Turquía e involucró a millones de personas. 
en la sociedad, en esta década, la islamización por parte del Estado y del partido orientado religiosamente parece generar una tendencia hacia la secularización de la sociedad, reforzada por las tendencias mundiales del consumismo. De esta manera, existe la posibilidad de que en años venideros, la islamización sea dominante tanto a nivel estatal como social, o bien que sea revertida y que la secularización sea la tendencia dominante. Para poder entender la dirección que tomarán estas transformaciones, es necesario presentar una perspectiva histórica y sociológica de la secularización en el mundo y en Turquía.

\section{MODELOS DE ESTADO LAICO EN PAÍSES MUSULMANES Y CRISTIANOS}

Cuando pensamos acerca de los problemas de un Estado moderno y democrático, se destacan tres dimensiones, es decir, evaluamos el proceso a partir de tres criterios. ${ }^{3}$ Estas dimensiones o criterios pueden ser explicados de la siguiente forma:

1) La primera dimensión es relativa a la diferenciación de los sistemas autónomos, subsistemas y/o campos: economía, política, y muchos complejos institucionales como ciencias, arte, filosofía, ética, y profesiones. Parsons (1973), y Habermas (1984 y 1987) coinciden en que la economía y la política son sistemas que funcionan independientemente el uno del otro, e independientemente de la religión. Asimismo, la economía es dirigida a través de los medios de monitoreo de intercambios, mientras que la política es regida mediante mecanismos de poder independientes de la religión y otras relaciones sociales. ${ }^{4}$ De manera similar, las ciencias, artes, filosofía, ética y otros campos equivalentes tienen su propia lógica de evaluación, de manera independiente o autónoma de la religión, de la economía de mercado, de la política y de otros ámbitos. ${ }^{5}$ Áreas de conocimiento

3 Casanova, J., Public Religions in the Modern World, Chicago, University of Chicago Press, 1994.

4 Véase Parsons, T. y Platt, G. M, The American University, Cambridge, Harvard University Press, 1973; Habermas, J., The Theory of Communicative Action, Reason and Rationalization of Society, Boston, Beacon Press, 1984, vol. 1; así como i. d., The Theory of Communicative ActionLifeworldand System: a Critique of Functionalist Reason, Cambridge, Polity Press, 1987, vol. 2.

5 Bourdieu, P. y Waquant, L.J.D., An Invitation to Reflexive Sociology, Chicago, The University of Chicago Press, 1992. 
como ingeniería, medicina, derecho, etcétera, han desarrollado también lógicas y éticas profesionales propias, tomando en consideración los avances de la tecnología, el mercado, el Estado, la sociedad civil y las tendencias mundiales.

2) La segunda dimensión o el segundo significado de secularización es relativo a la privatización de la religión. Se trata, en otras palabras, de remover la religión de la esfera pública para relegarla a la esfera privada. Esta dimensión ha sido debatida de forma acalorada durante las últimas décadas, especialmente por algunas sectas cristianas y algunos enfoques del islam que han insistido en el protagonismo de la religión en la esfera pública.

3) El tercer significado de la secularización está vinculado con la disminución de la observancia de los deberes religiosos, de las prácticas religiosas, ritos y rituales. ${ }^{6}$

La tesis de secularización ha sido expresada y formulada por casi todas las teorías y enfoques de las ciencias sociales. Las tres dimensiones de la secularización resumidas anteriormente han sido destacadas de forma diversa por las diferentes teorías de las ciencias sociales. Hace veinte años, antes del colapso de la Unión Soviética y al inicio de la última fase de la globalización, podíamos haber declarado que la dimensión diferenciada de la secularización no solamente era compartida por todos los enfoques y teorías de las ciencias sociales, sino que había alcanzado la condición de tendencia social universal, sin la cual las sociedades industriales modernas no podían reproducirse ni expandirse.

No obstante, ello ha sido cuestionado por algunos teóricos de la globalización y posmodernización, mediante la afirmación de que la dinámica de las redes globales erosiona la diferenciación entre las dimensiones económicas, políticas y sociales. Ha sido recombinada de diversas formas que adaptan procesos de integración, fragmentación, homogeneización, heterogeneización y bifurcación a nivel mundial. ${ }^{7}$

Las segunda y tercera dimensiones también han sido cuestionadas por los observadores de la secularización y de la modernización de las sociedades, dentro y fuera de Europa. ${ }^{8}$ Sin embargo, cabe señalar que a pesar de los

\footnotetext{
6 Casanova, J., op. cit.
}

7 Véase Castells, M., The Rise of the Network Society: the Information age: Economy, Society, and Culture, Oxford, Blackwell Publishers, 1996; Hardt, M. y Negri, A., Empire, Cambridge, Harvard University Press, 2000; y Urry, J., "Social Networks, Travel and Talk", The British Fournal of Sociology, Londres, vol. 54, junio 2003, pp. 155-175.

8 Casanova, J., op. cit. 
movimientos religiosos revivalistas y fundamentalistas de las últimas décadas, ambas dimensiones siguen manifestándose como tendencias, aunque ya no unilineales ni incuestionadas. ${ }^{9}$ La dimensión de la secularización más cuestionada ha sido la "privatización de lo religioso" o el paso de la religión de la esfera pública hacia la esfera privada. Incluso en los países cristianos, esa tesis ha sido objetada hasta nuestros días. ${ }^{10}$ Parece que se ha llegado a un acuerdo relativo, según el cual las Iglesias católicas han renunciado a cualquier pretensión de control sobre el Estado a cambio de que sea aceptada su presencia en la sociedad civil y en la esfera pública no estatal. ${ }^{11}$

Asimismo, parece claro que la secularización tuvo y tiene una trayectoria histórica diversa en el mundo. En este contexto, puede ser útil la siguiente tipología basada en las relaciones Iglesias-Estado en el mundo cristiano. ${ }^{12}$

1) El primer tipo es aquel donde está instituida una Iglesia nacional. Ha sido representado históricamente por el Reino Unido. ${ }^{13}$

2) El segundo tipo es el acuerdo mediante el cual el Estado se posiciona a una misma distancia respecto de todas las denominaciones/ religiones. Este tipo ha sido representado por Estados Unidos. ${ }^{14}$ Sin embargo, Casanova describió en 1994 dos patrones diversos en la transformación de Estados Unidos. El primero es el protestantismo evangélico: de una religión civil a una secta fundamentalista, y de allí a la Nueva Derecha Cristiana en la sociedad política. El otro sendero es hacia el catolicismo: de la denominación privada a la pública. ${ }^{15}$

3) El tercer tipo es aquel donde el Estado se encuentra en la misma cercanía con todas las denominaciones/religiones y contribuye financieramente a fomentar sus actividades. Durham considera que es donde

9 Idem.

10 Idem.

11 Idem.

12 Véase Casanova, J., Public religions in the modern world, Chicago, University of Chicago Press, 1994; Durham, W. Cole, Freedom of Religions or Belief in Constitutional Orders, documento presentado en la conferencia organizada por OSCE, Oficina de Instituciones Democráticas y Derecho Humanos, y por el Comité Estatal de Asuntos Religiosos, Osh, 3 y 4 de diciembre de 2003; así como Willaime, J. P., "Religion, State and Society in Germany and France", documento presentado en el encuentro anual de la Asociación de Sociología de la Religión, Atlanta, Georgia, 15 de agosto de 2003, disponible en: http://hirr.hartsem.edu/sociology/sociology_online_articles_willaime.html.

13 Durham, W. Cole, op. cit.

14 Idem.

15 Casanova, J., op. cit. 
el Estado debe estar idealmente. Parece que en Europa, Alemania podría ser una buena ilustración de este modelo. ${ }^{16}$

4) El cuarto tipo es representado por Francia. Históricamente en este tipo, el Estado ha apoyado las reivindicaciones laicas en contra del establecimiento de una denominación religiosa, por ejemplo, apropiándose enérgicamente de las tierras de la Iglesia católica, y distribuyéndolas a los laicos. En este tipo de laicización jacobina, el Estado se purga de los símbolos y de las funciones religiosas. La legislación reciente en contra del velo y demás símbolos religiosos en las escuelas secundarias sigue esta tradición. ${ }^{17}$

5) El quinto tipo fue descrito por Casanova como "religiones modernas públicas", ${ }^{18}$ y representa trayectorias de las Iglesias católicas nacionales en los tiempos modernos. El primer ejemplo se llevó a cabo en España donde la Iglesia estatal sufrió una especie de desestabilización, y, por lo tanto, renunció a cualquier reclamo sobre el control del Estado y acordó ser representada en la sociedad civil.

6) En Polonia se pasó de una Iglesia de la nación a una sociedad civil. ${ }^{19}$

7) En Brasil la trayectoria fue de Iglesia oligárquica a Iglesia del pueblo. ${ }^{20}$

8) Respecto de los patrones de la Iglesia ortodoxa en países con mayorías de esta denominación, tales como Grecia o Rusia, se deberán llevar a cabo estudios similares a los de Casanova.

Ahora bien, ¿qué podemos decir de los patrones de modernización y de secularización en el mundo islámico? Gellner en su libro titulado Muslim Society (1981), desarrolló una tipología de los países musulmanes, usando dos dimensiones. La primera es relativa al grado de religiosidad: fundamentalismo o religiosidad intensa en un polo, y, religiosidad moderada o secularismo en el otro. La segunda dimensión atañe al grado de radicalismo sociopolítico en un polo, y el conservadurismo en el otro. En la combinación de ambos grupos de clasificaciones, surgen cuatro opciones o tipos. ${ }^{21}$

16 Durham, W. Cole, "Freedom of Religion or Belief in Constitutional Orders", texto presentado en una conferencia organizada por OSCE Office of Democratic Institutions and Human Rights, and State Committee for Religious Affairs of the Kyrgyz Republic, Osh, 3 y 4 de diciembre de 2003.

17 Willaime, J. P., op. cit.

18 Casanova, J., op. cit.

19 Idem.

20 Idem.

21 Gellner, E., Muslim Society, Cambridge, Cambridge University Press, 1981, p. 69. 
1) La primera opción o tipo ha sido la experiencia secular de Turquía, donde las instituciones políticas occidentales y los valores sociales fueron introducidos radicalmente y acoplados con una religiosidad moderada y/o secularismo. La forma actual de este tipo podría presentar una reversión, que será discutida a continuación en este trabajo.

2) El segundo tipo es el polo opuesto, el patrón de Arabia Saudita, donde fueron acoplados la secta fundamentalista del islam sunita/wahabista y el sistema sociopolítico conservador-tradicionalista. ${ }^{22}$

3) El tercer tipo o patrón fue representado por Argelia, donde un sistema sociopolítico radical fue articulado con un alto grado de religiosidad. ${ }^{23}$

4) El cuarto tipo/patrón de la modernización o secularización fue representado por Túnez, donde un sistema social-político conservadortradicionalista fue acoplado con un grado moderado de religiosidad y/o secularismo. La promesa de la "Primavera árabe" de los años 2011 y 2012 permitió presentar una situación más optimista (democrática) en Túnez.

5) Irán representa el tipo de transformación consistente en una secularización forzada durante la época del sha, en contraste con la revolución islámica y junto con la "sunificación" de la secta chiita del islam durante sus transformaciones recientes. ${ }^{24}$

6) La experiencia secular en Egipto desde el periodo de Mohamed Alí hasta la revolución nasserista y su forma actual es un modelo híbrido que combina el tercer y cuarto tipo, pero que definitivamente es un tipo distinto. ${ }^{25}$ La "Primavera árabe" atrajo desarrollos antagonistas de secularización e islamización, a tal grado que resultó en un golpe de Estado militar.

7) El séptimo tipo o patrón puede ser descrito como el modelo de transformación baazista en Siria e Irak. Al igual que Egipto, este tipo también es híbrido, pero con sus propias características. ${ }^{26}$ En particular, la ocupación de Irak por una coalición liderada por el presidente

22 Véase Gellner, E., idem; así como Azmeh, A., Islam and Modernities, Londres, Verso Publications, 1993, pp. 104-121.

23 Gellner, Ernest, op. cit., p. 69.

24 Véase Najmabadi, E., "Hazards of Morality and Modernity: Women, State and Ideology in Contemporary Iran", en Kandioti, D. (ed.), Women, Islam and the State, London, MacMillan, 1991; y Parsa, M., Social Origins of Iranian Revolution, Nueva Jersey, Rudgers University Press, 1989.

25 Asad, T., Formations of the Secular: Christianity, Islam and Modernity, California, Standford University Press, 2003.

26 Joseph, S., "Elite Strategies for the State Building: Women, Family, Religion and State in Iraq and Lebanon", en Kandioti, D. (ed.), Women, Islam and the State, Londres, Macmillan, 1991. 
Esta obra forma parte del acervo de la Biblioteca Jurídica Virtual del Instituto de Investigaciones Jurídicas de la UNAM

Bush de Estados Unidos resultó en un desastre político y social mientras que la "Primavera árabe" en Siria llevó a la aparición del Estado islámico en Irak y Siria.

8) Las experiencias de secularización forzada de los países de Asia central tras la revolución soviética deben clasificarse en sus formas actuales después del colapso del modelo soviético como un tipo separado con sus propios subtipos. ${ }^{27}$ En las sociedades turcas postsoviéticas tales como Kirguistán y Kazajstán, se estableció una especie de campo religioso pluralista o "mercado", en el cual están operando sectas islámicas y no islámicas, denominaciones y organizaciones no gubernamentales religiosas que están compitiendo entre ellas ferozmente, aunque de manera pacífica. En países como Uzbekistán, Turkmenistán y Tayikistán, el "mercado" religioso está más restringido. ${ }^{28}$

Dicho lo anterior, en este trabajo intentaré dar cuenta de manera breve de las transformaciones del primer modelo en el mundo islámico, esto es, el caso turco. Es necesario presentar dicho caso en términos de una perspectiva diferenciada en un marco de secularización modernizante. En un primer momento, esta perspectiva será redefinida en el marco de un enfoque general de investigación que emerge de la experiencia occidental. En un segundo momento, señalaremos de forma breve las relaciones entre economía, religión y Estado. En tercer lugar, analizaremos el Estado y sus relaciones con el islam político, y por último, en conclusión, se resumirán brevemente los debates en la sociedad civil y la esfera pública y su relación con la religión.

III. RELACIONES DE ECONOMÍA, ESTADO, INSTITUGIONES EDUGATIVAS Y RELIGIÓN: HALLAZGOS DE UNA INVESTIGACIÓN EN TURQUÍA

\section{Marco teórico de la investigación}

Este trabajo se basa en los en datos de investigaciones recientes, que llevamos a cabo entre los años 2008-2011 con el apoyo del Consejo de Investigación Científica y Tecnológica de Turquía. ${ }^{29}$ El marco teórico de esta

27 Froese, P., "Forced Secularization in Soviet Russia: Why an Atheist Monopoly Failed", Fournal for Science Study of Religion, Estados Unidos, 2004, pp. 35-50.

28 Aksit, B. et al., "Islamist Civil Society Organizations", en Aktay, Y. (ed.), Islamism in Turkey, Iletisim Yayınları, 2004, pp. 664-681.

29 El proyecto de investigación fue realizada por Bahattin Aksit, Recep Sentuk, Onder Kucukural y Kurtulus Cengiz. El título del proyecto fue "La estructura social y la religión en Turquía”, núm. 108 K 202. El libro fue publicado como Aksit, B. et al., Türkiye'de Dindarlk: 
Esta obra forma parte del acervo de la Biblioteca Jurídica Virtual del Instituto de Investigaciones Jurídicas de la UNAM

investigación asume que en las sociedades modernas, la economía, el Estado, la esfera privada de la familia y las relaciones de género, así como la religión llevan lógicas relativamente autónomas entre sí, interconectándose a través de diversos canales. Se presentará a continuación, en el cuadro "Marco teórico para las preguntas de la entrevista a profundidad", una breve conceptualización del sustento teórico y las preguntas de investigación derivadas de ella.

El surgimiento y expansión de las sociedades modernas a través de la diferenciación de esferas/sistemas/campos de economía, Estado, instituciones educativas y economía doméstica han sido conceptualizados por los fundadores de la sociología del siglo XIX y resumidos por Parsons, Habermas en $1984,{ }^{30} 1987^{31}$ y $1989^{32}$ y Bourdieu en 1992. Esta teoría de la secularización-modernización en Europa occidental, como el primer lugar de estos desarrollos, ha postulado que las sociedades modernas se diferenciaron a través de tres revoluciones fundamentales. La primera es la revolución industrial que opera una separación entre la economía y el Estado, y hace de la primera un campo relativamente autónomo con su propia lógica. La segunda es una revolución democrática, que transforma el Estado absolutista en un Estado-nación moderno o una sociedad política, e instituye a los sujetos como ciudadanos y a la comunidad como sociedad civil. La tercera revolución es educativa, y lleva a cabo una distinción entre las universidades y otras instituciones educativas, como fiduciarias de la sociedad. ${ }^{33}$ Estas revoluciones diferenciadas permiten distinguir dentro del sistema social cuatro subsistemas relativamente autónomos, ${ }^{34} \mathrm{o}$ dicho a la manera de Chatterjee, presentar las sociedades políticas y civiles como cuatro sociedades diferenciadas: sociedad económica, sociedad política, sociedad civil y sociedad del conocimiento. ${ }^{35}$ Además de estas tres revoluciones y de la diferenciación de las cuatro sociedades, existe otra diferenciación básica en

Sosyal Gerilimler Ekseninde İnanç ve Yaşam Biçimleri, (Religiosidad en Turquía: modos de vida y creencia en el contexto de las tensiones sociales), Estambul, Ilotismo, 2012.

30 Habermas, J., The Theory of Communicative Action, Reason and Rationalization of Society, Boston, Beacon Press, 1984, vol. 1.

31 Habermas, J., The Theory of Communicative Action. Lifeworld and System: A Critique of Functionalist Reason, Cambridge, Polity Press, 1987, vol. 2.

32 Habermas, J., The Structural Transformation of the Public Sphere, Cambridge, Polity Press, 1989.

33 Parsons, T., The System of Modern Societies, Nueva Jersey, Printice-Hall, 1971.

34 Idem.

35 Chatterjee, P., The Politics of the Governed: Reflections on the Popular Politics of the Most of the World, Nueva York, Colombia University Press, 2004. 
Esta obra forma parte del acervo de la Biblioteca Jurídica Virtual del Instituto de Investigaciones Jurídicas de la UNAM

el proceso de modernización-secularización de Occidente: la diferenciación entre esfera pública y esfera privada. ${ }^{36}$

En países cristianos con mayorías protestantes, la religión fue replanteada en la esfera privada, al ser interiorizada por el individuo y el núcleo familiar. Tales diferenciaciones y transformaciones liberaron del control directo de las instituciones religiosas a estas cuatro sociedades en la esfera pública; sin embargo, los dictados religiosos protestantes fueron interiorizados por los creyentes y considerados como parte de los valores culturales casi "invisibles" y normas que permean la acción y las relaciones sociales. En cambio, en los países católicos, la religión permaneció más visible en la esfera pública y en la sociedad civil, aunque renunció al control directo de las cuatro sociedades diferenciadas y especialmente, del Estado. ${ }^{37}$

El siguiente cuadro describe las esferas diferenciadas. La primera columna está enfocada al sistema económico, que representa una de las esferas más importantes en la vida diaria. En la segunda columna se presenta el sistema político como el factor determinante en la modelación de los aspectos jurídicos de la vida cotidiana. La tercera columna es relativa al tema del género y de la familia, como el aspecto más importante en la esfera privada. Las columnas cuarta y quinta abordan la religión, la cual es dividida entre creencias y prácticas. En las filas del cuadro, se enumeran cinco tensiones relacionadas con la experiencia religiosa.

A lo largo de esta investigación, que duró tres años, entre 2008 y 2011 , los primeros seis meses fueron dedicados a la observación de participantes en ocho provincias de varias regiones de Turquía. La observación de la forma de vivir de acuerdo con las creencias de los participantes (principalmente de las corrientes sunita y alevita), en el contexto de la estructura social diferenciada actual, mostró que Turquía estaba atravesada por experiencias de tensiones.

Estas tensiones son patentes en las observaciones de los participantes y en las discusiones con hombres y mujeres que tienen diferentes roles y posiciones, y se presentan de la siguiente forma: la tensión entre lo sacro y lo mundano es fuente de preocupación en todo tipo de actuaciones y actividades. Otra fuente de tensión es el contraste entre lo que está escrito en el libro sagrado, el Corán, y la experiencia diaria. Un tercer recurso de tensión se hace patente entre el conocimiento religioso y el científico, especialmente cuando los dos tipos de conocimiento son antagónicos entre sí. La cuarta fuente de tensión surge cuando las personas realizan prácticas con fines

\footnotetext{
36 Habermas, véase notas 30, 31 y 32.

37 Casanova, J., op. cit.
} 
Esta obra forma parte del acervo de la Biblioteca Jurídica Virtual del Instituto de Investigaciones Jurídicas de la UNAM

públicos siendo que éstas son de índole privada, tal es el caso de rezar de forma pública o privada (aunque en etapas tempranas de la secularización de Turquía la práctica del rezo fue desplazada a la esfera privada). El quinto punto es relativo a las tensiones entre las interpretaciones tradicionales y modernas de las actividades cotidianas, de los significados religiosos y de las actuaciones. Las interrogantes que pueden representar esas tensiones y sus posibles soluciones son formuladas en las celdas de la sección transversal del siguiente cuadro.

\section{MARCO TEÓRICO PARA LAS PREGUNTAS \\ DE LA ENTREVISTA A PROFUNDIDAD ${ }^{38}$}

\begin{tabular}{|c|c|c|c|c|c|}
\hline & $\begin{array}{c}\text { Sistema } \\
\text { económico }\end{array}$ & $\begin{array}{l}\text { Sistema } \\
\text { politico }\end{array}$ & $\begin{array}{c}\text { Género } \\
\text { y familia }\end{array}$ & $\begin{array}{l}\text { Creencias } \\
\text { religiosas }\end{array}$ & $\begin{array}{l}\text { Práctica } \\
\text { religiosa }\end{array}$ \\
\hline $\begin{array}{l}\text { Sacro/ } \\
\text { mundano }\end{array}$ & $\begin{array}{l}\text { ¿Por qué } \\
\text { trabajas? } \\
\text { ¿Cuál es el } \\
\text { significado } \\
\text { del impuesto } \\
\text { religioso } \\
\text { para } \\
\text { ayudar a } \\
\text { otros? } \\
\text { (zekat) }\end{array}$ & $\begin{array}{l}\text { ¿Se debe } \\
\text { trabajar para } \\
\text { personas que } \\
\text { trabajan para } \\
\text { Dios? } \\
\text { ¿Qué } \\
\text { relación tienen } \\
\text { la política y la } \\
\text { religión? } \\
\text { ¿Cuál es el } \\
\text { lugar de los } \\
\text { intereses } \\
\text { materiales/ } \\
\text { temporales } \\
\text { en la } \\
\text { política? }\end{array}$ & $\begin{array}{l}\text { Reglas del } \\
\text { matrimonio } \\
\text { y religión; } \\
\text { selección } \\
\text { del cónyuge, } \\
\text { sexualidad. }\end{array}$ & $\begin{array}{l}\text { ¿Crees en } \\
\text { Dios? } \\
\text { ¿Crees en } \\
\text { una vida } \\
\text { en el más } \\
\text { allá? }\end{array}$ & $\begin{array}{l}\text { ¿Por qué } \\
\text { las personas } \\
\text { rezan/ } \\
\text { practican } \\
\text { rituales? } \\
\text { ¿Son } \\
\text { obligatorios } \\
\text { los rezos y } \\
\text { prácticas } \\
\text { religiosas? } \\
\text { ¿Sirven los } \\
\text { rituales para } \\
\text { los intereses } \\
\text { religiosos o } \\
\text { mundanos? }\end{array}$ \\
\hline $\begin{array}{l}\text { Escritural } \\
\text { experiencia }\end{array}$ & $\begin{array}{l}\text { ¿Qué } \\
\text { sentido } \\
\text { tienen los } \\
\text { intereses, } \\
\text { limosnas } \\
\text { religiosas/ } \\
\text { impuestos?, } \\
\text { ¿los ingresos } \\
\text { vienen de } \\
\text { Dios? }\end{array}$ & $\begin{array}{l}\text { Cuando el } \\
\text { derecho } \\
\text { religioso y el } \\
\text { derecho } \\
\text { secular están } \\
\text { en conflicto, } \\
\text { ¿cuál debes } \\
\text { escoger? }\end{array}$ & $\begin{array}{l}\text { ¿Es tu vida } \\
\text { familiar acor- } \\
\text { de al Corán y } \\
\text { a la Sunna? } \\
\text { ¿Hay en el } \\
\text { Corán y la } \\
\text { Sunna algún } \\
\text { ejemplo de } \\
\text { vida }\end{array}$ & $\begin{array}{l}\text { ¿Visita de } \\
\text { templos } \\
\text { religiosos } \\
\text { versus el } \\
\text { Corán? } \\
\text { ¿Qué } \\
\text { pensar } \\
\text { de las } \\
\text { creencias y } \\
\text { prácticas }\end{array}$ & $\begin{array}{l}\text { ¿Qué opinas } \\
\text { respecto de } \\
\text { la innovación } \\
\text { religiosa, } \\
\text { órdenes/ } \\
\text { comunidades } \\
\text { religiosas, } \\
\text { diferentes } \\
\text { denomina- } \\
\text { ciones en el } \\
\text { islam? }\end{array}$ \\
\hline
\end{tabular}

38 Cuadro tomado de Aksit et al., Turkiye'de Dindarlkk: Sosyal Gerilimler Ekseninde Inanc ve Yasam Bicimleri, cit., pp. 533-535. 
Esta obra forma parte del acervo de la Biblioteca Jurídica Virtual del Instituto de Investigaciones Jurídicas de la UNAM

\begin{tabular}{|c|c|c|c|c|c|}
\hline & $\begin{array}{l}\text { Sistema } \\
\text { económico }\end{array}$ & $\begin{array}{l}\text { Sistema } \\
\text { politico }\end{array}$ & $\begin{array}{c}\text { Género } \\
\text { y familia }\end{array}$ & $\begin{array}{l}\text { Creencias } \\
\text { religiosas }\end{array}$ & $\begin{array}{l}\text { Práctica } \\
\text { religiosa }\end{array}$ \\
\hline $\begin{array}{l}\text { Escritural } \\
\text { experiencia }\end{array}$ & $\begin{array}{l}\text { ¿Está la } \\
\text { ganancia } \\
\text { prohibida } \\
\text { por la } \\
\text { religión? }\end{array}$ & & $\begin{array}{l}\text { familiar, } \\
\text { crimen de } \\
\text { honor o ley } \\
\text { moral? }\end{array}$ & $\begin{array}{l}\text { supersticio- } \\
\text { sas? } \\
\text { ¿Se tiene la } \\
\text { necesidad } \\
\text { de un guía } \\
\text { espiritual? }\end{array}$ & \\
\hline $\begin{array}{l}\text { Escritural } \\
\text { experiencia }\end{array}$ & $\begin{array}{l}\text { ¿Se debe } \\
\text { obtener la la } \\
\text { autorización } \\
\text { religiosa? }\end{array}$ & & & & \\
\hline $\begin{array}{l}\text { Conocimiento } \\
\text { religioso/ } \\
\text { conocimiento } \\
\text { científico }\end{array}$ & $\begin{array}{l}\text { ¿Ciencia } \\
\text { de lo } \\
\text { económico } \\
\text { versus la } \\
\text { religión? } \\
\text { ¿Se debe } \\
\text { obtener un } \\
\text { permiso } \\
\text { religioso o } \\
\text { un consejo } \\
\text { científico } \\
\text { para los ne- } \\
\text { gocios? }\end{array}$ & $\begin{array}{l}\text { ¿Conocimien- } \\
\text { to legal secular } \\
\text { versus el } \\
\text { conocimiento } \\
\text { legal } \\
\text { religioso? }\end{array}$ & $\begin{array}{l}\text { ¿Qué opinas } \\
\text { de los bebés } \\
\text { de probeta? } \\
\text { ¿Abortar es } \\
\text { correcto si el } \\
\text { niño tuviera } \\
\text { alguna } \\
\text { discapaci- } \\
\text { dad? }\end{array}$ & $\begin{array}{l}\text { ¿Están en } \\
\text { conflicto la } \\
\text { ciencia y la } \\
\text { religión? } \\
\text { ¿Crees en } \\
\text { la creación } \\
\text { o evolu- } \\
\text { ción? }\end{array}$ & \\
\hline $\begin{array}{l}\text { Público/ } \\
\text { privado }\end{array}$ & \begin{tabular}{|l} 
¿Debe \\
gastarse \\
dinero para \\
propósitos \\
públicos o \\
privados? \\
¿Qué opinas \\
respecto del \\
consumo, \\
ostento y la \\
actitud de \\
desperdicio? \\
¿Tienen \\
relación la \\
religión y la \\
economía?
\end{tabular} & $\begin{array}{l}\text { ¿Deberían las } \\
\text { reglas políticas } \\
\text { y jurídicas es- } \\
\text { tar conformes } \\
\text { con la } \\
\text { religión o con } \\
\text { las } \\
\text { condiciones } \\
\text { materiales? }\end{array}$ & $\begin{array}{l}\text { Relaciones } \\
\text { masculino- } \\
\text { femenino. } \\
\text { ¿Las mujeres } \\
\text { se deben } \\
\text { cubrirse la } \\
\text { cabeza y el } \\
\text { cuerpo? } \\
\text { ¿Qué opinas } \\
\text { respecto del } \\
\text { coqueteo, la } \\
\text { cohabitación, } \\
\text { el } \\
\text { matrimonio } \\
\text { religioso y el } \\
\text { aborto? } \\
\text { ¿Debe haber } \\
\text { matrimonios } \\
\text { entre Alevi y } \\
\text { Sunita? }\end{array}$ & $\begin{array}{l}\text { ¿Debería } \\
\text { estar la } \\
\text { religión en } \\
\text { la esfera } \\
\text { privada o } \\
\text { pública? }\end{array}$ & $\begin{array}{l}\text { ¿Se relacio- } \\
\text { nan la esfera } \\
\text { pública y las } \\
\text { manifestacio- } \\
\text { nes religio- } \\
\text { sas? } \\
\text { ¿Se debe } \\
\text { tener una } \\
\text { práctica reli- } \\
\text { giosa } \\
\text { individual } \\
\text { o en } \\
\text { comunidad? }\end{array}$ \\
\hline
\end{tabular}


Esta obra forma parte del acervo de la Biblioteca Jurídica Virtual del Instituto de Investigaciones Jurídicas de la UNAM

MODELOS DE ESTADO SECULAR / LAICO:...

\begin{tabular}{|c|c|c|c|c|c|}
\hline & $\begin{array}{c}\text { Sistema } \\
\text { económico }\end{array}$ & $\begin{array}{l}\text { Sistema } \\
\text { politico }\end{array}$ & $\begin{array}{c}\text { Género } \\
\text { y familia }\end{array}$ & $\begin{array}{l}\text { Creencias } \\
\text { religiosas }\end{array}$ & $\begin{array}{l}\text { Práctica } \\
\text { religiosa }\end{array}$ \\
\hline $\begin{array}{l}\text { Tradicional } \\
\text { Imoderno }\end{array}$ & $\begin{array}{l}\text { ¿Se debe } \\
\text { creer de } \\
\text { acuerdo con } \\
\text { la lógica de } \\
\text { la econo- } \\
\text { mía o de } \\
\text { acuerdo con } \\
\text { la religión/ } \\
\text { tradición? }\end{array}$ & $\begin{array}{l}\text { ¿Cuál es la im- } \\
\text { portancia del } \\
\text { secularismo y } \\
\text { /o democra- } \\
\text { cia? } \\
\text { ¿Justicia o } \\
\text { equidad? }\end{array}$ & $\begin{array}{l}\text { ¿Se debe } \\
\text { enviar a los } \\
\text { niños a } \\
\text { cursos religio- } \\
\text { sos o a otras } \\
\text { actividades } \\
\text { como baile y } \\
\text { música? }\end{array}$ & $\begin{array}{l}\text { ¿Es posible } \\
\text { una } \\
\text { reforma en } \\
\text { el islam? } \\
\text { ¿Puede el } \\
\text { islam ser } \\
\text { reinter- } \\
\text { pretado } \\
\text { dependien- } \\
\text { do de la } \\
\text { época? }\end{array}$ & $\begin{array}{l}\text { ¿Se debe } \\
\text { rezar en el } \\
\text { cumpleaños } \\
\text { de } \\
\text { Moham- } \\
\text { med? ¿Se } \\
\text { deben visitar } \\
\text { santuarios } \\
\text { sagrados? }\end{array}$ \\
\hline $\begin{array}{l}\text { Tradicional } \\
\text { /moderno }\end{array}$ & & $\begin{array}{l}\text { ¿Islam y/o } \\
\text { democracia? } \\
\text { ¿Unión } \\
\text { Europea o } \\
\text { Estados } \\
\text { Unidos? } \\
\text { ¿Otomanos, } \\
\text { Ataturk o } \\
\text { Medio } \\
\text { Oriente? }\end{array}$ & $\begin{array}{l}\text { ¿Deben ir } \\
\text { las niñas a la } \\
\text { escuela } \\
\text { después de } \\
\text { una } \\
\text { determinada } \\
\text { edad? } \\
\text { ¿Pueden } \\
\text { trabajar las } \\
\text { mujeres en } \\
\text { público con } \\
\text { los hombres? } \\
\text { ¿Con sus } \\
\text { esposos? }\end{array}$ & & $\begin{array}{l}\text { ¿Se debe usar } \\
\text { una vesti- } \\
\text { menta reli- } \\
\text { giosa? ¿Bar- } \\
\text { ba y burka } \\
\text { religiosa? } \\
\text { ¿Deben los } \\
\text { hombres } \\
\text { usar una } \\
\text { vestimenta } \\
\text { religiosa? }\end{array}$ \\
\hline
\end{tabular}

\section{La economía turca y su relación con la religión}

La forma más corta de describir el desarrollo de la economía o de la sociedad económica en Turquía es a través de la periodización de 92 años, a partir del establecimiento de la República en 1923. Una de las cronologías más frecuentes es la siguiente: 39

1) El primer periodo entre 1923 y 1929 fue caracterizado por políticas económicas liberales. Este periodo liberal terminó con la gran depresión de 1929.

39 Para una discusión más detallada sobre la transformación de la estructura económica de Turquía en sus diversos periodos, véase Keyder, C., State and Class in Turkey: A Study in Capitalist Development, Londres, Verso Publications, 1987; así como Aksit, B. y Aksit, E. E., "Shifting Conceptions of Science, Religion, Society and State in Turkey", Middle East Critique, Suecia, vol. 19, núm. 1, 2010, pp. 71-87. 
Esta obra forma parte del acervo de la Biblioteca Jurídica Virtual del Instituto de Investigaciones Jurídicas de la UNAM

2) El segundo periodo entre 1929 y 1945 fue inspirado por la experiencia soviética de la planeación central estatal. Fue una economía mixta dominada y dirigida por el sector económico estatal.

3) El tercer periodo entre 1945 y 1960 consistió en una lenta liberalización de la fase estatal.

4) El cuarto periodo fue planeado como una economía mixta (19601980), que empezó con el establecimiento de la Organización Estatal de Planeación en 1960.

5) El quinto periodo inició con decisiones radicales de liberalización tomadas en 1980 y programas de ajuste estructural que fueron adoptados para sintonizar la economía a los estándares de la economía neoliberal, que se volvió dominante a nivel internacional.

6) El sexto periodo comenzó con el acoplamiento de las costumbres de la Unión Europea en 1995 y la candidatura a la Unión Europea en 1999. Sin embargo, la fecha de afiliación aún no ha sido acordada y, por lo tanto, las estructuras y las prácticas económicas se han dejado a la (des)coordinación de redes globales y a la dinámica de nivel nacional y regional.

Otra variante de esta cronología económica presenta los siguientes periodos largos. El periodo de industrialización por importación sustituta (1930-1980) y el periodo de industrialización orientada a la exportación desde los años 1980 hasta nuestros días.

El enfoque de la importación substituta fue promovido por el Estadonación y este tipo de industrialización promueve de manera creciente el Estado centralizado con una sociedad nacionalista y de políticas populistas. Este tipo de desarrollo económico populista también promovió el clientelismo en la sociedad política, pero no una sociedad civil con instituciones más democráticas. ${ }^{40}$ La adopción del enfoque de industrialización orientada a la exportación en Turquía fue seguida inmediatamente por una tercera intervención militar que se llevó a cabo entre 1980 y 1983. La liberalización económica fragilizó a la economía, como lo ilustran las crisis económicas de 1994 y de 2001-2002.

Los últimos trece años, de los 35 años de desarrollo económico neoliberal, fueron de la mano con un desplazamiento de la dominación de la economía por fracciones de la burguesía industrial y financiera seculares, hacia fracciones comerciales e industriales periféricas orientadas hacia el islam. A

40 Véase Keyder, C., State and Class in Turkey: a Study in Capitalism Development, Londres, Verso Publications, 1987; y Chatterjee, P., The Politics of the Governed: Reflections on the Popular Politics of the Most of the World, Nueva York, Colombia University Press, 2004. 
nivel político, este periodo fue caracterizado por tres mandatos del Partido Justicia y Desarrollo. Durante esta fase, se llevaron a cabo protestas a favor de una mayor democratización del Estado, y a favor de la secularización, en contra de la islamización de la esfera pública y del sistema político.

En la segunda mitad de los años 1990 hubo algunas discusiones acerca del ascenso del capital islámico ${ }^{41}$ que desafiaba el sistema secular, pero fueron desplazadas a un segundo plano durante la última década. La banca sin intereses y/o con participaciones entró a Turquía durante los años 1990; sin embargo, la cuestión de si su participación en el sistema bancario alcanzó un nivel crítico para influir en el sistema como un conjunto no es conocida y no ha sido discutida abiertamente en la actualidad.

He aquí un breve resumen de las opiniones que resultaron de las entrevistas a profundidad, respecto de las preguntas de la columna sobre el sistema económico en el cuadro acerca de la influencia de la religión en las actividades económicas diarias.

Los entrevistados pueden ser clasificados en cuatro grupos de acuerdo con sus opiniones acerca de la lógica del sistema económico con las enseñanzas de la religión y las tensiones que han experimentado al tomar decisiones. El primer grupo considera que el campo económico está operando desde su propia lógica a partir de la economía como ciencia social, en donde la religión no puede ni debe interferir. Los miembros de este primer grupo afirman que sus decisiones son tomadas con base en el conocimiento científico. Este grupo parece representar un tercio de la población adulta.

El segundo grupo opina que los actores económicos deben manejar sus actividades económicas tomando en cuenta los principios y normas religiosos mientras sea posible. Por ejemplo, no manejarán intereses al considerarlos como usura, la cual es prohibida por la religión. Sin embargo, si no es posible hacer una inversión sin un crédito bancario que implique una tasa de interés, tomarán su decisión de acuerdo con su propia lógica y razonamiento antes expresado.

El tercer grupo tomaría la misma decisión, tras haber consultado personas educadas de un modo religioso, y haber recibido su autorización.

El cuarto grupo no tomará decisiones en contra de las reglas religiosas. Incluso, algunos de ellos consideran que el Estado debe organizarse de acuerdo con las prescripciones religiosas e intervenir en actividades económicas conforme a las reglas de la Sharia. ${ }^{42}$

41 Nota de la traductora. El capital islámico se compone por un grupo de religiosos que a mediados de los años 1990 se volvieron ricos y acumularon un gran capital económico.

42 Guadro tomado de Aksit et al., Turkiye'de Dindarlkk: Sosyal Gerilimler Ekseninde İnanc ve Yasam Bicimleri, cit., pp. 320-327. 
Esta obra forma parte del acervo de la Biblioteca Jurídica Virtual del Instituto de Investigaciones Jurídicas de la UNAM

\section{Las relaciones Estado-religión}

Los Estados-nación se han establecido ya sea mediante una revolución desde abajo - una revolución democrática como la Revolución francesa-, o mediante una revolución desde arriba, como Alemania, Japón y Turquía. ${ }^{43}$ La experiencia turca de una revolución modernizante desde arriba se dio junto con la imposición del nacionalismo republicano-secularista, en el marco de un Estado central fuerte y una sociedad civil periférica débil. ${ }^{44}$ Con la finalidad de resumir 92 años de la era republicana en términos de cambios políticos, proponemos una cronología tentativa similar a la de las transformaciones económicas. ${ }^{45}$

1) Se establece una República secular con la destrucción del imperio otomano y del califato. Emerge un Estado-nación secular y se da un paso de aldeas tipo Gemeinschaft - tribus y comunidades-, a una sociedad o Gesellshaft, caracterizada como un Estado modernizado y centralizado con un sistema partidario único, de 1923 hasta1946.

2) Se da una transición hacia un sistema multipartidista en 1946 con la llegada al poder en 1950 de un partido de oposición. Es un periodo de dos políticas de partidos hasta la primera intervención militar en 1960.

3) Se adopta una nueva Constitución después del referéndum de 1961. El país se abre a la democracia, resurge la antigua izquierda junto con la nueva izquierda. Surge la generación del 1968 - de la cual soy miembro-, y se expanden y proliferan los sindicatos de trabajadores.

4) La segunda intervención militar en 1971 se lleva a cabo como reacción de la elite estatal en contra de los partidos en la sociedad

43 Véase Moore, B., Social Origins of Dictatorship and Democracy, Londres, Penguin Books, 1966; y Trimberger, K., Revolution from Above: Military Bureaucracy and Development in Fapan, Turkey, Egypt and Peru, Nueva Jersey, Transaction books, 1978.

44 Véase Mardin, S., "Center-Periphery Relations: A Key to Turkish Politics?", Daedalus, Massachusetts, vol., 102, núm. 1, 1973, pp. 69-190; i. d., "Some Notes on Normative Conflict in Turkey", en Berger, P. (ed.), The Limits of Social Cohesion: Conflict and Mediation in Pluralist Societies, Boudler, Westview Press, 1998; Heper, Metin, The State Tradition in Turkey, Walkington, Eothen Press, 1985; i. d. "The Strong State as a Problem for the Consolidation of the Democracy, Turkey and Germany Compared", Comparative Political Studies, California, vol. 25, núm. 2, 1992, pp. 125-151; y Keyder, C., op. cit.

45 Para una tentativa similar veáse Keyder, C., op. cit., 1987 y Aksit, B., "Shifting Conceptions of Science, Religion, Society and State in Turkey", Middle East Critique, vol. 19, 2010, pp. 71-87. 
política, de la proliferación de sindicatos, de las actividades de la generación de 1968 y de la acumulación de capital. El capitalismo tiende a independizarse del Estado. En la segunda mitad de los años 1970, un frente de gobiernos nacionalistas se establece en contra de las fuerzas y de los movimientos secularistas, socialistas y socialdemócratas. La polarización entre izquierda y derecha se agudiza y se superpone a la polarización entre sunitas y alevistas, lo cual generó enfrentamientos político-ideológicos a finales de los años 1970, que llevaron a la tercera y última intervención militar en $1980 .{ }^{46}$

5) Una tercera Constitución más restrictiva y represiva es adoptada mediante referéndum en 1982. Todos los partidos, incluyendo al Partido Republicano del Pueblo - fundador de la República - son disueltos, y la sociedad política es aplastada. La Junta militar sólo permitió a tres partidos instituirse y participar en las elecciones de 1983, de las cuales surgió un gobierno civil. Para las elecciones de1987, había más partidos autorizados. Sin embargo, no es sino hasta las elecciones de 1991 cuando los antiguos partidos pueden restablecerse, al surgir de manera exitosa de la contienda y al establecer un gobierno de coalición, desplazando la polarización izquierda-derecha de los años 1970 a un segundo plano.

6) Muchos partidos entran en las elecciones de 1995, no obstante, el partido religioso, que había sido clausurado dos veces al ser considerado como una amenaza a la naturaleza secular del Estado, obtiene el porcentaje más alto de los votos $(21 \%)$ y establece un gobierno de coalición en 1996. En 1997, junto con las organizaciones de la sociedad civil, el ejército impugna la coalición de gobierno con motivo de sus actos antiseculares y el gobierno fue derrocado como resultado de esta impugnación, conocida como la intervención posmoderna. Más tarde, el partido es clausurado por la Corte Constitucional con cargos de violación al secularismo.

7) La coalición establecida después de las elecciones de 1999 impulsa algunos cambios constitucionales para democratizar el Estado y preparar al país para una candidatura a la Unión Europea. Al pasar por una crisis económica y el gobierno lleva al país a elecciones anticipadas en 2002. Esta contienda fue dominada por una facción del anteriormente clausurado partido del islam político, con $35 \%$ de los votos, lo que le aseguró dos terceras partes de los escaños parlamentarios. Se llevaron a cabo más cambios constitucionales acompaña- 
dos de una intensa actividad legislativa para descentralizar el Estado y modificar la repartición de competencias. Tales reformas jurídicas se llevaron a cabo en el marco de un programa de acción nacional para la afiliación a la Unión Europea. Estas dos últimas etapas fueron caracterizadas por intensos debates relativos a la secularización/ laicización versus la islamización, los cuales sustituyeron aquellos relativos a la izquierda versus la derecha, o el socialismo versus el capitalismo en los años 1960 y 1970 . A partir de 1995, estos debates se han vuelto más intensos con la proliferación de discursos sobre el islam, el islam político y la secularización/laicización.

Estos debates han girado acerca de la naturaleza secular del Estado y de la implementación del secularismo en las instituciones públicas y la esfera pública, y fueron especialmente agudos en 1996 y 1997, cuando el partido considerado como representativo del islam Político estaba en el poder. Generaron un incremento de los movimientos de masa y de manifestaciones que condujeron al llamado golpe posmoderno de 1997. Estos debates se han mantenido de diversas maneras, a veces moderadas y a veces agudas, a partir de la llegada al poder en 2002 del partido Justicia y Desarrollo (AKP), un partido escindido del partido islamista político, con declaraciones sobre su islamismo y enfatizando su perfil conservador-democrático. El nuevo partido prometió transformar las estructuras jerárquicas del Estado secular removiendo las estructuras e instituciones restrictivas, y abriendo el camino para la democratización, y de forma simultánea, la islamización de la sociedad.

En 2004, dos años después del ascenso al poder del PJD/AKP, se promulgó una nueva Ley de Reforma de la Administración Pública, que prometía más participación y descentralización de las estructuras estatales. Sin embargo, algunos artículos, al menos un tercio de ellos, fueron vetados por el presidente de la República, con el motivo de que la nueva ley otorgaba una autoridad generalizada y sin restricción a las autoridades locales, y restringía el poder del Estado centralizado en áreas específicas. El presidente de la República, de tendencia secular y nacionalista, y quien además había sido el jefe anterior de la Corte constitucional, argumentó que, de acuerdo con la Constitución vigente, la autoridad general pertenece al Estado unitario, mientras que las autoridades locales, el gobierno local y los municipios tienen su jurisdicción en áreas geográficas específicas del país bajo el control del gobierno central. Ciertamente, el miedo al separatismo kurdo tuvo relevancia en esta decisión. 
Además, de acuerdo con el presidente de la República, la Ley de Reforma de la Administración Pública abrió el camino para la contratación de mujeres islámicas con velo en las oficinas gubernamentales locales. Se recordó que tanto la Corte Constitucional turca como la Corte Europea de Derechos Humanos consideraron que en el Estado secular las mujeres que usan el velo islámico no pueden ser autorizadas a trabajar o acudir a las escuelas y universidades públicas sin antes retirarlo. Un intenso debate se desató en torno a la decisión de la Corte Constitucional sobre el velo en Turquía. ¿Cuál es el alcance de la esfera pública para un musulmán moderno en un país secular como Turquía? ¿Cuál es el rol de la religión en el Estado y en la esfera pública? Parece que mientras el antiguo Partido Islamista en el poder de 1995 a 1997 reclamaba una visión religiosa en las instituciones estatales, el partido en el poder en 2005 aseguraba la naturaleza secular al Estado, pero pedía al mismo tiempo el reconocimiento de la religión en la esfera pública y en la sociedad civil.

El problema del velo islámico en las universidades fue resuelto después de la llegada al poder del PJD /AKP por segunda vez en 2007 y especialmente cuando llegó por tercera vez en 2011. Se ha autorizado que las mujeres con velo trabajen en instituciones públicas y parece que en las próximas elecciones de junio de 2015, algunos miembros femeninos del parlamento usarán el velo islámico. El péndulo oscila desde la elección de 1999, cuando a un miembro del parlamento con velo islámico se le impidió prestar juramento para empezar con su cargo, hasta las elecciones de 2015 con la presencia de miembros del parlamento con velo. Esta problemática ha sido ampliamente investigada mediante un trabajo de encuestas, pero el tiempo y el espacio no son suficientes para incluirla en este documento.

Nos enfocaremos, en cambio, en la discusión de la relación entre el islam y la democracia con base en las entrevistas a profundidad presentadas en la columna de sistema político del cuadro. Debe aclararse desde un principio que esta problemática abarca un amplio espectro de opiniones. El grupo de entrevistados que piensa que el islam y la democracia son incompatibles se encuentran en dos campos opuestos.

El primero está constituido por islamistas, los cuales creen que la democracia diluye los principios de la religión. Por lo tanto, consideran que la ley islámica estricta ha de regir el país como ley absoluta dada por Dios, en lugar de las leyes pluralistas y relativistas hechas por los hombres.

El segundo grupo, que piensa que el islam es incompatible con la democracia, lo constituye el polo secular, el cual considera que las leyes deben basarse en la razón secular y científica como única fuente de derecho y guía absoluta en el mundo. 
Un tercer grupo está conformado por personas religiosas que parecen estar cómodas con el sistema económico y político que está consolidado a nivel nacional e internacional. Para ellos, una democracia pluralista que brinda espacios relativamente libres para la práctica de sus creencias tanto en la esfera pública como en la privada parece ser la mejor opción disponible.

Finalmente, el cuarto grupo agrupa a las personas seculares que están dispuestas a vivir en una sociedad democrática y pluralista en la cual las comunidades, así como las asociaciones religiosas y seculares coexistan y se reorganicen en lugar de pelear entre sí, destruyéndose o subordinándose.

\section{CONCLUSIÓN}

En uno de sus artículos más provocadores, Mardin expuso que la experiencia secular de Turquía eclipsó "los procesos otomanos de intermediación difusa" tales como las redes de órdenes sufies y otras asociaciones fuera de la esfera privada y el Estado Central. ${ }^{47}$ El Estado central fuerte y la sociedad periférica débil iban a ser conectados mediante las nuevas instituciones intermediarias laicas y republicanas como "casas del pueblo", ${ }^{48}$ los clubes, las asociaciones culturales y por supuesto el Partido Republicano del Pueblo, el único partido de la república hasta 1946. Como ha sido presentado brevemente en este trabajo, a partir de la transición a un sistema multipartidista en 1946, y desde entonces, han aparecidos muchos partidos y asociaciones políticas-ideológicas en la sociedad política. Además, después de las migraciones ruralesurbanas masivas en el periodo 1950-1980, la sociedad civil se desarrolló de forma continua, inicialmente con la construcción de mezquitas y mediante asociaciones de embellecimiento de barrios y pueblos. Sin embargo, durante la década 1970, surgieron movimientos de "organización de masas democráticas", discursos y redes en forma polarizada ideológicamente. Estas nuevas organizaciones, que luchaban entre sí y contra el Estado, eran asociaciones de todo tipo, pero especialmente sindicatos de trabajadores y organizaciones de cámaras profesionales de ingenieros, médicos y abogados. Durante los años 1990, estas diferentes organizaciones y asociaciones fueron renombradas como organizaciones de la sociedad civil (OSC), en lugar de organizaciones no gubernamentales $(\mathrm{ONG})$ como en las sociedades occidentales.

Un año después del terremoto ocurrido en Marmara en 1999, llevé a cabo de manera conjunta con otros colegas una investigación acerca de las

\footnotetext{
47 Mardin, S., "Some Notes on Normative Conflict in Turkey", cit.

48 Nota de la traductora. Las casas del pueblo son asociaciones seculares republicanas donde la gente fue educada para ser ciudadanos seculares durante la era revolucionaria del Estado turco secular.
} 
asociaciones de la sociedad civil en Turquía. El estudio de tres periódicos durante un año después del terremoto hizo patente el perfil de un Estado central lento e ineficiente, en oposición a una sociedad civil de aparición reciente ágil. ${ }^{49}$ Sobre la base de los datos de la encuesta, una segunda fuente de datos fue recogida a través de un análisis por conglomerados de 39 OSC. El análisis de conglomerado se basó en 24 declaraciones de tipo Likert, que fueron diseñadas para capturar los valores y normas actuales en Turquía, tal como el papel del Estado en la formación de la sociedad civil, la relación entre el Estado, los ciudadanos y la sociedad, la participación política, los movimientos sociales, liderazgo en las organizaciones de la sociedad civil, el papel de los intelectuales en la formación de la sociedad civil, el lugar de las sectas religiosas en la sociedad civil, la radiodifusión en lengua kurda, la disolución de los partidos políticos y la prohibición del velo en las universidades. El análisis de conglomerados de los datos de la encuesta indicó los siguientes resultados: las organizaciones de nivel más abstracto son agrupados en dos aglomerados que pueden ser llamados OSC principales y OSC opositoras. El aglomerado de las OSC principales está compuesto de dos grupos: el primero, la principal-liberal se divide en cuatro subgrupos de acuerdo con lo siguiente: los sindicatos con inclinación izquierdista; las cámaras profesionales; las OSC liberales y las OSC kemalistas. La segunda, principalconservadora, se divide en tres subgrupos: sindicatos islamistas y nacionalistas; organizaciones de empleadores, comerciantes y artesanos; y las OSC nacionalistas y conservadoras islamistas. Estos son los siete grupos o conglomerados que constituyen el primer grupo de las OSC principales. El segundo grupo, en el nivel más abstracto, están las OSC opositoras, que se divide de la manera siguiente: un primer grupo se inclina hacia la izquierda y el otro en la dirección islamista. Hay una organización de derechos humanos en cada uno de estos dos conglomerados. El conglomerado principal agrupa a las asociaciones de oposición izquierdistas e islamistas ya que tienen puntos de vista parecidos en torno al Estado y a la sociedad civil, debido a enfrentamientos similares con el Estado. Los miembros de estas OSC opositoras apoyaron mucho las ideas acerca de la libertad individual, los derechos de los ciudadanos contra el Estado, la autonomía de la políticas del ejército y otros.

Aun cuando la corriente principal y la de oposición de las OSC tuvieron evaluaciones relativamente similares en torno al papel del Estado, que

49 Aksit, B. et al., "Civil Society Organizations and State in the Context of Earthquake as Represented in Three Newspapers in Turkey", Culture and Modernity, Ankara, Turkiye Kultur Arastırmaları ve Tetragon yayını, 2003, pp. 157-179. 
Esta obra forma parte del acervo de la Biblioteca Jurídica Virtual del Instituto de Investigaciones Jurídicas de la UNAM

es visto como un obstáculo para el desarrollo de la sociedad civil, y la existencia de una división centro-periferia, están muy diferenciados entre sí, principalmente debido a sus respuestas sobre los temas críticos de la agenda político-cultural, como el islam político y la cuestión kurda. Ciertas OSC liberales y apolíticas, así como OSC políticamente conservadoras, tienen la misma opinión sobre la visión excluyente del Estado hacia las situaciones relacionadas con el Islam político y la etnia kurda. Las opiniones acerca del Estado centralista, de los derechos y libertades del individuo, y, sobre todo, las implicaciones de temas relacionados con el islam y la cuestión kurda diferencian a las OSC islamistas y a las de izquierda entre sí mismas. En otras palabras, las OSC islamistas e izquierdistas se dividen en dos grandes grupos: las conservadoras/principales y las de oposición. En este marco, algunas OSG izquierdistas, más cercanas al Estado centralista burócrata con una preferencia por la perspectiva secular kemalista, se diferenciaron de otras OSC de izquierda del segundo conglomerado, ya que éstas apoyan los derechos humanos, son críticos hacia el militarismo, el centralismo y el Estado kemalista burocrático. En segundo lugar, las OSC islamistas se diferencian entre sí, principalmente debido a las diferentes posturas sobre los derechos humanos, la problemática kurda y la democracia..$^{50}$ Un repaso histórico de la experiencia modernizante turca revela que dos conflictos o temáticas dominaron los discursos de la sociedad civil en la esfera pública: la secularización y el nacionalismo. Mardin apunta que el islam versus el secularismo republicano se ha sobrepuesto al centro versus la periferia, y la elite versus las masas. ${ }^{51}$ Sin embargo, cabe señalar que el nacionalismo turco versus el kurdo se presenta como un eje transversal en algunas de estas polaridades.

Para concluir, se puede afirmar que en Turquía surgió una sociedad civil democrática y pluralista y una esfera pública en la cual se permite con mayor frecuencia la presencia de símbolos religiosos y étnicos, y donde los enemigos son considerados cada vez más como adversarios de oposición

50 Aksit, B. et al., "Civil Society in Turkey: Its Development and Squeeze between Nation-State, Globalisation and Communiterianism" (en turco), en Dikmen, A. A. (ed.) Political Thought and Modernization in Republican Period, Ankara, Turk Sosyal Bilimler Dernegi-İmaj Yayinları, 2002, pp. 401-427; Aksit, B. et al. "Discourses of Civil Society in Turkey: Opinions of Members and Managers of Civil Society Organizations towards State and Society" (en turco), en Ornek A. (ed.), Civil Society Organizations, Localization and Local Government, Estambul, Tarih Vakfi Yayınları, 2002, pp. 133-154; Aksit, B. et al., "Civil Society Organizations and State in the context of Earthquake as Represented in Three Newspapers in Turkey" (en turco), en Pultar, G. et al. (eds.) Culture and Modernity, Ankara, Turkiye Kultur Arastırmalar1Tetragon yayını, 2003, pp. 157-179.

51 Mardin, "Some Notes on Normative Conflict in Turkey", cit., p. 225. 
política que pueden ser confrontados mediante el debate. Sin embargo, una paradoja puede contraponerse a esta optimista nota final. La paradoja reside en las reformas democratizadoras relacionadas con la Unión Europea. El actual partido democrático conservador "Justicia y Desarrollo", con raíces en el Islam político, ha estado llevando a cabo algunas reformas democratizadoras, por un lado; sin embargo, por el otro, promovió algunas leyes orientadas a la seguridad que restringen los derechos reconocidos en las reformas democratizadoras. La paradoja está relacionada con la posibilidad de islamizar la sociedad, y de este modo fortalecer las estructuras de autoridad jerárquica basadas en la fe, y prever un Estado secular que tenga la misma distancia o cercanía para todas las religiones y sectas, creyentes y no creyentes. El actual gobierno trabaja en la dirección de un cambio de las prácticas elitistas excluyentes de los gobiernos anteriores hacia el islamismo y el nacionalismo kurdo. Sin embargo, es preocupante para los sectores seculares que el actual gobierno fomente prácticas excluyentes respecto a ellos.

Además, los nuevos desarrollos globales parecen estar reforzando algunas tendencias en la dirección de desdiferenciación, desmodernización y desecularización o postsecularización que ponen en peligro las lógicas relativamente autónomas de sectores como la economía, el sistema universitario y los campos de las ciencias y las artes. El actual partido (con orientación religiosa) que está en el poder parece tomar la iniciativa y trabajar para el fortalecimiento de estas tendencias en contra del Estado secular y los sectores de la sociedad secular. Los resultados de las elecciones de junio de 2015 nos mostrarán que tendencia prevalecerá.

\section{BIBLIOGRAFÍA}

Aksit, B., "Social Change and Cleavage in a Middle-Sized Turkish City", PhD Dissertation, Department of Sociology, Illinois, University of Chicago, 1975, disponible en University Microfilms Ann Arbor, Michigan.

-, Social Change in Villages, Towns and Cities in Turkey (título original en turco), Ankara, Turhan Kitabevi, 1985.

, "Islamic Education in Turkey: Medrese Reform in Late Ottoman Times and Imam- Hatip Schools", en TAPPER R. (ed.), Islam in Modern Turkey: Religion Politics and Literature in a Secular State, Londres, I B Tauris and School for Oriental and African Studies, University of London, 1991. 
Esta obra forma parte del acervo de la Biblioteca Jurídica Virtual del Instituto de Investigaciones Jurídicas de la UNAM

y AKsiT, E. E., "Shifting Conceptions of Science, Religion, Society and State in Turkey", Middle East Critique, Suecia, vol. 19, núm. 1, 2010. et al., Turkiye'de Dindarlk: Sosyal Gerilimler Ekseninde Inanc ve Yasam Bicimleri (Religiosity in Turkey: Modes of Life and Belief in the Context of Social Tensions), Estabul, Iletisim Publications, 2012.

et al., "Islamist Civil Society Organizations" (en turco), en AKTAY, Y. (ed.), Islamism in Turkey, Ankara, Iletisim Yayınları, 2004.

y Coskun, M. K., "İmam-Hatip Schools in the Context of Modernization in Turkey" (en turco), en AKTAY, Y. (ed.), Islamism in Turkey, Ankara, Iletisim Yayınları, 2004.

et al., "Civil Society in Turkey: Its Development and Squeeze between Nation-State, Globalization and Communitarianism" (en turco), en Dikmen, A. A. (ed.) Political Thought and Modernization in Republican Period, Ankara, Turk Sosyal Bilimler Dernegi-İmaj Yayınları, 2002.

Managers of Civil Society Organizations towards State and Society" (en turco), en Ornek, A. (ed.), Civil Society Organizations, Localization and Local Government, Estambul, Tarih Vakfi Yayınları, 2002.

, "Civil Society Organizations and State in the context of Earthquake as Represented in Three Newspapers in Turkey" (en turco), en PULTAR, G. et al. (eds.), Culture and Modernity, Ankara, Turkiye Kultur ArastırmalarıTetragon yayını, 2003.

AL-AzMeH, A., Islam and Modernities, Londres, Verso Publications, 1993.

ASAD, T., Formations of the Secular: Christianity, Islam and Modernity, California, Stanford University Press, 2003.

Bardakoglu, A., "Moderation in Islam: Turkish Experience, Mission and Vision of the Diyanet as Public, Independent and Civil Institution", Middle East Center, University of Utah, núm. 21-22, February 2004, disponible en: http://wrere.diyanet.gov.tr.

Bourdieu, P. y Wacquant, L. J. D., An Invitation to Reflexive Sociology, Chicago, The University of Chicago Press, 1992.

Casanova, J., Public Religions in the Modern World, Chicago, University of Chicago Press, 1994.

Castells, M., The Rise of the Network Society: the Information Age: Economy, Society, and Culture, Oxford, Blackwell Publishers, 1996.

Chatterjee, P., The Politics of the Governed: Reflections on the Popular Politics of the Most of the World, Nueva York, Columbia University Press, 2004. 
Esta obra forma parte del acervo de la Biblioteca Jurídica Virtual del Instituto de Investigaciones Jurídicas de la UNAM

CAKIR, R. et al., Imam-Hatip Schools: Myths and Realities (en turco), Estambul, TESEV Research Report, 2004.

Calhoun, C. (ed.), Habermas and the Public Sphere, Cambridge, The MIT Press, 1992.

Durham, W. Cole, "Freedom of Religion or Belief in Constitutional Orders", Conferencia en OSCE Office of Democratic Institutions and $\mathrm{Hu}-$ man Rights, and State Committee for Religious Affairs of the Kyrgyz Republic, Osh, 3 y 4 de diciembre, 2003.

FIRAT, K., "Urban Alevilik: Self Perceptions in Two Neighborhood of Ankara", M. A. Thesis, Ankara, Department of Sociology, Graduate School of Social Sciences, Middle East Technical University, 2004.

Froese, P., "Forced Secularization in Soviet Russia: Why an Atheistic Monopoly Failed", Journal for Scientific Study of Religion, Washington, vol. 43, núm. 1, 2004.

Habermas, J., The Theory of Communicative Action, Reason and Rationalization of Society, Boston, Beacon Press, 1984, vol. 1.

- The Theory of Communicative Action. Lifeworld and System: A Critique of Functionalist Reason, Cambridge, Polity Press, 1987, vol. 2. Press, 1989.

HARDT, Michael y NEGRI, Antonio, Empire, Cambridge, Harvard University Press, 2000.

HePer, Metin, The State Tradition in Turkey, Walkington, Eothen Press, 1985. -, "THE Strong State as a Problem for the Consolidation of the Democracy, Turkey and Germany Compared", Comparative Political Studies, California, vol. 25, núm. 2, 1992.

Gellner, E., Muslim Society, Cambridge, Cambridge University Press, 1981. JaLAL, A., "The Convenience of Subservience: Women and the State of Pakistan”, en KAndioti, D. (ed.), Women, Islam and the State, Londres, MacMillan, 1991.

JosePH, S., "Elite Strategies for State Building: Women, Family, Religion and State in Iraq and Lebanon", en Kandioti, D. (ed.), Women, Islam and the State, Londres, MacMillan, 1991.

Keyder, C., State and Class in Turkey: A study in Capitalist Development, Londres, Verso Publications, 1987.

Laclau, E., The New Reflections on the Revolution of Our Time, Nueva York, Verso Publications, 1990. 
Esta obra forma parte del acervo de la Biblioteca Jurídica Virtual del Instituto de Investigaciones Jurídicas de la UNAM

Mardin, S., "Center-Periphery Relations: A Key to Turkish Politics?", Daedalus, Massachusetts, vol. 102, núm. 1, 1973.

, "Some Notes on Normative Conflict in Turkey", en BERGER, P. (ed.), The Limits of Social Cohesion: Conflict and Mediation in Pluralist Societies, Boudler, Westview Press, 1998.

Moore, B., Social Origins of Dictatorship and Democracy, Londres, Penguin Books, 1966.

NAJMABADI, E., "Hazards of Morality and Modernity: Women, State and Ideology in Contemporary Iran", en KANDIOTI, D. (ed.), Women, Islam and the State, London, MacMillan, 1991.

Olson, E. A., "Muslim Identity and Secularism in Contemporary Turkey: «Headscarf Dispute»", Anthropological Quarterly, Washington, vol. 58, núm. 4, 1985.

OzDAlgA, E., The Veiling Issue, Officail Secularism, and Popular Islam in Turkey, Richmond Surrey, Curzon Press, 1998.

PARSA, M., Social Origins of Iranian Revolution, Nueva Jersey, Rudgers University Press, 1989.

Parson, T., The System of Modern Societies, Nueva Jersey, Printice-Hall, 1971. y Platt, G. M., The American University, Cambridge, Harvard University Press, 1973.

Trimberger, K., Revolution From Above: Military Bureaucracy and Development in Japan, Turkey, Egypt and Peru, Nueva Jersey, Transaction Books, 1978.

URRY, John, "Social Networks, Travel and Talk", The British Fournal of Sociology, Londres, vol. 54, junio 2003.

WiLLaIME, J. P., "Religion, State and Society in Germany and France", texto presentado en la reunión anual de la Association for the Sociology of Religion, Atlanta, agosto 2003, disponible en: http://hirr.hartsem.edu/sociology/ sociology_online_articles_willaime.html. 


\title{
LAICIDAD, SEGULARIZACIÓN Y PLURALISMO. REFLEXIONES DESDE EL CASO URUGUAYO
}

\section{Néstor DA COSTA*}

\begin{abstract}
SUMARIO: I. Introducción. II. El proceso laicizador uruguayo. III. Laicidad, espacio público, educación y política. IV. La laicidad referida a lo político. V. Los diversos énfasis de la laicidad. VI. La Iglesia católica y la laicidad uruguaya. VII. Laicidad, secularización y pluralismo. VIII. Bibliografia.
\end{abstract}

\section{INTRODUCGIÓN}

Uruguay es un pequeño país del sur de América Latina que construyó una experiencia de laicidad fuertemente inspirada en el modelo francés y que incluso llegó a niveles de mayor radicalidad. Esta asunción hace necesario compartir algunas de las características de la laicidad uruguaya. Todos hablamos desde algún lugar y un tiempo concreto, más allá de nuestros esfuerzos por tener lecturas "avalorativas" como sociólogos.

Previamente recordemos que el término "laicidad" no tiene un significado unívoco ni dentro ni fuera de fronteras ni muchos menos universal, pese a que los uruguayos creemos que es lo más natural del mundo, y cuando salimos al exterior volvemos impresionados por cómo se vive lo religioso dentro del espacio público en otros países.

Entiendo necesario tomar el fenómeno de la laicidad como un proceso, o varios procesos, más que como un modelo predefinido a seguir o alcanzar. Asume diferentes modalidades y formatos según diversos lugares, historias, actores involucrados. Son pocos los países donde el término laicidad tiene una significación importante. Sabemos que no tiene traducción a idiomas

* Docente e investigador en el Instituto Universitario CLAEH (Uruguay) y en la Universidad Católica del Uruguay. 
Esta obra forma parte del acervo de la Biblioteca Jurídica Virtual del Instituto de Investigaciones Jurídicas de la UNAM

como el inglés o el alemán, o sea que en esas comunidades lingüísticas no tiene significación cultural.

¿Qué es la laicidad para un uruguayo? Si lo miramos desde Uruguay quizá no podamos llegar tampoco a una respuesta única, sino a identificar elementos presentes en la construcción social del concepto y en la disputa por la apropiación del significado e implicaciones del mismo. Si nos atenemos a una revisión de las apariciones del asunto en el debate público, en Uruguay apreciaremos que el término "laicidad" surge ligado, la mayor parte de las veces, al sistema educativo estatal, a la separación Iglesia católica-Estado, a la presencia de lo religioso en lo público y, en muchas ocasiones, se presenta acompañado de una expresión, la expresión "violación de la laicidad".

Usualmente hay dos énfasis distintos en este enunciado violatorio: por un lado la vulneración de la neutralidad de lo estatal, entendido como lo público ante lo religioso, y por otro la vulneración de neutralidad de lo estatal ante lo político partidario o ideológico. La historia uruguaya indica que la separación entre el Estado y la Iglesia católica se produjo en la Constitución nacional de 1919. Dicha separación se concretó en un clima de fuertes enfrentamientos entre los actores de la época. La separación no fue solamente institucional y formal, distanciando dos institucionalidades, sino que implicó un desplazamiento de lo religioso a la esfera de lo privado. Se desplazó lo religioso de lo estatal y también de lo público, del espacio público, recluyéndolo en la esfera de lo privado.

Es innegable y determinante la influencia de la laicidad francesa en la construcción del modelo de laicidad uruguaya. Las elites uruguayas constructoras del Estado naciente a fines del siglo XIX y comienzos del XX tenían en Francia su fuente de inspiración. A propósito del modelo francés me gustaría citar a la colega canadiense Micheline Milot quien señala:

La laicidad francesa ha estado y todavía lo está, fuertemente articulada y unida a una concepción de pertenencia ciudadana que pocas naciones occidentales han adoptado. La ciudadanía republicana francesa corresponde a una utopía política referida a aquello que en la pertenencia nacional de cada ciudadano se traduce por una relación directa con el Estado, lazo que excluye toda mediación por pertenencias a una categoría social, a un grupo o una Iglesia. La construcción de ciudadanía supone que sean relegadas a un segundo plano las adhesiones comunitarias que ponen en riesgo la relación política. ${ }^{1}$

Precisamente este enfoque es también el que asumió el modelo de laicidad uruguayo en el que el Estado y lo público se identifican, y los ciuda-

1 Milot, Micheline, La laicidad, Madrid, CCS, 2009. 
Esta obra forma parte del acervo de la Biblioteca Jurídica Virtual del Instituto de Investigaciones Jurídicas de la UNAM

danos tienen en aquél a su gran protector y proveedor de bienes necesarios para la vida material y simbólica. ${ }^{2}$ Un modelo de corte fuertemente jacobi$\mathrm{no}^{3}$ con su correspondiente carga de Ilustración.

La separación Iglesias-Estado es parte del fenómeno para el caso uruguayo, pero no todo se resume a ella. Esta separación implica y expresa neutralidad del Estado frente a lo religioso. Esa neutralidad asume en Uruguay dos vetas interpretativas, por un lado, entendida como imparcialidad frente a las creencias de los ciudadanos, y, por otro, como prescindencia o ignorancia de las mismas y ésta última es la que ha sido hegemónica en el Uruguay durante prácticamente todo el siglo XX y llega hasta nuestros días, aunque quizá con menos fuerza que en épocas anteriores.

El énfasis en la neutralidad reposa sobre el supuesto de la centralidad de los ciudadanos y el reconocimiento a éstos de sus derechos y opciones como parte constitutiva del conjunto social. En tanto el segundo énfasis mencionado, el de la prescindencia o ignorancia, se apoya en un supuesto por el cual el conjunto social, encarnado en el Estado no puede "ver" lo religioso, no le interesa, ignorándolo, prescindiendo de él.

En síntesis, estas dos formas implican una distinta actitud hacia los ciudadanos; la primera los reconoce como tales y acoge sus opciones, en tanto que la segunda impone a los ciudadanos la necesidad de alejar de lo público (de la polis) sus convicciones.

\section{EL PROGESO LAICIZADOR URUGUAYO}

Para comprender la laicidad uruguaya actual tenemos que referirnos aunque sea muy brevemente al proceso laicizador e identificar algunos de los principales eventos del mismo. Es necesario mencionar que la Iglesia católica uruguaya fue, al igual que las demás instituciones coloniales, de débil y tardía implantación en lo que entonces fuera la Banda Oriental y luego la República Oriental del Uruguay. El territorio uruguayo no ofrecía atractivo para los colonizadores al no tener riquezas propias e incluso la ciudad de Montevideo (originalmente San Felipe y Santiago de Montevideo) fue fundada tardíamente, recién en 1724. La debilidad de implantación de la Iglesia católica como institución colonial, continuó en el tiempo con un clero escaso y disperso, y la también tardía erección de la diócesis de Montevideo (única del país por décadas).

2 Andachat, Fernando, Signos reales del Uruguay imaginario, Uruguay, Trilce, 1992.

3 El jacobinismo era una corriente en la Revolución francesa que proclamaba una voluntad de unificación al elminar todos los factores individuales o colectivos de diversidad. 
Esta obra forma parte del acervo de la Biblioteca Jurídica Virtual del Instituto de Investigaciones Jurídicas de la UNAM

El proceso laicizador uruguayo tuvo características peculiares que lo diferencian de los demás países de América del Sur. A fines del siglo XIX y comienzos del XX, se procesó en el Uruguay un fuerte enfrentamiento entre el naciente Estado uruguayo que reclamaba para sí el control de diversos aspectos de la vida colectiva, y la Iglesia católica que administraba determinados espacios que hoy entendemos como propios del Estado. Esa pugna por posiciones sociales y políticas ${ }^{4}$ se expresa encontrando a la Iglesia católica en posiciones de combate intransigente a la modernidad. Otros actores ya han sido mencionados como las elites locales inspiradas en el modelo francés, la masonería y las Iglesias protestantes.

La Iglesia católica vivió un conflicto ad extra y un conflicto ad intra, en tanto que también dentro de ella se procesaba una fuerte pugna entre las que han sido identificadas como las dos principales tendencias de la época, una comprometida en una ofensiva romanizadora y ultramontana conforme a la posición del Papa Pío IX, y la otra, de orden más liberal, no dogmática, antiultramontana, “....se notó dentro de la Iglesia una tensión que llevó al conflicto entre una línea fuertemente ortodoxa y ultramontana, y una línea liberal". ${ }^{5}$

Este largo conflicto entre actores diversos, aunque los principales eran el Estado naciente y la Iglesia católica, conoció momentos de mayor y menor tensión; sin embargo, nunca llegó a niveles de enfrentamiento que provocaran derramamiento de sangre. Se enumeran a continuación algunos de los principales hitos de este proceso.

El primer obispo de Montevideo desarrolló una tarea de unificación interna en consonancia romana y en seguimiento a Pio IX y su Syllabus. Unificación sobre la base de la primacía de su postura de fuerte impronta romana y la expulsión del Uruguay de las corrientes liberales encarnada en la expulsión de los franciscanos.

En 1861, tras un largo conflicto en relación con la negativa de las autoridades eclesiásticas de enterrar en un cementerio a un connotado masón, se produjo un fuerte enfrentamiento que culminó con lo que se conoce localmente como la "secularización de los cementerios", esto es, el paso de la administración de los cementerios por parte del Estado en detrimento de la Iglesia católica.

En 1862 se produjo el destierro del Vicario apostólico (no había obispo) en función de decisiones encontradas con el gobierno. Entre 1865 y 1878 se desarrolló lo que se ha llamado "el conflicto intelectual", consistente en el

4 Cateano, Gerardo y Geymonat, Roger, La secularización Uruguaya (1859-1919). Catolicismo y privatización de lo religioso, Montevideo, Taurus, 1997.

5 Rodé, P., Promoción del laicado, Apuntes tomados en los Cursos de Complementación Cristiana, Montevideo, 1963. 
Esta obra forma parte del acervo de la Biblioteca Jurídica Virtual del Instituto de Investigaciones Jurídicas de la UNAM

enfrentamiento en medios de comunicación y centros de pensamiento liberales y católicos que habían surgido poco antes.

En 1877 se promulgó la Ley de Educación, que implicó la desconfesionalización de la educación pública, lo que fue interpretado por parte de la Iglesia católica como la expulsión de Dios del sistema educativo uruguayo; por otra parte, fue hasta 1878 que se creó la primera diócesis del Uruguay, Montevideo, y se nombró su primer obispo.

En 1879 se promulga la Ley del registro civil por la que todo lo concerniente a registros de estado civil, nacimientos, casamientos y defunciones, pasaba a manos del Estado en detrimento de la Iglesia católica.

En 1885 se promulgó una de las leyes más duras y que significó fuertes enfrentamientos, la llamada "Ley de conventos". A través de esta ley se declaraba sin existencia legal a todos los conventos y casas de oración, a la vez que se prohibía el ingreso de religiosos extranjeros al país. En el mismo año se promulgó la Ley de Matrimonio Civil que establecía la obligatoriedad del casamiento civil previo al religioso, así como la imposibilidad de casarse por la Iglesia sin casarse previamente a nivel civil.

Como estrategia de resistencia y organización del sector católico, la Iglesia promovió los Congresos católicos de los cuáles emergieron organizaciones como la Unión Social, la Unión Económica y la Unión Cívica que reunían a los católicos en ámbitos específicos del quehacer social económico y político, creándose espacios de la vida social de núcleos de resistencia y de creación de áreas católicas en paralelo, como por ejemplo sindicatos, partidos políticos, etcétera.

En 1906, se produjo la remoción de todos los crucifijos de los hospitales. En 1907 se suprimió toda referencia a Dios y los evangelios en el juramento de los parlamentarios. En el mismo año se promulgó la ley de divorcio por sola voluntad de la mujer.

En 1919 se produjo la separación institucional entre la Iglesia y el Estado estableciéndose en el artículo 5o. de la nueva Constitución lo siguiente:

Todos los cultos religiosos son libres en el Uruguay. El Estado no sostiene religión alguna. Reconoce a la Iglesia Católica el dominio de todos los templos que hayan sido, total o parcialmente construidos con fondos del erario nacional, exceptuándose sólo las capillas destinadas al servicio de los asilos, hospitales, cárceles u otros establecimientos públicos. Declara asimismo exentos de toda clase de impuestos a los templos consagrados actualmente al culto de las diversas religiones. ${ }^{6}$

6 Véase Constitución de la República Oriental del Uruguay, desde 1919 a la fecha todas las reformas constitucionales han dejado intocado este artículo. 
También en 1919 se llevó a cabo por ley lo que se conoce como la "secularización de los feriados" que consistió en el cambio de denominación legal de los días feriados, de ahí que la Navidad pasó a denominarse "día de la familia"; el día de la Epifanía - 6 de enero- pasó a denominarse día de los niños; la Semana Santa fue nombrada Semana de Turismo, entre otros. Esa denominación legal existe hasta hoy, aunque la apropiación cultural ha hecho que el 25 de diciembre sea llamado Navidad.

Fue en esa época que se procedió al cambio de nombres de varias ciudades y localidades (más de 30) que perdieron sus nombres de santos a favor de nombres laicos, por ejemplo, Santa Isabel pasó a llamarse Paso de los Toros, o San Fernando cambió a Maldonado.

Esos dos contendores, que efectivamente disputaban espacios, se enfrentaban bajo las premisas de cada uno; el ejemplo francés como ideal, un claro jacobinismo, la impronta de la Ilustración, por un lado; y el combate a la modernidad en forma intransigente, por el otro, resistiendo la pérdida de espacios hasta ahora ocupados por ella, actitudes que - se entendía entonces - iban contra la voluntad de Dios, al oponérse.

Resulta ejemplificante, para dar cuenta del clima de la época y los extremos del enfrentamiento, hacer referencia a los llamados "banquetes de la promiscuidad". Eran eventos organizados por connotadas personalidades públicas del mundo liberal, convocando en la prensa de la época a realizar el día viernes de semana santa, grandes parrilladas en la esquina opuesta a la catedral y algunas Iglesias destacadas. El nivel del enfrentamiento era ciertamente fuerte y la dialéctica del mismo generó un claro anticlericalismo, en el que mucha responsabilidad tuvo, también, la actitud intransigente de la Iglesia católica.

Siguiendo a Casanova, parece verificarse que en aquellos lugares en que la religión, y en este caso la Iglesia católica, resistió los cambios propios del proceso de secularización, entendida ésta como "diferenciación de las esferas seculares de las instituciones y normas religiosas", ${ }^{7}$ en forma fuerte, lo religioso culminó privatizándose a la vez que se generó un robusto anticlericalismo. Ya Emile Poulat lo había indicado. Efectivamente la Iglesia católica y también el "creer religioso" fueron desplazados hacia los márgenes de la sociedad, volviéndose algo privado, reducido a la esfera de lo íntimo, familiar, saliendo de la esfera ya no sólo estatal sino también pública.

La Iglesia católica terminó aceptando la salida de lo público y su nuevo lugar social. Coincidentemente con una larga crisis de autoridad provocada

\footnotetext{
7 Casanova, José, Religiones públicas en el mundo moderno, Madrid, PPC, 2000.
} 
Esta obra forma parte del acervo de la Biblioteca Jurídica Virtual del Instituto de Investigaciones Jurídicas de la UNAM

por la ausencia del único obispo uruguayo tras la muerte del arzobispo Mariano Soler en 1908, se estuvo sin obispo hasta la separación institucional de 1919.

La Iglesia católica se recluyó en lo privado y así lo evidencian las cartas pastorales y documentos de la época, mayoritariamente centrados en las costumbres personales. Recién en la década de 1960 se produce un cambio al respecto volviéndose a una preocupación por lo público, aunque abandonando la pugna por la instalación como religión del Estado. Este desplazamiento a lo privado influyó a todo el espectro religioso del país y no sólo a la Iglesia católica.

Durante décadas se pensó que la secularización implicaba privatización de lo religioso pero esas perspectivas han sido rebatidas por estudios que culminan afirmando que la privatización de lo religioso no es una tendencia estructural moderna ni un elemento constitutivo de la secularización, ${ }^{8}$ sino un fenómeno que se da sólo en determinadas situaciones.

\section{LAICIDAD, ESPACIO PÚBLICO, EDUCACIÓN Y POLÍTICA}

El tipo de laicidad que se construyó en Uruguay pone un fuerte énfasis en la ausencia de lo religioso en lo público, prácticamente identificando lo estatal con lo público, con la polis. Existen pocos símbolos religiosos en el espacio público uruguayo y cada vez que alguna iniciativa propugna la instalación de uno se generan debates en los que intervienen variados actores marcando su posición contraria o favorable.

Un caso paradigmático fue la instalación de la llamada "Cruz del Papa" y se remonta a 1987 cuando, con motivo de la primera visita de un Papa a Uruguay, se erigió un gran altar en un espacio público de la ciudad, al costado del cual se instaló una cruz de más de treinta metros de altura. En aquella ocasión, el Papa Juan Pablo II llegó hasta Montevideo para firmar el acuerdo de paz entre Argentina y Chile que ponía fin a los diferendos que llevaron a ambos países al borde del enfrentamiento armado por una disputa territorial en el Canal de Beagle, y celebrar una misa multitudinaria. Finalizada la visita papal y desmontado el altar, el presidente de la República, agnóstico declarado, propuso que la cruz podía quedar instalada en ese lugar como recuerdo de la primera visita de un Papa a Uruguay, quien según sus palabras "había unido a todos los uruguayos en un sentimiento común de tolerancia y respeto"9 afirmando que "el viejo concepto de una

\footnotetext{
8 Idem.

9 La Mañana, Montevideo, 2 de abril de 1987.
} 
Esta obra forma parte del acervo de la Biblioteca Jurídica Virtual del Instituto de Investigaciones Jurídicas de la UNAM

Iglesia libre en un Estado libre en el Uruguay no es una propuesta sino una convivencia libremente asumida". ${ }^{10}$

Sin embargo, tal iniciativa disparó un debate de gran magnitud ya que se ponía en cuestión la pertinencia o no del emplazamiento de un símbolo religioso en el espacio público. ${ }^{11}$ Mientras unos propugnaban que quedara en donde estaba, otros entendían que era una ofensa y una "violación de la laicidad" que un símbolo "particular" que pertenecía sólo a una porción de la población fuera impuesto al conjunto, instalándose en el espacio público que era de todos.

El debate se extendió en el tiempo y se profundizó; prácticamente todos los legisladores participaron en el mismo. Los alineamientos partidarios se rompieron y dentro de cada partido político se podían encontrar posiciones dispares. Un senador del partido de gobierno afirmaba que si se concretaba que la cruz quedara emplazada en el espacio público "la República habrá retrocedido en sus tradiciones laicas y nacionales". ${ }^{12}$ Otro senador oficialista propugnaba: "no creo que sea un espectáculo edificante para un país liberal y laico como el nuestro, que, en el sitio de la concurrencia ciudadana, en la calle pública se erija el símbolo de una Iglesia”. ${ }^{13}$

Cabe citar la intervención de un diputado de la oposición expresando que "un jefe de Estado uruguayo no puede promover medidas que impliquen una lesión al principio de la laicidad" haciendo también referencia a la condición de masón de Manuel Oribe, fundador del Partido Nacional (que no era su partido) en el siglo XIX mencionando que "no tenía la cruz como símbolo, sino un compás, una escuadra, una cuchara, un nivel, una plomada", concluyendo "setenta años de convivencia pacífica y tolerante desembocan ahora en un punto de discordia en la sociedad uruguaya". ${ }^{14}$

Otra intervención, elocuente por sí misma, es la de un diputado oficialista: "Lisa y llanamente, el dogma de la cruz y este pretendido homenaje como símbolo hoy son un contrasentido. Insistir en su mantenimiento es pretender cerrar o agraviar a los ojos de quienes han logrado sobrepasar

\footnotetext{
10 Idem.

11 La prensa escrita de la época proporciona una amplísima información sobre el particular al divulgar opiniones, publicar cartas de los lectores a favor y en contra, así como ser vehículo de comunicados oficiales de diversos actores sociales.

12 El Diario, Montevideo, 5 de mayo de 1987; y La Mañana, Montevideo, 6 de mayo de 1987.

13 Intervención del senador A. Traversoni del Partido Colorado (gobierno), Diario de Sesiones de la Cámara de Senadores, t. 305.

14 Intervención del senador C. Cigliuti del Partido Colorado, Diario de Sesiones de la Cámara de Senadores, t. 305.
} 
Esta obra forma parte del acervo de la Biblioteca Jurídica Virtual del Instituto de Investigaciones Jurídicas de la UNAM

el oscurantismo espiritual en el que una gran parte de la humanidad aún está sumida". ${ }^{15}$

El proyecto de ley logró aprobación en la Cámara de Senadores y pasó a la Cámara de Diputados donde el debate fue también muy vasto. Los temas de la polémica volvieron a reiterarse: el lugar de lo religioso en lo público o en lo privado, las relaciones entre la Iglesia y el Estado, las diversas concepciones de laicidad, pluralismo, tolerancia, identidad nacional y valores nacionales, religión como oscurantismo. Finalmente el proyecto de ley logró ser aprobado y la cruz se mantuvo en el espacio público.

Sin embargo, y en claro contraste con el debate de la cruz del Papa, a pocos años del mismo, el gobierno local de Montevideo decidió erigir una estatua de Iemanjá en el espacio público, tras la iniciativa de un grupo de paes y maes. La erección de dicha estatua no concitó debates públicos ni la alarma que generó la cruz papal. Este comportamiento claramente diferente para cada uno de los dos casos, siendo que en ambos se trató de la instalación de un símbolo religioso en la esfera pública, indica que el asunto tiene al menos dos vectores, por un lado, lo religioso en lo público, y, por otro, el actor religioso involucrado. Parece no ser lo mismo si el símbolo es propuesto o identificado con la Iglesia católica que si es propuesto o identificado con los cultos afrobrasileños.

El rechazo a los símbolos religiosos en lo público o a la expresión de las Iglesias en los asuntos públicos, o la expresión pública de la fe de las personas, es parte del modelo hegemónico de laicidad uruguaya.

\section{LA LAICIDAD REFERIDA A LO POLÍTICO}

Hay otro aspecto siempre presente en relación a la laicidad en Uruguay y es el referido a la "violación de la laicidad en lo político-ideológico". Este aspecto está referido a la pretensión de imparcialidad y en cierta forma de autonomía del Estado, ya no en relación a una creencia religiosa o Iglesia, sino también de concepciones políticas partidarias, ideológicas o filosóficas.

Un trabajo reciente, todavía inédito, ${ }^{16}$ pasa revista a las denuncias por "violación de la laicidad en lo político". Citemos algunos casos para clarificar más específicamente lo que estamos refiriendo.

El 19 de junio de 2003, el ex presidente de la República, Luis Alberto Lacalle, reivindica su gestión presidencial en un acto oficial, en una escue-

15 Intervención del diputado Y. Fau, quien posteriormente fuera ministro de Educación y Cultura.

16 Intervención del diputado Asiaín del Partido Colorado. 
la agraria (pública). El Frente Amplio (coalición de izquierda y centro izquierda, entonces en la oposición y hoy en el gobierno) lo acusa de violar la laicidad. A raíz de este episodio se cita al presidente de la Administración Nacional de Educación Pública (ANEP) a la Comisión de Educación y Cultura de la Cámara de Representantes para dar explicaciones. El 20 de junio de 2003, el presidente de la Administración Nacional de Educación Pública (ANEP) afirmó en declaraciones de prensa que dentro de la educación existen casos de violación de la laicidad a través de la politización de los temas, en muchas ocasiones con una tendencia de izquierda. Dijo que esa tendencia se presenta más en el ente público especializado en la formación de profesores y en la enseñanza secundaria pública.

En octubre de 2004 el Consejo de Educación Secundaria investiga las denuncias realizadas por parte de algunos alumnos y padres de tres liceos sobre presuntas violaciones a la laicidad, que comprometen a docentes que disertaron en clase sobre sus preferencias políticas.

En 2006 el ministro de Educación y Cultura del gobernante Frente Amplio, concurre a la Comisión de Educación y Cultura del Parlamento para responder por varias denuncias de violación de laicidad formuladas por la oposición, referidas a la exposición que hizo en un liceo público un diputado del gobierno en torno a una acción militar desarrollada por los Tupamaros antes de la dictadura.

En 2009 un diputado opositor denunció que en una clase de sexto año de la escuela 138, la maestra organizó un simulacro de elección. Los alumnos debían votar entre los candidatos que disputaban las elecciones internas de los partidos políticos. La votación general resultó mayoritaria para José Mujica entre todos los candidatos, tanto del Frente como de los demás partidos. La maestra organizó un improvisado festejo tras la elección, que incluyó un baile.

Estos son sólo algunos ejemplos de los que hay muchos más, los cuales he citado porque ponen en evidencia el otro énfasis de la laicidad uruguaya, el de una pretendida imparcialidad absoluta del Estado, en relación a visiones particulares ya sea político partidarias o ideológicas.

Como se apreciará todos los casos citados y los no citados aquí por razones de extensión del texto se producen en relación al sistema educativo estatal, que tiene alrededor del $80 \%$ de la matrícula educativa del país y que se proclama "imparcial". Volviendo a la cita de Milot, es necesario "relegar a segundo plano las adhesiones comunitarias" 17 ya no sólo religiosas atribuyéndole al Estado una pretendida imparcialidad cuasi sacra, como si quie-

\footnotetext{
17 Milot, Micheline, op. cit.
} 
Esta obra forma parte del acervo de la Biblioteca Jurídica Virtual del Instituto de Investigaciones Jurídicas de la UNAM

nes ocupan el Estado estuvieran dotados de una cualidad que les permitiera abandonar toda subjetividad.

\section{LOS DIVERSOS ÉNFASIS DE LA LAICIDAD}

Estas dos caras de la laicidad uruguaya, la referencia a la imparcialidad ante lo religioso y las instituciones religiosas, por un lado, y la referencia a la imparcialidad ante lo político-ideológico, por otro, parten de los aspectos que caracterizan a esta sociedad.

Refiriéndonos a la primera, es necesario destacar que el término laicidad aparece cargado de significados y actitudes diversas, según situaciones concretas y en relación a los énfasis que desarrollan e imponen los diversos actores sociales. Es así que la imparcialidad, como ya se mencionara, puede estar referida a respeto o a prescindencia, también se pueden encontrar énfasis antirreligiosos, énfasis anticlericales, así como una expresión de fe ligada a la construcción de la República, como concepciones de corte menos restrictivos.

Uruguay se construyó sobre la base de oleadas de inmigrantes que fueron integrados a un solo ser nacional, con una única lengua y con una obsesión por la integración de los diversos, lo que Rama ha llamado la "hiperintegración"18 y la uniformidad expresada en variadísimos aspectos desde el color de los edificios públicos (estaba reglamentado que no podían tener otro color que el de los materiales utilizados para su construcción), hasta la túnica escolar blanca con moño azul que deben usar obligatoriamente todos los escolares que asistan a la educación pública.

Ese ánimo hiperintegrador, negador de las diferencias, disciplinador y centralizador en el Estado ha sido la principal matriz de la sociedad uruguaya. Lo sigue siendo, pero ahora no con la misma solidez y debe enfrentar el desafío de la diversidad como valor crecientemente aceptado a nivel internacional y local. Las prácticas de los ciudadanos parecen indicar que ese edificio homogéneo y único ha comenzado a resquebrajarse. La laicidad uruguaya se encuentra ante el desafío de reexpresarse en códigos culturales distintos a los fundacionales.

\section{LA IGLESIA GATÓLICA Y LA LAICIDAD URUGUAYA}

La pequeña Iglesia católica local (Uruguay tiene un 42\% de católicos) ha recibido recientemente la creación de un cardenal, el segundo en su historia.

18 Rama, Germán. La democracia en Uruguay. Una perspectiva de interpretación, Buenos Aires, Grupo Editor Latinoamericano, 1987. 
Esta obra forma parte del acervo de la Biblioteca Jurídica Virtual del Instituto de Investigaciones Jurídicas de la UNAM

En el acto público realizado por el nuevo jerarca frente a su feligresía, en la puerta de la Catedral de Montevideo, el cardenal Sturla expresó:

Me gusta decir que somos una Iglesia pobre y austera. No tenemos muchos recursos, ni somos un 'lobby' poderoso. Al mismo tiempo somos una Iglesia libre. No tenemos ataduras y hemos aprendido a ser parte de esta sociedad plural donde decimos con sencillez nuestra palabra. Entendemos la laicidad como sana pluralidad en el respeto mutuo, en el aporte de todos para construir una sociedad más justa, más libre, más humana. El diálogo y el acercamiento entre creyentes y no creyentes, entre las distintas comunidades cristianas, y las diversas religiones, es un bien para nuestro país que siempre estamos llamados a acrecentar. ${ }^{19}$

\section{LAICIDAD, SEGULARIZACIÓN Y PLURALISMO}

En los hechos, hasta el momento he venido considerando una distinción analítica entre laicidad y secularización y se habrá apreciado que he citado a Casanova quien - a mi entender - ha aportado claros elementos distintivos en lo que llamó la tesis de la secularización, así como las subtesis, la tesis de la diferenciación de esferas y ganancia de autonomía de las mismas en relación a lo religioso y las subtesis que implicaban, en primera instancia, la privatización de lo religioso, y, luego, la desaparición. Casanova afirma la veracidad de la tesis y el equívoco de las dos subtesis.

Independientemente de que se asuma o no la perspectiva propuesta por Casanova, podemos considerar al fenómeno de la secularización como proceso de transformación social, cultural y simbólico, de largo aliento, donde lo religioso es un elemento más en ese proceso de transformación. En tanto que el término "laicidad" parece estar más enfocado a las formas concretas de construcción de la convivencia, y de relación entre el Estado y las confesiones religiosas, aunque fundamentalmente la Iglesia católica (con excepción de Turquía).

En cuanto al término "laicidad", las aportaciones de Milot contribuyen a distinguir los componentes básicos del fenómeno definiéndolo como un acuerdo para la convivencia que asegure la libertad de conciencia y, a la vez, de expresión. Estos acuerdos asumen formas específicas dentro de procesos históricos particulares.

19 Discurso del cardenal Sturla, arzobispo de Montevideo en la celebración de recepción de su cardenalato en Montevideo el 15 de marzo de 2015, disponible en: $h t t p: / / w r e r e . a r q u i d i o-$ cesis.net/wp-content/uploads/2015/04/Entre-Todos-N.\%C2\%BA-350.pdfSurla. 
No hay una laicidad, o quizá no existe "la laicidad" sino formas de vivir ese proceso social con características particulares. Los énfasis de las diversas "laicidades" no son universales intercambiables o aplicables como si se tratara de un molde trasplantable. Cada comarca construye y reconstruye, da significado y resignifica su forma de vivir la laicidad y esto se hace a través de la pugna de diversos sectores sociales que intervienen en la sociedad.

Entre esos grupos podemos encontrar las propias Iglesias, aunque cabe diferenciar la Iglesia católica de las Iglesias protestantes, ya que la primera era hegemónica, vinculada al Estado desde los tiempos de la colonia; en tanto que las Iglesias protestantes eran minorías que pugnaban por su lugar social y reconocimiento. También cabe destacar el rol de las elites gobernantes constructoras del Estado, así como otro actor, todavía poco estudiado en América Latina, como es la masonería que en muchos casos encontraba dobles pertenencias a esta institución y a algunas iglesias protestantes. ${ }^{20}$

Secularización y laicidad son entonces procesos más que modelos acabados. Eso implica considerarlos en sus respectivos contextos histórico-concretos en que se desarrollaron y se desarrollan. Quizá se requiera de la realización de estudios comparados que puedan arrojar pistas acerca de estos dos procesos.

En las últimas décadas la diversidad se ha vuelto un valor de creciente reconocimiento en las sociedades contemporáneas y en varios lugares de la tierra, sobre todo en occidente se transita hacia el reconocimiento del derecho a la diversidad de sus ciudadanos, a distintos niveles. Los modelos de laicidad están desafiados a encontrar nuevos equilibrios y formatos que se hagan cargo del respeto a esa diversidad, también en lo referido a lo religioso.

Esta diversidad propone nuevos desafíos, exige encontrar formas de enfrentarlas, y, en la experiencia de dar respuesta a esas situaciones, se pueden apreciar al menos dos grandes tendencias, la tendencia a la inclusión y la tendencia a la segregación. Cada una de éstas tiene implicaciones distintas. Por un lado, se acentúa el reconocimiento de los ciudadanos y sus opciones como valor, por el otro se acentúa la centralidad del Estado por sobre los ciudadanos.

¿Veremos a nuestras sociedades avanzar hacia fórmulas incluyentes que garanticen cada vez más la convivencia plural a la vez que instituciones religiosas que asuman también la pluralidad? Creo que éste es uno de los desafíos del tiempo actual. Al menos en una mirada desde Uruguay.

20 Coitinho, Mirtha, Testigos de un silencio. Metodismo y masonería en el Uruguay del siglo XIX, Montevideo, Planeta, 2009. 
Esta obra forma parte del acervo de la Biblioteca Jurídica Virtual del Instituto de Investigaciones Jurídicas de la UNAM

Termino con la frase de un sociólogo francés - como no podía ser de otra manera para un uruguayo-- "La laicidad no es todo al César y nada a Dios, sino todo a la conciencia y a la libertad de los hombres llamados a vivir juntos, a pesar de todo lo que les separa, opone y divide". ${ }^{21}$

\section{BIBLIOGRAFÍA}

Andachat, Fernando, Signos reales del Uruguay imaginario, Montevideo, Trilce, 1992.

Casanova, José, Religiones públicas en el mundo moderno, Madrid, PPC, 2000.

Cateano, Gerardo y Geymonat, Roger, La secularización uruguaya (18591919). Catolicismo y privatización de lo religioso, Montevideo, Taurus, 1997.

Coitinho, Mirtha, Testigos de un silencio. Metodismo y masonería en el Uruguay del siglo XIX, Montevideo, Planeta, 2009.

Milot, Micheline, La laicidad, Madrid, CCS, 2009.

POulat, Emile, Notre laïcité publique. "La France est une Republique laïque", París, Berg International, 2003.

RAMA, Germán, La democracia en Uruguay. Una perspectiva de interpretación, Buenos Aires, Grupo Editor Latinoamericano, 1987.

Rodé, P., Promoción del laicado, Apuntes tomados en los Cursos de Complementación Cristiana, Montevideo, 1963.

21 Poulat, Emile, Notre lä̈ité publique. "La France est une Republique lä̈qu”, París, Berg International, 2003. 
Esta obra forma parte del acervo de la Biblioteca Jurídica Virtual del Instituto de Investigaciones Jurídicas de la UNAM www.juridicas.unam.mx

Gapítulo SEgundo

LAICIDAD Y LIBERTADES LAICAS 


\title{
RELIGIÓN, SEGULARIZACIÓN Y MATRIMONIO ENTRE PERSONAS DEL MISMO SEXO
}

\author{
Fernando ARLETTAZ*
}

\begin{abstract}
SUMARIO: I. Introducción. II. La protección legal de las parejas homosexuales. III. El matrimonio entre personas del mismo sexo en la línea de la secularización. IV. ¿Ha sido el combate por el matrimonio un combate laico?

V. Conclusiones. VI. Bibliografia.
\end{abstract}

\section{INTRODUCGIÓN}

En este texto nos proponemos presentar algunas ideas sobre el matrimonio entre personas del mismo sexo desde el punto de vista de la secularización. Nuestro propósito es avanzar en tres movimientos. En primer lugar, señalaremos las tendencias contemporáneas en lo relativo a la protección de las parejas constituidas por dos personas del mismo sexo, ya sea mediante el recurso a la figura legal del matrimonio, ya sea mediante otros medios legales de protección.

Luego pondremos en relación la transformación del matrimonio en el sentido de su ampliación subjetiva para permitir a las parejas homosexuales el acceso a él, con la idea de secularización. Nuestra hipótesis es que la apertura del matrimonio a las parejas homosexuales forma parte de una evolución secularizadora de esta figura, que la ha ido alejando progresivamente del modelo cristiano en el que se fundamenta, al menos en el contexto del derecho occidental. Si se prefiere poner esto mismo en términos más generales, podría señalarse que la protección de las parejas homosexuales mediante figuras propias del derecho de familia (el matrimonio, el régimen de parejas de hecho, la unión civil) forma parte de la progresiva secularización de ese sector del derecho.

\footnotetext{
* Laboratorio de Sociología Jurídica, Universidad de Zaragoza.
} 
En tercer lugar, veremos que las Iglesias cristianas, mayoritarias en los contextos en los que se están produciendo las transformaciones de las que hablamos, tienen una posición de resistencia o, al menos, reticencia frente a ellas. Esta perspectiva viene a reforzar nuestra lectura de las transformaciones jurídicas como parte de un proceso de secularización que mina la capacidad de definición moral de las Iglesias y al que ellas se oponen. Por supuesto, hay algunas excepciones (como las Iglesias protestantes de los países nórdicos, que tienen posiciones aperturistas en muchos casos). Sin embargo, estas Iglesias excepcionales se encuentran en contextos sociales que pueden claramente definirse como altamente secularizados.

\section{LA PROTEGCIÓN LEGAL}

DE LAS PAREJAS HOMOSEXUALES

El tratamiento legal de las uniones homosexuales puede ser diverso, y sus características concretas dependen de la forma en que cada legislación nacional aborda el tema. En un plano ideal puede pensarse en distintas vías. ${ }^{1}$ En primer lugar, posibilitar directamente el matrimonio entre personas del mismo sexo, equiparando las uniones homosexuales a las heterosexuales, tanto en lo referente a los efectos jurídicos cuanto en lo referente a los alcances simbólicos. En segundo lugar, regular la existencia de parejas de hecho, mediante una legislación aplicable tanto a las parejas heterosexuales como a las homosexuales. Dentro de esta posibilidad cabe pensar en leyes de parejas de hecho de máximos (que las equiparan al matrimonio en lo relativo a los efectos jurídicos, aunque no se identifiquen las dos formas en un plano simbólico); y leyes de parejas de hecho de mínimos (con efectos jurídicos disminuidos respecto del matrimonio). Las parejas de hecho pueden tener una mayor o menor formalización (en algunos sistemas jurídicos basta con la mera existencia de la pareja; en otros es necesaria alguna formalización sea a través de un registro, de un contrato de solidaridad, de un contrato convivencial o de alguna otra forma semejante). En tercer lugar, regular la existencia de una unión civil homosexual, como estado civil específico para las uniones homosexuales. En este caso, es posible que la unión civil confiera los mismos derechos que el matrimonio o que por el contrario represente un estatuto inferior.

La terminología utilizada varía de país en país, añadiéndose a esta diversidad la complejidad resultante de la utilización de diferentes idiomas con equivalencias no siempre exactas entre sí. Para lo que nosotros hemos

1 Calvo Borobia, Kerman, "Matrimonio homosexual y ciudadanía", Claves de Razón Práctica, Madrid, núm. 154, 2005, pp. 32-38. 
denominado parejas de hecho, a veces se usa la expresión parejas estables, parejas no casadas, parejas registradas, pacto o contrato de solidaridad o, incluso, unión civil (civil partnership). Aun a costa de no ser fieles a la terminología legal utilizada en algunos ordenamientos jurídicos, y en razón de unificar la diversidad de regímenes legales bajo un sistema coherente, nosotros hemos reservado esta última expresión para aquellos regímenes legales que confieren protección a las parejas homosexuales mediante un mecanismo que es específico para éstas y que representa entonces un equivalente (o un equivalente disminuido, según los derechos que se otorguen) de lo que el matrimonio es para las parejas heterosexuales.

Por ello, la existencia de un régimen de unión civil específico para las parejas homosexuales pierde sentido desde el momento en que se habilita el acceso de éstas al matrimonio. En cambio, es perfectamente posible la coexistencia de un régimen de matrimonio (o de matrimonio y unión civil) con uno de parejas de hecho. Así, al lado del régimen matrimonial heterosexual (con o sin régimen de unión civil homosexual), o del régimen matrimonial tanto heterosexual como homosexual, es posible regular un sistema de parejas de hecho.

Los caminos legislativos y jurisprudenciales seguidos por los Estados han sido variados. No podemos aquí sino hacer una somera mención de ellos, intentando señalar algunos patrones generales. Agruparemos los casos por región geográfica.

El primer país del mundo en dar protección a las parejas homosexuales fue Dinamarca, mediante un sistema de unión civil aprobado en 1989. En 2012 Dinamarca permitió el acceso al matrimonio. Varios Estados europeos, en particular los nórdicos, siguieron el mismo camino, reconociendo primeramente la protección de un régimen de unión civil y luego de matrimonio. Así sucedió en Noruega (unión civil 1993, matrimonio 2008), Suecia (unión civil 1995; matrimonio 2008), Islandia (unión civil 1996, matrimonio 2010) y Finlandia (unión civil 2001, matrimonio 2015). En 2004 se estableció un sistema de unión civil en el Reino Unido, en 2013 el matrimonio homosexual se declaró legal en Inglaterra y Gales y en 2014 en Escocia.

En cambio, otros países europeos reconocieron la unión civil y se mantienen en este régimen. Tal sucede en Alemania (2001), Suiza (2004) y la República Checa (2006). Eslovenia tiene un régimen de unión civil (2005) y una ley de acceso al matrimonio que está aprobada (2015) pero pendiente de promulgación. Si esta ley entra finalmente en vigor, Eslovenia se convertirá en el primer país de antigua órbita soviética en reconocer el matrimonio homosexual. 
Un camino diferente fue el de aquellos países que extendieron el régimen de parejas de hecho a las parejas homosexuales. Algunos de los que optaron por esta vía se mantienen en ella. Tal es el caso de Hungría (1996), Croacia (2003), Austria (2003, 2009) y Andorra (2005).

Otros Estados, en cambio, luego de permitir el acceso al régimen de parejas de hecho permitieron el acceso al matrimonio. Holanda aprobó en 1998 una ley de parejas de hecho, y en 2000 permitió el acceso al matrimonio. También Bélgica había aprobado una ley de parejas de hecho (1998) y permitió luego el acceso al matrimonio (2003); idéntico camino siguieron Francia (parejas de hecho, 1999; matrimonio, 2013), Portugal (parejas de hecho, 1999, 2001; matrimonio, 2010), Luxemburgo (parejas de hecho 2004, matrimonio en 2014). En España existieron leyes relativas a parejas de hecho en diferentes fechas (ya que no fueron adoptadas de modo único por el gobierno central, sino escalonadamente por los gobiernos de las comunidades autónomas) y, finalmente, en 2005 se aprobó el matrimonio entre parejas del mismo sexo.

La evolución predominantemente legislativa propia de la experiencia europea contrasta con lo sucedido en los Estados Unidos, donde el poder judicial tuvo un rol protagónico en la protección de las parejas homosexuales. En los Estados Unidos el debate se abrió cuando en 1993 la Corte Suprema de Hawái declaró que la ley local que prohibía el matrimonio entre personas del mismo sexo era inconstitucional, a menos que el Estado demostrara que había una razón suficiente para establecer una diferencia con las parejas heterosexuales. A partir de entonces, hubo reacciones en sentidos opuestos. Muchos Estados aprobaron leyes conocidas como DOMA (Defense of Marriage Acts) que no sólo reafirmaban el carácter heterosexual del matrimonio en ese Estado, sino que impedían reconocer matrimonios homosexuales celebrados en otros lugares. Algunos Estados incorporaron incluso enmiendas constitucionales que prohibían a las legislaturas aprobar normas que reconocieran el matrimonio entre personas del mismo sexo o que, yendo todavía más allá, prohibían cualquier tipo de protección legal a las parejas homosexuales. En contraste, las cortes supremas de algunos Estados reconocieron el derecho de las parejas homosexuales al matrimonio o a la unión civil, y algunas legislaturas hicieron lo propio al admitir el matrimonio, la unión civil específica para las parejas homosexuales o regular un estatuto de pareja de hecho para todo tipo de parejas.

Si bien en un primer momento pareció que eran mayoritarios los Estados con normas que excluían la protección de las parejas homosexuales (ya sea por la vía del matrimonio o por cualquier vía), desde 2014 esta ten- 
Esta obra forma parte del acervo de la Biblioteca Jurídica Virtual del Instituto de Investigaciones Jurídicas de la UNAM

dencia comenzó a revertirse. Un alto porcentaje de normas legales o constitucionales que prohibían la protección de las parejas homosexuales fueron declaradas inconstitucionales por jueces federales o por Cortes federales de apelación.

Debido a la particular evolución jurisprudencial y legislativa de cada Estado es bastante difícil organizar los casos en un esquema coherente. Sin embargo, y realizando un esfuerzo de simplificación, podemos señalar un primer grupo de estados que reconocieron haber admitido originalmente el matrimonio, ya sea por vía legal o jurisprudencial. Así sucedió en California (en 2008 se autorizó el matrimonio por vía jurisprudencial; poco después se aprobó por referéndum la llamada Proposition 8 que introdujo una prohibición constitucional del matrimonio entre personas del mismo sexo; sin embargo, esta enmienda fue declarada inconstitucional por jueces federales de distrito y de apelación, y, en 2013, la Corte Suprema declaró que los promotores de la Proposition 8 carecían de legitimación para cuestionar las decisiones de inconstitucionalidad de los jueces inferiores); Connecticut (decisión judicial de 2008; ley de 2009); Delaware (ley de unión civil en 2011 y de matrimonio en 2013); Distrito de Columbia (ley de 1992 que reconoció unos pocos derechos a las parejas homosexuales y que fue bloqueada por el Congreso de los Estados Unidos hasta 2002; progresiva ampliación de estos derechos con posterioridad; leyes de 2009 que reconocen el matrimonio homosexual celebrado en otro Estado, primero, y establecen el matrimonio homosexual en el Distrito, después); Hawái (la decisión judicial de 1993, que ya nombramos, ordenó que un tribunal inferior considerara la validez de la restricción del matrimonio sólo a las parejas heterosexuales; en 1998 se introdujo una enmienda constitucional que impide el reconocimiento judicial de las parejas homosexuales y permite a la legislatura restringir el matrimonio sólo a las parejas heterosexuales; en 2011 se aprobó una ley de unión civil; en 2013 se aprobó el matrimonio); Illinois (ley de unión civil en 2011; ley de matrimonio en 2013); Iowa (reconocimiento judicial en 2009); Maine (ley de 2009, rechazada por votación popular ese mismo año, y aceptada por votación popular en 2012); Maryland (ley de 2012 ratificada por votación popular ese mismo año); Massachusetts (decisión judicial de 2003; ley de 2009); Minnesota (ley de 2013); Nueva Hampshire (ley de 2009); Nueva Jersey (ley de unión civil en 2007; en 2013 decisión judicial que admite el matrimonio); Nuevo México (luego de una controversia debido a que la ley no permite ni prohíbe expresamente estos matrimonios, en 2013 una decisión judicial admitió el matrimonio); Nueva York (ley de 2011); Rhode Island (ley que reconoce unión civil en 2011; reconocimiento de matrimonios 
Esta obra forma parte del acervo de la Biblioteca Jurídica Virtual del Instituto de Investigaciones Jurídicas de la UNAM

celebrados en otros Estados en 2012; ley de matrimonio en 2013); Vermont (ley de unión civil en 2000 y ley de matrimonio en 2009); Washington (ley de unión civil en 2007 y de matrimonio, aprobada en referéndum, en 2012); Wyoming (una sentencia de un juez federal de 2014 reconoció el derecho a contraer matrimonio).

Un segundo grupo de Estados está constituido por aquellos que tenían originalmente prohibiciones constitucionales de protección a las parejas homosexuales, y que fueron luego declaradas inconstitucionales. Tal sucedió en Alabama (enmienda constitucional de 2005 que prohíbe el acceso al matrimonio y a cualquier otra forma de reconocimiento familiar, votada en referéndum; declarada inconstitucional en 2014 por un juez federal); Alaska (en 1998 se aprobó una enmienda constitucional votada en referéndum que prohíbe el reconocimiento del matrimonio entre personas del mismo sexo; pero en 2014 un juez federal de Alaska reconoció el derecho a contraer matrimonio entre personas del mismo sexo; al mismo tiempo, una Corte Federal de Apelaciones del 9o. circuito, al que pertenece Alaska, falló a favor del matrimonio homosexual); Arizona (enmienda constitucional de 2008 que prohíbe el matrimonio entre personas del mismo sexo, declarada inconstitucional por un juez federal en 2014; el pronunciamiento del 9o. circuito antes mencionado también alcanza a Arizona; algunas jurisdicciones permiten el registro de parejas); Arkansas (enmienda constitucional de 2004 que prohíbe el reconocimiento de cualquier estatus familiar para parejas homosexuales; en 2014 un juez declaró que la prohibición era inconstitucional, la sentencia está pendiente de apelación ante la Corte Suprema estadual, pero se aplica provisionalmente); Colorado (enmienda constitucional de 2006 que prohíbe el matrimonio; en 2009 se reconocieron ciertos derechos a las parejas homosexuales y en 2013 se estableció un régimen de unión civil; en 2014 un juez federal declaró inconstitucional la prohibición constitucional de matrimonio, y una decisión en el mismo sentido del décimo circuito, al que pertenece Colorado, quedó firme cuando la Corte Suprema Federal se negó a revisarla); Florida (enmienda constitucional de 2008 que prohíbe el reconocimiento de cualquier estatus familiar; en 2014 varios jueces federales declararon inconstitucional la prohibición; algunas jurisdicciones reconocen ciertos derechos a las parejas); Idaho (enmienda constitucional de 2006 que prohíbe el reconocimiento de cualquier estatus familiar, declarada inconstitucional por la Corte de Apelaciones del 9o. circuito en 2014); Indiana (enmienda constitucional de 2011 que prohíbe el reconocimiento del matrimonio homosexual, declarada inconstitucional por la Corte de Apelaciones del 7o. circuito en 2014); Kansas (enmienda 
Esta obra forma parte del acervo de la Biblioteca Jurídica Virtual del Instituto de Investigaciones Jurídicas de la UNAM

constitucional de 2004 que prohíbe el reconocimiento de cualquier estatus familiar, declarada inconstitucional en 2014 por un juez federal); Missouri (enmienda constitucional de 2004 que prohíbe reconocimiento del matrimonio, declarada inconstitucional por varios jueces federales, pendiente de recurso ante Corte de Apelaciones); Montana (enmienda constitucional de 2004 que prohíbe el matrimonio, en 2014 un juez federal declaró inconstitucional la prohibición, la decisión de la Corte de Apelaciones del 9o. circuito es aplicable en Montana); Nevada (enmienda constitucional de 2002 que prohíbe el reconocimiento del matrimonio; en 2009 se aprobó un régimen para las parejas; en 2014 la Corte de Apelaciones del 9o. circuito declaró inconstitucional la prohibición); Carolina del Norte (enmienda constitucional de 2012 que prohíbe el reconocimiento de cualquier estatus familiar a las parejas homosexuales; en 2014 fue declarada inconstitucional por varios jueces federales); Oklahoma (enmienda constitucional de 2004 prohíbe el reconocimiento de cualquier estatus familiar a las parejas homosexuales; en 2014 fue declarada inconstitucional por la Corte de Apelaciones del décimo circuito y la Corte Suprema federal rechazó estudiar el caso); Oregón (enmienda constitucional de 2004 que prohíbe el reconocimiento de cualquier estatus familiar; en 2007 se aprueba un régimen de unión civil; en 2014 la enmienda constitucional fue declarada inconstitucional); Pennsylvania (ley de 2004 que prohíbe el reconocimiento de cualquier estatus familiar; en 2014 declarada inconstitucional por un juez federal); Carolina del Sur (enmienda constitucional de 2006 que prohíbe el reconocimiento de cualquier status familiar; en 2014 un juez federal declaró inconstitucional la enmienda); Utah (enmienda constitucional de 2004 que prohíbe cualquier reconocimiento familiar; declarada inconstitucional en 2014 por la Corte de Apelaciones del décimo circuito, la Corte Suprema se negó a revisar el caso); Virginia (enmienda constitucional de 2006 que prohíbe cualquier reconocimiento familiar; declarada inconstitucional en 2014 por la Corte de Apelaciones del 4o. circuito); West Virginia (ley de 2000 que prohíbe reconocimiento matrimonial; en 2014 es declarada inconstitucional por la Corte de Apelaciones del 4o. circuito y la Corte Suprema federal rehúsa revisar el caso); Wisconsin (enmienda constitucional de 2006 que prohíbe cualquier reconocimiento familiar, aunque una ley de 2009 creó una especie de unión civil; la enmienda fue declarada inconstitucional en 2014 por la Corte de Apelaciones del 7o. circuito).

Finalmente, un tercer grupo de Estados está constituido por aquellos que todavía mantienen la prohibición de la protección a las parejas homosexuales. En muchos de ellos hay decisiones judiciales contrarias a estas 
determinaciones, aunque todavía están pendientes de resolución. Así sucede en Georgia (enmienda constitucional de 2004 que prohíbe el reconocimiento de cualquier estatus familiar); Kentucky (enmienda constitucional de 2004 que prohíbe cualquier tipo de reconocimiento familiar; declarada constitucional por una Corte de Apelaciones del 6o. circuito, pendiente de recurso ante la Corte Suprema Federal); Luisiana (enmienda constitucional de 2004 que prohíbe cualquier reconocimiento familiar, declarada inconstitucional por juez federal, pendiente de recurso ante Corte de Apelaciones del 5o. circuito); Michigan (enmienda constitucional de 2004 que prohíbe cualquier reconocimiento familiar, declarada inconstitucional por un juez federal y pendiente de apelación ante una Corte del 6o. circuito); Mississippi (enmienda constitucional de 2004 que prohíbe el reconocimiento del matrimonio, declarada inconstitucional en 2014 por un juez federal, pendiente de apelación ante Corte del 5o. circuito); Nebraska (enmienda constitucional de 2000 que prohíbe cualquier reconocimiento familiar, declarada inconstitucional en 2015 por un juez federal, decisión pendiente de recurso ante Corte de Apelaciones); Dakota del Norte(enmienda constitucional de 2004 que prohíbe el reconocimiento de matrimonios); Ohio (enmienda constitucional de 2004 que prohíbe el reconocimiento de cualquier estatus familiar; una decisión judicial del 6o. circuito declara constitucional la prohibición, pero la sentencia está pendiente de apelación ante la Corte Suprema Federal; algunas ciudades permiten el acceso a un régimen de pareja de hecho); South Dakota (enmienda constitucional de 2006 prohíbe cualquier reconocimiento familiar; en 2015 un juez federal declara inconstitucional la enmienda, pero la sentencia todavía no está firme); Tennessee (enmienda constitucional de 2006 que prohíbe el reconocimiento de matrimonio; declarada constitucional por la Corte de Apelaciones del 6o. circuito en 2014, está pendiente de resolución por la Corte Suprema federal); Texas (enmienda constitucional de 2005 que prohíbe reconocimiento familiar; en 2014 un juez federal declara inconstitucional la enmienda, pero su decisión está pendiente de revisión por la Corte Apelaciones del 5o. circuito).

En el ámbito federal se adoptó en 1996 la Defense of Marriage Act (DOMA federal) que limitó la definición de matrimonio, para efectos federales, a las uniones heterosexuales. La ley fue declarada inconstitucional en 2013 por la Corte Suprema en el caso Edith Schlain Windsor (United States v. Edith Schlain Windsor, 570 US [2013]). La Corte Suprema federal decidió que la DOMA federal es inconstitucional porque viola principios de equal liberty, due process y equal protection, al denegar protección federal a una realidad que los Estados (que son los competentes para regular las relaciones domésticas) 
han definido como matrimonio. Nótese que el argumento no era que la igualdad exigía el acceso de las parejas homosexuales al matrimonio, sino que la igualdad exigía que el gobierno federal reconociera los matrimonios homosexuales si los Estados admitían su celebración. ${ }^{2}$

El paso más importante todavía pendiente es la afirmación del derecho a contraer matrimonio de las parejas homosexuales por parte de la Corte Suprema federal. Como dijimos en el párrafo anterior, de momento la Corte sólo ha dicho que el gobierno federal no puede desconocer los efectos de los matrimonios entre personas del mismo sexo si los Estados han autorizado su celebración. Pero no ha dicho que los Estados estén obligados a autorizar esa celebración. Como vimos al analizar la situación en los diferentes Estados, existen casos pendientes ante la Corte Suprema en los cuales ésta deberá pronunciarse sobre el hecho de si la legislación estadual que restringe el acceso al matrimonio resulta de algún modo contraria a la constitución federal. ${ }^{3}$

En Canadá, por otra parte, la evolución comenzó con la aceptación de la extensión del régimen de las parejas de hecho también a las parejas homosexuales, primero por el gobierno de Quebec (1999) y luego por el gobierno federal de Canadá (2002). Un paso importante fue franqueado cuando varias provincias aceptaron un régimen de unión civil intermedio entre el simple concubinato y el matrimonio. Unos años después, algunos tribunales comenzaron a cuestionar que la definición del matrimonio, que es competencia del gobierno federal, no abarcara también a las parejas homosexuales, y dictaron sentencias obligando a los funcionarios competentes a la celebración de matrimonios entre personas del mismo sexo. Esta situación fue uniformada en 2005 con la aprobación, mediante ley federal, de la extensión al régimen matrimonial en favor de las parejas homosexuales.

También en América Latina varios países han reconocido protección a las parejas homosexuales. En general la tendencia ha sido a reconocer primeramente la protección mediante regímenes de parejas de hecho y luego ampliar el acceso al matrimonio. En razón del carácter federal de muchos de los países de la región, algunas o todas estas leyes no fueron adoptadas a

2 Sobre esta sentencia véase Ceccherini, Eleonora, “Quando l'eguaglianza non basta. Brevi riflessioni sulla giurisprudenza statunitense in tema di 'same-sex marriage' alla luce della sentenza Windsor", en Ferrari, Daniele (a cura di), Lo status giuridico delle coppie same sex: una prospectiva multilivello, Padua, Primiceri Editore, 2014.

3 Más información, Estado por Estado y en relación con la situación a nivel federal, puede encontrarse en la página web de la organización Freedom to marry disponible en: http://www:freedomtomarry.org/. 
nivel del Estado central. El primer país en la región en reconocer el matrimonio homosexual fue Argentina, que desarrolló disposiciones locales a través de las cuales se reconocía cierto estatuto jurídico a las parejas de hecho, tanto homosexuales como heterosexuales. Finalmente, el proyecto de ley que autoriza los matrimonios entre personas del mismo sexo fue aprobado en 2010.

De igual manera, en México se dieron primeramente en algunos de los estados de la Federación leyes de parejas de hecho, tanto para parejas heterosexuales como homosexuales. En 2009 la Ciudad de México aprobó el matrimonio para parejas del mismo sexo. La Corte Suprema Federal, en 2010, aceptó la validez constitucional de estos matrimonios y declaró que los demás estados de la Federación estaban obligados a reconocerlos como válidos. En 2011, en el estado de Quintana Roo, comenzaron también a celebrarse matrimonios entre personas del mismo sexo. Finalmente, en 2012 la Corte Suprema de Justicia de la Nación determinó que la ley de Oaxaca, que sí establece expresamente que el matrimonio es una unión de hombre y mujer, es contraria a la Constitución. En 2014 el estado de Coahuila aprobó mediante ley el acceso al matrimonio para parejas del mismo sexo.

Lo mismo sucedió en Uruguay y Brasil. En Uruguay las uniones civiles eran posibles desde 2007. En 2013 el Parlamento uruguayo aprobó la extensión del matrimonio. En Brasil una decisión del Tribunal Supremo federal de 2011 equiparó las parejas de hecho homosexuales a las heterosexuales. Más adelante, el Superior Tribunal de Justicia resolvió un recurso en el sentido de que no existía obstáculo legal a la celebración de matrimonio entre personas del mismo sexo ya que las disposiciones del Código Civil debían interpretarse de conformidad con la Constitución.

En otros países la posibilidad del matrimonio no ha sido todavía reconocida, al menos de modo completo. En Colombia una decisión de la Corte Constitucional de 2011 equiparó las parejas heterosexuales y las homosexuales. La decisión dio un plazo al legislador para que regulara la situación, estableciendo que si luego del vencimiento de ese plazo el legislador no se había pronunciado, la sentencia sería directamente aplicable. Luego del vencimiento del plazo, la situación es dudosa: en principio las parejas homosexuales tendrían derecho a acceder al matrimonio, pero no está regulado el mecanismo para hacerlo. En algunos lugares se han celebrado matrimonios ante notarios. En Ecuador la Constitución de 2008 amplió el concepto de uniones de hecho (que el Código Civil preveía sólo para las 
Esta obra forma parte del acervo de la Biblioteca Jurídica Virtual del Instituto de Investigaciones Jurídicas de la UNAM

parejas heterosexuales) a las parejas homosexuales, aunque reservando la adopción sólo a las parejas heterosexuales. ${ }^{4}$

Fuera del ámbito europeo y americano hay otros casos que vale la pena mencionar. El Parlamento sudafricano legalizó el matrimonio entre personas del mismo sexo en 2006, un año después de que la Corte Suprema declarara que las normas anteriormente vigentes violaban la Constitución del país. En 2005 Nueva Zelanda adoptó un régimen de unión civil, y en 2013 aprobó también el matrimonio entre personas del mismo sexo. Mediante una reforma de 2009 el gobierno federal australiano equiparó a las parejas de hecho homosexuales y a las heterosexuales. En 2013 Canberra aprobó una ley permitiendo el matrimonio entre personas del mismo sexo.

\section{EL MATRIMONIO ENTRE PERSONAS DEL MISMO SEXO EN LA LÍNEA DE LA SECULARIZACIÓN}

En el apartado anterior nos hemos referido a la evolución legal reciente en lo relativo a la protección de las parejas homosexuales. En términos generales, puede decirse que la tendencia, al menos en América y Europa, es a una progresiva extensión de la protección de las parejas formadas por personas del mismo sexo. El punto más alto de esta protección desde un punto de vista jurídico-formal es la apertura del matrimonio a las parejas homosexuales.

En este apartado queremos insistir en que el alejamiento de la figura matrimonial respecto de la estructura heterosexual que la ha caracterizado a lo largo de su existencia histórica en Occidente puede ubicarse en la línea de la progresiva secularización del matrimonio. Los caracteres de la matriz cristiana del matrimonio, sobre la cual se asientan los regímenes jurídicos europeos y americanos, se han ido modificando en los últimos cinco siglos, en un proceso que bien puede calificarse como de secularización del matrimonio y que es, a nuestro juicio, una muestra de la secularización del derecho en general. En efecto, el proceso de secularización del derecho, vinculado a su racionalización y a su estatalización, ha cristalizado en los diferentes sectores del ordenamiento jurídico. En el caso de la regulación de la familia esto ha sido particularmente notorio.

4 Para un mayor detalle de la situación de América Latina puede consultarse nuestro trabajo Arlettaz, Fernando, "Secularización, laicidad y matrimonio entre personas del mismo sexo en América Latina", Laicidad y Libertades: Escritos Jurídicos, España, núm. 14, 2014, pp. 55-90. 
Esta obra forma parte del acervo de la Biblioteca Jurídica Virtual del Instituto de Investigaciones Jurídicas de la UNAM

Los cambios producidos por la secularización pueden descubrirse en la regulación del matrimonio en cuanto ha pasado de institución sagrada a una mera relación contractual entre dos partes. No podemos ni queremos hacer aquí una historia general del matrimonio. Por ello, nos limitaremos a presentar las características generales del matrimonio cristiano, como punto de partida para el análisis de su secularización. ${ }^{5}$

La Iglesia católica ha afirmado desde antiguo que el matrimonio pertenece a un doble orden: al natural y al sobrenatural. Pertenece, por un lado, al orden natural, que determina su esencia, fines y propiedades. Para esta concepción, el matrimonio es una realidad inscrita en la misma naturaleza humana. Pero, por otro lado, pertenece también al orden sobrenatural, que determina que todo matrimonio entre bautizados es en sí mismo sacramento. Como en los primeros tiempos de su existencia la Iglesia católica carecía de regulación integral del matrimonio, aceptó el matrimonio romano de la sociedad en la que se insertó, pero sólo en la medida en que era compatible con su visión del derecho natural y divino. El matrimonio canónico se distinguió así del matrimonio romano en varios puntos. El matrimonio romano era, al igual que el canónico que lo suplantó, heterosexual y monogámico; pero a diferencia del matrimonio canónico, era puramente consensual, no formal y disoluble, además de no estar sometido a un ordenamiento jurídico religioso. Cuando decimos puramente consensual queremos decir que el matrimonio romano no tenía el carácter institucional que luego tendría el canónico. El matrimonio romano no era concebido como una verdadera institución, sino como un mero hecho productor de efectos jurídicos. Para que existiera matrimonio era necesaria la affectio maritalis, entendida, no como voluntad inicial de contraer, sino, como voluntad constante y continuada de mantenerse en esa situación, manifestada por personas púberes titulares del ius connubi. A la affectio maritalis debía sumarse la coniunctio, o convivencia marital. Si cualquiera de ambos elementos desaparecía, el matrimonio quedaba disuelto. Si estos elementos se daban entre dos personas que no eran titulares del ius connubi, el resultado no era el matrimonio sino el concubinato.

A partir del siglo IV, con la transformación del cristianismo en religión oficial del imperio romano, apareció el matrimonio justinianeo, como resultado de la cristianización del matrimonio romano. Desde el siglo X, el matrimonio canónico fue el único vigente en la Europa cristiana, sometido a la legislación y jurisdicción de la Iglesia católica, con alguna intervención

5 Tratamos con mayor profundidad la idea de la secularización del matrimonio, y la inserción de la regulación de las parejas homosexuales en ella, en nuestro trabajo Arlettaz, Fernando, Matrimonio homosexual y secularización, México, UNAM, 2015. 
Esta obra forma parte del acervo de la Biblioteca Jurídica Virtual del Instituto de Investigaciones Jurídicas de la UNAM

complementaria de la autoridad civil. A partir de ese momento, el matrimonio canónico estuvo ya doctrinariamente delineado en sus aspectos fundamentales, aunque terminó de fijarse definitivamente en torno del siglo XIII. En muchos lugares, sin embargo, el matrimonio canónico se combinaba con la subsistencia de diversas costumbres de origen germánico. ${ }^{6}$

Una primera característica de esta matriz cristiano-canónica del matrimonio es su íntegra regulación religiosa. La Iglesia reivindicó potestad legislativa y jurisdiccional sobre el matrimonio. En el pasado, esta potestad pretendía extenderse sin distinción de personas, lo cual era coherente con la concepción de una unidad político-religiosa católica: si todos los miembros de la comunidad cívica son y deben ser católicos, la Iglesia tiene potestad sobre todos los matrimonios. Luego de la quiebra de la unidad religiosa de Occidente, y de la resignación por parte de la Iglesia a esta situación, la potestad fue reducida al matrimonio de los católicos.

La regulación religiosa impone también una forma religiosa a la celebración del matrimonio. Dado que lo relevante para la existencia del matrimonio es el consentimiento, debería bastar la existencia de éste, sin ninguna formalidad, para la existencia del matrimonio. Por eso, en los primeros tiempos de la Iglesia se reconocía validez tanto al matrimonio celebrado in facie ecclesia, es decir, ante la autoridad eclesiástica, como al matrimonio clandestino, puramente informal. Este último, sin embargo, fue prohibido por el Concilio de Trento. El problema político (y económico) que se buscaba solucionar era el de la duplicidad de matrimonios, uno público y otro clandestino. Esto se logró mediante el establecimiento, como requisito indispensable para la validez del matrimonio, de su celebración pública y del registro del consentimiento matrimonial.

Una segunda característica de la matriz cristiana de matrimonio es su carácter consensual-institucional. El matrimonio está basado en el consentimiento de los contrayentes: es el consentimiento de presente el que hace al matrimonio. Sin embargo, a diferencia del matrimonio romano, que exigía el consentimiento continuado para la permanencia del matrimonio, para el derecho cristiano sólo interesa el consentimiento inicial, que además es irrevocable. Sin embargo, el consentimiento matrimonial sólo tiene eficacia como acto generador de la relación matrimonial: no funciona para regular

6 Las fuentes fundamentales de regulación del matrimonio canónico, que recogen y ordenan las fuentes dispersas anteriores, son las siguientes, Iglesia católica, Sesión XXIV del Concilio de Trento: doctrina sobre el sacramento del matrimonio, cánones del sacramento del matrimonio y decreto Tametsi sobre la reforma del matrimonio, 1563; Iglesia católica, Código de Derecho Canónico; Iglesia católica, 1965, Constitución Pastoral Gaudium et Spes sobre la Iglesia en el mundo actual; Iglesia católica, Código de Derecho Canónico, 1983. 
Esta obra forma parte del acervo de la Biblioteca Jurídica Virtual del Instituto de Investigaciones Jurídicas de la UNAM

el contenido de tal relación. Hay libertad de contraer matrimonio, pero no libertad contractual para regular su contenido. $\mathrm{Al}$ aceptar, consensualmente, la entrada en el matrimonio, se acepta la entrada en el régimen de una institución cuyos contornos están regulados por la ley.

En tercer lugar, el matrimonio cristiano es monogámico, heterosexual (por su concepción del matrimonio como orientado a la procreación, según la doctrina medieval) e indisoluble (sólo puede ser disuelto por la muerte de uno de los cónyuges, en principio). Éstos son, pues, los rasgos esenciales de la matriz canónico-cristiana del matrimonio, que irán mutando en el proceso de secularización.

El proceso de secularización del matrimonio se realizó por grados, afectando a distintos caracteres de la matriz cristiana recién esbozada. ${ }^{7}$ El primer paso apareció con la reforma protestante. El carácter afectado aquí fue el primero de los señalados, la sumisión del matrimonio a la legislación y jurisdicción religiosas. Para los protestantes el matrimonio no es sacramento. Por eso, aunque es celebrado en forma religiosa, su regulación y jurisdicción corresponden a las autoridades civiles. Esto viene a confirmar el rol del protestantismo como motor histórico de la secularización, por una vía distinta y complementaria a la de la clásica afirmación de corte weberiano sobre su naturaleza desmitificadora.

En las diferentes corrientes del protestantismo el matrimonio sigue siendo visto como una institución destinada a la procreación y al establecimiento de lazos familiares, a partir de un vínculo originariamente consensual. Sin embargo, el matrimonio no es un sacramento, sino más bien un estado social. El modelo luterano de matrimonio, que se desarrolló en Alemania en el siglo XVI y se expandió a Austria, Suiza y Escandinavia, enfatizaba la idea de que el matrimonio es una realidad terrenal, sujeta al Estado, y gobernado por las leyes de Dios a través de los magistrados. Para Lutero el matrimonio es un asunto de este mundo. Aunque fue instituido por Dios al crear a la primera pareja humana, no ha sido objeto de una revelación especial o de una legislación divina. Para los luteranos, la Sagrada Escritura reconoce la competencia de las autoridades civiles para la regulación del matrimonio, del mismo modo que les reconoce competencias generales para velar por la justicia en las sociedades humanas.

7 Sobre la secularización del matrimonio puede verse el trabajo de Cobo Sáenz, María Inés, "La secularización del matrimonio en los países católicos: algunas referencias europeas y americanas", en Lasarte Álvarez, Carlos et al., Perspectivas del derecho de familia en el siglo XXI. XIII Congreso Internacional de Derecho de Familia, Sevilla, 2004. También véase Velasco Villar, Santos, "El proceso de secularización del matrimonio canónico y su concreción técnicojurídica”, Ius Canonicum, España, vol. 25, núm. 49, 1985, pp. 175-208. 
El carácter de vínculo social fue resaltado por la tradición matrimonial calvinista, aparecida en Ginebra y expandida en la segunda mitad del siglo XVI por Europa Occidental y América del Norte a través de los grupos hugonotes, pietistas, presbiterianos y puritanos. Aunque para los calvinistas el matrimonio es algo más que un contrato, tampoco para ellos es un sacramento. Es un compromiso social resguardado por las leyes civiles.

Algo parecido sucedió con el modelo anglicano, nacido en Gran Bretaña y exportado a América del Norte. De hecho, el matrimonio anglicano está regulado por los Canons of the Church of England y por leyes seculares. Incluso los Canons tienen carácter de leyes estatales, dado el estrecho vínculo entre la Iglesia anglicana y el Estado inglés. ${ }^{8}$

En los países católicos, en cambio, la regulación siguió siendo canónica hasta fines del siglo XVIII o principios del siglo XIX. A partir de ese momento, el monopolio eclesiástico sobre la regulación y jurisdicción del matrimonio fue cediendo a favor del monopolio estatal sobre el mismo. ${ }^{9}$ De este modo, a fines del siglo XVIII, coexistían en Europa diferentes tradiciones jurídicas en materia familiar. Éstas resultaban del juego de las divisiones religiosas, las especificidades consuetudinarias y la oposición entre los países de derecho civil y herencia romana, por un lado, y los países del common law por otro. ${ }^{10}$ El elemento decisivo era, en todo caso, el religioso. A partir del siglo XIX, con la profundización del proceso de secularización del matrimonio, las diferencias entre los países europeos se fueron reduciendo.

La evolución secularizadora se manifestó también respecto de la forma del matrimonio, cuya concreción más clara fue la aparición de la forma de celebración civil. A partir de la Reforma protestante se había suscitado la cuestión de la competencia para la celebración del matrimonio,

8 Sobre estos modelos véase Witte, John Jr., From Sacrament to Contract: Marriage, Religion, and Law in the Western Tradition, Kentucky, Westminster John Knox Press, 1997. Véase también Greiner, Albert, "L’enseignement de Luther sur le mariage", Fac-Réflexion, París, núm. 16, 1990, pp. 39-51; y Witte, John Jr., "John Calvin on Marriage and Family", en Selderhuis, Herman (ed.), The Calvin Handbook, Cambridge, Michigan, William B. Eerdmans Publishing, Grand Rapids, 2009.

9 La cuestión es mucho más compleja de lo que se puede presentar aquí, dado que en algunos ordenamientos jurídicos el derecho estatal remite a las normas religiosas para la regulación de algunos aspectos del matrimonio. Así sucede, por ejemplo, con la remisión a la forma religiosa de celebración, de la que hablamos en los párrafos siguientes, pero también con la remisión a otros aspectos del régimen matrimonial, sobre los cuales no nos explayaremos.

10 Halpérin, Jean-Louis, "Les fondements historiques des droits de la famille en Europe", Informations sociales, París, núm. 129-1, 2006, pp. 45 y 46. 
Esta obra forma parte del acervo de la Biblioteca Jurídica Virtual del Instituto de Investigaciones Jurídicas de la UNAM

hasta entonces en manos de la autoridad religiosa católica. La forma civil apareció por primera vez en Holanda, a fines del siglo XVI, para permitir a los disidentes calvinistas celebrar su matrimonio ante el magistrado estatal. Pero el sistema no se impuso de modo general sino hasta el siglo XIX. Hasta el siglo XVIII, los países católicos siguieron sometidos al matrimonio-sacramento, bajo la forma de celebración del derecho canónico. Los países protestantes impusieron, en muchos casos, una bendición por parte del pastor de la Iglesia establecida. El anglicanismo estaba más próximo en este punto del derecho canónico católico que de las formas luteranas o calvinistas. Sin embargo, dado el carácter nacional y estrechamente vinculado al Estado que asumieron las Iglesias protestantes, puede hablarse ya de un comienzo de secularización de la forma de celebración del matrimonio, en cuanto ésta quedó en manos de funcionarios religiosos que eran, de algún modo, también representantes del Estado. El matrimonio bajo forma estrictamente civil era todavía, a fines del siglo XVIII, marginal: sólo estaba presente en los Países Bajos y en Francia, para los protestantes solamente, desde 1787.

El rol de Francia fue aquí central: la Constitución de 1791 y el Código Civil napoleónico sometieron el matrimonio a la forma civil de celebración. De todos modos, la evolución fue gradual. La primera ola de codificación, que dio nacimiento al Código General de Prusia (1794), al Código napoleónico (1804) y al Código Civil austriaco (1811), y luego a otros códigos inspirados por estos modelos, realizó un compromiso variable según los países entre la tradición jurídica existente y el aporte del movimiento racionalista. Así, el Código napoleónico combinó la institución del matrimonio civil, único reconocido por la ley y anterior a un eventual matrimonio religioso, con instituciones más conservadoras, como un poder de corrección paterno que permitía el envío de los menores a prisión por orden del padre. Los códigos de Prusia y Austria mantuvieron el matrimonio confesional y prohibieron las uniones entre cristianos y no cristianos.

El matrimonio civil se expandió luego por los territorios europeos, convirtiéndose en un factor de uniformidad del derecho de familia en este aspecto. Algunos países siguieron sometidos al régimen del Código napoleónico después de $1814 ;^{11}$ otros adoptaron el régimen civil con posterioridad. ${ }^{12}$ La asunción por parte del Estado de la regulación pública de

\footnotetext{
11 Renania, Bélgica (independiente desde 1830) y los Países Bajos.

12 El matrimonio civil apareció al lado del matrimonio religioso en Inglaterra, Noruega, Prusia y Suecia. Surgido primero como opción para quienes no practicaban la religión dominante, el matrimonio civil se volvió la única forma jurídica válida en Italia, en Prusia y luego
} 
la forma de celebración y del régimen matrimonial es propia de un Estado secular, que se separa de las autoridades religiosas y es imparcial respecto de las creencias de los ciudadanos.

Hoy, junto con aquellos países en los que el matrimonio bajo forma civil es una opción al lado del matrimonio bajo forma religiosa están aquellos Estados que sólo reconocen la forma civil del matrimonio, ${ }^{13}$ lo que ejemplifica el caso de mayor secularización del régimen matrimonial en este sentido. Pero incluso en el caso del régimen mixto hay un cierto grado de secularización de la forma, no sólo por la introducción de la forma civil como alternativa, sino porque el reconocimiento de la forma religiosa viene dado por la ley estatal, que hace una especie de remisión al orden interno de una confesión religiosa para determinar la forma de la celebración matrimonial. Este sistema es propio de algunos países católicos, en los que la forma civil coexiste con la forma canónica, produciéndose luego en algunos casos una apertura a los grupos minoritarios. ${ }^{14}$

Algo parecido sucede en algunos Estados protestantes, aunque el camino seguido aquí fue distinto. La secularización de la forma de celebración matrimonial se produjo mediante la asunción por la legislación estatal de la regulación de la forma religiosa del matrimonio, en razón del carácter nacional de las Iglesias protestantes en esos territorios, juntamente con la regulación paralela de un matrimonio bajo forma civil. De este modo, el matrimonio civil fue introducido como una alternativa al matrimonio religioso, pero en un sistema en el que ambos tienen carácter inmediatamente estatal por los vínculos entre las Iglesias nacionales y el Estado. Luego se aceptó también la posibilidad de la celebración bajo otras formas religiosas. ${ }^{15}$

Puede resultar paradójico señalar que las raíces de la secularización del régimen legal y de la forma de celebración del matrimonio se encuentran en la propia tradición cristiana. Sin embargo, aunque paradójica, esta perspectiva parece confirmar las intuiciones de las teorías clásicas de la secularización (que en este punto conservan su vigencia) respecto del hecho que fue la propia evolución de la tradición judeocristiana la que provocó el desarrollo

en toda Alemania en la segunda mitad del siglo XIX. El matrimonio religioso resistió en los códigos de Portugal y España, en Polonia, en Rusia y en Grecia; y volvió a ganar terreno en Italia después de los acuerdos de Letrán en 1929.

13 En Europa: Alemania, Austria, Bélgica, Francia, Luxemburgo, Países Bajos. En América Latina: Argentina, Bolivia, Cuba, Ecuador, El Salvador, Guatemala, Honduras, México, Paraguay, Perú, Puerto Rico, Uruguay y Venezuela.

14 En Europa: Italia, España, Irlanda, Portugal. En América Latina: Brasil, Colombia, Costa Rica, Chile, Haití, Nicaragua, Panamá y República Dominicana.

15 En Europa: Dinamarca, Finlandia, Suecia, Reino Unido. 
de la secularización. ${ }^{16}$ De hecho, el Concilio de Trento, al exigir un determinado procedimiento público para la celebración del matrimonio, produjo una notable racionalización de su régimen. Como luego del Concilio de Trento las Iglesias protestantes adquirieron un carácter nacional y en los países católicos el régimen matrimonial pasó a manos de la autoridad civil, el Estado asumió las funciones matrimoniales públicas antes definidas por el régimen canónico. Pero no deja de ser cierto que la secularización provocó sólo la transferencia a la autoridad estatal de unas formas matrimoniales preexistentes, definidas por las actas conciliares de Trento. ${ }^{17}$

La indisolubilidad del matrimonio se vio afectada por la incorporación del divorcio vincular. Éste ya había asomado en la reforma protestante, aunque en modo no unánime en las distintas corrientes. La tendencia general era a admitirlo al menos en caso de adulterio. El régimen jurídico de la Revolución francesa reconoció también el divorcio. ${ }^{18}$ En las distintas legislaciones civiles que lo incorporaron a partir de entonces, el alejamiento del patrón de indisolubilidad fue mayor o menor, según el tipo de divorcio reconocido: divorcio por justa causa, divorcio por razones meramente objetivas (no convivencia durante un determinado lapso), divorcio consensual o incluso divorcio unilateral sin justa causa (lo que tradicionalmente se ha conocido como repudio).

La progresión de la admisión del divorcio fue lenta y compleja. En este camino se opusieron habitualmente los partidarios de la estabilidad de las familias y los partidarios de la libertad individual. Hasta mediados del siglo XIX su aplicación estaba limitada a una zona reducida. ${ }^{19}$ A fines del siglo XIX y principios del XX el divorcio se extendió en Europa

16 Para una evaluación global de las teorías de la secularización ver nuestro trabajo, Arlettaz, Fernando, Religión, esfera pública, mundo privado, Zaragoza, Prensas Universitarias de Zaragoza, 2015.

17 Una segunda afectación del carácter relativo a la forma fue, con mucha posterioridad, el reconocimiento de efectos jurídicos a la cohabitación no matrimonial que da lugar a una pareja de hecho, en el último cuarto del siglo XX. Aunque no se trata de un régimen matrimonial propiamente dicho, el reconocimiento de efectos jurídicos a las parejas de hecho es un paso más en la desformalización de las relaciones de pareja.

18 El divorcio fue introducido en 1792 con el matrimonio civil. Hubo sin embargo un movimiento de reacción bajo la Convención y el Directorio, que llegó hasta el Código Civil. Este último redujo las causas de divorcio, entendiéndolo además como mera separación de cuerpos. El divorcio vincular fue restablecido en 1884, durante el proceso laicizador de la III República.

19 Renania y Bélgica, bajo el régimen del Código napoleónico, aunque las rupturas matrimoniales eran pocas por el predominio de la religión católica; los países escandinavos, Escocia, algunos cantones suizos (Ginebra, Vaud, Neuchâtel, Zurich), los Países Bajos y Prusia, en donde predominaba la población protestante. 
occidental; y en Europa oriental después de la Primera Guerra Mundia. ${ }^{20}$ En los países católicos, donde el divorcio encontró fuertes resistencias de la Iglesia, su reconocimiento fue muy posterior. ${ }^{21}$

El carácter consensual-institucional del matrimonio también se fue modificando, en lo relativo al último elemento del binomio. Las corrientes legislativas del siglo XX fueron permitiendo un mayor ámbito para la autonomía de la voluntad en cuestiones familiares, lo que dio lugar a un doble proceso de contractualización y privatización del matrimonio. El origen de la radicalización del carácter contractual del matrimonio debe verse en la Revolución francesa. Para los revolucionarios franceses, liberar a los ciudadanos implicaba, en primer lugar, liberarlos en el ámbito de su vida privada. Por ello, la Revolución transformó el derecho matrimonial, fortaleciendo el principio de la autonomía de la voluntad en las relaciones familiares. Sin embargo, aunque la doctrina del matrimonio-contrato se desarrolló fuertemente en esta época gracias a un contexto de creciente contractualización de las relaciones civiles en general, hay que recordar que esta doctrina provenía ya del derecho romano. ${ }^{22}$

En definitiva, el derecho comenzó a ver a la familia como una comunidad de individuos, de modo que el interés familiar colectivo pasó por la protección de los intereses individuales de los miembros del grupo. Ejemplos directos de esta "desinstitucionalización" pueden verse en la retirada del derecho penal del ámbito de las relaciones familiares, así como la reducción del rol del derecho civil en su regulación. Ejemplo indirecto es el que resulta de las uniones de hecho, estructuras cuasi matrimoniales que como consecuencia de la informalidad de su origen, no se hallan sometidas al conjunto de derechos y deberes propios del régimen matrimonial.

La desaparición del carácter heterosexual del matrimonio es el último movimiento en el proceso de secularización. La heterosexualidad del matrimonio resulta indispensable en cualquier concepción cristiana no sólo por la explícita mención en las sagradas Escrituras, sino también por la identificación de la reproducción como una de las finalidades del matrimonio. Por esta misma vinculación existió durante largo tiempo en las Iglesias cristianas, y se mantiene hoy todavía en la Iglesia católica, una marcada hostilidad hacia las prácticas anticonceptivas. ${ }^{23}$

20 A mediados del siglo XIX en Inglaterra. A fines del siglo XIX y principios del XX en Alemania y Suiza.

21 En el último tercio del siglo XX en Italia, Portugal, España e Irlanda.

22 Durand, Jean-Paul "Code civil et droit canonique", Pouvoirs, París, núm. 107, 2003, p. 71 .

23 Isambert, François-André, "La sécularisation interne du christianisme", Revue Française de Sociologie, París, vol. 17, núm. 4, octubre-diciembre 1996, pp. 573-589. 
La relación entre las reformas del régimen matrimonial que llevaron a una ampliación de su contenido subjetivo, las creencias y prácticas de las comunidades religiosas puede analizarse desde un doble punto de vista. En primer lugar, es posible analizar un aspecto interno, referido a los debates que pueden darse al interior de las propias comunidades religiosas sobre cuál es la aproximación más adecuada a la situación de las parejas homosexuales desde la propia tradición. Además, en el caso de aquellas comunidades religiosas en las que existen opiniones divergentes, aparece la cuestión de si se impone algún tipo de sanción a quienes no se ajustan a la posición dominante dentro de la comunidad.

En este sentido, los debates sobre la reforma al régimen matrimonial estatal resultan externos a las comunidades religiosas, ya que no exigen un cambio en la concepción teológica o espiritual que la comunidad religiosa pueda tener al respecto. Una reforma al régimen estatal sobre la familia de ninguna manera exige de las comunidades religiosas que modifiquen su propia concepción al respecto ni las obliga a celebrar uniones que no encajan dentro de los requisitos que ellas han definido para esas celebraciones.

Sin embargo, hay al menos dos puntos de contacto entre los debates sobre la modificación del régimen estatal del matrimonio y las comunidades religiosas. Es decir, dos vías por las cuales las posiciones internas de las organizaciones religiosas se externalizan. El primer punto de contacto es que, en los Estados democráticos, las organizaciones religiosas son instituciones de primer orden en la configuración de la opinión pública, e intervienen en la esfera pública participando en los debates que allí tienen lugar. Se plantea así para las comunidades religiosas la cuestión de la toma de posición a este respecto. El segundo punto de contacto es menos general, y se refiere al régimen legal de aquellos países en los que las comunidades religiosas están autorizadas a celebrar matrimonios con efectos jurídicos reconocidos por el Estado. Aquí se plantean dos cuestiones. La primera es si las comunidades religiosas y sus ministros están obligados por el derecho estatal a celebrar matrimonios entre personas del mismo sexo, y, en su caso, qué posición adoptan las comunidades ante esa obligación. La segunda cuestión es la de decidir internamente, en ausencia de obligación impuesta por el derecho estatal, si celebrarán o no tales matrimonios.

El posicionamiento de las organizaciones religiosas frente al cambio del régimen legal del matrimonio en su ampliación a las parejas homosexuales, o incluso al reconocimiento de otros regímenes jurídicos equiparables (parejas de hecho, uniones civiles) en cuanto están abiertos a las uniones homosexuales ha ido desde el rechazo frontal hasta, en algunos casos, su 
aceptación abierta. Sin embargo, en mayor o menor medida la mayoría de ellas se ha opuesto a la mutación del régimen legal, y ha desplegado, tanto en el ámbito interno como en el internacional, su capacidad de expresión y de presión para evitar los cambios que mencionamos más arriba, con resultados diversos.

La oposición de estos grupos puede leerse como un rechazo a las tendencias que llevan a una pérdida de influencia sobre las características de la regulación familiar. El protagonismo religioso en las discusiones parlamentarias y en los debates mediáticos denota una estrategia de conservación de sus poderes institucionales. Lo que lleva a las religiones a salir a escena es su propio retroceso. Como explica Marcel Gauchet, ${ }^{24}$ el avance de la secularización como separación entre lo religioso y lo político las obliga a mostrar su identidad diferenciada frente a esas tendencias. La reaparición de lo religioso bajo estas características no corresponde, entonces, a un retorno de lo religioso, sino más bien a la adaptación de la fe religiosa a las condiciones modernas y posmodernas de la vida social y personal que no implican una estructuración religiosa de la experiencia humana.

\section{IV. ¿HA SIDO EL COMBATE POR EL MATRIMONIO UN COMBATE LAICO?}

Como ya insinuamos, en la mayoría de los países en los que se otorgó algún tipo de protección a las parejas homosexuales la transformación normativa encontró resistencia o al menos reticencia en muchos (aunque no todos) los grupos religiosos. Ya explicamos en el apartado anterior que esta renuencia se comprende bien en la medida en que se lee la apertura del matrimonio a las parejas del mismo sexo como parte del proceso de secularización del matrimonio.

Una pregunta vinculada con la anterior, aunque no idéntica, es la relativa a la relación entre matrimonio entre personas del mismo sexo y laicidad. Las teorías de la secularización, que ya hemos mencionado, tienen una pretensión puramente descriptiva: son puntos de vista sobre cómo la religión se reubica, transforma o decrece en un contexto de modernidad. No tienen una pretensión directiva en relación con el sistema jurídico. La aproximación de la laicidad, en cambio, es normativa. Defender la laicidad es defender la perspectiva de que resulta conveniente colocar cierta distan-

24 Gauchet, Marcel, La religión en la democracia, Barcelona, El Cobre Ediciones, 2003, pp. 38 y 39 . 
Esta obra forma parte del acervo de la Biblioteca Jurídica Virtual del Instituto de Investigaciones Jurídicas de la UNAM

cia entre lo religioso y lo jurídico (cómo deba interpretarse esta distancia es otra cuestión, demasiado amplia para ser discutida aquí). ${ }^{25}$

Hemos sostenido la idea de que el matrimonio entre personas del mismo sexo forma parte, como cuestión de hecho, de la secularización del matrimonio. Ahora bien, la relación entre matrimonio homosexual y laicidad es más ambigua. Es una cuestión discutible hasta qué punto la laicidad como concepto político exige que el matrimonio se abra también a las parejas homosexuales. Es verdad que el carácter heterosexual del matrimonio tiene, en nuestra cultura jurídica, un origen religioso. Desde este punto de vista, favorecer la transformación del matrimonio es favorecer la separación entre lo religioso y lo político. Pero no es menos cierto que, a pesar de este origen religioso, es posible defender el matrimonio puramente heterosexual desde un punto de vista no religioso.

En cualquier caso, y como cuestión de hecho (una vez más), es constatable que diferentes plataformas de combate laico se han posicionado a favor de la ampliación del matrimonio. ${ }^{26}$ Es decir, más allá de si desde un punto de vista puramente hermenéutico es posible asociar matrimonio homosexual y laicidad, lo cierto es que los actores del terreno sí han hecho esta asociación. En definitiva, la laicidad se ve involucrada en el tema del matrimonio homosexual del mismo modo que se vio involucrada en el tema de la transformación del matrimonio religioso en matrimonio civil, y en la discusión sobre el divorcio. ${ }^{27}$

Y a esto por supuesto se agrega la ya nombrada posición de resistencia o renuencia (con algunas puntuales excepciones) de los actores religiosos a la ampliación del matrimonio. La Iglesia católica se ha manifestado a través de su Catecismo y de otros documentos rechazando de plano la posibilidad de un régimen jurídico de protección para las parejas homosexuales. ${ }^{28}$ Esta posición se despliega en el contexto de su conocida afirmación de que

25 Explicamos esta diferencia en nuestro trabajo, Arlettaz, Fernando, "La laicidad vista desde el paradigma de la secularización", en Pelé, Antonio et al. (eds.), La laicidad, Madrid, Dykinson, 2014, pp. 209 y ss.

26 Véase, por ejemplo, Europa laica, disponible en: wrww. laicismo.org; y American Civil Liberties Union, disponible en wrwre.aclu.org.

27 Baubérot, Jean, “«Mariage pour tous»: enfin un vrai sujet de laïcité!”, Mediapart, París, 2012, disponible en: http://blogs.mediapart.fr/blog/jean-bauberot/051112/mariage-pour-tous-enfinun-vrai-sujet-de-laicite.

28 Iglesia católica, Catecismo de la Iglesia Católica, números 1601-1666, 1997; Pontificio Consejo para la Familia, Declaración acerca de la Resolución del Parlamento Europeo del 16/3/2000 sobre equiparación entre familia y 'uniones de hecho', incluso homosexuales, 2000; Congregación para la Doctrina de la Fe, Consideraciones acerca de los proyectos de reconocimiento legal de las uniones entre personas homosexuales, 2003. Resulta obvio decir que esta oposición a la regulación civil de 
Esta obra forma parte del acervo de la Biblioteca Jurídica Virtual del Instituto de Investigaciones Jurídicas de la UNAM

sólo la familia basada en una unión matrimonial heterosexual es digna de protección. Por esa misma razón, la hostilidad de la doctrina católica no está limitada a las uniones homosexuales, sino a cualquier unión (incluso heterosexual), no basada en el matrimonio.

Lo mismo ha sucedido en las conferencias episcopales nacionales, que se han manifestado contrarias a las reformas que culminaron en la adopción del régimen de parejas de hecho y del matrimonio homosexual en diferentes países. Así lo hemos señalado en otro trabajo ${ }^{29}$ respecto de los debates en Francia, España, Italia, Argentina, México, Brasil y Estados Unidos. La misma posición ha sido constatada por otros autores, en relación con estos $\mathrm{u}$ otros espacios nacionales..$^{30}$

El anterior papa ha insistido sobre la vinculación entre sexualidad y reproducción, al afirmar (con no poca paradoja si se tienen en cuenta antiguas luchas del catolicismo contra la ciencia moderna) que la evolución produjo la sexualidad justamente para permitir la reproducción de la especie. ${ }^{31}$ No parece que con el nuevo papa la situación haya cambiado en su fondo. Aunque algunas declaraciones públicas aparentan flexibilizar la posición católica sobre la aceptación de homosexuales en la Iglesia, se trata sólo de una mayor apertura pastoral hacia un colectivo que continúa siendo visto como marcado por el pecado. $\mathrm{Y}$ respecto del matrimonio entre personas del mismo sexo, así como de otras formas de reconocimiento de parejas homosexuales, el rechazo de la Iglesia católica sigue siendo el mismo. En un documento de 2014 se afirma que "los hombres y mujeres con tendencias homosexuales deben ser acogidos con respeto y delicadeza"; sin embargo, con cita de un documento anterior, se insiste en que "no existe ningún fundamento para asimilar o establecer analogías, ni siquiera remotas, entre las uniones homosexuales y el designio de Dios sobre el matrimonio y la familia" ${ }^{32}$

Los documentos en los que la Iglesia católica expresa su posición se dirigen a los católicos en general, y a los políticos católicos en particular. Estos

cualquier forma de relación para-matrimonial corresponde, en el ámbito interno de la Iglesia católica, con la afirmación de la total ilegitimidad de este tipo de uniones.

29 Arlettaz, Fernando, Matrimonio homosexual y secularización, cit.

30 Arriada Lorea, Roberto, "Las relaciones Estado-Iglesia en el Brasil del siglo XXI", en Blancarte, Roberto (coord.), Laicidad, religión y biopolítica en el mundo contemporáneo, México, El Colegio de México, 2013, pp. 113 y ss.; y Milot, Micheline, "Amplitud y límites de las libertades y la igualdad en el régimen laico canadiense”, ibidem, pp. 85 y ss.

31 Ratzinger, Joseph, Lumière du monde: Le pape, l'église et les signes des temps, Entretien avec Peter Seewald, Montrouge, Bayard, 2010.

32 Sínodo de los obispos, XIVAsamblea GeneralOrdinaria-Lavocaciónylamisióndelafamilia en la Iglesia y en el mundo contemporáneo - Lineamenta, 2014. La cita proviene del documento, mencionado más arriba, de la Congregación para la Doctrina de la Fe, 2003. 
últimos tendrían el deber de expresarse clara y públicamente en contra de tales regulaciones. Pero los documentos también están dirigidos a los no católicos, ya que pretenden basarse en argumentos racionales que podrían ser compartidos por todos. Por otra parte, si bien se reconoce que sólo la autoridad legítima tiene potestad para establecer las normas regulatorias de la vida social, se hace hincapié en que todos pueden y deben colaborar con la exposición de ideas para que esas normas respondan a los principios de justicia, lo que legitima la toma de posición por parte de la Iglesia.

Como hemos visto, la secularización se desarrolla en el sentido del alejamiento de la matriz cristiano-canónica del matrimonio y su aproximación a un modelo liberal-contractualista. Este modelo no sólo supone una ruptura directa con uno de los caracteres esenciales del matrimonio cristiano, como es su carácter heterosexual, sino que indirectamente afecta también el carácter institucional del matrimonio al ampliar el campo de elección del otro contrayente. He ahí por qué la Iglesia católica choca tan frontalmente con este tipo de reformas. No se trata sólo de la variación de uno de los caracteres del matrimonio. Se trata de un paso más en el camino de la des-institucionalización de una entidad que la Iglesia concibe precisamente bajo el prisma de su carácter institucional, y cuyos rasgos esenciales cree que están fuera de toda disponibilidad tanto por parte del legislador como por parte de los propios contrayentes.

La relativa unidad católica, al menos a nivel de la jerarquía eclesiástica, se opone a la diversidad de posiciones entre las comunidades protestantes, que es una consecuencia del pluralismo y de la descentralización del protestantismo. Esta diversidad se expresa tanto en el plano interno como en el plano externo (apoyo o rechazo de las iniciativas de regulación civil).

En los casos de Suecia, Noruega, Finlandia y Dinamarca, las respectivas Iglesias luteranas nacionales tienen posiciones variables, en general muestran una tendencia aperturista, aunque no carente de reticencias en algunos casos. En el caso de Dinamarca la legislación estableció la obligación de la respectiva Iglesia nacional de celebrar matrimonios homosexuales, lo que la Iglesia aceptó. ${ }^{33}$ En Suecia, aunque no existía obligación legal, la Iglesia nacional aceptó oficiar las ceremonias. ${ }^{34}$ Luego de la aprobación del matri-

33 La Iglesia luterana de Dinamarca (Iglesia nacional) aceptaba la bendición de las parejas homosexuales, aunque los ministros individuales podían oponerse por razones teológicas. La ley que estableció el matrimonio entre personas del mismo sexo obligó a la Iglesia oficial danesa a celebrarlos, aunque permitiendo que los pastores individuales se excusaran; véase el informe de prensa Folkekirken, The Danish Government: Same-sex Couples are to be able to Marry in Church, 2011.

34 La Iglesia luterana de Suecia (que dejó de ser Iglesia oficial en el año 2000) había venido ofreciendo bendiciones a parejas homosexuales desde 2007. En 2009, y en vista de una 
monio homosexual en Noruega, la Iglesia dio libertad a las congregaciones para decidir si celebraban o no tales matrimonios. ${ }^{35}$ En Finlandia, la Iglesia nacional bendecía las uniones civiles homosexuales; luego de la aprobación del matrimonio debe decidir qué posición adopta, aunque la jerarquía parece favorable a una redefinición del matrimonio religioso que incluya también a las parejas homosexuales. ${ }^{36}$

La Evangelische Kirche in Deutschland (que agrupa Iglesias luteranas, reformadas y unitarias) se ha expresado en el sentido de la preeminencia del matrimonio heterosexual, pero en contra de la discriminación de las parejas homosexuales y a favor de permitir la bendición de este tipo de uniones. ${ }^{37}$ La Iglesia Protestante Unida de Holanda (resultado de la fusión de la Iglesia Reformada de Holanda, la Iglesia Evangélica Luterana y el grupo de Iglesias Reformadas en Holanda) llama a la no discriminación de los homosexuales y, aunque no les permite el acceso al matrimonio, sí otorga bendiciones a las uniones homosexuales. ${ }^{38}$ La Federación de Iglesias Protestantes de Suiza se mostró a favor de la aprobación de la ley sobre uniones civiles. ${ }^{39}$

La Iglesia de Inglaterra se ha opuesto claramente al matrimonio entre personas del mismo sexo. Sin embargo, tratándose de otro tipo de uniones ha sido más ambigua. De hecho, ha llamado la atención sobre la necesidad

legislación que establecía el matrimonio homosexual no sólo bajo forma civil sino también religiosa, aceptó oficiar matrimonios homosexuales. Sin embargo, los ministros individuales pueden excusarse; véase el informe sobre el tema elaborado por la Iglesia luterana de Suecia, Svenska kyrkan, Information on the decision regarding same-sex marriages, 2009; véase también un informe del Comité Teológico que se encuentra disponible en versión española: Svenska kyrkan, Matrimonios de parejas del mismo sexo: consideraciones del Comité Teológico, 2009.

35 La Iglesia luterana de Noruega (Iglesia nacional), está dividida en cuanto a la consideración teológica de la homosexualidad; véase la resolución del sínodo de obispos Den Norske Kirke, Appointment and ordination in the Church of Norway of homosexuals living in partnership. Consequences of the Doctrinal Commission's 2006 statement, 2007. Luego de la aprobación de la ley de matrimonio en 2009, la Iglesia dio libertad a sus congregaciones para decidir si celebran o no tales uniones.

36 La Iglesia luterana de Finlandia (Iglesia nacional), aprobó primeramente una oración de intercesión para estos casos (véase Suomen Ev. Lut. Kirkko, The General Synod approved guidelines on facing same-sex couples, 2010) y luego aceptó la bendición de las parejas homosexuales bajo unión civil (Suomen Ev. Lut. Kirkko [¿ं?]: Registered partnership). El arzobispo líder de la Iglesia se felicitó tras la aprobación de la ley que permite el matrimonio homosexual (Finnish Lutheran leader 'rejoices' over same-sex marriage vote, YLE Uutiset).

37 Evangelische Kirche in Deutschland, EKD supports blessing for homosexuals as part of pastoral care, 1996 y Evangelische Kirche in Deutschland, Improve the legal status of homosexual partnerships, 2000.

38 Protestantse Kerk, The Uniting Protestant Churches in the Netherlands and homosexuality, 2004.

39 Fédération des Églises Protestantes de Suisse, Couples du même sexe. Loi sur le partenariat enregistré, 2005. 
Esta obra forma parte del acervo de la Biblioteca Jurídica Virtual del Instituto de Investigaciones Jurídicas de la UNAM

de protección de las parejas homosexuales e incluso ha indicado la necesidad de desarrollar acción pastoral respecto de estas parejas, aunque no acepte bendiciones formales..$^{40} \mathrm{Al}$ interior de la Iglesia de Escocia, de origen calvinista, existe diversidad de opiniones; luego de la aprobación del matrimonio homosexual los servicios jurídicos de la Iglesia señalaron que, a menos que se produzca una reforma de las normas legales sobre celebración de matrimonios por parte de la Iglesia de Escocia, los ministros no pueden celebrar matrimonios entre personas del mismo sexo. ${ }^{41}$

La Federación Protestante de Francia (que agrupa Iglesias luteranas, reformadas y de otros orígenes) tiene una posición matizada. Aunque ha sostenido que no se puede equiparar una pareja homosexual a una heterosexual, también ha llamado la atención sobre la necesidad de afrontar los nuevos desafíos de la época. En esta línea, señalando la necesidad de respeto de las personas homosexuales y la responsabilidad legislativa de los poderes públicos, se opuso al matrimonio entre personas del mismo sexo. ${ }^{42}$

En España, la Federación de Entidades Religiosas Evangélicas (que agrupa Iglesias luteranas, reformadas y de otra filiación) se pronunció a favor del reconocimiento de ciertos derechos a las parejas homosexuales, pero no dentro del régimen jurídico del matrimonio, sino de una institución especial que se cree al efecto. Las Iglesias evangélicas españolas dejaron constancia de que la gran mayoría de los protestantes defiende la separación entre la Iglesia y el Estado, y que es obligación del gobierno legislar a favor de todos los ciudadanos, aunque el sentido de esa legislación no coincida con la visión cristiana que ellos profesan. ${ }^{43}$ Una posición semejante se encuentra en el Consejo Nacional de los Evangélicos de Francia. ${ }^{44}$

40 Church of England, House of Bishops issues pastoral statement on Civil Partnerships, 2005; y Church of England, A Response to the Government Equalities Office Consultation -Equal Civil Marriage'- from the Church of England, 2012.

41 Church of Scotland, A challenge to unity: same-sex relationships as an issue in theology and human sexuality, 2011; Church of Scotland, Marriage and Civil Partnership (Scotland) Act 2014 ('the 2014 Act') Advice from the Principal Clerk, 2014.

42 Commission d'éthique de la Fédération Protestante de France, L'homosexualité : éléments de réflexion, 1997; Fédération Protestante de France, Église et homosexualité: dossier de travaildocument de base, 2002; Conseil de la Fédération Protestante de France, Déclaration à propos du 'mariage pour tous', 2012.

43 Federación de Entidades Religiosas Evangélicas de España, Consideraciones sobre el proyecto de ley para la equiparación de derechos de las uniones matrimoniales entre personas del mismo sexo, 2005; Federación de Entidades Religiosas Evangélicas de España, Modificación del Código Civil en materia de matrimonio para conseguir la equiparación matrimonial de las parejas homosexuales (s/f).

44 Conseil National des Evangéliques de France, Que croient les évangéliques? (s/f); Conseil National des Évangéliques de France, Projet de loi sur le mariage et l'adoption: le CNEF interpelle les parlementaires, 2012. 
Esta obra forma parte del acervo de la Biblioteca Jurídica Virtual del Instituto de Investigaciones Jurídicas de la UNAM

Las Iglesias protestantes estadounidenses tienen posiciones divididas. De hecho, el tratamiento de la homosexualidad, la ordenación de ministros gays o lesbianas y la celebración de uniones de personas del mismo sexo constituyen, desde los años 1980, una de las principales causas de división de las Iglesias estadounidenses. ${ }^{45}$

En razón del hecho de que en muchos Estados los ministros religiosos tienen competencia para la celebración de matrimonios bajo el régimen civil o de uniones civiles, la adopción de un régimen legal que permite el acceso a esas figuras por parte de parejas homosexuales obliga a las Iglesias a tomar una decisión sobre su futura actuación. Así, mientras algunas Iglesias han aceptado este nuevo rol conferido por la legislación estatal, otras han solicitado salir del sistema o al menos obtener excepciones respecto de las parejas homosexuales. ${ }^{46}$

Las Iglesias bautistas, ${ }^{47}$ las metodistas ${ }^{48}$ y los mormones $^{49}$ se oponen frontalmente a cualquier reconocimiento de las uniones homosexuales. En el caso de las comunidades de oposición más fuerte es notable el apoyo de algunos think tanks y lobbies de orientación conservadora. En cambio, las Iglesias episcopalianas, ${ }^{50}$ las evangélico-luteranas ${ }^{51}$ y las presbiterianas $^{52}$ se ubican en posiciones más flexibles. No se puede descartar que las

45 Coulmont, Baptiste, "Devant Dieu et face au droit? Le mariage religieux des homosexuels aux Etats-Unis", Critique Internationale, París, núm. 25, 2004, p. 47.

46 Ibidem, pp. 74-78.

47 American Baptist Churches USA, Responses / Actions Pertaining to Homosexuality, 2009.

48 United Methodist Church, Council Rejects Resolution on Same-Sex Marriages, 2009. United Methodist Church, What is the Denomination's Position on Homosexuality?, 2008.

49 The Church of Jesus Christ of Later-day Saints, The family: A Proclamation to the World, 1995; The Church of Jesus Christ of Later-day Saints, Same-Gender Attraction, 2006. Aunque no sea estrictamente una Iglesia protestante, hemos decidido incluirla aquí por su cercanía con las posiciones más rígidas de estas Iglesias.

50 Episcopal Church, Standing Commission on Liturgy and Music Response to 2009, Resolution C056: Liturgies for Blessings, 2010.

51 Evangelical Lutheran Church in America, Social Statement: Human Sexuality: Gift and Trust, 2009. Evangelical Lutheran Church in America, Sexuality: Some Common Convictions, 1996.

52 Presbyterian Church, Civil Unions and Marriage Issues: Questions and Answers, 2010. Presbyterian Church, Family Paper Approved: Assembly also Adopts Call Affirming Civil Rights of SameSex Couples. Las Iglesias unitarias celebran uniones de personas del mismo sexo y permiten la ordenación de ministros gays y lesbianas. Los Congregacionalistas, aunque dan gran autonomía a las asambleas locales, permiten en general tanto las celebraciones como la ordenación de pastores homosexuales y lesbianas. Entre los Presbiterianos hay divergencias de opinión, pero muchos aceptan las uniones homosexuales. Sobre esto véase Coulmont, Baptiste, "États-Unis. Le mariage religieux des couples de même sexe", en Descoutures, Virginie, Mariages et homosexualités dans le monde, París, Autrement, 2008, pp. 73-81. 
Esta obra forma parte del acervo de la Biblioteca Jurídica Virtual del Instituto de Investigaciones Jurídicas de la UNAM

posturas más aperturistas de algunas denominaciones sean una estrategia destinada a aumentar, o al menos, a evitar una disminución en el número de fieles. ${ }^{53}$

La postura de radical oposición tanto en algunas comunidades protestantes estadounidenses como, más claramente, en los lobbies conservadores de raíz cristiana se encuadra en la histórica ubicación de estos grupos en contra de la homosexualidad. El énfasis en las cuestiones sexuales existía ya en los fundamentalistas de comienzos del siglo XX. Para muchos grupos fundamentalistas, el feminismo y la homosexualidad son enfermedades contra las que hay que luchar.

En qué medida las posiciones de las comunidades protestantes estadounidenses pueden verse trasladadas a otras comunidades protestantes americanas es una cuestión abierta. En Canadá, por ejemplo, los obispos de Nuevo Westminster (pertenecientes a la comunión anglicana) aceptaron la posibilidad de otorgar la bendición a las parejas homosexuales. ${ }^{54}$

En sentido contrario, un ejemplo de oposición radical puede hallarse en la Alianza Cristiana de Iglesias Evangélicas de Argentina $^{55}$ y en la Federación Confraternidad Evangélica Pentecostal (también de Argentina). ${ }^{56}$ Estas dos organizaciones convocaron una manifestación en contra de la aprobación legislativa del matrimonio homosexual, postura de la que se desvinculó expresamente la tercera gran organización evangélica argentina (y la más antigua de todas), la Federación Argentina de Iglesias Evangélicas. ${ }^{57}$

Las Iglesias evangélicas mexicanas se manifestaron en contra del matrimonio entre personas del mismo sexo aprobado en el Distrito Federal. ${ }^{58} \mathrm{La}$

\footnotetext{
53 Idem.

54 Diocese of New Westminster, New Westminster Synod and Bishop approve same-sex blessings, 2002.
}

55 Alianza Cristiana de Iglesias Evangélicas de la Argentina, Aborto y homosexualidad, la postura de las Iglesias cristianas evangélicas afiliadas a ACIERA, 2003; Alianza Cristiana de Iglesias Evangélicas de la Argentina, Preocupación frente a la Ley de Unión Civil, 2003; Alianza Cristiana de Iglesias Evangélicas de la Argentina, Homosexualidad: reafirmando valores evangélicos, 2003; Alianza Cristiana de Iglesias Evangélicas de la Argentina, Postura de ACIERA respecto al matrimonio y la homosexualidad, 2009.

56 Federación Confraternidad Evangélica Pentecostal, El lunes 31 de mayo todos al Congreso!, 2010; Federación Confraternidad Evangélica Pentecostal, Masiva concurrencia evangélica a la plaza de los dos Congresos, 2010; Federación Confraternidad Evangélica Pentecostal, Después de la movilización del 31 de mayo, 2010.

57 Federación Argentina de Iglesias Evangélicas, La FAIE no adhiere ni apoya la marcha "Un mensaje de los niños: Queremos mamá y papá”, 2010.

58 Diario Evangélico Berea, Iglesias evangélicas de México rechazan los matrimonios homosexuales, 2010. 
Esta obra forma parte del acervo de la Biblioteca Jurídica Virtual del Instituto de Investigaciones Jurídicas de la UNAM

misma posición adoptaron muchas Iglesias evangélicas colombianas frente al régimen de parejas de hecho que permitía las parejas homosexuales. ${ }^{59}$

Las Iglesias protestantes brasileñas muestran también la diversidad que particulariza al mundo protestante. Las Iglesias luteranas, aunque señalan que el matrimonio ha sido tradicionalmente entendido como la unión de dos personas de sexo diferente, guardan al respecto la flexibilidad general que caracteriza al luteranismo. ${ }^{60}$ La Iglesia presbiteriana, en cambio, manifiesta un frontal rechazo a cualquier forma de sexualidad ejercitada fuera del matrimonio heterosexual. ${ }^{61}$ Las Iglesias pentecostales también se oponen frontalmente a cualquier forma de reconocimiento.

Como último ejemplo, fuera del ámbito europeo y americano, resulta interesante señalar que en un sentido semejante a la Iglesia de Inglaterra se expresó la Iglesia anglicana de Sudáfrica, luego de que la Corte Suprema de ese país extendiera el concepto de matrimonio del common law a las parejas homosexuales. ${ }^{62}$

\section{Gonclusiones}

Tres grandes conclusiones pueden extraerse de las ideas que hemos ido desarrollando hasta aquí. La primera es que existe una tendencia evidente, al menos en Europa occidental y América, a la protección de las parejas homosexuales mediante diferentes mecanismos jurídicos. La equiparación de las parejas homosexuales con las heterosexuales para efectos de matrimonio, por supuesto, no es ni mucho menos general, aunque sí creciente. Y en aquellos Estados en los que las parejas homosexuales no pueden acceder al matrimonio existen otros mecanismos alternativos de protección en el contexto del derecho a la vida familiar (regímenes de parejas de hecho o de unión civil).

Por supuesto, no puede preverse hasta qué punto continuará extendiéndose esta tendencia, aunque a juzgar por los cambios legislativos y jurisprudenciales de estos últimos años no parece que vaya a detenerse. Ejemplo claro es lo sucedido a lo largo de 2014 en los Estados Unidos, donde una fuerte oleada jurisprudencial ha venido derribando las normas legales o

59 Diario Evangélico Berea, Evangélicos colombianos marchan contra el aborto y la unión homosexual, 2006.

60 Portal Luteranos, Matrimônio, família e sexualidade humana proposta de diretrizes e procedimentos para um diálogo respeitoso, 2007.

61 Igreja Presbiteriana do Brasil, Um engano chamado 'Teologia Inclusiva' ou 'Teologia gay', 2013 .

62 Anglican Church of Southern Africa, Statement from The Church of the Province of Southern Africa, 2005. 
constitucionales que prohibían la protección de las parejas homosexuales o al menos su acceso al matrimonio.

Del mismo modo, no es posible saber de antemano si otras culturas jurídicas receptarán esta transformación. Desde luego esto resulta altamente improbable en el corto o mediano plazo, por no decir completamente imposible, en el caso del mundo musulmán. Aquí el fuerte rechazo a la homosexualidad todavía se trasluce en un sistema normativo restrictivo, cuando no directamente represor. En el antiguo mundo comunista sucede algo parecido (baste recordar las recientes leyes que penalizan la "propaganda homosexual" en Rusia). Sin embargo, algún antiguo miembro del bloque soviético, hoy miembro de la Unión Europea y más "occidentalizado", Eslovenia, se ha desmarcado claramente al aprobar, como hemos visto, una ley sobre matrimonio homosexual que está pendiente de promulgación. Finalmente, y siempre fuera del ámbito americano y europeo, aunque dentro de la órbita de influencia del derecho anglosajón, hemos mencionado la protección legal de las parejas homosexuales en Australia, Nueva Zelanda y Sudáfrica.

La segunda conclusión es que esta expansión de la protección de las parejas homosexuales, en cuanto implica ampliar la figura matrimonial en su definición subjetiva, puede incluirse en la progresiva secularización del derecho de familia en general y del matrimonio en particular. Esta secularización se pone de manifiesto como alejamiento del matrimonio de los caracteres propios de la matriz cristiana en la que se origina. Igualmente, las transformaciones del matrimonio se asocian a un cambio profundo en la consideración moral y legal de la homosexualidad. Durante mucho tiempo considerada una práctica desviada (desde el punto de vista moral) e ilícita (desde el punto de vista jurídico), la homosexualidad pasó a ser considerada una práctica legalmente permitida como parte del derecho a la vida privada. La adopción de regímenes de protección de las parejas homosexuales va un poco más allá, al considerar a la homosexualidad no como una simple práctica lícita, sino más radicalmente como una forma familiar digna de protección.

La tercera conclusión, íntimamente vinculada con la idea según la cual la ampliación del matrimonio se ubica en la línea de su secularización (del mismo modo que el establecimiento de regímenes de protección no matrimoniales forma parte de la secularización del derecho de familia en general) es que la resistencia, o al menos la reticencia, ha caracterizado el posicionamiento de buena parte de las Iglesias cristianas frente a las reformas normativas. 
Es posible hablar de tres grandes posiciones frente a la regulación de las parejas homosexuales. En primer lugar, podemos encontrar la situación de oposición radical a cualquier tipo de regulación que implique conferir a las parejas homosexuales, total o parcialmente, derechos que tradicionalmente han sido reconocidos al matrimonio. Ésta ha sido la posición de la Iglesia católica, de algunas ramas del protestantismo estadounidense (metodistas, bautistas) y de algunos grupos de la comunión anglicana. Esta fuerte oposición, sin embargo, no ha impedido que se regularan regímenes de protección de los colectivos homosexuales en aquellos lugares en los que estos grupos religiosos tienen una posición dominante.

La segunda posición está ejemplificada por aquellas comunidades protestantes que adoptan posturas favorables al reconocimiento de las uniones homosexuales, cuyos casos más radicales tal vez sean los de la Iglesia luterana de Suecia y la Iglesia luterana de Dinamarca, que celebran matrimonios homosexuales. Una posición de abierta aceptación de los matrimonios homosexuales es francamente excepcional en el mundo cristiano, y no deja de tener significación que se trate de las Iglesias luteranas de aquellos países que mejor se adecuan a la descripción clásica de la secularización.

Finalmente, la tercera categoría es intermedia a las dos anteriores, y corresponde a las Iglesias cristianas que caen entre los dos polos del espectro. En general el posicionamiento aquí es el de favorecer la protección de las minorías sexuales, aunque sin llegar a aceptar un estatuto de total equiparación con las parejas homosexuales. En algunos casos la reticencia puede ser sólo a la utilización del nombre matrimonio para las figuras legales que instrumenten la protección, aunque su contenido sustantivo sea equivalente al de éste.

\section{BIBLIOGRAFÍA}

ARlettaz, Fernando, "Secularización, laicidad y matrimonio entre personas del mismo sexo en América Latina", Laicidad y Libertades: Escritos Furidicos, España, vol.14, 2014.

, "La laicidad vista desde el paradigma de la secularización", en PELÉ, Antonio et al. (eds.), La laicidad, Madrid, Dykinson, 2014.

, Matrimonio homosexual y secularización, México, UNAM, Instituto de Investigaciones Jurídicas, 2015.

- Religión, esfera pública, mundo privado, Zaragoza, Prensas Universitarias de Zaragoza, 2015. 
Esta obra forma parte del acervo de la Biblioteca Jurídica Virtual del Instituto de Investigaciones Jurídicas de la UNAM

ARriadA LOREA, Roberto, "Las relaciones Estado-Iglesia en el Brasil del siglo XXI", en BLANCARTE, Roberto (coord.), Laicidad, religión y biopolitica en el mundo contemporáneo, México, El Colegio de México, 2013.

BAUBÉROT, Jean, “«Mariage pour tous»: enfin un vrai sujet de laïcité!”, $M e^{-}$ diapart, 5 de noviembre de 2012, disponible en: http://blogs.mediapart.fr/ blog/jean-bauberot/051112/mariage-pour-tous-enfin-un-vrai-sujet-de-laicite.

Calvo Borobia, Kerman, "Matrimonio homosexual y ciudadanía", Claves de Razón Práctica, España, núm. 154, 2005.

CECCHERINI, Eleonora, "Quando l'eguaglianza non basta. Brevi riflessioni sulla giurisprudenza statunitense in tema di 'same-sex marriage' alla luce della sentenza Windsor", en FERRARI, Daniele (ed.), Lo status giuridico delle coppie same sex: una prospectiva multilivello, Padua, Primiceri, 2014.

Cobo SÁenz, María Inés, "La secularización del matrimonio en los países católicos: algunas referencias europeas y americanas", en LASARTE ÁLVAREZ, Carlos et al. (coords.), Perspectivas del derecho de familia en el siglo XXI: XIII Congreso Internacional de Derecho de Familia, Sevilla, 2004.

Coulmont, Baptiste, "Églises chrétiennes et homosexualités aux ÉtatsUnis, éléments de compréhension", Revue Françáise d'Études Américaines, París, núm. 95, 2003.

, "Devant Dieu et face au droit? Le mariage religieux des homosexuels aux Etats-Unis", Critique Internationale, Francia, núm. 25, 2004.

, "États-Unis. Le mariage religieux des couples de même sexe", en Descoutures, Virginie, Mariages et homosexualités dans le monde, París, Autrement, 2008.

Durand, Jean-Paul, "Code civil et droit canonique", Pouvoirs, Francia, núm. 107, 2003.

GAUCHET, Marcel, La religión en la democracia, Barcelona, El Cobre Ediciones, 2003.

GrEINER, Albert, "L'enseignement de Luther sur le mariage", Fac-Réflexion, París, núm. 16, 1990.

HALPÉRIN, Jean-Louis, "Les fondements historiques des droits de la famille en Europe", Informations sociales, París, núm. 129-1, 2006.

ISAMBERT, François-André, "La sécularisation interne du christianisme", $R e^{-}$ vue Française de Sociologie, París, vol. 17, núm. 4, octubre-diciembre de 1976.

Milot, Micheline, "Amplitud y límites de las libertades y la igualdad en el régimen laico canadiense", en BLANCARTE, Roberto (coord.), Laicidad, religión y biopolítica en el mundo contemporáneo, México, El Colegio de México, 2003. 
Esta obra forma parte del acervo de la Biblioteca Jurídica Virtual del Instituto de Investigaciones Jurídicas de la UNAM

RATZINGER, Joseph, Lumière du monde: Le pape, l'église et les signes des temps. Entretien avec Peter Seewald, Montrouge, Bayard, 2010.

VELASco VILLAR, Santos, "El proceso de secularización del matrimonio canónico y su concreción técnico-jurídica", Ius Canonicum, España, núm. vol. 25, núm. 49, 1985.

WiTTE, John Jr., From Sacrament to Contract: Marriage, Religion, and Law in the Western Tradition, Kentucky, Westminster John Knox Press, 1997. "John Calvin on Marriage and Family", en SELDERHUis, Herman (ed.), The Calvin Handbook, Cambridge, Michigan, William B. Eerdmans Publishing, Grand Rapids, 2009. 


\title{
LAICIDAD FRANCESA Y LOS DERECHOS DE LAS MUJERES: ¿EXISTE ALGUNA RELAGIÓN ENTRE EL SEGULARISMO FRANGÉS Y LA IGUALDAD PARA LAS MUJERES?*
}

\section{Blandine CHELINI-PONT**}

\begin{abstract}
SUMARIO: I. Los dos modelos del secularismo estatal y la igualdad de género. II. El modelo francés. III. Derechos de las mujeres en Francia.

IV. Conclusiones. V. Bibliografia.
\end{abstract}

\section{LOS DOS MODELOS DEL SECULARISMO ESTATAL Y LA IGUALDAD DE GÉNERO}

En octubre del 2013, en la Universidad de París VIII Saint-Denis, el profesor Menachem Mautner de Tel Aviv dio una conferencia titulada "Las religiones tradicionales frente al proceso de secularización en el Mediterráneo", en la cual habló acerca de la religión en la política y en las sociedades civiles. En su discurso, asumió el pensamiento de Jonh Rawls en el liberalismo político por un lado, ${ }^{1}$ y por el otro, el de Jürgen Habermas, relativo al espacio público ${ }^{2}$ y al protagonismo de la religión en las democracias liberales. Para Mautner, ambos coinciden en que la justificación y la formulación de políticas en la democracia no deben ser desgastadas por las agendas religiosas. Sin embargo, difieren sobre el lugar que deben tener las religiones en la deliberación democrática. Rawls considera como necesario el arrinconamiento de las religiones en el proceso político, cuando Habermas acepta su participación en la deliberación democrática y en los contenidos generales de manejo de los valores democráticos.

* Traducción realizada por Diana Alejandra Avila Pérez, becaria de la Cátedra Extraordinaria "Benito Juárez", UNAM, Instituto de Investigaciones Jurídicas.

** Aix-Marseille Université, Francia.

1 Rawls, John, Liberalismo político, Nueva York, Columbia University Press, 2011.

2 Habermas, Jürgen et al., El poder de la religión en la esfera pública, New York, Columbia University Press, 2011. 
Esta obra forma parte del acervo de la Biblioteca Jurídica Virtual del Instituto de Investigaciones Jurídicas de la UNAM

Ciertamente, esta diferencia acerca del lugar de las religiones en la democracia deliberativa corresponde a la doble naturaleza del liberalismo democrático en los términos de neutralidad estatal, con una oposición visible entre dos formas "históricas" de neutralidad. La primera forma de neutralidad estricta corresponde mutatis mutandis a la visión de Rawls, y se ilustra en el secularismo americano y en la laicidad francesa. La forma habermasiana es más flexible, al constituir una modalidad combinada (un secularismo sensato, como dice la jerarquía católica). Dentro de esta visión puede ubicarse el secularismo europeo en general, que podemos definir como tradición europea de la neutralidad. ${ }^{3}$

Un buen ejemplo de esta diferenciación puede encontrarse en el trato que dio el Tribunal Europeo de Derechos Humanos (TEDH) respecto de la cuestión de los crucifijos en salones de clase en Italia. Las dos decisiones subsecuentes del Tribunal en 2009 y 2011 hicieron patente la doble cara de la neutralidad del Estado laico en la tradición liberal, de acuerdo con la doble naturaleza que acabamos de describir. En la primera decisión de noviembre de 2009, ${ }^{4}$ el juez falló a favor de los demandantes en contra del Estado italiano, al considerar en esta ocasión que un símbolo religioso tan poderoso como el crucifijo constituía una restricción o una intrusión en el campo de la conciencia, además de violar el artículo 9o. de la Convención y el artículo 2o. de su Protocolo número 1. Esta primera decisión corresponde a los estándares estadounidenses y franceses, para los cuales los símbolos religiosos son considerados como un llamado directo a la conciencia, y, por tanto, no pueden ser exhibidos por el Estado. ${ }^{5}$ En la segunda decisión, que revertió la primera mediante un giro muy comentado, la Gran Sala modificó su criterio

3 Para un panorama de los Estados seculares existentes, véase Thayer, Donly D. et al. (ed.), Religión y el Estado secular: reportes nacionales, Madrid, Universidad Complutense Publicaciones, 2015.

4 TEDH, Sentencia del 3 de noviembre de 2009, S. Lausi c. Italia, 30814/06, disponible en: http://hudoc.echr.coe.int/sites/eng/pages/search.aspx?i=001-95589\#\{“itemid":["001-95589"]\}.

5 “\$55. La presencia del crucifijo puede ser fácilmente interpretada por los alumnos de todas las edades como un símbolo religioso, y ellos sentirán que han sido educados en un ambiente escolar marcado por una religión en particular. Lo que puede ser alentador para algunos alumnos religiosos puede ser a su vez perturbadoramente molesto para alumnos de otras religiones o aquellos que no profesan religión alguna. Este riesgo es particularmente fuerte entre alumnos que pertenecen a minorías religiosas. La libertad negativa de la religión no está restringida a la ausencia de servicios o educación religiosa. Se extiende a prácticas y símbolos que expresan, de forma particular o general, una creencia, religión o ateísmo. Este derecho negativo merece una protección especial si es el Estado el que expresa una creencia y los disidentes se colocan en una situación de la cual no pueden salirse, si no es haciendo, esfuerzos desproporcionados y actos de sacrificio". TEDH, Gran Sala, Lautsi c. Italia, aplicación núm. 30814/06, 18 de marzo de 2011. 
con base en el margen de apreciación de los Estados y a partir del cumplimiento del artículo 2o. del Protocolo Adicional a la Convención. Asimismo, consideró que la obligación de neutralidad e imparcialidad del Estado no prohibía la presencia de símbolos religiosos en los locales de las instituciones educativas públicas, ni en ningún otro lugar dependiente del Estado. La Gran Sala hizo una sutil distinción entre el proselitismo activo por parte del Estado y los símbolos religiosos pasivos desplegados desde la sociedad. Este segundo fallo remite a una visión "flexible" de la neutralidad europea, que se presenta como no-interferencia del Estado en las creencias de la sociedad civil. La sola exhibición de un símbolo religioso, inclusive por parte del Estado, no puede en sí misma constituir una intrusión en las conciencias, ni ser considerada como una intención proselitista. El hecho que el crucifijo sea un símbolo religioso fuerte no implica necesariamente que pueda afectar la libertad religiosa de los padres y de los hijos. La simple presencia de crucifijos no supone un "adoctrinamiento" ni tampoco la conversión a la fe cristiana de los niños que acuden a la escuela pública donde son visibles tales símbolos.

Siguiendo con este ejemplo de sensibilidad opuesta, relativa a la neutralidad del Estado laico en una democracia liberal, podemos retomar la cuestión de la instrucción religiosa en las escuelas públicas. La solución de los Estados estrictamente neutrales es la de no incluir dicha educación en los programas oficiales y dejarla a la consideración de los padres de familia, de acuerdo con el derecho de transmitir a sus hijos sus propias convicciones. Sin embargo, el TEDH propuso una solución interesante al examinar dos casos referentes a Turquía (sunita) y a Noruega (luterana), donde se imparte una instrucción religiosa única y obligatoria. El juez consideró que la impartición de la religión compartida por la mayoría de la población no es incompatible con el artículo 2o. del Primer Protocolo Adicional, con la condición de que exista un sistema de exención integral o una alternativa educativa para aquellos que no quieran seguirla.

En una misma lógica, en el caso Lautsi de 2011,6 el juez consideró que la educación religiosa debe tener como límite último la prohibición de cualquier "proselitismo" o coacción hacia el alumno y la prohibición de cualquier "adoctrinamiento". Finalmente, dejó claro que la noción del margen de apreciación estatal funciona no sólo en lo relativo a la organización del ambiente escolar (posibles símbolos religiosos), sino también respecto de los contenidos educativos (posible educación religiosa).

6 TEDH, Gran Sala, Lautsi c. Italia, 30814/06, 18 de marzo de 2011, disponible en: http://hudoc.echr.coe.int/eng\#\{ "fulltext":["lautsi\%202009"],"documentcollectionid2":["GRANDCHA MBER","CHAMBER"],"itemid":["001-104040"]\}. 
Esta obra forma parte del acervo de la Biblioteca Jurídica Virtual del Instituto de Investigaciones Jurídicas de la UNAM

Ahora bien, ¿podemos aplicar a la condición legal de la mujer esta diferencia de sensibilidad ya mencionada? En otros términos, ¿podemos distinguir entre una laicidad estricta que, por una parte, prohíbe la educación confesional y los signos religiosos en escuelas públicas, y por la otra, una neutralidad más "flexible" que considera a la religión como un elemento esencial de la sociedad civil que debe ser promovido, aceptado y tomado en cuenta en escuelas públicas y en los demás espacios? ¿Podemos decir que en la mayoría de los Estados estrictamente neutrales, donde los símbolos y la educación religiosa están prohibidos en la escuela pública, existe una correlación, una conexión lógica entre la neutralidad estricta y una preocupación genuina para la igualdad de género? ¿Existe, en estos Estados laicos, alguna propensión hacia la lucha política y la creación de políticas en contra de la discriminación sexual? ¿Acaso se da una mejor promoción de la equidad de género con un mayor potencial de logros legales? En cambio, respecto de la relación entre laicidad e igualdad, los Estados "flexibles", como por ejemplo los regímenes de cooperación, parecen reconocer un lugar especial para la religión no sólo como una libertad importante, sino también como un recurso de valores para la sociedad civil e incluso como una parte inalienable de la cultura colectiva. ¿Son estos Estados más sensibles a la diferenciación sexual, y menos sensibles a la desigualdad que afecta a la mujer? Para tomar un ejemplo más distante al europeo, en el sistema secular de la India basado en el pluralismo religioso, ¿qué lugar sobra para la igualdad de las mujeres, cuando su vida diaria es condicionada por el estatuto personal, cuando las tratan como menores de edad, y les impiden conseguir el cumplimiento de sus derechos, aun ante los tribunales más altos?

La importancia de la religión en la construcción de la igualdad, así como la importancia de la igualdad en las dinámicas religiosas es probada. Los recientes debates en Francia sobre el "Matrimonio para todos" o sobre la reproducción asistida ilustran bien el entramado entre género y religiones. En Francia, quizá, la oposición persistente entre normas religiosas e igualdad entre el hombre y la mujer ha desaparecido en las Iglesias cristianas, sin embargo sigue siendo patente desde la lógica de equidad de género, esto es, la equidad de las sexualidades. Ahí, podemos hablar de un "divorcio" entre las normas religiosas y las sexualidades de género. En Francia, en medio de las objeciones al matrimonio de parejas homosexuales, la mayoría de las denominaciones religiosas ha expresado públicamente su hostilidad, ya que el derecho a casarse de dichas parejas y el tipo de filiación consecuente afecta su visión de la familia natural y de la diferenciación natural/divina entre géneros, entendidos como diseño di- 
vino. Inclusive, tanto el judaísmo como el protestantismo francés, se ha posicionado sobre esta temática retomando los argumentos católicos. Detrás de la amplia movilización popular en contra del proyecto de ley, la Iglesia católica francesa fungió como un actor clave, tal como lo fue y lo sigue siendo en España, Italia, Polonia y en otras partes. Desde un punto de vista más general, existe en la visión católica una continuidad entre la defensa de un secularismo suave - también llamado "sana laicidad"- y la protección de la familia y de la procreación "natural", así como de la heterosexualidad en las leyes civiles. ¿Podrían esas posturas públicas y políticas no tener gran influencia en países de secularismo suave?

Después de haber presentado de forma resumida el modelo francés, nos preguntaremos acerca de la conexión de dicho modelo con la igualdad de género y los derechos de la mujer, puesto que hoy en día, relacionamos estrechamente ambos elementos en el marco de la laicidad francesa. ¿Es esta pareja verdaderamente relevante? ¿Cómo y por qué funciona? ¿Acaso es posible verificar una conexión lógica entre ambas, según la cual sería un país más secular, protegería más y promovería los derechos, así como la equidad entre hombres y mujeres?

\section{EL MODELO FRANCÉS}

En primer lugar, ¿cómo definir el modelo francés de laicidad? Este modelo ha sido discutido por eminentes especialistas, y es objeto de persistentes disputas académicas y debates públicos. Para los defensores ortodoxos de la identidad laica, el Estado laico debe mantenerse absolutamente separado de las religiones que son consideradas como peligrosas debido a su apetito de poder y su influencia en las conciencias de las personas. Desde esta perspectiva, la religión es considerada como un código de pensamientos y comportamientos obligatorios, invasora de la libertad de pensar y actuar de las personas. El Estado laico se presentaría entonces como la emanación de un código moral o un ideal metalegal, el idéal laïque, derivado de una sociedad emancipada, progresiva, humanista y compasiva. Parafraseando las palabras del filósofo Eric Voegelin, los defensores de esta identidad laica son "gnósticos", conscientes y convencidos. ${ }^{7}$

7 "La República es una filosofía antes de ser un régimen; es una Iglesia laica cuyo dogma es el libre pensamiento y cuyo sacerdote es el maestro de escuela" (traducción libre). Emile-Auguste Chartier, dit Alain. El autor contemporáneo más representativo de la defensa de la tesis "Laicidad-identidad" es Henri Peña-Ruiz, véase La laïcité, París, Flammarion, 
Esta obra forma parte del acervo de la Biblioteca Jurídica Virtual del Instituto de Investigaciones Jurídicas de la UNAM

Los pensadores ortodoxos nunca fueron mayoritarios en el panorama académico y político francés, el cual se caracteriza por su gran diversidad crítica. La mayor parte de los estudiosos - historiadores, abogados y filósofos - consideran que el Estado laico francés surgió como resultado de un conflicto extraordinario, que ciertamente tenía raíces anticlericales, pero que su liberalismo social logró obstaculizar por la fuerza de una idea universal que servía de orden sustituto trascendental. Al mismo tiempo, estos estudiosos reconocen que los conflictos se amainaron, a partir de una síntesis que se llevó a cabo a inicios de los años 1960, y que el Estado laico francés estableció finalmente las condiciones para una convivencia pacífica de las creencias en el territorio nacional. ${ }^{8}$ Así, el Estado laico francés garantiza la neutralidad e igual acceso a los servicios públicos, la no discriminación en el campo religioso, y la igualdad de los ciudadanos ante la ley, de igual manera, protege la libertad de creencias y de conciencia de los ciudadanos.

La responsabilidad de este Estado laico en la secularización (indiferencia religiosa) de la sociedad francesa aún es debatida. ¿Son - se han vueltolos franceses menos católicos debido al colapso colectivo de las prácticas religiosas de los años 1960, a causa del fuerte anticlericalismo transmitido por el sistema educativo público, o debido a la renovación de la población francesa por migrantes que no tenían una cultura religiosa particular o que no eran católicos? $\mathrm{Al}$ respecto, las opiniones están fuertemente divididas. ${ }^{9}$

Finalmente, otra escuela de pensamiento académico intenta liberar a la laicidad francesa de su fantasía mesiánica antigua, enfatizando las implicaciones concretas de los valores consolidados por la Constitución. En primer lugar, estos pensadores buscan hacer más técnicas y operativas las posibilidades ofrecidas por las normas jurídicas. Asimismo, buscan fomentar una reflexión en torno al futuro de los franceses en una sociedad pluralista, para ser incluso más visionarios y prospectivos hasta el punto de proponer una nueva versión de la imaginación nacional en la que la diversidad se integra como un valor positivo. ${ }^{10}$

2003; del mismo autor, Histoire de la laïcité, genèse d'un idéal, París, Gallimard, 2005, collection La Découverte. Véase también Nicolet, Claude, L’idée républicaine en France, París, Gallimard, 1982.

8 Rémond, René (ed.), Histoire de la France religieuse, París, Seuil, 2004, t. 3, Du Roi très chrétien à la Laïcité républicaine, XVIIIème-XIXème siècles, 3a. parte, "Une vitalité religieuse toujours forte"; Airiau, Paul, Cent ans de laïcité française. 1905-2005, París, Presses de la Renaissance, 2005; Tripier, Yves, La laïcité, ses prémices et son évolution depuis 1905 (le cas breton), París, L'Harmattan, 2003.

9 Battut, J. y Vand, Join-Lambert, 1984, la guerre scolaire a bien eu lieu, Bruselas, Desclée de Brower, 1995.

10 Baubérot, Jean, Vers un nouveau pacte lä̈que?, París, Seuil, 1990. 
De esta forma, el modelo francés es envolvente, a pesar del esfuerzo de las autoridades políticas francesas para imponer una narrativa nacional que representaría la verdadera o la eterna religión civil francesa, lo que es difícilmente cierto. Por nuestra parte, acotamos que este modelo ha movido polaridades: no es tan estable y su evolución depende ya sea de decisiones judiciales o legislativas, ya sea de prácticas sociales nuevas que invierten el marco legal de la laicidad francesa.

Probablemente, la polaridad más profunda del modelo francés es la importancia fundamental del Estado, su gran proyección soberana, la cual se antepone al orden democrático y a las libertades de los ciudadanos. Este Estado, símbolo moderno de la autoridad política y de la autonomía, está separado y neutro. En tal separación-neutralidad subyacen los principios constitucionales actuales, y el Estado encarna un orden político que voluntariamente se desprende y se deshace de cualquier autoridad, norma o visión religiosa, para posicionarse como la guía de los principios universales. La modernidad política francesa fue, en palabras de Philippe Portier, ${ }^{11}$ disociativa. Los franceses no son una nación bajo Dios, sino preferentemente, una nación bajo valores universales.

Entre estos valores, existe la libertad. Nos encontramos aquí frente a otra polaridad del secularismo francés: la de la libertad, de la cual deriva la libertad religiosa, entre varias. Esta polaridad se encuentra en alguna manera opuesta a la del Estado. Es difícil determinar cuál polaridad se antepone sobre la otra, es decir, cuál es el núcleo de la laicidad francesa. Dos tendencias permanentes entran en conflicto según los acontecimientos: ¿debe prevalecer el orden neutral del Estado o la libertad de los ciudadanos? Hacer hincapié en lo primero es considerar que el Estado separado y neutro ha de supervisar el seguimiento del orden cívico, del orden público y casi consecuentemente del orden social. Desde esta perspectiva, es fácil entender, como tradición estatal, que los franceses no tengan dificultad en prohibir legalmente el velo en la escuela pública. La enseñanza pública es considerada como una de las funciones esenciales y constitucionales del Estado francés, a la cual dedica su mayor presupuesto, precisamente porque se considera que la tarea educativa pública incluye la formación de una ciudadanía ilustrada.

En la misma lógica, sigue siendo sencillo entender la prohibición de los rostros cubiertos en las calles, al ser los espacios públicos, colectivos y comunes considerados bajo la autoridad estatal, la cual tiene competencia para controlar el orden público, potencialmente no concreto intangible. Inclusi-

11 Portier, Philippe y Lagrée, Geneviève, La modernité contre la religion?, Rennes, Presses Universitaires de Rennes, Collection Sciences des Religions, 2010, Introducción. 
Esta obra forma parte del acervo de la Biblioteca Jurídica Virtual del Instituto de Investigaciones Jurídicas de la UNAM

ve, el Consejo Constitucional francés ha usado la expresión "orden público inmaterial" para declarar la conformidad de la ley a la Constitución, al considerar que el orden público incluye el respeto a los valores republicanos comunes de los franceses. Es probable que esta tendencia de neutralidad - especialmente estricta para los servidores y servicios públicos - se extienda a los estudiantes y otras personas en las universidades y a los individuos en el ámbito laboral. Esta probabilidad debe ser entendida bajo las circunstancias en las que viven los franceses.

Existe también otra tendencia, que no es menos fuerte, ni menos histórica, que podemos llamar "protección y eficacia de las libertades". Es cada vez más fuerte, y corresponde a un movimiento en nuestras sociedades contemporáneas hacia el reclamo de un espacio religioso más amplio para los individuos. Los juristas la relacionan, desde la perspectiva de la interpretación legal de la neutralidad del Estado, con la protección más amplía, la mejor seguridad de la libertad de conciencia, creencias, convicciones, pensamiento y expresión de los ciudadanos. En el artículo 1o. de la Constitución francesa, la República dice respetar todas las creencias. Jean Baubérot ha mostrado perfectamente como la famosa Ley de 1905 de Separación de las Iglesias y del Estado fue concebida por sus promotores como una ley tranquilizadora de la libertad de conciencia y de culto. ${ }^{12}$ Estas libertades son consideradas hoy entre los valores más altos de la República francesa laica, y la ley mejora su ejercicio y potencial. Derivado de lo anterior, podemos presentar a la laicidad francesa como un modelo de libertad religiosa y de libertad de conciencia; es por ello que el Consejo de Estado francés ha colocado la libertad religiosa entre los tres términos definitorios de la laicidad (jcomo una trinidad!) en su reporte de 2004 sobre laicidad.

\section{DereGhos De LAS MUJERES EN Francia}

Prosigamos ahora con nuestra intención original de cuestionar la igualdad de género como una polaridad inseparable de la laicidad francesa. De hecho, durante la disputa acerca de la prohibición del velo islámico en la escuela, la necesidad para las alumnas de mantener una actitud neutral fue inevitablemente vinculada con la cuestión de la igualdad entre hombres y mujeres. ¿Es esta polaridad fundada o bien cuestionable?

La igualdad jurídica entre hombres y mujeres no fue un tema relevante para los primeros republicanos en el poder, al final del siglo pasado. Nadie

12 Baubérot, Jean, Histoire de la laïcité en France, París, PUF, QSJ, 2013. 
contestaba la pobre situación legal de las mujeres en el Código civil napoleónico que perduró hasta la Segunda Guerra Mundial - 1938 para ser más preciso - época en que una ley terminó con la minoría legal de la mujer en el matrimonio y le dio su plena capacidad. El Código Civil, al concebir el matrimonio como secular, civil y casi obligatorio, empeoró la situación de las mujeres, con base en un marco autoritario y patriarcal, hasta un punto no antes alcanzado. Este modelo persistió por décadas, sin cambio alguno en sus formas, excepto con la introducción del divorcio en 1884. El derecho al voto de las mujeres nunca fue tema de discusión de los republicanos, los cuales consideraban — si esta idea hubiera pasado por su cabeza - que las mujeres no eran un electorado favorable a los partidos republicanos, dada su supuesta cercanía con la Iglesia católica. En realidad, un consenso conservador y tácito se llevó a cabo entre los republicanos progresistas y laicos, así como los católicos tradicionales monárquicos, para excluir naturalmente a las mujeres de cualquier derecho político y civil de tradición ilustrada. ${ }^{13}$

Sin embargo, la reflexión acerca de la educación femenina y la apertura progresiva de escuelas secundarias públicas y de universidades públicas para las mujeres, la necesidad de formar y contratar profesoras para las nuevas escuelas primarias públicas que iban progresivamente a reemplazar muchas de las católicas, presentó a la educación intelectual femenina como un proyecto republicano. La igualdad jurídica entre mujeres y hombres no fue mencionada en el artículo 1o. de la Constitución francesa de 1958, el cual coloca directamente la igualdad en la órbita secular, desde la perspectiva del principio de no discriminación. La República, declarada inmediatamente como laica, tiene como primera "tarea" asegurar la igualdad ante la ley de todos sus ciudadanos, sin distinción de origen, raza o religión, pero los padres fundadores de la actual Constitución francesa no hicieron una distinción entre sexos en su criterio de no discriminación. De hecho, su silencio fue lo contrario de un olvido. Desde la Segunda Guerra mundial, la condición legal de la mujer había mejorado dramáticamente, debido a su contribución y sacrificio en la Resistencia francesa y a otras razones culturales. Después de haber votado exitosamente por primera vez en 1945, las mujeres francesas habían dado un paso grande y silencioso con la afirmación en el artículo 3o. del preámbulo de la primera Constitución de la posguerra, en 1946, que señala: "La ley garantiza a la mujer, en todos los ámbitos, derechos iguales a los del hombre". El preámbulo de 1946 quedó incluido, con la Declaración de los Derechos del Hombre y del Ciudadano, en la Consti-

13 Rochefort, Florence, Le pouvoir du genre, lä̈ité et religions, 1905-2005, Toulouse, Presses Universitaires du Mirail, 2008. 
Esta obra forma parte del acervo de la Biblioteca Jurídica Virtual del Instituto de Investigaciones Jurídicas de la UNAM

tución de 1958. Este proceso permitió abrir una fase histórica de cambio legal para las mujeres, con una especie de segunda secularización de la ley civil que modificó la normatividad en relación a la familia y afianzó los derechos de las mujeres en el marco familiar y en otros ámbitos.

La lucha por los derechos de igualdad entre el hombre y la mujer fue uno de los principales combates políticos de la historia francesa a partir la Segunda Guerra mundial. Esta lucha consistió en dos movimientos paralelos, los cuales, aunque aparentemente antinómicos, hicieron que Francia conservara la tasa de natalidad más alta de Europa y, a la vez, una de las tasas más elevadas de mujeres que trabajan. Respecto del primer movimiento, el Estado francés escogió deliberadamente la vía de la política familiar mediante la incitación fiscal y la política de ayuda financiera a las familias, de acuerdo con el número de hijos. Por otro lado, amplió la legislación protectora para las mujeres embarazadas, favoreció los modos colectivos de guardia para los hijos de las madres trabajadoras, y multiplicó las escuelas maternales que se encargan de los niños durante los horarios laborales. Ello permitió preservar la vida de las familias, la educación de los niños y su seguridad, así como las necesidades y actividades económicas de las personas. Asimismo, la ley de 1983 sobre la igualdad en el trabajo tomó en cuenta las especificidades "femeninas" laborales, las cuales fueron denunciadas como indebidamente ventajosas en 1988 por la Corte Europea de Justicia. Respecto del segundo movimiento, el derecho francés destruyó en un periodo de cuarenta años, progresivamente y a tirones, el modelo napoleónico de la familia patriarcal, autoritaria y desigual. Podemos citar la ley de 1965 relativa a los regímenes matrimoniales: esta ley fue verdaderamente revolucionaria. Dio a las mujeres una libertad "financiera" que habían perdido desde Napoleón. Ya podían, sin la "autorización" de su marido, abrir una cuenta bancaria, usar libremente sus ingresos y gestionar solas sus propios bienes. La potestad paternal fue reemplazada por la autoridad parental ejercida de manera conjunta por ambos esposos.

La ley de 1972 impuso la igualdad de salarios entre hombres y mujeres por el trabajo equivalente (aunque se sigue trabajando en ello). En 1975, la ley autorizó el divorcio por consentimiento mutual y quitó al adulterio su carácter penal (ya no es una causa perentoria de divorcio aunque siga siendo la primer causa de divorcio por falta). Si bien el divorcio está lejos de ser siempre mutual, la disposición evita la obligación de "culpa" específica para separarse. Hoy en día, los procedimientos de divorcios son iniciados en su mayoría por mujeres. De manera global, el derecho del divorcio evolucionó desde entonces, al pasar de un derecho que daba a las exesposas y madres 
una indemnización compensatoria, un derecho a la custodia casi sistemático y una pensión alimenticia para cada niño a cargo, a un derecho que comparte en mayor medida la custodia entre ambos padres (custodia alternada) y que toma en cuenta la independencia financiera de las mujeres en la diminución de los montos compensatorios. Desde los años 1980, varias leyes han sido tomadas para evitar la coacción directa y privada de los hombres sobre las mujeres, especialmente en las parejas casadas: en 1981, el crimen de violación recibió una definición legal que incluye su existencia dentro de las parejas casadas. Las violencias conyugales fueron cada vez más penalizadas.

Esta segunda edad de la secularización francesa se construyó principalmente con base en una política pública constante de liberalización y de promoción del control de la fecundidad desde los años 1970, sin importar el partido en el poder. En dicha promoción, se generaron conflictos bastante vivos - pero no tan vivos ni divisores como en Estados Unidos - con la Iglesia católica y con parte de la clase política y de la población respecto de la legalización del aborto. Podemos presentar algunas fechas claves de este largo proceso societal. El control de la fecundidad mediante la contracepción fue autorizada en 1967 bajo la presidencia del general De Gaulle, primeramente para todas las mujeres casadas, luego para todas las mujeres mayores de edad (a partir de 1972), y finalmente para las jóvenes menores de edad, bajo la supervisión de un organismo público llamado el Planning familial (la Planificación familiar de 1974). El aborto, despenalizado en 1975 bajo estrictas condiciones de precocidad embrionaria, fue transformado en "interrupción voluntaria de embarazo" en 1981, pero siguió siendo muy regulado en sus condiciones materiales. Sin embargo, la denominación misma de la ley era significativa: lo que el marco legal del aborto tomaba en cuenta era precisamente la voluntad personal de la mujer o de la joven menor de edad en aceptar o rechazar su embarazo. Tanto la contracepción como el aborto legal fueron cubiertos por el seguro social desde los años 1980. Al respecto, no hubo en Francia una batalla de opinión comparable con la del Obamacare en Estados Unidos, mientras que la cuestión del matrimonio homosexual suscitó, recientemente, movilizaciones enormes. El número de abortos en Francia se mantuvo estable desde 1975: alrededor de 200,000 por 830,000 nacimientos anuales $(57.1 \%$ fuera del matrimonio, contra $37.2 \%$ en 1994).

De forma paralela, otro aspecto esencial de la "liberación" de las mujeres no fue la despenalización de la sexualidad fuera del matrimonio, la cual nunca existió en el derecho francés desde la Revolución, sino la despenalización de la sexualidad de los menores. En efecto, la mayoría de edad 
sexual en Francia es fijada a la edad de 15 años. Si la ley castiga de forma severa a toda persona mayor que tiene relaciones sexuales con una persona de menos de 15 años, después de esta edad, y a partir de 1945, los jóvenes de ambos géneros estuvieron libres de tener relaciones sexuales con cualquier persona, incluido relaciones homosexuales desde una ley de 1982: solamente importa su consentimiento, que la otra persona no sea de su familia y que no sea una autoridad institucional, como un profesor por ejemplo. El derecho francés es extremadamente liberal en materia sexual, y la ausencia de todo control legal de la vida sexual de las adolescentes y mujeres, así como la prohibición misma de una autoridad absoluta de los padres sobre la sexualidad de sus hijos después de 15 años cumplidos favoreció de rebote la libertad de la vida y del movimiento de las mujeres en Francia.

Un último aspecto de esta mutación de la secularización francesa: la promoción de la igualdad mediante el carácter mixto de la escolaridad y la educación académica. El carácter mixto de la educación ha sido una política constante del Ministerio de la Educación Nacional desde los años 1960. La educación mixta es obligatoria en las escuelas públicas y se ha vuelto la norma en las escuelas privadas, las cuales son católicas en un 90\%. Por lo tanto, la cuestión de la condición femenina en Francia es objeto de un conjunto de políticas públicas continuas desde los años 1960. Bajo un gobierno de derecha, fue creada en 1974 la Secretaría de Estado de la Condición Femenina, que se transformó en 1982 en el Ministerio de los Derechos de la Mujer.

En este terreno, la cuestión de las prácticas religiosas culturales y de las prácticas legales, así como relacionales y familiares de las poblaciones extranjeras o francesas de origen extranjero, entra en conflicto con el derecho francés de la familia, la igualdad jurídica conquistada por las mujeres y con toda la simbólica progresista y emancipadora que existe atrás del derecho y de las leyes de la República. Tomemos por ejemplo el sitio del Ministerio de los Derechos de las Mujeres. ${ }^{14}$ Este sitio es particularmente interesante en la presentación de sus informaciones. ¿Qué nos enseña en primer plano? La creación reciente de un sitio de información dedicado a la interrupción voluntaria del embarazo (en el rubro del derecho a disponer de su cuerpo) y de un programa reciente de promoción de la igualdad entre niños y niñas en la escuela. Pero lo más interesante es la importancia de tres temáticas agrupadas: el matrimonio forzado, las violencias hacia las mujeres y las mutilaciones sexuales. Estos tres temas se encuentran en diferentes entradas: ya sea directamente (matrimonios forzados, prioridad de la

14 Véase http://femmes.gouv.fr/. 
primera página), ya sea en el rubro violencias hacia las mujeres, o bien, en el expediente Derecho de las mujeres e igualdad, donde encontramos un rubro Mujeres e inmigración. Finalmente, en el expediente Igualdad en derecho y en dignidad hay también un apartado completo sobre las Mujeres de la inmigración, que incluye los tres temas precitados. ${ }^{15}$ Es necesario detenernos sobre este expediente, ya que es muy esclarecedor: el término de dignidad es usado pero jamás explicitado claramente. Sin embargo, las situaciones combatidas son claramente expuestas: violencias conyugales, matrimonios forzados, mutilaciones, repudios, poligamia. Dos guías son puestas a disposición de los usuarios para luchar en contra de estas plagas, las cuales, de acuerdo con el sitio, son aparentemente específicas en las mujeres inmigradas: la guía de la igualdad entre los hombres y las mujeres procedentes de la inmigración y otras más específicas como "Mujeres marroquís: ¡sus derechos en Francia!" sobre el procedimiento de matrimonio y las condiciones de su validez en ambos países, su disolución y las condiciones del divorcio, la custodia de los hijos y la transmisión de la herencia. ${ }^{16}$ En esta misma página, una lista de diversas asociaciones de apoyo está a disposición.

Por lo mismo, existe en Francia una política verdaderamente consciente de la confrontación entre las prácticas culturales y los derechos "extranjeros" frente a la defensa de las mujeres, en particular las que proceden de la inmigración. También existe una repetición muy mediática de la prohibición del llamado matrimonio forzado, en el cual las familias presionan a las jóvenes para que se casen con una persona escogida por la familia. El contexto francés es muy sensible - es lo menos que se puede decir-, a la aparente incompatibilidad entre la igualdad de las mujeres en Francia, fuertemente orientada hacia la desaparición de la autoridad unilateral ejercida por la familia y por el hombre dentro del matrimonio. También está fuertemente establecida con base en el derecho legal de disponer de su cuerpo en materia sexual y reproductiva: la moral religiosa de los monoteísmos es muy sensible al control de la sexualidad humana y más particularmente al de las mujeres. Esta moral se encuentra particularmente en la situación legal y cultural de las mujeres extranjeras de origen musulmán.

Lo entendemos, la cuestión del velo islámico y a fortiori, de manera mucho más frontal, la cuestión del velo integral se analiza a partir de estas coordenadas. La igualdad entre los hombres y las mujeres se ha vuelto un pilar de la segunda secularización francesa jurídica y socialmente validada.

\footnotetext{
15 Véase http://femmes.gouv.fr/dossiers/egalite-en-droits-et-dignite/femmes-de-limmigration/.

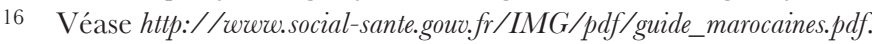


Esta obra forma parte del acervo de la Biblioteca Jurídica Virtual del Instituto de Investigaciones Jurídicas de la UNAM

Todo ello se produjo antes de 1989. Fue en esta fecha que ocurrió el primer caso del velo islámico en la escuela pública. Y de forma inmediata, el carácter represivo de la religión musulmana, que obliga a las mujeres a usar el velo por pudor bajo la presión y el control de los hombres y de su entorno, encendió los debates, los cuales se enfocaron precisamente a la cuestión de la prohibición del velo en la escuela para defender la libertad y la igualdad de las mujeres.

La profunda conexión entre la laicidad francesa y la igualdad de las mujeres se ha perfeccionado después de 1989 y se da en contra de lo que podemos llamar un orden conservador y en ocasiones religioso. Los últimos cambios fueron hechos en el contexto de una política pública voluntaria y continua, fuera cual fuera la tendencia política de todos los gobiernos franceses, han adoptado claramente posturas de emancipación legal y social para las mujeres, establecido una narrativa muy positiva en ellas.

\section{Conclusiones}

\section{Acerca de la Ley de 2010 que prohíbe ocultar el rostro} en el espacio público, conocida como Ley antiburka

La laicidad del Estado francés ha constituido por mucho tiempo un problema político mayor en una sociedad que permanece en su mayoría católica. En la actualidad, la laicidad se entiende de forma menos estrecha en los tribunales superiores y en la academia, a la vez de haberse vuelto un tema ideológico en las diferentes corrientes políticas francesas. Además de la neutralidad del Estado y de sus servicios, una laicidad constitucional asegura con cada vez más sutileza la libertad religiosa de los ciudadanos y el pluralismo de convicciones. Pero la laicidad, tal como la Ilustración francesa, es también una visión del mundo para la cual la emancipación de la conciencia, la libertad de pensamiento y de acción son un objetivo político. Como ideología progresista que defiende el valor último de todos los ciudadanos en su conjunto, pasó de ser un valor fundamental de la izquierda francesa a un valor central de la derecha populista. Ya no son los católicos y los movimientos minoritarios quienes son objeto de la sospecha de la administración y de la opinión pública —una sospecha aprovechada por los partidos políticos-, sino los musulmanes, población de origen migratorio con una demografía en constante incremento, que están atravesados por diferentes corrientes más o menos radicales, de quienes se cree puedan romper el equilibrio secular que 
implica discreción religiosa en el espacio público, pero también visibilidad de la igualdad entre todos los ciudadanos.

Además de la confusión que hemos visto entre la visibilidad y el proselitismo ofensivo, existe otra muy común entre el islam, la amenaza islámica y la revocación de la identidad de grupos sociales que están en situación de desventaja económica, pero que se encuentran lo suficientemente organizados para vivir replegados. Este miedo francés - que no es una cuestión de racismo o de discriminación contra las "llegadas recientes" - explica la compleja focalización del público y de los legisladores en contra de los símbolos religiosos en el espacio público, ya que éste, más allá de su función pública, "refleja" el caractère lä̈que de la sociedad francesa. Este factor "cultural" ha luchado de manera creciente para encontrar su justificación en un mundo de globalización religiosa, pero es imposible desecharlo simplemente como una especie de residuo que habría de desaparecer o como una muestra de la intolerancia francesa.

El sentimiento republicano en Francia no debe ser considerado solamente como una ideología laica, una visión puramente antropocéntrica que busca remplazar las visiones del mundo preexistentes fuertemente teñidas de religión y basadas en una jerarquía, la sagrada. Si puede funcionar como tal en el discurso oficial, también opera a otro nivel como forma de cultura y sistema de creencias cuyo objeto es la República, concebida como una comunión sagrada. ${ }^{17}$ Es necesario considerar el proceso de articulación en su globalidad: por un lado, las expresiones convencionales y elitistas de la identidad republicana que se ubican en el ámbito público y en los mecanismos de socialización tales como las escuelas, los partidos políticos y las festividades; por otro lado, "las fundaciones sagradas de la República", los "recursos profundamente culturales" (símbolos, memorias, mitos, y tradiciones) ${ }^{18}$ sobre los cuales recaen los ciudadanos de la República para conservar su identidad. Por lo tanto, el sentimiento republicano se presenta como una mezcla social, cultural, político y religioso, que compone una aleación resistente al paso del tiempo. ${ }^{19}$

En el caso del velo integral, esta mezcla inextricable explica en gran parte la desconfianza de la opinión pública y la respuesta casi instantánea de la legislatura, si no para hacerlo desaparecer, al menos para disminuir su proliferación en las calles del país. El velo integral toma una posición

17 Smith, Anthony D., Chosen People. Sacred Sources of National Identity, Oxford, Oxford University Press, 2003, pp. 9 y 18.

18 Ibidem, p. 31.

19 Ibidem, p. 25. 
Esta obra forma parte del acervo de la Biblioteca Jurídica Virtual del Instituto de Investigaciones Jurídicas de la UNAM

prominente, con una violencia simbólica que no debe ser ignorada como algo que no importa o que fuera propio de otro tiempo; se relaciona con la tradición de la emancipación y la igualdad que es la base del orden civil y cívico, que expresa la conquista del espíritu filosófico en contra del peso de las tradiciones religiosas y sociales que colocaron a las mujeres en un papel subordinado y constreñido. Aplicado a las mujeres, este ideal de emancipación ha pasado a ser parte de la leyenda de la "Gran nación francesa". Tal vez la cifra de velos integrales en Francia es muy reducida, y el ruego de las mujeres menos favorable de lo que se imagina; tal vez las mujeres que se cubren el rostro sienten que al hacerlo están ejerciendo su libertad absoluta. ${ }^{20}$ Pero estamos aquí en la representación ideal del ser, y para los franceses es motivo de orgullo haber sido siempre, y tal vez los primeros, preocupados en mejorar la "condición femenina".

\section{El velo integral versus la condición femenina: el nuevo "combate laico"}

A esta idea de condición femenina subyace una postura que va en dirección opuesta al velo integral femenino. ¿Cuál es el significado del velo integral en el contexto francés? Significa la exclusión de las mujeres de la vista de los transeúntes, sean quienes sean. Y son las mujeres las únicas afectadas por esta práctica de vestimenta, distintiva y exclusivamente. La desigualdad en sentido amplio que esta prenda representa surge de que, en el espacio público, el principio de igualdad implica un código de reconocimiento mutuo. Y en el contexto francés, lo mínimo es ver y ser visto "cara a cara" entre seres humanos. En los antiguos Estados segregacionistas de los Estados Unidos o Sudáfrica, la idea de separar a los blancos de los negros se basaba en la negativa de los primeros de ver a los segundos en los mismos lugares que ellos frecuentaban, y al ser obligados ya sea en autobuses, escuelas, universidades u hospitales, los negros eran escondidos de los blancos. Pues bien, uno no se esconde de la vista de otros en un país donde la igualdad de los seres humanos es un principio constitucional. Esto sería una ruptura del "pacto" implícito que da vida a la comunidad. ¿Qué queda de este pacto si la mitad de la población se excluye o es excluida por una prenda que la esconde de los ojos de los transeúntes? Sobre dicha desigualdad se superpone la igual-

20 No sólo ejercitarían su libertad absoluta, pero frecuentemente tomarán un descanso con su ambiente social o familiar — notoriamente por conversión- practicando por sí una forma de ascetismo voluntario lejos de cualquier restricción. Haciendo esto corresponderían a la postura "ultra", entre todas las posibles posturas de creencia, en los tiempos posmodernos que caracterizan a las sociedades contemporáneas. 
Esta obra forma parte del acervo de la Biblioteca Jurídica Virtual del Instituto de Investigaciones Jurídicas de la UNAM

dad de género: solamente las mujeres, por razón de sexo, deben usar esta prenda que las esconde de los demás. El uso del velo integral elimina de las calles la diversidad sexual, la cual tiene un significado profundo en un país donde el sistema educativo se ha esforzado, por cuarenta años, para establecer una convivencia obligatoria en las escuelas desde una edad temprana. Últimamente, las demandas para la no diversidad se han multiplicado en Francia, en especial en las albercas públicas, e incluso si se justifican por modestia u obligación religiosa, son perjudiciales para principio de igualdad entre hombres y mujeres. El hecho de que esto exista o haya existido en algunos países como Afganistán con los talibanes, o Nigeria con Boko Haram, donde el velo completo y el rechazo de la educación formal para las jóvenes van de la mano, ancla ipso facto la correlación entre la prenda y la desigualdad sexual que simboliza.

Finalmente, esta prenda que oculta el rostro indica una discriminación importante en la vestimenta. Puede ser incluida en la larga lista de obligaciones aplicadas por los sistemas de castas, como aquellos establecidos en el Antiguo Régimen, o aquel mucho más trágico de los judíos en las calles de la Alemania nazi, reconocibles por sus estrellas amarillas. El velo integral es como una quintaesencia de todas estas imaginaciones repulsivas. Las mujeres son segregadas, discriminadas y desconocidas por todos los que no están "autorizados" para verlas. Cuando una vestimenta separa tanto, ya sea al esconder el rostro de una mujer por el hecho de ser mujer, o al obligar a una persona a usar una campana por ser leprosa, el enfoque es similarmente intolerable en una sociedad de ciudadanos. Incluso cuando este comportamiento sólo involucre una minoría extrema, sigue siendo altamente hiriente e incompatible con las ideas de orden público y de la dignidad humana, especialmente al entenderse el orden público ${ }^{21}$ como los requerimientos mínimos de la vida en sociedad y los principios constitucionales de libertad e igualdad. ${ }^{22}$

\section{Una política frontal en contra de las prácticas tradicionales o religiosas}

Hemos entendido que existe en Francia una política frontal enfocada a la protección de la mujer en contra de las prácticas culturales, tradicionales

21 Véase el caso celebrado en relación con "lanzamiento de enanos", Commune de Morsang-sur-Orge, núm. 136727, 27 de octubre, 1995.

22 Decisión de conformidad con la ley de 2010 por el Consejo Constitucional, disponible en: http://wrere.conseil-constitutionnel.fr/conseil-constitutionnel/francais/les-decisions/acces-par-date/ decisions-depuis 1959/2010/2010-613-dc/decision-n-2010-613-dc-du-07-octobre-2010.49711. html. 
Esta obra forma parte del acervo de la Biblioteca Jurídica Virtual del Instituto de Investigaciones Jurídicas de la UNAM

y religiosas, así como en contra de leyes extranjeras cuando sus estatutos familiares son considerados como contrarios al orden público francés. Una vez más, es imposible desconectar esta política de extrema sensibilidad para la fe subsumida de mujeres extranjeras o francesas de familias migrantes, a la cuestión del velo islámico prohibido en la escuela. Es como si el orden musulmán se burlara de la igualdad de la mujer, así como de la tradición secular. Si ello no fue necesariamente cierto antes de 1989, los primeros casos de niñas con velo en la escuela crearon cierta identidad entre la igualdad de género y laicidad francesa. Y es muy difícil hoy en día negar esta confusión como parte de un estereotipo, una estigmatización o un racismo social, especialmente cuando la presión islámica sobre los franceses musulmanes parece incrementarse. Más allá del caso francés y su posible intolerancia, ¿podríamos decir que existe una correlación mayor entre igualdad de género en un contexto laico que en un modelo cooperativo u orientado religiosamente? En Francia, la lógica de la igualdad jurídica entre ciudadanos de ambos géneros está relacionada ahora en la filosofía constitucional con el Estado laico y la libertad religiosa. En palabras de Florence Rochefort, la cuestión del género, en el contexto francés, constituye una brecha propicia para analizar las relaciones entre Estados, religiones y sociedades, y sospechamos que sea el caso en todas partes.

$\mathrm{Al}$ lado de la ley, existe todo un abanico de representaciones interiores, valores, y prácticas que interactúan en el proceso de emancipación de la mujer. En este largo proceso, las religiones tradicionales no han sido buenas compañeras, aunque se deba admitir excepciones, como el caso de las Iglesias protestantes que postulan una perfecta igualdad y dignidad, a tal grado de que las mujeres comparten en la actualidad las funciones sacerdotales. Si hablamos de la Iglesia católica, los discursos sobre la mujer han evolucionado mucho - aparte de la teología sobre la familia y de la lucha frontal en contra del aborto-, y hoy la mayoría de católicos creen sinceramente que su religión es la más favorable para las mujeres, especialmente debido a su compromiso educativo para las niñas y su respeto profundo hacia su condición. Sin embargo, la doctrina de la Iglesia católica ha podido ser usada para las causas más conservadoras.

De manera general, las agendas religiosas no tienen como prioridad mejorar las vidas de las mujeres ni luchar en contra de los estereotipos que las mantienen subordinadas. Más grave todavía, algunos grupos religiosos usan todos sus recursos para "limitar" los reclamos "feministas" y reemplazarlos por modelos muy conservadores, tal como lo hacen los grupos y partidos islamistas que procuran mostrar sus avances en la sociedad con el 
incremento del uso del velo en la calle. Los más determinados buscan inclusive modificar las Constituciones y códigos civiles, especialmente, las disposiciones garantistas de los derechos de las mujeres, o suspender la aplicación de las leyes que no están conformes con los principios sagrados de la Sharia. El conservadurismo religioso ha ganado fuerza desde los años 1990, potenciando su impacto y ciertos éxitos para frenar los derechos de las mujeres a nivel internacional. Lejos de haberse reducido, el lugar de la religión en el campo social y político ha logrado ampliarse, demostrándolo de manera exitosa en el combate contra el derecho al aborto. Pero lo más preocupante es la multiplicación de los cambios legislativos que se vuelven rápidamente normas sociales intangibles que reducen el rol de la mujer. La pregunta es la siguiente: si las leyes que son sometidas a lo religioso tienen el poder de implementar un conservadurismo social sin empatía por la causa de la mujer, ¿es cierto que la promoción de la igualdad y de la libertad para las mujeres sólo es posible en el marco de un régimen laico que limita el papel de la religión en la deliberación pública y en el proceso de creación normativo? Lo anterior, especialmente si el Estado laico tiene un secularismo claramente igualitario y un proyecto político emancipador. Es por ello que parece plausible admitir que, en materia de derechos de las mujeres, la neutralidad estricta del Estado, relacionada con un cierto distanciamiento vis à vis la religión en el proceso político, es un sistema protector y una garantía muy fuerte para el pluralismo religioso y para la protección de minorías religiosas.

\section{BIBLIOGRAFÍA}

Airiau, Paul, Cent ans de lä̈ité française. 1905-2005, París, Presses de la Renaissance, 2005.

BATtUT, J. y VAND, Join-Lambert, 1984, la guerre scolaire a bien eu lieu, Bruselas, Desclée de Brower, 1995.

BAUbÉROT, Jean, Vers un nouveau pacte lä̈que?, París, Seuil, 1990.

, Histoire de la laïcité en France, París, PUF, QSJ, 2013.

Habermas, Jürgen, et al., El poder de la religión en la esfera pública, Nueva York, Columbia University Press, 2011.

Nicolet, Claude, L'idée républicaine en France, París, Gallimard, 1982.

PeÑA-RuIZ, Henri, La laïcité, París, Flammarion, 2003.

, Histoire de la laïcité, genèse d'un idéal, París, Gallimard, collection La Découverte, 2005. 
Esta obra forma parte del acervo de la Biblioteca Jurídica Virtual del Instituto de Investigaciones Jurídicas de la UNAM

PORTIER, Philippe y LAGRÉE, Geneviève, La modernité contre la religion?, Rennes, Presses Universitaires de Rennes, 2010, colección Sciences des Religions.

RAWLS, John, Liberalismo político, Nueva York, Columbia University Press, 2011.

RÉmOnD, René (ed.), Histoire de la France religieuse, París, Seuil, 2004, t. 3, Du Roi très chrétien à la Laïcité républicaine, XVIIIème-XIXème siècles.

ROCHEFORT, Florence, Le pouvoir du genre, laïcité et religions, 1905-2005, Toulouse, Presses Universitaires du Mirail, 2008.

Smith, Anthony D., Chosen People. Sacred Sources of National Identity, Oxford, Oxford University Press, 2003.

Thayer, Donly D. et al. (ed.) Religión y el Estado Secular: Reportes Nacionales, Madrid, Universidad Complutense Publicaciones, 2015.

TrIPIER, Yves, La laïcité, ses prémices et son évolution depuis 1905 (le cas breton), París, L'Harmattan, 2003. 


\title{
DEREGHOS DE LA NIÑEZ: EDUGACIÓN LAICA Y VIDA EN FAMILIA
}

\author{
Rodolfo VÁZQUEZ*
}

SUMARIO: I. Introducción. II. Dos concepciones contrapuestas de los derechos. III. Derecho a una educación laica. IV. Derecho a una vida en familia.

V. Bibliografia.

\section{INTRODUCGIÓN}

En 1976, en un célebre artículo, Neil MacCormick afirmaba con razón que "los derechos de los niños constituyen un buen caso para poner a prueba a la teoría de los derechos en general". ${ }^{1}$ Como sabemos, existen dos teorías sobre la naturaleza de los derechos: la teoría de la elección (o de la voluntad o capacidad racional), por un lado, y la teoría del interés (o de los beneficios o necesidades), por el otro. Defenderé esta última concepción y la pondré a prueba analizando dos derechos relevantes para la niñez: ${ }^{2}$ el derecho a una educación laica y el derecho a una vida en familia.

\section{DOS CONCEPCIONES CONTRAPUESTAS DE LOS DERECHOS}

La teoría voluntarista de los derechos pone el acento en el valor de la libertad de las personas, en su capacidad racional para elegir y materializar sus planes de vida. Parten del supuesto liberal, en la línea de Mill, de que cada individuo es el mejor juez de lo que es bueno o malo para sus vidas, nadie mejor que el propio individuo para conocer lo que prefiere. Este tipo de afir-

* Profesor del Instituto Tecnológico Autónomo de México.

1 MacCormick, Neil, "Los derechos de los niños. Un test para la teoría de los derechos", trad. de Neus Torbisco, en Fanlo, Isabel (comp.), Derechos de los niños. Una contribución teórica, México, Fontamara, 2004, p. 61.

2 Por economía, usaré en el texto las expresiones "niñez" o "menor" para referirme a "las personas menores de edad" o a las "niñas, niños y adolescentes". 
mación es, precisamente, la que choca de manera frontal con la situación de la niñez porque, de acuerdo con esta teoría, si algo distingue a los menores es que no siempre saben, ni siquiera normalmente, aquello que es mejor para sus vidas. Por ello, un liberal coherente pondría en serias dudas la posibilidad de dar cuenta de los posibles derechos de los menores, pues éstos no gozan de las condiciones básicas para hacer exigibles racionalmente sus deseos y preferencias. Un ejemplo claro de esta postura lo encontramos en Carl Wellman. Para este autor, la libertad o el poder son elementos esenciales de los derechos, y ambos presuponen en el titular una cierta capacidad moral para actuar. Los menores gradualmente adquieren tal capacidad hasta hacer propio el contenido de los derechos, pero mientras no logren tal posicionamiento pleno, no poseen derechos humanos en absoluto. ${ }^{3}$ De igual manera, Onora O'Neill nos previene sobre la "utilidad" del enfoque fundado sobre los derechos del menor asimilando a éstos, por ejemplo, a la categoría de víctimas de discriminación, como sucede para el caso de las mujeres o de los grupos étnicos. Estos últimos son capaces de reivindicaciones autónomas y su condición de grupos discriminados responde a situaciones artificiales, políticas o culturales. Por el contrario, los menores son incapaces de tales reivindicaciones y su estado de vulnerabilidad responde a condiciones biopsíquicas que son por naturaleza pasajeras. Por supuesto, esta condición vulnerable del menor exige un compromiso aún más robusto por parte de terceros. O’Neill propone la construcción de una categoría de deberes que sean independientes de las pretensiones del destinatario. Se trataría de deberes positivos sin derechos, obligaciones imperfectas si se quiere, que exigirían no un asistencialismo arbitrario, sino un paternalismo justificado. ${ }^{4}$ El propósito, finalmente, tiene una causa noble, a saber: reforzar la idea de responsabilidad de terceros y no restarle fuerza atribuyendo derechos a quienes no están en condiciones de poder ejercerlos. En buena medida esta fue la concepción imperante hasta que en 1990 entró en vigor la Convención sobre los Derechos del Niño.

Para las teorías del interés los menores gozan de ciertos derechos. De acuerdo con MacCormick, "al menos desde su nacimiento, todo niño tiene el derecho a ser alimentado, cuidado, y, si es posible, querido, hasta que llegue a ser capaz de cuidarse por sí mismo o por sí misma... Si alguien no reconociera que cada niño tiene ese derecho lo consideraría un simple caso de ceguera moral". ${ }^{5}$ Se trata de derechos morales que pueden o no estar re-

3 Wellman, Carl, "El crecimiento de los derechos de los niños", en Fanlo, I. (comp.), Derechos de los niños..., cit., pp. 57 y ss.

4 Véase O’Neill, Onora, "Children's Rights and Children's Lives", en Alston, Philip et al. (eds.), Children, Rights and the Law, Oxford, Clarendom Press, 1992, pp. 24 y ss.

5 MacCormick, N., op. cit., pp. 62 y ss. 
conocidos jurídicamente. Más aún, es precisamente porque los niños tienen esos derechos que conviene que existan disposiciones jurídicas que obliguen a terceros: padres biológicos, adoptivos, familias extensas o al Estado. De esta manera, la teoría del interés se presenta no sólo con una mayor capacidad explicativa para dar cuenta de los derechos del menor, sino que amplía considerablemente la gama de derechos sólo si pensamos, con Liborio Hierro, en la importancia moral y en la diversidad de necesidades fundamentales y objetivas de los individuos. ${ }^{6}$ Creo que este sentido integral de los derechos bajo el principio del "interés superior de la niñez" es el cambio más significativo que se introduce en la Convención desde 1990 y que, poco a poco, ha ido permeando en todas las disposiciones normativas estatales. La Convención, como sabemos, parte de cuatro principios normativos: 1) principio de no discriminación que expresa el tratamiento igual de los niños sin distinción por motivos de raza, color, religión, opinión política, origen nacional, étnico o social, posición económica, impedimentos físicos, nacimiento o cualquier otra condición del mismo niño, de sus padres o de sus representantes legales; 2) principio de aplicación de los derechos, haciendo especial referencia al cumplimiento de los derechos económicos, sociales y culturales exigiendo a los Estados Parte adoptar las medidas hasta el máximo de los recursos disponibles; 3) principio de respeto a los padres en la dirección y orientación de los hijos en el ejercicio de sus derechos; 4) principio del interés superior del niño reconociendo su bienestar por encima de otros intereses como principio para regular las decisiones de las autoridades públicas. México no ha sido la excepción en la adopción de estos principios, como puede apreciarse en la Ley General de los Derechos de Niñas, Niños y Adolescentes, ${ }^{7}$ coherente con la modificación al artículo 4o. constitucional, reformado en octubre de 2011.

Señaladas las líneas principales de ambas teorías, regreso brevemente al debate, preguntándome con MacCormick por qué resulta relevante diferenciar con claridad entre el deber de cuidado, alimentación y afecto de los adultos hacia los menores, y el derecho del menor a ser cuidado, alimentado

6 Véase Hierro, Liborio, "El niño y los derechos humanos", en Fanlo, I. (comp.), Derechos de los niños..., cit., pp. 177 y ss.

7 Decreto por el que se expide la Ley General de los Derechos de Niñas, Niños y Adolescentes, y se reforman diversas disposiciones de la Ley General de prestación para la Atención, Guidado y Desarrollo Integral Infantil, México, 6 de noviembre de 2014. En la Ley se especifican aún más los principios rectores: el interés superior de la niñez, la igualdad sustantiva, la no discriminación, la inclusión, el derecho a la vida, a la supervivencia y al desarrollo, la participación, la interculturalidad, la corresponsabilidad de los miembros de la familia, la sociedad y las autoridades, la transversalidad en la legislación, políticas públicas, actividades administrativas, económicas y culturales, la autonomía progresiva, el principio pro persona, el acceso a una vida libre de violencia y la accesibilidad (artículo 6o.). 
y recibir afecto por parte de los adultos; o planteado en términos de Ronald Dworkin, ¿por qué debemos tomarnos los derechos de la niñez en serio?

Pienso con ambos autores (y contra las propuestas voluntaristas, por ejemplo en las versiones de O'Neill o Wellman ya citadas) que poner el acento en los deberes hacia los menores siempre se hará con vistas a fines ulteriores, de alguna forma determinados por los terceros comenzando por las finalidades de los mismos padres. Así, por ejemplo, a la pregunta de por qué debemos cuidar, alimentar y dar afecto a los menores podría responderse con finalidades muy diversas como, por ejemplo, incrementar la riqueza de la comunidad convirtiéndolos en seres productivos; o procurar una mayor alegría y cohesión en las relaciones de pareja o familiares; o bien, robustecer la convivencia política y social. Se trataría, en una palabra, de incrementar el bienestar general convirtiendo a los niños en los instrumentos por excelencia para tal propósito.

Nadie mejor que Jonathan Swift en ese exquisito ensayo Una humilde propuesta, en la que, con gran ironía, lleva al absurdo la propuesta utilitarista: convertir a los niños en manjares apetecibles para las clases pudientes en un juego sumamente positivo en donde todos ganan incrementando el bienestar al eliminar la pobreza y haciendo más eficientes los escasos recursos del Estado. ${ }^{8}$ Por cierto, no necesitamos trasladarnos al siglo XVIII para ser testigos de la instrumentalización de los niños. Hoy día nos resulta familiar escuchar hablar de los "niños de engorde", los "niños escudo", los "niños para turismo sexual", los "niños para promocionales de productos comerciales", los "niños coyotillos", "los niños sicarios", etcétera. Es claro que hay de finalidades a finalidades, y nadie dudaría de que educar a los niños para convertirlos en ciudadanos activos para la vida política del Estado es un fin más noble que el de servir para el turismo sexual. Sin embargo, sea para una o para otra, el criterio sigue siendo de tipo consecuencialista. El adulto establece las finalidades, de acuerdo con sus preferencias, en una suerte de discriminación por edad, o como algunos han preferido denominar: "elitismo adulto" o, simplemente, "adultismo".

Por ello, tiene mucho sentido hacerse la pregunta: ¿por qué importan los menores? Pienso que la respuesta no puede ser otra más que el hecho de que sus intereses y necesidades constituyen un bien, algo valioso que merece ser reconocido y protegido. Son títulos que los menores poseen y que el Estado debe velar con más empeño, dada su especial condición de vulnerabilidad. Es tomarse sus derechos "en serio" poniendo un límite o freno a cualquier pretensión utilitarista. Tales derechos no son objeto de negociación en

8 Swift, Jonathan, Una humilde propuesta... y otros escritos, trad. de Begoña Gárate Ayastuy, Madrid, Alianza, 2002. 
el mercado, no están sujetos al regateo. Constituyen, en la feliz expresión de Ernesto Garzón Valdés, un "coto vedado".

De igual manera, si asumimos el enfoque de los intereses se pueden identificar con más claridad aquéllos propios del menor en tanto persona, niño o adolescente, y en este último, los correspondientes al joven y al futuro adulto, de acuerdo con la terminología propuesta por Tom Campbell. ${ }^{9}$ Las necesidades para cada una de estas etapas no son las mismas. El menor goza de todos los derechos universales correspondientes a su calidad de persona, pero también de acuerdo con el proceso evolutivo de desarrollo, gozará de derechos adecuados a su condición de niño (hasta los 12 años, o hasta los 15, si atendemos a que es ésta la edad mínima para trabajar, como sucede en el caso de México) o de adolescente (hasta los 18 años). A cada etapa corresponden intereses y necesidades, con sus debidos derechos; y sería un grave error pasarlas por alto o minimizarlas exigiendo a los niños virtudes propias de los adolescentes mayores o de los adultos. Así, por ejemplo, tiene todo el sentido del mundo preguntarse si es de interés del niño el ejercicio del derecho a votar, o participar en simulacros parlamentarios y representar las actividades de los congresistas, o asumir responsabilidades matrimoniales; o bien con respecto a los adolescentes, si es su responsabilidad sustituir a los padres en el cuidado de sus hermanos menores; o del niño y de los adolescentes menores a trabajar para el sustento del hogar, o someterlos a fatigas extenuantes para forjar su carácter. Pienso que robarles a los niños su infancia, negándoles su derecho al juego o a las actividades recreativas, o a los adolescentes el interés lúdico y responsable en sus necesidades sexuales, o a ambos la construcción de su autoestima, en ocasiones con decisiones difíciles y riesgosas, por una suerte de adultismo, es una violación grave por comisión o por omisión, de sus derechos.

Quiero detenerme en el análisis de dos derechos de la niñez cuya importancia resulta especialmente relevante para cada una de las etapas sucesivas de su desarrollo: los derechos a una educación laica y a una vida en familia.

\section{DEREGHO A UNA EDUGACIÓN LAICA}

Entre los derechos de la niñez, la educación es sin duda uno de los más relevantes y, por supuesto, no está exento también de un posible consecuencialismo adultista. A fin de cuentas, se argumenta: ¿no son los hijos una extensión

9 Campbell, Tom, "Los derechos del menor en tanto que persona, niño, joven y futuro adulto", trad. de Maribel Narváez Mora, en Fanlo, I. (comp.), Derechos de los niños..., cit., pp. 107 y ss. 
natural de sus padres?, ¿no justifica esta relación natural un derecho a priori de los padres sobre sus hijos? El peligro, como es obvio, es caer en un autoritarismo moral bajo la suposición de que los niños son una especie de propiedad de los padres, que impide reconocer en ellos a seres humanos con intereses, necesidades y derechos.

No hay duda alguna de que los padres tienen prioridad sobre otro tipo de instituciones en la educación de sus hijos, simplemente por razones empíricas, como son las razones psicológicas. Pero debe reconocerse que el derecho de los niños a la educación tiene que prevalecer sobre las preferencias de los mismos padres cuando el ejercicio de éstas pueda limitar el desarrollo pleno de aquéllos. Restringir tales libertades, por medio de la coerción legal, evita daños a terceros - los niños - y crea las condiciones que hacen posible el gozo de las capacidades de estos últimos. A este respecto, vale la pena recordar las palabras en disidencia del juez William O. Douglas, refiriéndose a los niños pertenecientes a la Old Order Amish, en el conocido caso Wisconsin v. Yoder:

Un niño Amish puede querer ser un pianista o un astronauta o un oceanógrafo. Para lograrlo deberá apartarse de la tradición Amish... Si sus padres conservan al niño fuera de la escuela más allá de la primaria, entonces el niño quedará imposibilitado de participar en el nuevo y apasionante mundo de la diversidad que tenemos hoy día... Si es constreñido a la forma de vida Amish por aquellos que tienen autoridad sobre él y si su educación es truncada, su vida entera puede ser impedida y deformada. ${ }^{10}$

De acuerdo con el juez Douglas, el bien de la educación, especialmente de la educación básica, debe prevalecer sobre la libertad religiosa o las tradiciones de los padres de la Old Order Amish. Y la razón parece clara: tal tipo de educación tiene relación directa con la formación de la autonomía de los menores y no con su ejercicio; y tal formación es una condición sine qua non para la satisfacción de las necesidades y derechos del menor. Si esto es así, entonces está plenamente justificado interferir en las preferencias de los padres cuando éstos obstaculizan la formación básica de sus hijos. Debe rechazarse la hipótesis naturalista de que los hijos son una prolongación "ontológica" de sus padres. Esta hipótesis sólo puede conducir a la justificación de cualquier tipo de indoctrinación adultista que, reitero, atentaría contra los derechos de los menores. En materia educativa, la Convención sobre Derechos del Niño menciona en sus artículos 28 y 29, entre otros objetivos:

10406 us 205 (1972), citado por Stephen, Macedo, Liberal Virtues, Oxford, Clarendon Press, 1990. p. 268. 
desarrollar la personalidad, las aptitudes y la capacidad física y mental del niño hasta el máximo de sus posibilidades y preparar al niño para asumir una vida responsable en una sociedad libre, con espíritu de comprensión, paz, tolerancia, igualdad de los sexos y amistad entre todos los pueblos, grupos étnicos, nacionales y religiosos y personas de origen indígena.

El caso de los padres Amish, y las limitaciones a su libertad religiosa, obliga a plantearnos no tanto el problema de la justificación de la educación en general, sino el tipo de educación que debe impartirse en particular. Estoy convencido de que toda educación básica, sea pública o privada, debe adecuarse, antes que a cualquier otro valor de carácter cívico o democrático, a la laicidad. Pero ¿qué debe entenderse por laicidad y cuál es el alcance de la misma en materia educativa?

Entiendo por laicidad la doctrina que sostiene la imparcialidad del Estado ante las diversas creencias de los ciudadanos en materia de religión o de convicciones metafísicas. Esto quiere decir que: 1) las creencias religiosas o metafísicas, su transmisión y enseñanza se localizan en el ámbito privado; 2) en tanto expresión de un derecho individual, el Estado debe proteger la libertad ideológica, que se manifiesta también en la no profesión de creencia religiosa alguna, así como las ideas antirreligiosas o antimetafísicas; 3) las faltas a la moral de inspiración religiosa no tienen trascendencia política y más bien el Estado debe definir los delitos mediante criterios universalizables: no existe el delito de blasfemia; y 4) se debe privilegiar el criterio de argumentación y consentimiento de los individuos, a través del voto y del principio de mayoría, frente a la pretensión de la custodia de verdades reveladas por la divinidad a través de sacerdotes y jerarquías eclesiásticas o comunidades fundamentalistas. ${ }^{11}$

Con respecto a lo público y lo privado, debe aclararse que si bien el ámbito primordial de las creencias religiosas es el privado, la libertad religiosa comprende también el derecho a expresar e intentar expandir las propias creencias en el ámbito público: "desde la construcción de lugares de culto y de enseñanza religiosa hasta las procesiones y el proselitismo casa por casa". ${ }^{12}$ Lo que importa entender es que el perímetro correcto del ejercicio de esos derechos debe situarse estrictamente dentro de la sociedad civil y no traspasar a la utilización del Estado. Éste debe mantener una posición

11 Véase Ruiz Miguel, Alfonso, "Laicidad, laicismo, relativismo y democracia", en Vázquez, Rodolfo (coord.), Laicidad. Una asignatura pendiente, México, Coyoacán, 2007, pp. 159 y160; véase también Blancarte, Roberto, "Laicidad: la construcción de un concepto universal", ibidem, p. 35.

12 Ruiz Miguel, Alfonso, op. cit. 
de imparcialidad frente a todos los cultos, sin privilegiar alguna confesión religiosa por encima de las demás.

Asimismo, hay que distinguir entre laicidad pasiva y laicidad activa. Para Michelangelo Bovero y Luis Salazar Carrión, el adjetivo "laico" puede entenderse desde un punto de vista mínimo de modo tal que, para que un Estado sea laico, basta con que sea neutral en relación con los diferentes credos religiosos. Sin embargo, reducir la laicidad de esa manera, piensan estos autores, abre las puertas al nihilismo, al relativismo, al indiferentismo o al cinismo. Para evitar caer en tal situación, es necesario que el pensamiento laico no se entienda como la ausencia de valores, sino como la manera de presentar y defender ciertos principios y valores: un principio práctico, la tolerancia; y un principio teórico, el antidogmatismo. De esta manera, la laicidad exige una educación racional-ilustrada, condiciones de legalidad y un derecho positivo que reconozca y garantice efectivamente los derechos fundamentales de todas las personas por igual. ${ }^{13}$

En otros términos, cada uno de los valores cívicos ya mencionados en un inicio - pluralismo, imparcialidad, tolerancia, solidaridad, deliberación democrática - se constituyen en condiciones de posibilidad necesarias para la existencia y ejercicio de una educación laica. Son valores que se desprenden del mismo proceso de discusión democrática y su importancia radica precisamente en servir de cauce para posibilitar el reconocimiento y ejercicio de los derechos humanos, y específicamente para nuestro caso, los derechos de los menores. Es claro que no nacemos con tales valores. Se requiere de un trabajo lento, acorde con los intereses y necesidades propios de cada etapa de maduración del menor. En este sentido, me parece muy razonable la advertencia de Stephen Macedo al señalar que los valores cívicos no se adquieren en la edad adulta, sino que requieren de todo un proceso educativo que se inicia desde la niñez. Cito a Macedo in extenso:

Desde temprano y a lo largo de sus vidas, los ciudadanos liberales aprenden y aplican normas públicas en su interacción con otros. Los niños aprenden de sus padres y de los juegos infantiles a respetar las reglas y a jugar con justicia. Ellos critican, discuten, escuchan a otros, votan, participan en los debates, cambian de opinión, y ayudan a implementar las reglas en su casa, en la escuela, en sus trabajos, en los juegos, y con sus amigos. De manera gradual aprenden a contener sus impulsos, respetar a otros como iguales, y a dirigir y aplicar sus energías con diligencia. Aprenden a hacer juicios sobre ellos mismos y a adquirir

13 Véase Bovero, Michelangelo, "Laicidad y democracia. Consideraciones sobre pensamiento laico y política laica", Nexos, México, julio de 2002; y Salazar Carrión, Luis, "Religiones, laicidad y política en el siglo XXI", en Vázquez, Rodolfo (coord.), Laicidad. Una asignatura pendiente, cit., pp. 149 y ss. 
la medida de su individualidad y autonomía. Aprenden algo sobre los procedimientos justos, la imparcialidad, y el respeto hacia aquellos que son diferentes; desarrollan virtudes judiciales, legislativas y ejecutivas. Todo esto sin control político, aunque fuertemente influenciado por nuestras prácticas políticas. Sería un error, entonces, ver la participación en campañas y elecciones como la única o la sola fuente primaria de la virtud pública: la vida privada ha recorrido un largo camino para ayudar a preparamos en los deberes públicos. ${ }^{14}$

La laicidad "activa" debe distinguirse de la idea popularizada por Sarkozy en la visita de Benedicto XVI a Francia (septiembre de 2008) sobre la laicidad "positiva". Esta última en términos de uno de sus críticos es "aquella fórmula institucional que respeta la libertad de creer o no creer (en dogmas religiosos, claro) porque ya no hay más remedio, pero considera que las creencias religiosas no sólo no son dañinas sino beneficiosas social y sobre todo moralmente". ${ }^{15}$ Apoyándose en Jean Baubérot, Fernando Savater critica con razón tal tipo de laicidad, porque significa: "Una forma de neoclericalismo, confesional, pero no confeso. Y eso porque un Estado realmente laico no sólo no puede dejarse contaminar por ninguna religión, ni privilegiar ninguna de las existentes sobre las demás, sino que tampoco puede declarar preferible tener una religión o no tenerla". ${ }^{16}$

Durante los gobiernos panistas en México se abrió, una vez más, el debate en torno al tema de la laicidad educativa en las escuelas públicas. Se argumentó, entonces, nada menos que por el Ombudsman nacional, que la prohibición de la enseñanza religiosa en las escuelas era una forma de discriminación negativa hacia aquellos padres de familia que sin tener recursos suficientes para enviar a sus hijos a escuelas privadas confesionales debían enviarlos, contra sus convicciones, a escuelas públicas laicas. ${ }^{17}$ En el mismo sentido, para el entonces presidente del Episcopado mexicano, las leyes mexicanas debían garantizar la libertad religiosa, que es mucho más amplia en su contenido que la libertad de creencia y culto. Hacer valer la libertad religiosa es hacer valer el derecho de los padres de familia a que sus hijos sean educados conforme a su fe, y el Estado debe implementar las condiciones y los recursos para que tal libertad religiosa no se vea limitada. ${ }^{18}$ No

14 Macedo, Stephen, Liberal Virtues, Citizenship: Virtue, and Community in Liberal Constitutionalism, Oxford, Clarendon Press, 1990, pp. 273 y 274.

15 Savater, Fernando, "Siempre negativa, nunca positiva", El País, Madrid, 16 de octubre de 2008, Opinión, pp. 31 y 32.

16 Idem.

17 Véase una crítica a la posición del Ombudsman nacional, José Luis Soberanes, en Volpi, Jorge, "Soldados de Cristo", Proceso, México, núm. 1484, 10 de abril de 2005, p. 54.

18 Véase la entrevista de Rodrigo Vera al presidente del Episcopado mexicano en Aguiar Retes, Carlos, Proceso, México, núm. 1574, 31 de diciembre de 2006, pp. 13 y ss. 
está de más considerar la advertencia de Claudio Magris con respecto a las consecuencias que se podrían seguir de este argumento:

En nombre del deseo de los padres de hacer estudiar a sus hijos en escuelas que se funden en principios (religiosos, políticos o morales), surgirían escuelas inspiradas en los diversos harapos ocultistas de cada vez mayor difusión, en conventículos estrafalarios e ideologías de todo género. Hay ciertamente padres racistas nazis, estalinistas deseosos de educar a sus hijos (a nuestras expensas) en el culto de su Moloch; padres que pedirían escuelas en las que sus pimpollos no se sienten junto a condiscípulos meridionales. Nacerían probablemente escuelas satanistas, otras prestas a llamar como 'expertos' a cartománticos y magos y así sucesivamente. ${ }^{19}$

Por supuesto, no es objeto de debate el hecho de que en materias como historia y educación cívica se explique el fenómeno religioso y se enseñe una historia comparada de las religiones. Pero la pretensión del prelado iba más lejos en el sentido de incluir la enseñanza de una religión como parte del curículum escolar y financiarla por el Estado. A esta pretensión debían añadirse otras demandas: el voto pasivo de los ministros de culto; el derecho a expresar sus opiniones en materia política y a asociarse con fines políticos; que las asociaciones religiosas posean medios de comunicación masivos; y que las Iglesias reciban subsidios públicos mediante la recaudación de un impuesto especial que recogería y distribuiría el Estado. ${ }^{20}$ $\mathrm{Al}$ comentar estas demandas, un católico como Pablo Latapí manifestaba su inconformidad cuando decía que:

....se habla de un 'Estado confesional' que vendría en sustitución del 'Estado laico'... A los católicos que vamos depurando nuestra idea de la Iglesia en la dirección contraria - como una comunidad de fieles en la fe cuya seguridad no estriba en el poder temporal, sino en la confianza en Dios, como aparece en el Evangelio - nos chocan profundamente estas demandas de la jerarquía eclesiástica. $^{21}$

19 Citado por Ruiz Miguel, Alfonso, op. cit., p. 165.

20 Estas demandas se orientan a la eliminación del inciso $e$ del artículo 130 constitucional: "Los ministros no podrán asociarse con fines políticos ni realizar proselitismo a favor o en contra de candidato, partido o asociación política alguna. Tampoco podrán en reunión pública, en acto de culto o de propaganda religiosa, ni en publicaciones de carácter religioso, oponerse a las leyes del país o a sus instituciones, ni agraviar, de cualquier forma, los símbolos patrios".

21 Latapí, Pablo, Andante con brío, México, Fondo de Cultura Económica, 2008, pp. 37 y 38. Varios líderes religiosos manifestaron su desacuerdo con las pretensiones de la Iglesia católica. El obispo primado de la Iglesia Anglicana en México, Carlos Touché, dijo desco- 
En la Ley General de los Derechos de Niñas, Niños y Adolescentes, ya mencionada, se señala explícitamente el derecho de las niñas, niños y adolescentes a la libertad de convicciones éticas, pensamiento, conciencia, religión y cultura en el marco de un Estado laico acorde con las reformas a los artículos 24 y 40 constitucionales. ${ }^{22}$ Hasta donde puedo entender el alcance de estas reformas, por lo que hace a la educación, deberían incluir no sólo a la educación pública sino también a la educación privada, es decir, a todo tipo de educación que se imparte en México en tanto constituidos en un Estado laico. Si esto es así, entonces el inciso a) de la fracción VI del artículo 3o., que exceptúa a los particulares de apegarse a la fracción I, donde expresamente se hace referencia a la educación laica impartida por el Estado incurre en una incoherencia. No veo por qué la exigencia de educación democrática debe universalizarse incluyendo a la educación privada y no deba exigirse lo mismo con respecto a la laicidad, ahora entendida como una propiedad del Estado junto con su carácter republicano, representativo, democrático y federal. Si además, reforzamos el derecho de aquellos que ejercen patria potestad, tutela o guarda y custodia de niñas, niños y adolescentes para guiarlos de conformidad con sus creencias religiosas y sus tradiciones culturales en el ámbito de la educación privada entonces tenemos el camino libre, como decía Claudio Magris, para que los adultos adoctrinen a los menores en sus creencias, que en algunos casos podrán ser tolerantes, pero en otros, con sesgos claramente fundamentalistas.

De igual manera, en la misma Ley se hace referencia a los fines de la educación entre los que se señala:

Promover la educación sexual integral conforme a su edad, el desarrollo evolutivo, cognoscitivo y madurez, de las niñas, niños y adolescentes que le permitan a niñas, niños y adolescentes ejercer de manera informada y responsable sus derechos consagrados en la Constitución Política de los Estados Unidos Mexicanos, en las Leyes y los Tratados Internacionales de los que el Estado mexicano sea parte. ${ }^{23}$

El texto final de la Ley contrasta con la iniciativa aprobada por el Senado en la que se señalaba: "Promover la educación sexual integral, que contribuya al desarrollo de competencias que le permitan a niñas, niños y adolescentes ejercer de manera informada y responsable sus derechos se-

nocer si "detrás hay un intento de los obispos católicos por recuperar el poder y la influencia que tuvieron en el pasado, lo cual significaría un retroceso". Milenio, México, 20 de marzo de 2008, Política, p. 13.

22 Op. cit., artículo 62.

23 Ibidem, artículo 58, párrafo VIII. 
xuales y reproductivos". ${ }^{24}$ Así de simple, lisa y llanamente, sin remisiones a otras normatividades de superior jerarquía, como aparece en la versión final, y acotando los márgenes interpretativos.

De nueva cuenta la presión conservadora de corte religioso, con el pretexto de la protección de los menores de edad, logra eliminar la mención explícita a los derechos sexuales y reproductivos del texto definitivo. No es algo inocuo. En la versión inicial se ponía nombre y apellido al ejercicio responsable de los derechos de la niñas, niños y adolescentes, con el propósito de asumirlos con plena conciencia, desde muy temprana edad, para prevenir, por ejemplo, embarazos no deseados, o enseñar la forma de defenderse y denunciar acciones tan indignas y humillantes como el acoso sexual por parte de los adultos. Entre estos adultos merecería un capítulo especial, en el libro de las infamias, el abuso y la violencia sexual practicados, irónicamente, por "los hombres (y mujeres) de dios" que tienen a su cargo, desafortunadamente, la educación básica de niñas, niños y adolescentes.

\section{DERECHO A UNA VIDA EN FAMILIA}

Pese al tinte conservador que deja ver el enunciado de este inciso, su calificación dependerá de la concepción de familia que se adopte, y más en general, del alcance que se quiera dar a la idea de procreación, y el debate, ya un tanto añejo, pero con consecuencias siempre actuales, de la llamada procreación asistida y los derechos correspondientes.

Desde el punto de vista de una ética conservadora el problema de la procreación asistida debe ser abordado a partir de tres premisas básicas: 1) existe un manifiesto interés por preservar los valores y principios de la familia cuyo núcleo se constituye por la pareja heterosexual que decide optar por la paternidad-maternidad; 2) el nuevo ser no debe instrumentalizarse hacia otros fines que no sean el asegurarle que será recibido en el seno social, con las mejores condiciones para su formación y crecimiento armónicos (se entiende que este fin sólo es alcanzable si se cumple el inciso anterior); 3) la reproducción humana asistida no es una alternativa al proceso reproductivo natural, sino una técnica destinada a tratar la infertilidad de las parejas cuando ya han fallado otras técnicas o procedimientos terapéuticos, por lo que sólo debe aplicarse a parejas infértiles.

24 Iniciativa de Decreto que expide la Ley General para la Protección de Niñas, Niños y Adolescentes y reforma diversas disposiciones de la Ley General de Prestación de Servicios para la Atención, Cuidado y Desarrollo Integral Infantil, remitida a la Cámara de Senadores el 1 de septiembre de 2014. 
A partir una perspectiva laica liberal, ninguna de las tres premisas sería aceptable tanto por consideraciones fácticas como por razones normativas. Con respecto a la premisa 1, es un hecho que en muchas sociedades actuales, entre los diversos planes de vida, son empleados y aceptados modos alternativos de procreación y formatos de familia distintos al de la pareja heterosexual con unión matrimonial formal. Vale la pena recordar las posibilidades existentes para tener un panorama lo más amplio posible de tales alternativas. He intentado ordenarlas en forma descendente de aceptación social consciente de su alcance subjetivo:

- Niños nacidos de parejas heterosexuales en uniones matrimoniales formales o de facto estables.

- Niños nacidos de matrimonios previos o de uniones de facto, pero ahora, o bien están en una situación uniparental o en una familia reincorporada después del divorcio y nuevo matrimonio.

- Niños adoptados en otra familia, a través de adopción "tradicional" donde la madre que renuncia no tiene contacto con el niño que dio en adopción y el niño no tiene información sobre sus orígenes; o de adopción "abierta", donde la madre que renuncia puede mantener contacto con el niño y el niño puede tener acceso a la información sobre sus orígenes; o de adopción donde la madre que renuncia toma parte en la selección de los padres adoptivos.

- Niños nacidos de una situación de padres solteros o de madres solteras.

- Niños nacidos de los gametos de una pareja heterosexual a través de la inseminación artificial o de la fecundación in vitro y transferencia de embrión.

- Niños nacidos de parejas heterosexuales mediante la inseminación artificial de un donante.

- Niños nacidos de los gametos de donantes o de embriones de donantes mediante la fecundación in vitro y traslado de embrión.

- Niños nacidos por acuerdo de alquiler donde la madre sustituta aporta o no el óvulo.

- Niños nacidos de parejas homosexuales (lesbianas) a través de inseminación artificial de un donante.

- Niños adoptados por parejas de homosexuales masculinos. ${ }^{25}$

- Niños que podrán nacer por clonación a partir de la transferencia de núcleo en un óvulo. Transferencia que puede realizarse a partir de una

25 Con algunas ligeras modificaciones tomo esta tipología de Charlesworth, Max, Bioethics in a Liberal Society, Cambridge, Cambridge University Press, 1993, pp. 76 y 77. 
célula somática de hombre o de mujer. En este último caso con la posibilidad de que la mujer use su óvulo para clonar con una célula somática propia.

Hay que reconocer el hecho de que la organización familiar tradicional no sólo se está transformando vertiginosamente sino que, además, no se percibe con claridad que este cambio esté provocando consecuencias negativas en términos de cohesión social, ni que los niños producto de los nuevos métodos de reproducción asistida, sufran algún daño como efecto directo de los mismos.

Lo cierto es que las nociones de paternidad y maternidad pasan a ser títulos escindibles, y esta escisión no ha tenido que esperar a las técnicas de reproducción asistida, sino que la novedad fue introducida por la institución de la adopción. En efecto, es con esta institución que se hace patente que la familia, los padres, los hijos, no son "hechos naturales", sino un haz de relaciones jurídicas: "Es desde el ordenamiento [jurídico] desde el que se determina el modelo de familia lícita, esto es, si cabe, por ejemplo, que los menores puedan ser adoptados por parejas no casadas, de igual o distinto sexo, o por solteros". ${ }^{26}$

Con relación a la premisa 2, se objeta que las técnicas de reproducción asistida trastocarían, en alto grado, todas las relaciones filiales y las existentes de parentesco, así como las consagradas en la generalidad de los ordenamientos jurídicos contemporáneos. Se estaría violando, entre otras cosas, el derecho a ser concebido heterosexualmente en una familia con doble figura genital. Por otra parte, tales métodos abrirían opciones que posibilitarían la creación de niños por motivos moralmente dudosos: vanidad, conveniencia utilitaria, comercio de órganos o reemplazo de otros fallecidos. El niño pasaría a convertirse en un instrumento al servicio de los intereses egoístas de los progenitores. Aun en el caso de que se buscara una mejor calidad de vida para el niño, se estaría enviando el mensaje muy específico sobre el valor negativo de las vidas que no son perfectas, y los seres humanos perderían el derecho a aceptar aquello que es imperfecto. La crisis de la organización familiar tradicional daría por resultado una severa inestabilidad en la sociedad, para lo cual el derecho debe introducir y asegurar medidas restrictivas.

A todo ello se responde que, si bien es cierto prima facie existe un derecho del niño a una vida estable, a una "vida en familia", no hay estudios empíricos concluyentes - como ya se dijo- que demuestren que los niños educados con madres o padres solteros, heterosexuales u homosexuales,

26 Lora, Pablo, Entre el vivir y el morir, México, Fontamara, 2003, p. 23. 
Esta obra forma parte del acervo de la Biblioteca Jurídica Virtual del Instituto de Investigaciones Jurídicas de la UNAM

sufran daños que imposibiliten un adecuado desarrollo psicológico y una armoniosa integración social. Las precauciones que se deben tomar en ciertas circunstancias responden más a razones estratégicas, por ejemplo socioculturales, que no a razones morales sustantivas.

Asimismo, la instrumentalización de los niños por motivos no altruistas no parece ser una razón concluyente para calificar de incorrectas las técnicas de reproducción asistida. El mismo argumento podría utilizarse para todo tipo de método natural, en los que no se exige de los padres una moral supererogatoria o ideal. En cuanto a una posible comercialización, desgraciadamente éste es un fenómeno que no ha tenido que esperar a las técnicas de reproducción asistida. A lo único que invita a pensar este tipo de situaciones no es a la prohibición de las mismas, sino a la exigencia de una regulación apropiada y de una aplicación estricta de tal normatividad que haga valer la autonomía y dignidad de los niños con todos los derechos correspondientes.

Por lo que hace a la premisa 3, desde un punto de vista liberal, la tolerancia y aceptación de métodos alternativos de procreación y formatos de familia, y en varios de ellos su ratificación legal, ha permitido hablar en nuestros días de un "derecho a la libertad de procreación" - que supone tanto la colaboración coital como la no coital- y, consecuentemente, un derecho de acceso, sin discriminación alguna, a las nuevas formas de tecnología de reproducción. A este respecto vale la pena citar a la jurista norteamericana Lisa Ikemoto cuando sostiene que

La procreación de colaboración no coital presenta un conjunto más amplio de opciones comparada con la reproducción a través de las relaciones sexuales, dando a los participantes la oportunidad de determinar el origen del material genético, el método y el tiempo de la concepción, la mujer que llevará el niño y las personas que lo educarán. La viabilidad en la ampliación del conjunto de opciones proporciona a los individuos un mayor control sobre su destino genético, biológico y psicosocial y, por lo tanto, mayor autonomía. La Constitución debe proteger la autonomía de decisión en la procreación, ya que nuestro concepto de libertad requiere que el gobierno deje libres a los individuos para determinar temas tan fundamentales para sus personas. ${ }^{27}$

Si aceptamos que los formatos tradicionales de familia y matrimonio, heterosexual y monógamo, no son los únicos éticamente correctos para procrear, su aceptación exclusiva contradice los principios de una sociedad libe-

27 Véase Charlesworth, M., op. cit., pp. 77 y 78. 
ral, laica y, en concreto, atenta contra el principio de autonomía personal del que se infiere el derecho a la libertad de procreación y de acceso a las nuevas tecnologías de reproducción. ${ }^{28}$ Entre éstas, por supuesto, la posibilidad de que se permita la inseminación artificial a una mujer soltera, viuda, divorciada o lesbiana. Es en este contexto que tiene sentido hablar del derecho de acceso a las tecnologías de reproducción como no discriminatorio, es decir, a las que puedan acceder no sólo las personas o parejas infértiles, como una especie de último recurso, sino las mismas personas o parejas fértiles si así lo consideran necesario para la organización de su plan de vida. Si para ser usuaria de la IA (inseminación artificial) o la FIV (fecundación in vitro), no hay que ser infértil, entonces el derecho a la procreación asistida no es una expresión del derecho a la salud, sino un medio alternativo de reproducción, es decir, una manifestación del derecho al libre desarrollo de la personalidad.

Por otra parte, en legislaciones de corte conservador, es un hecho que se ponen límites a las técnicas de reproducción asistida prohibiendo la producción de más embriones de los que se requieren para obtener un éxito razonable en el proceso de implantación y de transferencia de embriones a la paciente. La razón de esta prohibición es evitar la generación de embriones sobrantes y su eventual crioconservación o destrucción. No deja de ser curioso el hecho de que el desarrollo de estas técnicas de reproducción asistida hará que en un futuro se logren mayores anidaciones en el útero de las que se logran "naturalmente". Una vez que esto ocurra, y dado el compromiso que las posiciones conservadoras asumen con el valor supremo de la vida humana, esta técnicas no sólo deberían ser moralmente toleradas, sino moralmente obligatorias, porque "protege mejor la vida y desarrollo exitoso del embrión que el mecanismo de implantación natural dispuesto por Dios". ${ }^{29}$

28 Este argumento se constituye en uno de los criterios más relevantes de la Corte Interamericana de Derechos Humanos (CIDH) para justificar el acceso a los métodos de reproducción asistida y a la decisión de procrear o no procrear. Véase Artavia Murillo y otros ("Fecundación in vitro") vs. Costa Rica, sentencia de 28 de noviembre de 2012. En el apartado 146 se afirma: "En segundo lugar, el derecho a la vida privada se relaciona con: i) la autonomía reproductiva, y ii) el acceso a servicios de salud reproductiva, lo cual involucra el derecho de acceder a la tecnología médica necesaria para ejercer ese derecho. El derecho a la autonomía reproductiva está reconocido también en el artículo 16 (e) de la Convención para la Eliminación de todas las Formas de Discriminación contra la Mujer, según el cual las mujeres gozan del derecho «a decidir libre y responsablemente el número de sus hijos y el intervalo entre los nacimientos y a tener acceso a la información, la educación y los medios que les permitan ejercer estos derechos». Este derecho es vulnerado cuando se obstaculizan los medios a través de los cuales una mujer puede ejercer el derecho a controlar su fecundidad. Así, la protección a la vida privada incluye el respeto de las decisiones tanto de convertirse en padre o madre, incluyendo la decisión de la pareja de convertirse en padres genéticos".

29 Lora, Pablo, op. cit., p. 31. 
Esta obra forma parte del acervo de la Biblioteca Jurídica Virtual del Instituto de Investigaciones Jurídicas de la UNAM

No debe llamar la atención que en la Ley General de los Derechos de Niñas, Niños y Adolescentes, en el capítulo "Del derecho a vivir en familia" 30 no haya ninguna referencia explícita al concepto de familia y a los diversos formatos de familia. No basta la mención genérica a "las personas que ejerzan la patria potestad o de sus tutores". En sede legislativa se podría haber dado un paso cualitativamente importante en aras del reconocimiento de la diversidad parental acorde con la diversidad procreativa. No se ha hecho, y este silencio, convalida posiciones conservadoras contrarias al carácter laico del Estado.

\section{BiBLIOGRAFÍA}

BLANCARTE, Roberto, "Laicidad: la construcción de un concepto universal", en VÁZQUEZ, Rodolfo (coord.), Laicidad. Una asignatura pendiente, México, Coyoacán, 2007.

Bovero, Michelangelo, "Laicidad y democracia. Consideraciones sobre pensamiento laico y política laica", Nexos, México, julio de 2002.

CAmpbelt, Tom, "Los derechos del menor en tanto que persona, niño, joven y futuro adulto", trad. de Maribel Narváez Mora, en FANLO, Isabel (comp.), Derecho de los niños: una contribución teórica, México, Fontamara, 2004.

HiERro, Liborio, "El niño y los derechos humanos", en FANLO, Isabel (comp.), Derechos de los niños. Una contribución teórica, México, Fontamara, 2004.

LataPí, Pablo, Andante con brío, México, Fondo de Cultura Económica, 2008.

LORA, Pablo, Entre el vivir y el morir, México, Fontamara, 2003.

MACCORMICK, Neil, "Los derechos de los niños. Un test para la teoría de los derechos", trad. de Neus Torbisco, en FANLO, Isabel (comp.), Derechos de los niños. Una contribución teórica, México, Fontamara, 2004.

Macedo, Stephen, Liberal Virtues, Citizenship: Virtue, and Community in Liberal Constitutionalism, Oxford, Clarendon Press, 1990.

O’NeILL, Onora, "Children's Rights and Children's Lives", en Alston, Philip et al. (eds.), Children, Rights and the Law, Oxford, Clarendon Press, 1992.

Ruiz Miguel, Alfonso, "Laicidad, laicismo, relativismo y democracia", en VÁZQUeZ, Rodolfo (coord.), Laicidad. Una asignatura pendiente, México, Coyoacán, 2007.

SALAZAR CARRIÓn, Luis, "Religiones, laicidad y política en el siglo XXI", en VÁzQUEz, Rodolfo (coord.), Laicidad. Una asignatura pendiente, México, Coyoacán, 2007.

30 Op. cit., capítulo cuarto, artículos 22-35. 
Esta obra forma parte del acervo de la Biblioteca Jurídica Virtual del Instituto de Investigaciones Jurídicas de la UNAM

SAVATER, Fernando, "Siempre negativa, nunca positiva", El País, Madrid, 16 de octubre de 2008, Opinión.

SwIFT, Jonathan, Una humilde propuesta... y otros escritos, trad. de Begoña Gárate Ayastuy, Madrid, Alianza, 2002.

VOLPI, Jorge, "Soldados de Cristo", Proceso, México, núm. 1484, 10 de abril de 2005.

Wellman, Carl, "El crecimiento de los derechos de los niños", en FanlO, Isabel (comp.), Derechos de los niños. Una contribución teórica, México, Fontamara, 2004. 
Esta obra forma parte del acervo de la Biblioteca Jurídica Virtual del Instituto de Investigaciones Jurídicas de la UNAM www.juridicas.unam.mx

\section{CAPÍTUlO TERCERO \\ LAICIDAD Y POLÍTICAS PÚBLICAS}




\title{
LAS POLÍTICAS EDUCATIVAS EN BRASIL: ENTRE EL CONFESIONALISMO Y LA LAICIDAD*
}

\author{
Luiz Antônio CunHA**
}

\begin{abstract}
SUMARIO: I. Introducción. II. La religión en la formación del país. III. Declive católico y ascensión evangélica. IV. La reacción católica. V. El Frente Cristiano en las instituciones escolares. VI. La lucha por la laicidad en la escuela pública.

VII. Conclusión y prospectiva. VII. Bibliografia.
\end{abstract}

\section{INTRODUCGIÓN}

Los vínculos entre la religión católica y la política siempre han sido estrechos en Brasil. Una cuarta parte de los diputados de la primera legislatura del país independiente (1822-1826) estaba constituida por sacerdotes y obispos; un sacerdote fue regente tras la abdicación del primer emperador; el gobierno sancionaba las bulas papales; la Iglesia estaba materialmente sostenida por el gobierno, el cual establecía también el programa escolar de los seminaristas. La República proclamada en 1889 separó la Iglesia católica del Estado, lo que generó la libertad de los cultos y la terminación de los salarios del clero, la creación del Registro y del matrimonio civil, así como la secularización de los cementerios. Sin embargo, a partir de 1931, la política y la religión vuelven a acercarse, especialmente a partir de la Constitución de 1988, cuando los evangélicos empiezan a tomar un papel importante en la vida política, en todos los niveles del poder legislativo, inaugurando, asimismo, una vía alterna a la legitimación religiosa del programa ideológico de la derecha.

La República suprimió la enseñanza religiosa en las escuelas públicas, sin embargo, fue retomada en 1931 cuando el fascismo pasó a ser parte de la ecuación política. Desde entonces, la religión integra el programa de escuelas primarias públicas mientras su carácter facultativo es tomado muy

\footnotetext{
* Traducción de Pauline Capdevielle.

** Universidad Federal de Río de Janeiro, Brasil.
} 
Esta obra forma parte del acervo de la Biblioteca Jurídica Virtual del Instituto de Investigaciones Jurídicas de la UNAM

poco en cuenta. A partir de los años 1980, lo que cambió fue el esfuerzo de las Iglesias evangélicas en oponerse al monopolio católico de la enseñanza religiosa en el sector público.

Si empleamos los conceptos de Pierre Bourdieu, ${ }^{1}$ podemos decir que el proceso de autonomización de los campos político y educativo vis à vis el campo religioso ha retrocedido en Brasil a partir de los años 1980.

\section{LA RELIGIÓN EN LA FORMAGIÓN DEL PAÍS}

Del siglo XVI al siglo XVIII, la religión desempeñó un papel estratégico en la conquista portuguesa de las tierras y pueblos del este del continente sudamericano: de ahí que la cruz y la espada fueran sus símbolos. En efecto, el Estado portugués mantenía una simbiosis política e ideológica con la Iglesia católica: el patronato. Ya que la Iglesia era dependiente del Estado, éste también era dependiente ideológicamente de ella. La acción pedagógica religiosa, tanto en el púlpito como en las instituciones escolares o en la Universidad de Coimbra, consolidó el orden existente, especialmente por medio del derecho divino del poder real.

Debido al patronato, sacerdotes de diferentes órdenes religiosas vinieron a Brasil con colonos, comerciantes, administradores de la Colonia y militares. La Iglesia católica reivindicó el trabajo de catequesis de los indígenas, para los cuales preconizaba una relación de servidumbre, en oposición a los colonos que querían convertirlos en esclavos. Al contrario, el clero legitimaba la esclavitud de los africanos, ${ }^{2}$ de la cual se aprovechaba directamente.

Tras la independencia en 1822, el Imperio brasileño conservó el patronato y la religión católica continuó siendo la religión de Estado. Asimismo, la doctrina católica estaba presente en la enseñanza en las instituciones escolares del país. Los docentes debían prestar juramento de la fe católica y podían ser castigados por perjurio. El Código penal de 1830 preveía multas y penas de cárcel para los que divulgaban en los discursos públicos o por escrito, ideas contrarias a las "verdades fundamentales de la existencia de Dios y la inmortalidad del alma". Se prohibió a los pocos evangélicos que vivían en el país, trabajar en la educación pública.

\footnotetext{
1 Bourdieu, P., Questions de Sociologie, París, Éditions de Minuit, 1980.

2 Se estima cerca de cuatro millones los africanos que fueron traídos como esclavos a Brasil desde la segunda mitad del siglo XVI hasta la mitad del XIX, cuando el tráfico fue abolido definitivamente. Este contingente corresponde a $38 \%$ del que fue traído al continente americano.
} 
Los africanos y sus descendientes, esclavos y liberados, no podían profesar sus religiones, consideradas contrarias a la fe, a la moral y a las buenas costumbres. Sólo les quedaba el sincretismo con las imágenes católicas, como forma de resistencia y sobrevivencia. Los indígenas, en cambio, cada vez más alejados de las ciudades, podían mantener sin problema sus cultos, en la medida en que no constituyeran una amenaza para el cristianismo dominante.

En la segunda mitad del siglo XIX, bajo el pontificado de Pío IX, la simbiosis Iglesia-Estado empezó a estorbar a ambos socios. La Santa Sede quería ampliar su control sobre el clero brasileño para desarrollar una actividad religiosa sin las limitaciones impuestas por el aparato estatal. Por otro lado, las fuerzas políticas emergentes, inspiradas por las doctrinas liberales, masónicas y positivistas estimaban que el Estado brasileño debía estar en sintonía con sus contemporáneos europeos, especialmente con Francia, y adoptar en consecuencia la neutralidad respecto a las creencias religiosas. En el origen de esta orientación ideológica se perfilaba el fuerte interés del sector de los terratenientes en reemplazar a los esclavos por una mano de obra europea, blanca y cristiana, aunque no necesariamente católica. Sin embargo, los inmigrantes evangélicos eran discriminados en todos los aspectos de la vida civil, desde el nacimiento hasta la muerte. Ritos civiles importantes como el matrimonio y el derecho a votar dependían de la pertenencia a la Iglesia católica. La contradicción entre la defensa de la "Iglesia libre en un Estado libre" - fórmula de Cavour muy citada por la elite política imperial - y las viejas prácticas confesionales provocaron conflictos que contribuyeron a la caída de la monarquía.

La República proclamada en 1889 y la Constitución de 1891 declararon a la Iglesia católica separada del Estado, la cual pasó de la esfera pública a la esfera privada. Se prohibió al Estado financiar cualquier tipo de actividad religiosa, y la educación religiosa fue vetada de las escuelas públicas. ${ }^{3}$ Durante algunos años, se introdujo, en lugar de la religión, la disciplina moral en las instituciones educativas secundarias, lo que venía coronando la jerarquía de las ciencias en el currículum escolar, de acuerdo con la doctrina de Auguste Comte.

A pesar de lo anterior, la sociedad se mantuvo religiosa, en particular, católica, pero se practicaban diferentes modalidades y grados de sincretismo, es-

A pesar de ello, ninguna propiedad eclesiástica fue confiscada, y el Estado preservó los ingresos del clero durante un año. Es tal vez lo que explica que el padre jesuita Joseph Burnichon, que publicó un libro en París veinte años tras la "privatización" de la Iglesia en Brasil, afirmó que había sido "benévola y más amigable" que en otros países. Freyre, G. Ordem e Progresso, Río de Janeiro, MEC/Livraria José Olympio, 1974, pp. 524 y 525. 
pecialmente en las capas populares. A pesar de la ausencia de base popular, la laicidad se erigió en una política del Estado republicano como la ideología de una elite intelectual de orientación francesa, liberal-masónica y/o positivista. ${ }^{4}$

La eclosión de la crisis de hegemonía en los años 1920 puso fin a la laicidad republicana e instituyó la "colaboración recíproca" entre la Iglesia y el Estado, el cual tenía para entonces el modelo de la Italia fascista. Debido a las huelgas obreras, inéditas en el país, y a los levantamientos militares en contra de la oligarquía agraria, la educación religiosa pasó a ser prescrita como un antídoto contra el desorden social y político.

La dictadura que se instaló tras la Revolución de 1930 promovió diferentes reformas educativas, entre otras, la reintroducción de la educación religiosa en las escuelas públicas. Mediante el decreto número 19.941 del 30 de septiembre de 1931, esta disciplina podía ser proporcionada en las escuelas primarias, secundarias o normales de la Unión, de los estados o de los municipios. Cuando esta enseñanza era proporcionada, los únicos motivos que podían exentar a los alumnos de las clases de religión eran $i$ ) el número insuficiente de alumnos, que no justificaba la creación de una clase exclusiva, o ii) una solicitud de dispensa de los padres o responsables de los alumnos.

La Constitución de 1934 incorporó los términos del decreto anterior y fue más lejos al determinar obligatoria la oferta de la educación religiosa y pasó a considerarla como una disciplina del currículum escolar primario. Desde entonces, todas las Constituciones señalan que la oferta de enseñanza religiosa será obligatoria en las instituciones escolares, pero como materia facultativa.

Durante la dictadura militar (1964-1985), la enseñanza religiosa en las instituciones escolares recibió un apoyo adicional que provenía de la introducción de la "educación moral y cívica" en la enseñanza fundamental, secundaria y superior. ${ }^{5}$ Esta disciplina se presentó como una fusión del pensamiento reaccionario, del catolicismo conservador y de la doctrina de la seguridad nacional.

En breve, respecto a la educación religiosa, podemos identificar tres etapas distintas en la historia de Brasil: $\imath$ ) la enseñanza de la religión católica en las instituciones escolares durante todo el periodo imperial (1822-1889); ii) la prohibición de la educación religiosa en las escuelas durante las cuatro

4 La laicidad a la francesa sirvió de modelo para otros países latinoamericanos, México y Uruguay son los que la incorporaron de manera más profunda y duradera.

5 Hasta en 1971, sólo la escuela primaria era obligatoria. A partir de este año, la enseñanza fundamental de ocho años se vuelve obligatoria, seguida de la enseñanza secundaria facultativa, de tres o cuatro años. 
Esta obra forma parte del acervo de la Biblioteca Jurídica Virtual del Instituto de Investigaciones Jurídicas de la UNAM

primeras décadas del periodo republicano (1889-1930), y iii) el apoyo del Estado a la enseñanza de la religión en las instituciones escolares públicas, como materia facultativa (de 1931 hasta la fecha).

\section{DECLIVE CATÓLICO Y ASCENSIÓN EVANGÉLICA}

El campo religioso pasa en la actualidad por transformaciones rápidas y profundas. En los años 1960 y 1970, el declive del número de adeptos del catolicismo fue mínimo pero continuo. A partir de ahí, el número de católicos no dejó de disminuir mientras crecía el número de evangélicos, especialmente pentecostales, y que bajaban también los efectivos de otras denominaciones tradicionales. ${ }^{6}$ Igualmente, la cifra de los adeptos de las religiones afrobrasileñas disminuyó en beneficio de las confesiones evangélicas, e incluso las primeras han proporcionado a las segundas pastores y obispos.

La siguiente tabla presenta los porcentajes de la distribución de respuestas a la pregunta “¿cuál es su religión?” en cuatro censos demográficos. ${ }^{7}$

\begin{tabular}{|l|c|c|c|c|}
\hline \multicolumn{1}{|c|}{ Respuestas } & 1960 & 1980 & 2000 & 2010 \\
\hline Católica romana & 93,1 & 89,2 & 73,6 & 64,6 \\
Evangélica & 4,0 & 6,6 & 15,4 & 22,2 \\
Otra & 2,4 & 2,6 & 3,7 & 5,2 \\
Sin religión & 0,5 & 1,6 & 7,3 & 8,0 \\
\hline \multicolumn{1}{|c|}{ Total } & 100,0 & 100,0 & 100,0 & 100,0 \\
\hline
\end{tabular}

Fuente: IBGE, Censos Demográficos de 1960, 1980, 2000 y 2010 (Tabulaciones avanzadas).

Vemos que los católicos pasaron de 93,1\% en 1960 a 64,6\% en 2010. De manera simultánea a este decrecimiento, los adeptos de las denominaciones evangélicas subieron de $4 \%$ a $22,2 \%$ en el mismo periodo. Dos factores principales explican esta reducción del número de católicos. En primer lugar, el alto grado de institucionalización de la Iglesia le impide actuar lo suficientemente rápido para adaptarse a las nuevas situaciones sociales, culturales y económicas del país. A pesar de esta rigidez institucional es también posible que la progresiva permeabilidad de la religión católica al proceso de secula-

\footnotetext{
6 Presbíteros, luteranos, metodistas y bautistas.

7 En algunos censos, los datos fueron obtenidos a partir de las declaraciones de toda la población adulta; en otros, de una muestra representativa de ésta. La población total del país es de 200 millones de habitantes; dos tercios viven en las ciudades, la mitad se encuentra en una decena de aglomeraciones metropolitanas.
} 
rización de la cultura haya generado cierto "desencantamiento del mundo", con la pérdida de una parte de los elementos "irracionales" del fenómeno religioso. El énfasis atenuado sobre la manipulación mágica de la vida, el abandono del latín como idioma ritual y la sustitución de la noción de pecado individual por el social, de conformidad con la Teología de la liberación, ilustra el abandono de elementos "irracionales" de la creencia y de las prácticas católicas. De forma paradójica, es esta "racionalización" la que ha alejado la Iglesia de la masa de fieles y ha favorecido el crecimiento de las Iglesias evangélicas, especialmente las pentecostales, para las cuales los fieles y los elementos "irracionales" se han mantenido como prioritarios. ${ }^{8}$

En efecto, el cambio de perfil religioso de la población brasileña está estrechamente vinculado con los grandes flujos migratorios internos de los últimos sesenta años, tanto de las regiones como del campo hacia la ciudad. En las regiones de expansión de la frontera agrícola, o en la periferia de las ciudades, especialmente en las regiones metropolitanas donde terminan por instalarse, estas poblaciones migrantes que acaban de perder sus vínculos de solidaridad con su tierra natal se encuentran desamparados ante la débil presencia de los servicios ofrecidos por el Estado y las políticas de desarrollo social. Al vivir la gran mayoría en condiciones precarias, a menudo al borde de la miseria, culturalmente desarraigadas, estas poblaciones desarrollan nuevas disposiciones sociales y nuevas formas de construcción de sus identidades culturales y es aquí donde la religión pasa a ocupar un lugar fundamental.

Las Iglesias evangélicas y sobre todo las pentecostales presentan las opciones religiosas más significativas para estos segmentos sociales, justamente entre los cuales el crecimiento demográfico es el más elevado. Las Iglesias pentecostales actúan rápidamente para formar nuevos pastores y para construir templos que se multiplican a gran velocidad, en los frentes de expansión agrícola y en los nuevos barrios urbanos precarios de las grandes ciudades. El crecimiento del pentecostalismo es entonces más grande en las regiones que se caracterizan por un importante dinamismo económico, lo que incluye las metrópolis. En las regiones más pobres y menos expuestas a los cambios sociales, la religión católica queda estable.

Aunque es dificil hacer previsiones seguras en la materia, muchos estiman que para los años 2020, de sostenerse este crecimiento, el número de

8 La tesis de Max Weber sobre el papel distinto de las creencias religiosas en el proceso de "racionalización" de Occidente, ha sido adaptado en Brasil por diferentes autores y de diferentes maneras. Pierucci, A. F., "Secularização em Max Weber — da contemporânea serventia de voltarmos a acessar aquele velho sentido", Revista Brasileira de Ciências Sociais, Brasil, vol. 13, núm. 37, junio, 1998. 
evangélicos será igual al de los católicos. En el estado de Río de Janeiro, la mayoría de la población ya no se declara católica; en el censo de 2010, los católicos representaban $45,8 \%$ de la población de dicho estado y los evangélicos 29, 3\%. La proporción de declarantes "sin religión" fue de 15,6\%, casi el doble del promedio nacional, lo que deja sugerir que la pérdida de fieles de la Iglesia católica, no se hace solamente a favor de las Iglesias evangélicas o de otra religión institucionalizada.

Ahora bien, si es sencillo proceder a una cartografía y un conteo de las religiones cristianas, no sucede lo mismo con las afrobrasileñas. Durante siglos, sus practicantes fueron empujados hacia el sincretismo como estrategia de sobrevivencia ante la represión religiosa y política, lo que explica que muchos de ellos se declaran todavía católicos, la religión de la mayoría que exige poco en términos de práctica y comportamiento. Esta es la razón por la cual el número de practicantes de las religiones afrobrasileñas está tan subestimado en los censos demográficos. ${ }^{9}$ Pero aún así, se puede afirmar que existe un declive nítido del número de adeptos de estas religiones.

Sin embargo, los sectores sociales en los cuales el pentecostalismo progresa son a menudo los mismos que cuentan con un gran número de practicantes de las religiones afrobrasileñas, esto es, las clases pobres. Al ser el candomblé y el umbanda religiones sin organizaciones burocráticas para articular su comunidad de culto, no tener clero organizado, y no hacer proselitismo ni ser visibles en televisión, quedan particularmente vulnerables a los ataques de las Iglesias pentecostales, las cuales, al querer tomar este mercado religioso, favorecen de esta manera una "guerra espiritual" en contra de las creencias que consideran como demoniacas. Ante los crecientes ataques pentecostales, estas religiones afrobrasileñas, al no tener un mayor valor simbólico dentro de la sociedad brasileña, pierden sus adeptos a pesar del apoyo político que el poder público les ofrece. Esta retirada de las religiones afrobrasileñas se explica también por el hecho de que algunas de estas Iglesias pentecostales procedan a un tipo de sincretismo que guarda siempre afinidades con la religiosidad de origen africano, por ejemplo, los ritos de posesión. Estas afinidades facilitan el paso de los adeptos del terreiro a los templos pentecostales.

Pero no son solamente los contingentes de fieles los que cambian; el campo religioso tampoco es el mismo respecto a la ocupación del espacio social. Hasta los años 1980, las religiones debían ocupar únicamente sus espacios privados, es decir, los templos y los terreiros, con excepción, por supuesto, de la Iglesia católica, que organizaba procesiones y peregrinacio-

9 En 2010, el censo demográfico sólo ha registrado medio millón de adeptos de las religiones afrobrasileños en todo el país, lo que está muy lejos de la realidad. 
nes, así como los congresos eucarísticos que reunían multitudes en la plaza pública. Desde entonces, las Iglesias evangélicas han empezado a ocupar las plazas y los estadios deportivos para ceremonias cultuales, las cuales reúnen multitudes de fieles. Pero además de ello, pasaron a ocupar también otra dimensión del espacio público: los medios electrónicos. Las Iglesias evangélicas mandaron instalar, o simplemente compraron emisoras de radio y televisión, de difusión abierta o por cable, para que sus fieles quedaran "conectados" en la prédica y programas de entretenimiento que consolidaran su fe y que los desviaran de sus competidores religiosos o paganos. La Iglesia católica hizo lo mismo y creó sus propios canales de televisión; sin embargo, como los sistemas de comunicación son concesiones del Estado, se necesita, para obtener dichas concesiones, la ayuda fundamental de un grupo político - la bancada - en el Senado o en la Cámara de Diputados.

Ciertamente, en el sistema político brasileño, los partidos son indispensables para la captación de los votos durante las elecciones; pero una vez electos, diputados y senadores se agrupan de acuerdo con sus intereses corporativos. En el Senado, en la Cámara de Diputados, en las asambleas de los estados de la Federación, así como en las cámaras municipales, estos grupos son conocidos con el nombre de bancadas y desempeñan un papel aun más importante que los mismos partidos. Asimismo, existe en cada nivel del Poder legislativo decenas de bancadas, tales como el Frente Parlamentario de Agricultores y Ganaderos (patronal), el Frente Parlamentario de la Agricultura de las Familias (campesino), el Frente Parlamentario de Apoyo al Deporte y el Frente Parlamentario Evangélico. La bancada evangélica está formada sobre todo por pastores pentecostales, que no siempre votan en bloque, salvo en las cuestiones relativas a los derechos sexuales y reproductivos, donde se alían con los católicos. Éstos, a su vez, no están organizados en bancada sino articulados por la Confederación Nacional de los Obispos (católicos) de Brasil - la CNBB - . Diputados y senadores organizan cada semana rituales de integración religiosa. Los evangélicos organizan cultos dentro de la Asamblea, mientras los católicos se reúnen afuera, en la sede la CNBB, en Brasilia.

\section{LA REACGIÓN CATÓLICA}

Este proceso de cambio acelerado del campo religioso indica dos situaciones que amenazan la posición dominante ocupada por la Iglesia católica en la historia del país: por un lado, el crecimiento de las Iglesias evangélicas; por el otro, el de los "sin religión". Para enfrentarlas, los dirigentes católicos han 
decidido invertir para recuperar el espacio perdido y evitar una pérdida más grande. Para ello, resolvierontomar diferentes caminos, entre otros, organizar grandes espectáculos como los cultos evangélicos pentecostales, enfocarse en las prácticas carismáticas y volver a valorizar los milagros, además de ofrecer de forma efectiva la educación religiosa en las instituciones escolares. Aunque se prescribe en la Constitución y en las leyes relativas a la educación, esta disciplina no siempre está disponible para los alumnos, sin duda debido a cierta laicidad difusa en el ámbito docente.

La acción de la CNBB en la elaboración, y más tarde, en la reforma de la Ley de las Directivas y de las Bases de la Educación Nacional (LDB), Ley 9.394, promulgada el 20 de diciembre de 1996 muestra cómo esta institución cambió su estrategia. El texto de la LDB contenía dos elementos importantes. El primero determinaba que la educación religiosa en las instituciones escolares debía ser proporcionada "sin cargos a los fondos públicos". El segundo elemento preveía dos formas de oferta de esta disciplina, defendidas por sectores rivales del catolicismo: la forma confesional, de acuerdo con la opción religiosa del alumno o de su responsable; y la interconfesional, resultado de un acuerdo entre las diferentes instituciones religiosas.

En víspera de la cuarta y última visita del Papa Juan Pablo II a Brasil, la LDB ha sido reformada por la Ley 9.475 del 22 de julio de 1997, cuyo relator fue un diputado católico, el padre Roque Zimermann. La CNBB acababa de pasar de una estrategia de competencia a una de confrontación. La prohibición de la utilización de recursos públicos en la enseñanza religiosa fue suprimida, de la misma manera que las menciones a las modalidades confesionales e interconfesionales de financiación a esta disciplina, la cual ha sido declarada "parte integrante de la formación básica del ciudadano". Una vez suprimida la mención a las dos modalidades de la educación religiosa, faltaba introducir la modalidad confesional como la única admitida por la legislación que se logró mediante la firma de un concordato entre el Estado brasileño y la Santa Sede. Fue la decisión más atrevida del alto clero católico en su estrategia de confrontación para recuperar el espacio perdido.

Este concordato fue firmado en noviembre de 2008 por el ministro brasileño de Relaciones Exteriores y por el secretario de Estado de la Santa Sede, como consecuencia de las negociaciones entabladas durante la visita del Papa Benedicto XVI a Brasil, en mayo de 2007. El documento fue homologado por la Asamblea Nacional, y el 11 de febrero de 2010, el presidente Lula firmó el decreto 7.107 que promulgaba el concordato BrasilSanta Sede.

Lo que nunca había pasado, ni siquiera durante el Imperio, se hizo realidad. Ello parecía imposible desde que la República inaugurada en 
Esta obra forma parte del acervo de la Biblioteca Jurídica Virtual del Instituto de Investigaciones Jurídicas de la UNAM

1889 había suprimido el patronato imperial, pero la dirección mundial de la Iglesia católica logró que el Estado brasileño firmara un tratado que le garantizaba privilegios en términos políticos, fiscales, de empleo, de educación y otros; como las negociaciones fueron secretas, se ignora si las partes hicieron concesiones.

El artículo 11 del concordato precisa que la educación religiosa católica y de las demás confesiones es facultativo y que constituye una disciplina del horario normal de las escuelas públicas de enseñanza primaria. Sin embargo, este artículo contradice en esencia el artículo 33 del texto reformado de la LBD-96, el cual determina que el contenido de la disciplina de la educación religiosa debe ser establecido por los sistemas de enseñanza (de la Unión, de los estados y de los municipios) tras la audiencia de las instituciones civiles constituidas por las diferentes confesiones religiosas. Asimismo, es posible que no exista una "educación religiosa católica", ni tampoco de otra confesión específica. Si este contenido es de carácter histórico, sociológico o antropológico, como lo pretenden algunas corrientes de la opinión, o bien un extracto de doctrinas religiosas concertadas, el resultado va a depender de la composición política de dichas instituciones civiles.

Diferentes sectores, entre ellos algunos religiosos, se han manifestado en contra del proyecto de concordato. Los debates más intensos entre políticos se llevaron a cabo en la Comisión de Relaciones Exteriores de la Asamblea Nacional, cuando cinco diputados - cuatro evangélicos y uno socialistase declararon inmediatamente en contra del documento entero. El resultado de la votación fue favorable en un $66 \%$ a la aprobación del texto, el cual contó con el apoyo de los diputados evangélicos que en ese momento habían propuesto un proyecto compensatorio de una Ley General de Religiones. Con el pretexto de arreglar dispositivos constitucionales relativos a la libertad de creencias y del libre ejercicio de los cultos religiosos, este proyecto consistía en una adaptación forzada del texto del concordato, en el cual la expresión "Iglesia católica" era reemplazada por la de "instituciones religiosas". La excepción fue el artículo relativo a la educación religiosa, que implícitamente preveía el interconfesionalismo.

Como consecuencia de estas correlaciones de fuerzas tendidas, la Cámara de Diputados tomó una decisión contradictoria: aprobó el concordato, beneficiando a la Iglesia católica pero también la Ley General de Religiones, beneficiando a las Iglesias evangélicas. Como si no fuera absurdo, aprobó dos orientaciones para la educación religiosa en las escuelas públicas: de acuerdo con la primera, debe ser confesional católica y de otras religiones; de conformidad con la segunda, debe ser implícitamente interconfesional. 
De manera diferente al concordato, que fue votado como un decreto legislativo y en un ritmo rápido, la ley que iba a dar a las Iglesias evangélicas el mismo estatus político que la Iglesia católica sólo fue un proyecto de ley entre otros, y terminó abandonado a las vicisitudes de la marcha ordinaria. En este momento, se encuentra en el Senado, con una opinión positiva de todas las comisiones, en espera del voto en sesión plena.

Esta competencia ostensible en las altas esferas, que se extiende a las asambleas legislativas de los Estados y a las cámaras municipales con diferentes marchas, no produce el mismo efecto en las instituciones escolares donde se constata la cooperación, o más bien, una cooperación competitiva a la base.

\section{El Frente Gristiano en las instituciones Escolares}

Pasemos ahora del nivel jurídico-político al nivel de la práctica en las instituciones escolares. Es necesario, antes que todo, trazar un breve perfil de las instituciones públicas de educación en Brasil. La educación fundamental y secundaria están a cargo de los estados y municipios; durante las dos décadas de la dictadura militar (1964-1985), los sistemas educativos de los estados y de los municipios fueron dirigidos por personas vinculadas a intereses privados, lo que generó una caída vertiginosa de la calidad de la educación proporcionada en las escuelas públicas, sobre todo por la reducción drástica del salario de los docentes. Entonces, se dio una nueva orientación en todo el país, tras el reclamo de las clases medias a favor de escuelas privadas, religiosas o no. A la inversa, las políticas educativas del periodo de redemocratización priorizaron desde entonces la expansión cuantitativa de la educación pública básica, la cual es actualmente considerada, en opinión de todos, como de baja calidad y destinada a los más pobres.

En 2005-2006, en el marco de la investigación efectuada en las instituciones escolares del estado de Río de Janeiro, Ana Maria Cavaliere ha llegado a la conclusión de que la escuela pública había sido colonizada por la religión, y que ésta lo había logrado gracias a la iniciativa o apoyo de los políticos.

Existe cierto acuerdo entre los docentes, los responsables de las políticas educativas y los políticos respecto de lo que creen constituye una amenaza de desorden social existente en los barrios populares, una amenaza que sería presente también en las escuelas bajo la forma de comportamientos indeseables, de agresividad y de resistencia de los alumnos hacia la escuela. Asimismo, la religión ha sido considera como la "solución" para el Estado y los docentes. De igual forma, el Estado renuncia a su función socializadora, al ceder a las instituciones religiosas una parte de sus responsabilidades. Los 
docentes, a su vez, sobrecargados debido a la falta de personal, no logran asegurar las actividades cotidianas de la escuela ni promover actividades artísticas, culturales, deportivas, comunitarias o de entretenimiento capaces de enriquecer el medio escolar y la vida de los niños y de sus familias. En pocas palabras, existe un vacío en la escuela $-\mathrm{y}$ es la religión la que lo llena-. Aunque exista un sentimiento más o menos difuso según el cual la escuela debería ser laica, los docentes terminan por capitular y aceptar la oferta que viene de fuera. En la práctica, las clases de religión están justificadas por los docentes como una herramienta adicional en la lucha por una vigilancia más eficaz de los alumnos, y en consecuencia, para la preservación de su autoridad. La percepción generalizada según la cual las familias de los alumnos estarían predispuestos a adherirse a un credo religioso hace útil este camino, inclusive para los docentes y los directores de escuela que no están personalmente comprometidos en una práctica religiosa.

En este contexto, el profesor de religión pasa a ocupar el lugar de auxiliar de la dirección en las actividades de orientación educativa, en los proyectos colectivos de la escuela, en las actividades culturales y conmemorativas. En algunos casos, este profesor llega a jugar un papel muy importante en la definición de las propuestas pedagógicas. Es así como la educación religiosa termina por colonizar sectores de la vida escolar vinculados con la formación general y la orientación educativa. La fuerte presencia de la religión en la escuela es un síntoma de su crisis de identidad y de su falta de eficacia. Llega, en efecto, en el momento exacto en donde la acción educativa escolar se debilita, y revela entonces, por un lado, la capitulación del Estado, y por el otro, el fracaso del sistema educativo en una acción más efectiva de socialización e incorporación social de las bases populares. ${ }^{10}$

En los suburbios de Río de Janeiro, son patentes los mecanismos de colaboración entre docentes y directores de escuela con las dos principales vertientes del cristianismo en lo que tienen en común, esto es, la lectura de la Biblia y la oración del "Padre Nuestro", así como en la oposición a lo que les es desfavorable, especialmente las tradiciones religiosas afrobrasileñas, y aun peor, al ateísmo y agnosticismo. Por otro lado, existen mecanismos de competencia, no siempre abierta, entre católicos y evangélicos, respecto del calendario de las festividades religiosas. Por ejemplo, los evangélicos han anatematizado la costumbre sincrética de la distribución de pasteles a los niños el día de San Cosme y San Damián. Ellos rechazan la figura de estos santos, muy apreciados por el catolicismo popular, y no esconden su horror respecto del origen sincrético de esta costumbre, ya que el candomblé y el

10 Cavaliere, A. M., "Quando o Estado pede socorro à religião", Revista Contemporânea de Educação, Brasil, núm. 2, 2006, p. 4. 
umbanda rinden homenaje a los orixás que asumen la forma de niños gemelos. Ocurre lo mismo con el nacimiento de Navidad, un montaje icónico en todo Brasil, vieja costumbre de las familias y de las escuelas, que es rechazado por los evangélicos, que lo asimilan a una costumbre idólatra. Al existir alumnos que vienen de familias evangélicas, los maestros y los directores de escuela terminan por abandonar estas costumbres ante la ofensiva de los rivales, y optar por una plataforma común. La desaparición de algunas manifestaciones tradicionales, aunque de origen católico, como las fiestas de San Juan, ${ }^{11}$ la supresión de los nacimientos y del Ave María en las oraciones colectivas, son buenos ejemplos de las concesiones católicas hechas en beneficio de la cooperación intereclesiástica en la escuela pública. La celebración común de Pascua y Navidad, así como la cita reiterada de extractos de la Biblia, convenientemente escogidos, refuerzan esta colaboración. ${ }^{12}$

La presencia de la religión en las escuelas públicas brasileñas de enseñanza primaria es muy diversa. Si bien la educación religiosa es una disciplina obligatoria, en la práctica no es siempre efectiva en los programas escolares, ello depende siempre de las prioridades coyunturales de los sistemas de educación de los estados y municipios, así como de las decisiones tomadas por cada una de las instituciones escolares. Pero aun sin la enseñanza de esta disciplina, el cristianismo suele estar presente como un componente moral que es bien recibido por parte de los alumnos y de sus familias. En breve, la religión es concebida por la mayoría de los docentes como la única base de los valores morales y de los criterios fundamentales de la vida en sociedad.

\section{LA LUCHA POR LA LAICIDADEN LA ESCUELA PÚBLICA}

Durante la Asamblea Nacional Constituyente de 1987-1988 fue necesario luchar por el mantenimiento de los logros anteriores, como el divorcio y el derecho legal al aborto en ciertas condiciones. Para extenderlos, era necesario garantizar las políticas públicas sobre los derechos sexuales y reproductivos como la prevención de las enfermedades sexualmente transmisibles; la educación sexual en la escuela; la descriminalización del aborto, inclusive en el caso de fetos anencefálicos; la legalización de la unión homoafectiva y la lucha en contra de la homofobia y todos los modos de discriminación hacia la orientación sexual. Algunos de estos temas dieron lugar posterior-

11 Sobre todo la fiesta de San Juan, en el solsticio de invierno del hemisferio sur, muy popular en todo Brasil.

12 Fernandes, V., (As)simetria nos sistemas públicos de ensino fundamental em Duque de Caxias (Rf): a religião no currículo, tese de doutorado, Faculdade de Educação da Universidade Federal do Río de Janeiro, Brasil, 2014. 
mente a medidas legales que ampliaron los derechos sexuales y reproductivos, pero la educación religiosa en las instituciones escolares se mantuvo prácticamente igual a lo que determinaba la Constitución de 1934.

Una vez terminadas las batallas en torno a la educación pública en la Constitución de 1988 y a la LDB de 1996, la lucha principal se llevó a cabo respecto del concordato entre Brasil y la Santa Sede, como ya lo hemos visto en el capítulo anterior. Aunque fue propuesto por el presidente de la República y aprobado por la Asamblea Nacional, el concordato generó manifestaciones favorables a la laicidad provenientes no solamente de los movimientos sociales, sino también del interior del Estado mismo. Asimismo, el procurador general de la República presentó ante la Corte Suprema - el STF - una acción directa de inconstitucionalidad - una ADI - tanto en contra del concordato Brasil-Santa Sede, como en contra de la LDB. Esta acción buscaba que la Corte Suprema interpretara ambos textos legales con base en la Constitución, para cerrar la puerta a la educación religiosa en las instituciones escolares, ya sea de carácter confesional o interconfesional, así como para rechazar la contratación de docentes vinculados con confesiones religiosas en la educación pública.

Esta disciplina debería favorecer la exposición y la discusión, sin ningún proselitismo, de doctrinas, prácticas, de la historia y de las dimensiones sociales de las religiones, así como de las posiciones no religiosas como el agnosticismo y el ateísmo, sin inclinación por parte de los educadores. Aquéllos deberían a su vez ser docentes de los sistemas públicos de enseñanza, admitidos según criterios que no deben incluir la acreditación de las instituciones religiosas. Haciendo esto, las instituciones escolares permitirían a los alumnos, hacer sus propias elecciones de acuerdo con el objetivo superior de formar personas dotadas de una capacidad de reflexión crítica.

De no ser posible interpretar el concordato de conformidad con la Constitución brasileña, la ADI solicita que se considere como inconstitucional la parte del artículo 11, precisamente, la que trata de "la educación religiosa católica y de las demás confesiones religiosas". La ADI fue recibida por la Corte Suprema y se encuentra en espera de las deliberaciones de los ministros. Ya sea que prospere o no, esta ADI habrá mostrado que el reclamo de laicidad proviene no solamente de la sociedad sino del propio sistema judicial. No se trata de un hecho aislado: el Movimiento del Ministerio Público Democrático, por ejemplo, da una atención especial a la cuestión de la laicidad del Estado e incluso de la educación pública, la cual ha recibido un apoyo importante. ${ }^{13}$

\footnotetext{
13 Véase al respecto el núm. 22 de la revista MPD Diálogo disponible en: wrwre.mpd.org.br.
} 
En la sociedad, los movimientos feministas y LGBT están a la vanguardia de la lucha en favor de la laicidad. Desde 2012, han organizado las Marchas para el Estado Laico en Río de Janeiro y en São Paulo. Aunque tímidas, estas manifestaciones eran inéditas en Brasil. En 2012, el Consejo Nacional de Educación ${ }^{14}$ aprobó un documento relativo a las Directivas Nacionales para la Educación en Derechos Humanos, un programa destinado a ser aplicado en todos los niveles y en todas las modalidades de la educación pública y privada. Este nuevo contenido, que no tomará necesariamente la forma de una disciplina específica, fue concebido y fundado con base en siete principios, uno de los cuales es precisamente la laicidad del Estado. No obstante, como este principio no ha sido definido, puede interpretarse de cualquier manera, de acuerdo con las orientaciones ideológicas que predominan en cada uno de los sistemas de educación de los estados y municipios. Estas directivas fueron homologadas por el ministro de Educación mediante resolución número 1/2012 aunque hasta la fecha no han sido aplicadas. De cualquier modo, constituyen el primer documento del Estado brasileño que se atribuye a sí mismo la laicidad como principio constitutivo. En todos los demás textos, la laicidad debe ser deducida de un laberinto jurídico que permite las conclusiones más contradictorias.

La bibliografía brasileña asumió el vector político de la laicidad desde hace poco tiempo. El primer libro publicado en Brasil que tuvo en su título la expresión "Estado laico" tiene por origen coloquios organizados por grupos feministas en la ciudad de Recife. ${ }^{15}$ Este libro ha reunido, además de las militantes feministas, a un sociólogo, un antropólogo, un diputado federal del Partido de los Trabajadores (el PT) y una mujer pastor de la Iglesia luterana en Brasil. Otros libros fueron publicados posteriormente, algunos sobre educación, tales como los libros de Fischmann en 2008, ${ }^{16}$ Lorea en $2008^{17}$ y Cunha en 2013. ${ }^{18}$ Fue después de ocho años de luchas en torno a

14 Constituido de 24 miembros, nombrados por el presidente de la República y propuestos por instituciones educacionales, sindicales, culturales y empresariales. La Iglesia católica está siempre representada directamente en el Consejo, lo que no es siempre el caso de las Iglesias evangélicas.

15 Batista, M. y Maia, B. (orgs.), Estado laico e liberdades democráticas, Recife, Articulação de Mulheres Brasileiras/Rede Nacional Feminista de Saúde/SOS Corpo-Instituto Feminista para a Democracia, 2006.

16 Fischmann, R. (org.), Ensino religioso nas escolas públicas - impactos sobre o Estado laico, São Paulo, FAFE/FEUSP/PROSARE, 2008.

17 Lorea, R. A. (org.), Em defesa das liberdades laicas, Porto Alegre, Livraria do Advogado Editora, 2008.

18 Cunha, L. A., Educação e religiões: a descolonização religiosa da escola pública, Belo Horizonte, Mazza Edições, 2013. 
la LDB que el ámbito académico tomó la medida de lo que estaba en juego; hasta entonces, la presencia de la religión en las escuelas públicas no era un tema de discusión en las tesis universitarias. A partir de 1996, año de promulgación de esta ley, la religión en las escuelas públicas fue objeto de 137 tesis de máster y de doctorado en diferentes ámbitos, inclusive en las ciencias sociales. Algunas de estas tesis tienen un aspecto normativo (por ejemplo, la mejora de la educación religiosa); otras tienen una perspectiva laica (por ejemplo, la explicitación de los mecanismos que imponen en los hechos la enseñanza religiosa).

Internet inauguró una forma de lucha nueva y eficaz a favor de la laicidad en la escuela pública brasileña. Los testimonios de alumnos registrados en YouTube, donde denuncian el proselitismo que padecen, así como el carácter obligatorio de las clases de religión, constituyen un arma importante en esta lucha para demoler los argumentos según los cuales esta disciplina toma en cuenta la opinión de los alumnos y de sus familias. Llegamos así, con estas denuncias, a comunicar la idea según la cual la educación religiosa es facultativa - lo que no es poco en este contexto de imposición cristiana hecha a despacho de la Constitución-. En Facebook, encontramos perfiles institucionales como "el Estado laico", o grupos como la "Marcha Nacional para un Estado Laico".

En 2006, fue creado en la Universidad Federal de Río de Janeiro el Observatorio de la Laicidad del Estado, redefinido, en 2013, como el Observatorio de Laicidad en la Educación, que ha guardado el siglo OLE y que desde entonces ha sido sostenido financieramente por una red virtual de voluntarios. ${ }^{19}$ El OLE pone a disposición un glosario de conceptos, de opiniones y de artículos publicados en la prensa, un panorama de la laicidad en la educación en otros países, así como vínculos de acceso a instituciones laicas en Brasil y en el extranjero. Un indicador de la receptividad del Observatorio puede encontrarse al buscar el término escola laica (escuela laica) en Google. El OLE aparece en las primeras líneas de la primera página del resultado de la búsqueda.

\section{CONCLUSIÓN Y PROSPECTIVA}

La presencia de actores religiosos en la política brasileña es tan antigua como el Estado nacional mismo. El clero católico actuó desde la Independencia en las diferentes instancias de los poderes legislativos y ejecutivos, incluso en los

\footnotetext{
19 Véase wrerredulaica.net.br.
} 
movimientos separatistas que se opusieron a Portugal y en las revueltas que marcaron la historia del Imperio. De acuerdo con la vieja fórmula, la Iglesia católica era parte del Estado como religión oficial; éste debía sostenerla totalmente y la controlaba en parte. La República interrumpió esta simbiosis tan íntima, pero aún así, no impidió la acción política del clero.

Ciertamente, sacerdotes y obispos redujeron su participación en la administración pública, pero mantuvieron una fuerte influencia mediante una creciente participación política vía política partidaria y por medio del contacto directo con alcaldes y regidores, gobernadores y presidentes, diputados y senadores.

Sin embargo, no ocurrió lo mismo con los evangélicos. Al contrario del clero católico, que siempre frecuentó los palacios del poder, los evangélicos tuvieron que forzar su entrada en un espacio ya ocupado. La apertura de escuelas de alta calidad, orientadas por una pedagogía activa, resultó ser una estrategia victoriosa en las últimas décadas del Imperio y las primeras de la República, un guiño al cual la elite cultural brasileña respondió de manera favorable. Pero aun así, los líderes evangélicos de las Iglesias tradicionales tuvieron que transigir con el catolicismo en el momento en que ampliaban su base política. En los años 1980, aparece un verdadero desafío para los católicos, en el momento en que ocurre la expansión de las Iglesias evangélicas pentecostales dentro de las capas populares, cuando inician su marcha para igualar el número de los fieles de la confesión dominante desde los tiempos coloniales.

Hay que decirlo: las tácticas de influencia sobre el Estado utilizadas por las Iglesias evangélicas son las mismas que las de la Iglesia católica en el pasado: van de la bancada de diputados a la captación de recursos financieros públicos para las actividades de asistencia. Pero poco importan las circunstancias, los evangélicos siguen siendo aprendices en comparación con sus rivales, que son veteranos en los campos religioso y político. La gran diferencia reside en el control de dos partidos políticos por parte de los evangélicos - el Partido Social Cristiano (PSC), controlado por la Asamblea de Dios, y el Partido Republicano Brasileño (PRB), controlado por la Iglesia Universal del Reino de Dios-. Los católicos brasileños intentaron crear una versión tropical del Zentrum Partei alemán o austriaco, pero se dieron cuenta rápidamente de que era más provechoso utilizar una estrategia de acción en varios partidos diferentes, con el objetivo de no interiorizar las divisiones que la práctica política requiere necesariamente. El PSC y el PRB funcionan más como elementos de mediación de la expresión política de cada una de las Iglesias que como agentes reclutadores de fieles. Lo cierto es que el número de diputados de la bancada evangélica en la Asamblea es 
por mucho inferior al número de los adeptos de otras confesiones cristianas no católicas en términos electorales. Se trata, sin embargo, de una bancada unida en la propuesta y en la defensa de una plataforma conservadora, incluso reaccionaria, como lo muestra el caso de la prohibición de todo tipo de aborto, aunque no esté unida respecto a la defensa de la educación religiosa obligatoria en las escuelas públicas.

Aun así, el brote de crecimiento y la acción conjunta de las Iglesias evangélicas tienen límites. No se puede suponer sensatamente que este crecimiento se sostendrá y que estas Iglesias tomarán el lugar de la Iglesia católica en la sociedad brasileña. Los católicos poseen, no hay que olvidarlo, una estructura dotada de un alto grado de centralización a pesar de las disensiones internas, mientras los evangélicos tienen en sus disputas teológicas y sus políticas prácticas la condición misma de su dinamismo. Además, la fuerte presencia mediática del Papa Francisco parece abrir nuevas vías de aggiornamento para la Iglesia católica.

Ya que, si bien es cierto que existe un gran espacio abierto para la acción de los líderes evangélicos en el campo político, no es menos cierto que su crecimiento implica también cambios sensibles en sus plataformas e ideologías. De acuerdo con la opinión del sociólogo de la religión más importante del país, no es Brasil quien se volverá culturalmente evangélico, sino la religión evangélica la que se convertirá en Brasil. ${ }^{20}$

Si tomamos en cuenta el pasado y el presente, podemos afirmar con seguridad que la Iglesia católica constituye un obstáculo más grande a la laicidad en la educación pública que las Iglesias evangélicas. La Iglesia católica siempre ha sostenido la educación religiosa en el programa de las instituciones escolares como una cuestión de doctrina, y actualmente, como una estrategia política. El compromiso de las Iglesias evangélicas en la defensa de esta disciplina no es estratégica sino más bien táctica. En efecto, éstas se posicionaron incluso en contra de esta enseñanza en las escuelas públicas; una parte lo acepta porque está prevista en la ley - y porque la principal competencia no debería ser la única en ocupar este espacio de proselitismo religioso - En el caso extremo, podrían retomar su antigua posición, como al inicio de los debates políticos relativos al concordato Brasil-Santa Sede.

La fuerte presencia de los líderes evangélicos en las diversas instancias del poder legislativo inquieta a los sectores laicos menos experimentados en el análisis político. Ante lo que perciben como un peligro evangélico (pentecostal, o fundamentalista), estos sectores apresuran una alianza con sectores católicos, buscando un inter, supra, pluri o multiconfesionalismo capaz de diluir esta fuerte presencia en el escenario político. Y al reforzar uno u otro

20 Prandi, R. "A conversão do pentecostalismo", Folha de São Paulo, 21 de julio de 2013. 
de los bandos, estos sectores laicos se vuelven en consecuencia actores del campo religioso y entran también en la disputa. Por supuesto, la Iglesia católica no olvidará agradecer a estos laicos positivos.

Y, para terminar, es necesario un esfuerzo prospectivo. Si la educación religiosa en las instituciones escolares se concretiza bajo la hegemonía cristiana, bien podemos suponer que la competencia entre católicos y evangélicos será clara y se volverá una fuente de conflictos en la escuela, conflictos que sus defensores quieren precisamente evitar.

Los procesos en curso hacen suponer que estos conflictos podrán, a largo plazo, favorecer objetivamente a la laicidad en la escuela pública. Ciertamente, no hay lugar en Brasil para una laicidad a la francesa, tal como se trató de implementar en las cuatro primeras décadas de la República. La Carta (francesa) de la Laicidad en la Escuela, no sería plenamente aceptada en Brasil ya que los símbolos religiosos personales son bien recibidos en la escuela pública, al ser usados tanto por profesores como por alumnos cristianos. Pero el progreso de la laicidad permitirá a los adeptos de los cultos afrobrasileños usar sus símbolos, lo que no pueden hacer hoy en día sin arriesgarse a ser acosados y reprimidos.

Habrá tal vez algún día en Brasil un lugar para una laicidad de carácter pragmático, como ocurre, por ejemplo, en Estados Unidos o en la India. La ausencia de educación religiosa en las escuelas sería resultado de la prohibición de la disputa en la escuela para la hegemonía religiosa. Las fuerzas sociales que sostendrían esta nueva laicidad no serían formadas por los que se declaran "sin religión", aunque su número haya aumentado más rápidamente que el de los adeptos de cualquier otra creencia; su dimensión relativa está reducida ante los religiosos, a lo que debemos agregar su desorganización política. La base social de esta nueva laicidad vendría del fuerte crecimiento de la base popular de las Iglesias evangélicas y de la completa libertad de culto para las religiones afrobrasileñas frente al sincretismo católico. Las primeras acogen a los sectores laicos; los otros jamás buscaron difundir sus creencias en las escuelas. Se trataría, asimismo, de una laicidad de disuasión.

Podemos esperar que la educación religiosa en las escuelas se suprima o bien que se ofrezca sólo y cuando sea solicitada por los interesados y proporcionada fuera de los horarios de clase; su costo deberá ser asumido por los interesados o por las instituciones religiosas mismas. Propuestas de este tipo fueron rechazas durante las discusiones anteriores.

El paso de la laicidad a la francesa al confesionalismo hoy existente y a una posible laicidad a la americana o al estilo hindú, podrá abrir nuevas perspectivas para la autonomización del campo educativo brasileño ante el campo reli- 
Esta obra forma parte del acervo de la Biblioteca Jurídica Virtual del Instituto de Investigaciones Jurídicas de la UNAM

gioso. La conquista de la laicidad en las escuelas públicas será entonces un paso inédito hacia la construcción de la democracia en Brasil.

\section{BIBLIOGRAFÍA}

Batista, M. y MaiA, B. (orgs.), Estado laico e liberdades democráticas, Recife, Articulação de Mulheres Brasileiras/Rede Nacional Feminista de Saúde/ SOS Corpo-Instituto Feminista para a Democracia, 2006.

Bourdieu, P., Questions de sociologie, París, Éditions de Minuit, 1980.

Cavaliere, A. M., "Quando o Estado pede socorro à religião", Revista Contemporânea de Educação, Brasil, núm. 2, 2006.

GunHa, L. A., Educação e religiões: a descolonização religiosa da escola pública, Belo Horizonte, Mazza Edições, 2013.

Cunha, L. A. y Cavaliere, A. M., "L'enseignement religieux dans les écoles publiques brésiliennes: formation des modèles hégémoniques. La politique dans les États de Rio de Janeiro et São Paulo", Éducation Comparée, Bélgica, vol. 62, 2007.

Diniz, D. et al., Laicidade e ensino religioso no Brasil, Brasília, Unesco/LetrasLivres, 2010.

FERNANDES, V., (As)simetria nos sistemas públicos de ensino fundamental em Duque de Caxias (R7): a religião no currículo, tese de doutorado, Faculdade de Educação da Universidade Federal do Rio de Janeiro, 2014.

Freyre, G., Ordem e Progresso, Río de Janeiro, MEC/Livraria José Olympio, 1974.

Fischmann, R. (org.), Ensino religioso nas escolas públicas - impactos sobre o Estado laico, São Paulo, FAFE/FEUSP/PROSARE, 2008.

LOREA, R. A. (org.), Em defesa das liberdades laicas, Porto Alegre, Livraria do Advogado Editora, 2008.

MARTEL, L. C. V., "Laico, mas nem tanto: cinco tópicos sobre liberdade religiosa e laicidade estatal na legislação constitucional brasileira", Revista Jurídica, Brasil, núm. 86, agosto-octubre, 2007.

PIERUCCI, A. F., "Secularização em Max Weber - da contemporânea serventia de voltarmos a acessar aquele velho sentido", Revista Brasileira de Ciências Sociais, Brasil, vol. 13, núm. 37, junio, 1998.

PRANDi, R., "A conversão do pentecostalismo", Folha de São Paulo, 21 de julio de 2013.

SAntos, I. y Esteves Filho, A. (orgs.), Intolerância religiosa X democracia, Río de Janeiro, CEAP, 2009. 
Este libro forma parte del acervo de la Biblioteca Jurídica Virtual del Instituto de Investigaciones Jurídicas de la UNAM

\title{
LAICIDAD Y POLÍTICAS PÚBLICAS EN ARGENTINA: DEREGHO, RELIGIÓN Y GULTURA COMO TELÓN DE FONDO
}

\author{
Juan Cruz ESQUIVEL*
}

\begin{abstract}
SUMARIO: I. Introducción. II. La gravitación de la religión y los modelos de laicidad. III. Las políticas públicas. IV. Políticas públicas en riesgo: entre la normativa, la formulación y su implementación. V. Bibliografía.
\end{abstract}

\section{INTRODUCGIÓN}

La comprensión de la trama relacional entre el Estado, las dirigencias políticas y las instituciones religiosas en las democracias contemporáneas, o en otros términos entre política, religión y ciudadanía, reviste múltiples aristas. La dinámica, la correlación de fuerzas, la historicidad de los vínculos, las agendas, las capacidades de influencia, las tensiones y disputas, las distensiones y negociaciones, echan luz sobre diversos escenarios que configuran disímiles modalidades de vinculación. Modalidades éstas que asumen distintas connotaciones si nuestro foco de análisis se ubica en el ámbito nacional, provincial o municipal. O si desentrañamos las normativas legales, las políticas públicas o la cultura política predominante.

Interesa aquí detenernos en el eje de las políticas públicas desplegadas en Argentina, posiblemente la dimensión más dinámica y, como tal, permeable a los vaivenes del perfil político de los gobiernos en cada periodo histórico, si lo comparamos con la normatividad jurídica y la cultura política. En el diseño y formulación de las políticas públicas, subyacen contenidos axiológicos que nos permiten evaluar el substrato laico o confesional y los matices que se reflejan. Bioética, derechos sexuales y reproductivos, género, educación, políticas de culto, representan algunas de las áreas de gestión pública sobre las cuales propongo emprender un recorrido analítico para dilucidar la fisonomía de la laicidad que define al Estado argentino.

* Consejo Nacional de Investigaciones Científicas y Técnicas, Conicet-UVA. 
La multiplicación de nuevos derechos que han emergido en el mundo contemporáneo, sumado al proceso de pluralización cultural - con la consiguiente tensión entre valores y convicciones divergentes-, han renovado el debate sobre las formas de gestionar la diversidad en las democracias del siglo XXI, así como sobre los diferentes formatos asumidos por la laicización de las instituciones políticas y el papel de la religión en el espacio público.

Es pertinente entonces reflexionar en primera instancia sobre las implicancias conceptuales y los usos sociales de la religión y de la laicidad, para luego focalizar el análisis en las políticas públicas en la Argentina reciente.

\section{LA GRAVITACIÓN DE LA RELIGIÓN Y LOS MODELOS DE LAICIDAD}

Durante la segunda mitad del siglo pasado predominó en las ciencias sociales una cosmovisión que situaba a la religión en el espacio de lo privado y postulaba que las creencias religiosas desaparecerían en un largo proceso evolutivo, signado por el "avance" del conocimiento científico y el progreso indefinido. Se llamó secularización a la proyección de esa lenta y continua desaparición de lo religioso. ${ }^{1}$ Más recientemente, Michel y Pace ${ }^{2}$ advierten el renovado interés por la temática religiosa en Europa y Estados Unidos, introduciéndose nuevos conceptos para dar cuenta de la presencia de la religión en el espacio público. "Des-secularización", "mundo postsecular", "retorno de lo sagrado" emergen como nuevas categorías de análisis. El propio Berger ha revisado en los últimos años sus premisas iniciales, al señalar el carácter eurocéntrico de las mismas y la tendencia a extrapolar escenarios del viejo continente a otras latitudes. ${ }^{3}$ La modernidad, según su renovada mirada, no supuso la declinación de lo religioso sino, en todo caso, un profundo proceso de pluralización de las creencias, concepciones y estilos de vida. La teoría de la secularización, comprendida bajo aquellos parámetros, se torna empíricamente insostenible para Berger.

En nuestras latitudes, no es posible pensar en un regreso de la religión a la esfera pública, ${ }^{4}$ habida cuenta de su presencia inacabada. Ha sido una

1 Berger, Peter, The Sacred Canopy: Elements of a Sociological Theory of Religion, Nueva York, Ancher books, 1967.

2 Michel, Patrick y Pace, Enzo, "Religion and Politics", Annual Review of the Sociology of Religion, Inglaterra, núm. 2, VII-XIII, 2011.

3 Berger, Peter, "Further thoughts on Religion and Modernity", Society, Estados Unidos, vol. 49, Issue 4, 2012.

4 Casanova, José, Public Religions in the Modern Word, Chicago, University of Chicago Press, 1994. 
constante la utilización de la religión por los partidos políticos y el Estado, así como la utilización de lo político y del Estado por los grupos religiosos como vehículo para la construcción de una identidad, un repertorio simbólico y una cohesión social.

La religión no sólo no ha declinado como fuerza pública ni se ha domiciliado exclusivamente dentro de una esfera de interioridad, sino que visibiliza su poder institucional cuando se debaten políticas públicas y normativas que involucran asuntos de educación, sexualidad o familia, tres tópicos de alta sensibilidad religiosa. La porosidad de la religión en la cultura y en la legislación nos fuerza a reconsiderar de maneras más complejas la trama de vinculaciones entre lo estatal, lo político, lo cultural y lo religioso.

Desde una mirada retrospectiva, si nos remontamos al retorno de la democracia en Argentina en 1983, dos procesos concomitantes anudan los vínculos entre lo político y lo religioso. En poco más de treinta años se han aprobado una serie de normativas en materia de familia, sexualidad y reproducción distantes de los preceptos axiológicos de las principales entidades confesionales. Fundamentalmente en la última década, esos tópicos han conformado un "bloque temático" con presencia creciente en las discusiones parlamentarias. Paralelamente, la cultura política argentina reproduce rasgos confesionales, sostenidos en la persistente apelación a lo religioso - a las instituciones, a sus referentes, al universo de símbolos y lenguajes - en los fundamentos discursivos y en la búsqueda de una intermediación religiosa a la hora de llevar a la práctica acciones gubernamentales en las más diversas áreas: salud, educación, vivienda, bienestar social, etcétera. Las políticas públicas, orientadas por el lógico seguimiento a lo que la normativa le prescribe y, al mismo tiempo, por un habitus arraigado de los decisores políticos, es el terreno donde se condensan las tensiones entre aquellos procesos convergentes.

La conjunción de ambos procesos explicaría el hiato existente entre la aprobación de normativas tendientes a la promoción de nuevos derechos ciudadanos y las lógicas que priman para obturar su aplicación, delineando un particular formato de laicidad. Particularidad que remite a derroteros jurídicos, históricos, políticos y culturales, que obligan a la deconstrucción de una definición unívoca de laicidad para comprender de modo más certero la modalidad relacional y la historicidad que singulariza el vínculo entre lo político y lo religioso en cada latitud.

A partir de un clivaje normativo, se postula que, en un régimen laico, el poder civil no se recuesta en símbolos y poderes religiosos para obtener 
Esta obra forma parte del acervo de la Biblioteca Jurídica Virtual del Instituto de Investigaciones Jurídicas de la UNAM

su legitimidad. ${ }^{5}$ Desde esa perspectiva, se reconoce a la laicidad en tanto modelo jurídico-político-cultural que, desprovisto de la impronta de una religión en particular, garantizaría la libertad de conciencia y la libertad de culto, en virtud de la neutralidad del Estado en materia religiosa. ${ }^{6}$ Habría cierto consenso en recalcar entonces que más que la separación formal entre Estado e Iglesias, es la observancia de las fuentes de legitimidad del poder civil lo que marcaría fundamentalmente la presencia de un Estado laico.

Ahora bien, los procesos de laicización estatal no han sido unívocos; por el contrario, han transitado por recorridos zigzagueantes, según las matrices culturales hegemónicas y las configuraciones históricas de cada país. No ha sido idéntica la modalidad asumida por la laicidad en contextos donde ha emergido como expresión del pluralismo religioso, que en lugares donde ha significado una liberación de las tutelas religiosas en la definición de la cosa pública. ${ }^{7} \mathrm{O}$ en aquellos otros signados por un predominio protestante, con Iglesias Nacionales que no han comprometido la emancipación estatal.

Como bien afirma Poulat, ${ }^{8}$ estamos frente a un término complejo que remite a contextos proliferantes. En la misma línea, Baubérot sostiene que la laicidad es un fenómeno que tiene orígenes múltiples y se nutre de experiencias diversas, las cuales terminan conformando formatos distintos. ${ }^{9}$ Desde esta perspectiva, no hay ciertamente una sola laicidad, sino múltiples laicidades e incluso múltiples laicidades que coexisten en una misma realidad nacional. De allí, la necesidad de comprender la génesis y el desarrollo de los procesos de construcción histórico-sociales de las formaciones políticas en cada ámbito en particular.

Desde otro enfoque, "laicidad" es un concepto definido por la separación Estado-Iglesias y la reclusión de lo religioso a la esfera de lo privado, ${ }^{10}$ colocando así al modelo francés como patrón referencial. Explícita o implícitamente, la tentación de "normativizar" un "deber ser" en torno a la idea de laicidad trae aparejada la fijación de un parámetro desde el cual evaluar los "avances" o "atrasos" de cada Estado o, en definitiva, de cada sociedad.

5 Milot, Micheline, La laicidad, Madrid, CCS, 2009.

6 Blancarte, Roberto, Los retos de la laicidady la secularización en el mundo contemporáneo, México, El Colegio de México, 2008.

7 Portier, Phillipe, La régulation étatique du croire dans les pays de l'Europe de l'Ouest, Juiz de Fora, UFJF, 2012.

8 Poulat, Emile, Notre laicité publique, París, Berg International, 2003.

9 Baubérot, Jean, Les laicités dans le monde, París, PUF, 2007.

10 Peña-Ruiz, Henri, La emancipación laica. Filosofia de la laicidad, Madrid, Laberinto, 2001. 
Habida cuenta que aún en el interior de un territorio nacional se advierten diversos tipos de laicidad estatal y, por lo tanto, no hay una sola manera de concebirla; más que recurrir a definiciones esencialistas de laicidad, nos proponemos aquí reconocer los componentes que conformarían la/s laicidad/es del Estado argentino, comprendiendo la pluridimensionalidad y la contingencia del concepto.

\section{LAS POLÍTICAS PÚBLICAS}

Anticipábamos en la introducción, que en la última década sucedió en Argentina un proceso de ampliación de derechos en diversos planos de la vida social. ${ }^{11}$ En las cuestiones de género, sexualidad y reproducción, se impulsaron desde el Estado nacional políticas para la distribución de preservativos y la píldora del día después en hospitales públicos; la permisión a la ligadura de trompas y vasectomía como prácticas quirúrgicas de anticoncepción; la adopción de niños en parejas homoparentales; investigaciones sobre fecundación asistida; planes de salud sexual y reproductiva; programas de educación que contemplan la cuestión de género y la diversidad sexual; normativas que contemplan la identidad de género y el matrimonio entre personas del mismo sexo; proyectos de despenalización del aborto.

El recorrido jurídico resalta la aprobación de legislaciones en casi todos los tópicos recién enumerados. Sin embargo, la aplicación de las leyes sancionadas dista de ser homogénea a lo largo y a lo ancho del territorio argentino. En varias provincias, la política pública que deriva de la normativa directamente no se implementa. Nos preguntamos entonces si la aprobación parlamentaria responde más a un contexto de profundización democrática, de defensa de los derechos humanos y de incorporación de minorías a umbrales de ciudadanía que, a un sostenido proceso de laicización de la cultura política predominante, entendido como autonomización de lo político ante lo religioso. O será que debemos repensar el concepto de laicidad para caracterizar el tipo de laicidad que singulariza a un Estado como el argentino que, en paralelo al impulso de nuevos derechos civiles, su clase dirigente

11 Bajo los gobiernos de Néstor Kirchner (2003-2007) y de Cristina Fernández de Kirchner (2007-2015), se reabrieron las causas de delitos de lesa humanidad cometidos en la última dictadura militar (1976-1983) en el marco de una activa política de derechos humanos; se restablecieron las negociaciones paritarias entre actores empresariales y sindicales; se sancionó una nueva legislación sobre los medios de comunicación, para los fines de democratizar la distribución y el acceso a frecuencias radiales y televisivas; se aprobó una normativa acerca del financiamiento de las campañas de los partidos políticos, para garantizar espacios más igualitarios para todas las opciones electorales. 
Esta obra forma parte del acervo de la Biblioteca Jurídica Virtual del Instituto de Investigaciones Jurídicas de la UNAM

continúa interpelando a las estructuras y actores religiosos como espacios legitimados de intermediación ante la sociedad civil.

Los entrelazamientos entre normatividad jurídica, política pública y cultura política, se muestran fragmentados, discontinuos y discordantes. Así, resulta inadecuado arribar a conclusiones definitivas abordando una dimensión de análisis disociada de las otras. Únicamente contemplando la complejidad que trasunta de la interacción entre los tres ejes podremos construir un mapa preliminar sobre los componentes de la laicidad estatal argentina.

En esa clave interpretativa, proponemos a continuación examinar las políticas públicas en bioética, derechos sexuales y reproductivos, género, educación, culto. ${ }^{12}$ Estas áreas de gestión estatal tienen como denominador común una alta sensibilidad religiosa traducida en presencia pública cuando entran en la agenda parlamezntaria o se discuten los contenidos axiológicos que subyacen a las acciones gubernamentales específicas. Es en esos terrenos donde se han librado conflictos - también acuerdos - con las jerarquías religiosas, en la carrera por modelar legislaciones y políticas públicas desde marcos valorativos disímiles.

\section{Bioética}

En bioética, al igual que en las políticas de género, sexualidad y reproducción, la Argentina exhibe, por lo menos en la intencionalidad de su Estado Nacional, un sostenido reconocimiento a los derechos civiles. Si bien la eutanasia no está contemplada, la Ley denominada de muerte digna número 26.742, sancionada en 2012, hace referencia a la autonomía de la voluntad: "el paciente tiene derecho a aceptar o rechazar determinadas terapias o procedimientos médicos o biológicos, con o sin expresión de causa, como así también a revocar posteriormente su manifestación de la voluntad". La normativa garantiza así la potestad de los pacientes con enfermerdades incurables o en estado terminal a rechazar intervenciones desproporcionadas a la perspectiva de mejoría, incluyendo la hidratación y la alimentación entre las medidas posibles de ser objetadas. ${ }^{13}$

12 El relevamiento fue realizado por el equipo de investigación conformado por Juan Cruz Esquivel, Karina Felitti, Guillermo Romero, Iris Schkolnik, Germán Torres y Claudia Touris, en el marco del proyecto Indicadores de laicidad en la Argentina democrática. Fundamentos jurídicos, políticos y culturales para evaluar la relación Estado-Iglesias, financiado por el Consejo Nacional de Investigaciones Científicas y Técnicas (Conicet).

13 Esquivel, Juan Cruz, "Religión y política. La influencia religiosa sobre las definiciones parlamentarias en materia de derechos sexuales y reproductivos", en Esquivel, Juan Cruz y 
Por su parte, el Instituto Nacional Central Único Coordinador de Ablación e Implante (INCUCAI) ha autorizado hasta el presente tres ensayos clínicos con células madre para evaluar potenciales terapias en el tratamiento de accidentes cerebro-vasculares, lesiones en el cartílago de rodillas y quemaduras.

Tanto el acceso a los procedimientos y técnicas médico-asistenciales de reproducción asistida como las cirugías para el cambio de sexo cuentan con respaldo jurídico. En el primer caso, la Ley número 26.862 contempla el derecho de toda persona mayor de edad, sin discriminación por orientación sexual, a acceder a los procedimientos y técnicas de reproducción médicamente asistida. Requiere de un consentimiento previo, el cual puede ser revocado hasta antes de producirse la implantación del embrión en la mujer. Y prescribe la inclusión de estos procedimientos, así como los de diagnóstico, medicamentos y terapias de apoyo en el Programa Médico Obligatorio (PMO).

A su vez, en los servicios públicos de salud es posible realizar cirugías para el cambio de sexo. La Ley número 16.743 establece que todas las personas mayores de dieciocho años de edad, a fin de garantizar el goce de su salud integral, "podrán acceder a intervenciones quirúrgicas totales y parciales y/o tratamientos integrales hormonales para adecuar su cuerpo, incluida su genitalidad, a su identidad de género autopercibida, sin necesidad de requerir autorización judicial o administrativa".

Este indudable reconocimiento a derechos civiles cohabita con la participación en diversos consejos consultivos o comités de bioética de agentes religiosos o no formalmente religiosos pero que vehiculizan las prescripciones axiológicas de sus instituciones confesionales. De acuerdo con el Decreto número 426/1998, se crea la Comisión Nacional de Ética Biomédica, integrada por un miembro en representación del Ministerio de Justicia; un miembro en representación de la Secretaría de Ciencia y Tecnología del Ministerio de Cultura y Educación - actualmente, Ministerio de Ciencia, Tecnología e Innovación Productiva - y tres miembros en representación de las confesiones religiosas oficialmente reconocidas, ${ }^{14}$ a propuesta de la Secretaría de Culto del Ministerio de Relaciones Exteriores y Culto de la Nación.

Vaggione, Juan Marco (comps.), Permeabilidades activas. Religión, politica y sexualidad en la Argentina democrática, Buenos Aires, Biblos, 2015.

14 Como se explicará más adelante, en Argentina, con excepción de la Iglesia católica, las demás confesiones religiosas deben registrarse en una dependencia estatal para ser reconocidas oficialmente. 
Esta obra forma parte del acervo de la Biblioteca Jurídica Virtual del Instituto de Investigaciones Jurídicas de la UNAM

\section{Género y derechos sexuales y reproductivos}

Argentina contempla la unión civil y/o el matrimonio entre personas del mismo sexo, así como la posibilidad de adopción en parejas del mismo sexo. Desde 2010, avala legalmente el matrimonio entre personas del mismo sexo. La Ley número 26.618 modifica el Código Civil para garantizar el enlace entre personas del mismo sexo y legalizar también la adopción de niños por parejas homoparentales. Básicamente, se eliminan los términos "hombre" y "mujer", reemplazándolos por "contrayentes". Sustentados en ese nuevo marco jurídico, los hijos de cónyuges del mismo sexo gozan de los mismos derechos que aquellos de parejas heteroparentales: bienes gananciales, acceso a previsiones sociales, etcétera.

En la misma sintonía, se registran políticas públicas orientadas a la promoción de la igualdad de género. Entre sus objetivos, el Consejo Nacional de la Mujer se propone "legitimar ante la sociedad la relevancia de la equidad de género para el fortalecimiento de la democracia", así como "impulsar políticas públicas con perspectiva de género que contribuyan a la superación de las diversas formas de discriminación contra las mujeres y promuevan las condiciones sociales adecuadas para garantizar a las mujeres el ejercicio efectivo de sus derechos". ${ }^{15}$ Se registran programas al interior de los ministerios que despliegan acciones integrales orientadas a la equidad de género e igualdad de oportunidades.

La Ley de cupo femenino número 24.012 resguarda las políticas públicas de igualdad de género. Establece que las listas que se presenten deberán tener mujeres en un mínimo del 30\% de los candidatos a los cargos a elegir y en proporciones con posibilidad de resultar electas.

El acceso a métodos anticonceptivos en servicios públicos de salud, incluso los de emergencia como la píldora del día después, está formalmente garantizado. En 2002, se sancionó la Ley Nacional número 25.673 de Salud Sexual y Procreación Responsable que se plantea "alcanzar para la población el nivel más elevado de salud sexual y procreación responsable, con el fin de que pueda adoptar decisiones libres de discriminación, coacciones o violencia" (artículo 2o.). Al año siguiente, se crea el Programa Nacional de Salud Sexual y Procreación Responsable, bajo la órbita del Ministerio de Salud de la Nación, con el propósito de vehiculizar el acceso igualitario a la información sobre la salud sexual y la procreación responsable y proveer los insumos y servicios de salud sexual y reproductiva a los hospitales y centros de salud de todo el territorio argentino.

\footnotetext{
15 Véase http://wrwr.cnm.gov.ar/Varios/ObjetivosConsejo.html.
} 
$\mathrm{Al}$ señalar las instituciones responsables de las tareas informativas, se hace una distinción entre las entidades educativas de aquellas prestadoras del servicio de salud. En el caso de las primeras, sean confesionales o no, se sostiene que deben cumplimentar la norma en el marco de sus convicciones. A las instituciones de salud de carácter confesional se las exceptúa de la distribución de anticonceptivos, si ello afectara a las convicciones de sus responsables y a los objetivos de la organización. La normativa prevé también el suministro de los métodos y elementos anticonceptivos a demanda del(a) beneficiario(a). Los mismos se hallan incluidos en el Programa Médico Obligatorio.

Desde 2006, se incorporaron las prácticas de ligadura de trompas de Falopio y ligadura de conductos deferentes o vasectomía, requeridas formalmente como método de planificación familiar y/o anticoncepción.

En cuanto a los métodos anticonceptivos de emergencia, se encuentran prescritos en el Programa Médico Obligatorio desde 2007 — resolución número 232 del Ministerio de Salud de la Nación - y forman parte de los protocolos de atención de los hospitales públicos.

El aborto permanece como una cuestión espinosa. Se contempla su despenalización en casos específicos como el de violación, riesgo de vida de la mujer y malformación del feto, pero no existen referencias para una ampliación que atienda la decisión soberana de la mujer. ${ }^{16}$ En la práctica, la situación resulta más compleja. Las denuncias por casos de aborto no punible que no consiguen efectivizarse se repiten sin solución de continuidad. Retrasos por impugnaciones judiciales, objeción de conciencia de los médicos que se traducen en objeciones de conciencia institucional ante la inactividad del centro de salud, activisimo de grupos religiosos - mayoritariamente católicos - conforman el abanico de factores que han obturado la posibilidad de realizar abortos en situaciones contempladas jurídicamente. En ese contexto, en 2010, el Ministerio de Salud de la Nación elaboró una guía técnica para la atención de abortos no punible con la finalidad de guiar los procedimientos para los casos tipificados. ${ }^{17}$ Los cambios en las autoridades ministeriales, las convicciones dispares sobre la materia y la ausencia de una política de Estado, atentaron contra la eficacia de ese material.

Por su parte, la Corte Suprema de Justicia retoma la cuestión, y el 13 de marzo de 2012 aprueba un protocolo para agilizar los pasos a seguir en

16 El artículo 86 del Código Penal establece que "el aborto practicado por un médico diplomado con el consentimiento de la mujer encinta, no es punible si se ha realizado con el fin de evitar un peligro para la vida o la salud de la madre... si el embarazo proviene de una violación o de un atentado al pudor cometido sobre una mujer idiota o demente".

17 Guía técnica para la atención integral de abortos no punibles. Cumplimiento efectivo de los derechos sexuales y reproductivos, Buenos Aires, Ministerio de Salud de la Nación, 2010. 
situaciones de aborto no punible, explicitando su interpretación del artículo 86 del Código Penal. Dictaminó que toda mujer víctima de una violación tiene derecho a interrumpir el embarazo con la presentación de una declaración jurada sobre el delito en el centro de salud, sin necesidad de autorización judicial. Asimismo, exhortó al Estado Nacional y a los Estados Provinciales a que sancionasen una normativa idéntica para así garantizar el acceso efectivo al aborto no punible.

Aunque el protocolo de la Corte Suprema parecía dar por finalizada las discusiones en torno al articulado del Código Penal, la disímil recepción por parte de los gobiernos locales de la explícita resolución judicial desembocó en singulares conflictos entre poderes institucionales, con el consiguiente aplazamiento de todo intento de normativizar y unificar la práctica médica frente a casos de embarazo producto de violación.

Según un informe de la Asociación de los Derechos Civiles (ADC), ${ }^{18}$ sólo en cinco provincias - Tierra del Fuego, Chubut, Santa Fe, Chaco y Jujuy - se han aprobado leyes o firmado resoluciones ministeriales en sintonía con el dictamen de la Corte Suprema de la Nación. En cambio, en ocho jurisdicciones se han fijado requisitos que tienden a dificultar el acceso a abortos no punibles. Son los casos de Salta, Córdoba, Entre Ríos, La Pampa, Ciudad de Buenos Aires, provincia de Buenos Aires, Río Negro y Neuquén. Distantes del fallo de la Corte, en algunas de esas provincias se establece un límite de tiempo para que las mujeres puedan acceder al aborto; en otras exigen que las niñas y adolescentes menores de 18 años cuenten con el consentimiento de sus padres para acceder a un aborto no punible; prescriben la intervención de un equipo interdisciplinario para verificar la procedencia del embarazo; preservan una visión restrictiva, considerando no punibles sólo los casos de aborto en mujeres "idiotas o dementes" víctimas de violación; precisan la necesidad de que la declaración jurada de la mujer violada se realice en el ámbito público con la asistencia tutelar del Ministerio Público, contradiciendo la orientación de la Corte Suprema de agilizar los procesos; contemplan la objeción de conciencia de los médicos al momento de atender a la paciente, cuando esta objeción debería plantearse al momento de implementarse el protocolo o cuando el médico se incorpora al equipo de profesionales de un centro de salud, para evitar dilaciones en el acceso a la práctica.

Las once jurisdicciones restantes - Mendoza, San Juan, San Luis, La Rioja, Catamarca, Tucumán, Formosa, Corrientes, Misiones, Santiago del

18 Herrero, Álvaro, “'Se cumple el fallo sobre aborto no punible?", 28 de marzo de 2013, disponible en: http://wwre.chequeado.com/el-explicador/1542-ise-cumple-el-fallo-sobre-abortono-punible.html. 
Estero y Santa Cruz - no cuentan con protocolos de atención. Si consideramos que la sentencia de la Corte estuvo motivada por los repetidos casos de dilaciones ante la falta de procedimientos claros, la carencia de dictámenes provinciales podría resultar funcional a quienes se proponen obturar toda práctica de aborto, aún en contextos amparados legalmente. De hecho, Mendoza se autoproclamó "pro-vida", en clara referencia contraria a las prácticas de interrupción del embarazo. ${ }^{19}$

\section{Educación}

En el terreno educativo, pese al mito de la educación laica, ${ }^{20}$ se observan diversos insterticios en los que se juega la complementariedad entre lo estatal y lo religioso: financiamiento estatal a instituciones educativas confesionales, participación de actores religiosos en espacios consultivos para la elaboración de las políticas públicas, presencia de símbolos religiosos en escuelas públicas, etcétera. Las subvenciones estatales se destinan al salario de los docentes en las escuelas de gestión privada, mayoritariamente confesionales.

La educación argentina ha contemplado desde sus inicios la enseñanza pública y privada, dentro de ésta, también la religiosa. Si bien el siglo XX fue testigo de idas y vueltas en esta materia - por la década del cuarenta, la educación religiosa era obligatoria en los colegios públicos y a fines de los años cincuenta, se suscitó un fuerte debate entre segmentos religiosos y grupos que reivindicaban la laicidad como modelo para la educación-, lo cierto es que se ha encontrado una fórmula que ha garantizado el acuerdo de los actores interesados. Si por un lado a nivel nacional no se prescribe la enseñanza religiosa en el sistema público, la Iglesia católica recibe cuantiosos subsidios estatales para el sostenimiento de su amplia red educativa en todo el país y en todos los ciclos de la enseñanza. Las demás confesiones religiosas reciben también una contribución oficial para mantener sus establecimientos educativos, pero el número de escuelas es infinitamente menor.

19 Clarín, Buenos Aires, 12 abril de 2012.

20 En 1884 fue aprobada la Ley de Educación Común número 1420, que sentó las bases para una educación obligatoria y gratuita. Más allá de que las representaciones construidas en torno a dicha legislación le impriman un carácter laico, lo cierto es que en ninguno de los 82 artículos se hace referencia a la cuestión de la laicidad como modelo educativo. Por el contrario, el artículo 8o. prescribía el dictado de la enseñanza religiosa en las escuelas públicas, aunque fuera del horario lectivo. La coincidencia con otras normativas que redujeron las potestades de la Iglesia católica en la regulación de la vida social - el Registro Civil en 1981 y el matrimonio civil en 1888-, confluyó para que se interpretara la Ley 1420 como estandarte de la laicidad. 
Como recién explicitábamos, la Ley de Educación Nacional aprobada en 2006 - número 26.606 - no contempla clases de religión en las escuelas públicas. Habida cuenta de que se trata de un sistema descentralizado, las regulaciones se encuentran bajo la órbita de cada jurisdicción. Merced a la autonomía provincial, se advierten casos, como los de Salta, Tucumán, Santiago del Estero y Córdoba, donde sí se dictan clases de religión en los colegios estatales.

Varios aspectos en torno a la cuestión educativa destellan de las políticas públicas educativas a nivel provincial. Por un lado, los fundamentos de la educación como valor social. En este plano, se cristalizan los preceptos más arraigados sobre la condición humana que permiten vislumbrar las orientaciones más o menos confesionales, más o menos laicas de la normativa vigente. Por otro lado, en algunos contextos, la posibilidad de impartir la enseñanza religiosa en las escuelas públicas. Aquí se deslizan algunos matices en cuanto al dictado de materias religiosas durante el horario lectivo o fuera del mismo. Y, en tercer lugar, las obligaciones del Estado en el financiamiento de la educación religiosa. Reafirmándose en las disposiciones de la Convención Americana sobre Derechos Humanos — más conocida como Pacto de San José de Costa Rica-, se reivindica el derecho de los padres y/o tutores legales a que sus hijos reciban la educación religiosa y moral de acuerdo a sus convicciones. A partir de esta consideración, se reconoce el derecho de las instituciones privadas, entre ellas, las religiosas, a la enseñanza educativa y a recibir las contribuciones estatales para garantizar su funcionamiento.

\section{Educación sexual}

En 2006, se sancionó la Ley 26.150, que prescribió la creación del Programa Nacional de Educación Sexual Integral, en la órbita del Ministerio de Educación de la Nación. En los Lineamientos Curriculares elaborados por sus autoridades se enfatiza ${ }^{21}$

...una concepción integral de la Educación Sexual, con una clara perspectiva de derechos humanos, una atenta disposición a impartir conocimientos rigurosamente validados por los avances científicos y una especial consideración de las particularidades que conlleva el hecho educativo.

Este enfoque integral tiene como propósito que la Educación Sexual brindada en las escuelas supere el mero estudio de la anatomía y la fisiología de

21 Lineamientos Curriculares para la Educación Sexual Integral, Buenos Aires, Ministerio de Educación de la Nación, 2008. 
la sexualidad, así como cualquier otro reduccionismo, sean éstos de carácter biológico, psicológico, jurídico, filosófico, religioso o sociológico.

$\mathrm{Al}$ mismo tiempo, la normativa avaló que cada comunidad educativa adaptara los contenidos a "su realidad sociocultural, en el marco del respeto a su ideario institucional y a las convicciones de sus miembros". De ese modo, las entidades religiosas gozan de cierta autonomía para impartir en sus escuelas una enseñanza en sexualidad a partir de sus principios axiológicos, abriéndose un difuso margen para que las escuelas religiosas definan sus pautas curriculares en torno a la educación sexual.

Asimimo, la participación de referentes de las instituciones religiosas, ya sea a modo de consulta o de participación en consejos para la elaboración de programas educativos, es recurrente. Una Comisión Interdisciplinaria de Especialistas, que contó con integrantes de varias confesiones religiosas (Miryan Andújar y María Inés Franck por el Consejo Superior de Educación católica, dependiente de la Conferencia Episcopal Argentina; el rabino Daniel Goldman, Claudia Lombardo por las Iglesias evangélicas), fue conformada para la definición de los Lineamientos Curriculares para la Educación Sexual Integral. ${ }^{22}$

La conformación del Programa de Educación Sexual Integral como espacio institucional dinamizó parcialmente las políticas gubernamentales en la materia. Se presentó el Programa en las jurisdicciones, se promovieron ámbitos de intercambio y la designación de referentes provinciales, se establecieron equipos intersectoriales de salud y educación, se elaboraron materiales pedagógicos y de sensibilización y se capacitaron docentes. A pesar de esas iniciativas integrales, por un abanico de factores que analizaremos en las conclusiones, resulta exiguo el cumplimiento de la Ley de Educación Sexual Integral.

\section{Culto}

La predominancia católica en la esfera estatal Argentina da cuenta de la inexistencia de una igualdad religiosa. Para comenzar, el artículo 2o. de la Constitución Nacional prevé el sostenimiento del culto católico apostólico romano. Una secuencia de normativas establece el financiamiento para arzobispos y obispos, sacerdotes en parroquias de frontera y seminaristas católicos. El vínculo con las restantes confesiones se canaliza por intermedio del Registro Nacional de Cultos. Creado en los tiempos de la dictadura

\footnotetext{
22 Véase http://wrew.bnm.me.gov.ar/giga1/normas/12611.pdf.
} 
Esta obra forma parte del acervo de la Biblioteca Jurídica Virtual del Instituto de Investigaciones Jurídicas de la UNAM

militar — Ley número 21.745-, supone que todas las entidades religiosas que ejerzan sus actividades de culto en Argentina, a excepción de la Iglesia católica, deben tramitar su inscripción y reconocimiento oficial, como condición previa a su actuación. A su vez, el Código Civil de la República Argentina especifica que la Iglesia católica tiene carácter público, mientras que las asociaciones civiles o religiosas - con esta figura se describen a los demás cultos-, asumen un carácter privado.

No sólo cuestiones monetarias marcan una situación jurídica desigual entre el catolicismo y los demás cultos. Elementos simbólicos que se enmarcan en un vínculo privilegiado con el Estado también refuerzan las diferencias. A través del Decreto número 1.233 (1998), el Estado expide credenciales a arzobispos, obispos, prelados y superiores mayores, acreditando su condición de tales. Pese a no ser considerados funcionarios estatales, otras huellas perduran del régimen de patronato. ${ }^{23}$ Los prelados católicos se encuentran homologados con las autoridades de gobierno. El Decreto número 1.131 incluye a los cardenales en la nómina de los beneficiados por la obtención del pasaporte diplomático. A su vez, los arzobispos y los obispos reciben el pasaporte oficial, al igual que los legisladores nacionales, los ministros de la corte suprema y los gobernadores de las provincias.

Las iconografías católicas que decoran organismos oficiales y la convocatoria para la realización del Tedeum no están prescriptas en la legislación, pero su permanencia y continuidad denota con claridad el indiscutido y naturalizado papel protagónico que detenta la Iglesia católica en el escenario público argentino.

Pero el diferenciado estatus que detenta la Iglesia católica no debe interpretarse como una encrucijada para las garantías de múltiples libertades. Rige en el país una plena libertad religiosa, de cátedra, de investigación y divulgación, sin registros de censura por motivos religiosos. Desde los inicios como nación independiente, la premisa de la libertad religiosa estuvo presente en las primeras legislaciones. En 1825, un tratado firmado con Gran Bretaña garantizó a los ingleses el libre ejercicio de su culto. Indicador de la relevancia de esta cuestión, el Congreso Constituyente de 1853 dedicó más de la mitad de sus sesiones a definir qué modelo de país se pretendía configurar en materia religiosa. La llegada de contin-

23 El acuerdo suscrito con la Santa Sede en 1966, puso fin al régimen de patronato, eliminando la intervención de la Presidencia en la designación de obispos, lo que facilitó la radicación de las órdenes religiosas y garantizó la libre distribución de las comunicaciones papales en todo el territorio. Véase Esquivel, Juan Cruz, "Laicidad, secularización y cultura política: las encrucijadas de las políticas públicas en Argentina", Revista Laicidad y Libertades. Escritos furídicos, España, vol. I, núm. 8, 2008. 
gentes inmigratorios de múltiples países europeos, portadores de culturas, religiones y lenguas diversas, requería un encuadre jurídico que facilitara su radicación. El artículo 14 de la carta magna resultante contempló la libertad de culto, erigiéndose como un valor consolidado y traducido en política de Estado.

\section{POLÍTICAS PÚBLICAS EN RIESGO:}

\section{ENTRE LA NORMATIVA, LA FORMULACIÓN Y SU IMPLEMENTAGIÓN}

Buena parte de la normatividad jurídica, que impele a la formulación de programas gubernamentales, encuentra dificultades a la hora de su ejecución. Como explicitábamos, sólo cinco de las veinticinco jurisdicciones provinciales han cumplido con la prescripción judicial referida al aborto. Análogamente, la implementación del conjunto de legislaciones ligadas a derechos sexuales y reproductivos dista de ser homogénea en la particular geografía argentina. Vaciamiento presupuestario, retraso en la conformación de responsables provinciales para poner en práctica las políticas públicas específicas, designación de un referente consensuado o directamente propuesto por la Iglesia católica quien imprime una gestión con contenidos axiológicos disímiles a los contemplados en la ley o simplemente el desvanecimiento del impulso inicial fruto del desgaste de la gestión, son algunos de los factores explicativos de este estado de situación.

Un caso paradigmático lo compone la aplicación de la Ley de Educación Sexual Integral. Una multiplicidad de factores nos permiten explicar la disparidad en la incorporación de la educación sexual en las escuelas de todos los niveles de enseñanza a lo largo y a lo ancho del país. En primer lugar, habida cuenta del número significativo de escuelas confesionales - mayoritariamente católicas - diseminadas por todo el país, el posicionamiento público de la Conferencia Episcopal Argentina, contrario a los contenidos de la ley, no ha pasado desapercibido. Esta afirmación no debe interpretarse desde una mirada lineal. Los procesos de desinstitucionalización también permean la estructura católica y repercuten en la cristalización de bisagras de autonomía de los colegios religiosos con respecto a las prescripciones que establecen las autoridades eclesiásticas. De allí que se registren experiencias de instituciones educativas religiosas que han incorporado parcialmente las pautas curriculares del Ministerio de Educación. Pero innegablemente la voz oficial de la Iglesia católica es contemplada por buena parte de las autoridades de los colegios confesionales y, del mismo modo, por los responsables de definir las políticas educativas en las jurisdicciones provinciales. 
Un segundo elemento a considerar es justamente la falta de voluntad política de algunas autoridades locales para avanzar en el cumplimiento de la ley nacional. Sea por sus convicciones religiosas, sea por la centralidad otorgada a la opinión del obispo local o por una combinación de ambos componentes, lo cierto es que la implementación de la normativa ha sufrido dilaciones por inacción del poder público provincial. La inexistencia de una asignación presupuestaria y de funcionarios designados para la gestión específica en algunas jurisdicciones evidencia el bajo grado de acatamiento a una legislación nacional.

Un tercer ingrediente gira en torno a la cultura docente y su nivel informativo. En líneas generales, desconocen la aprobación de una ley de educación sexual, así como los lineamientos curriculares. Y aun los que cuentan con esa información, su grado de capacitación para abordar la problemática es limitado. La recurrencia a sus experiencias y conocimientos previos, sin el ejercicio de desnaturalizar su percepción subjetiva, dificulta la generación de actitudes formativas. La utilización en mayor medida de los manuales de texto en lugar de los documentos oficiales nos habla de contenidos curriculares diseñados por las editoriales que, en muchos casos, no se ajustan a los lineamientos establecidos por el Programa de Educación Sexual Integral.

Un cuarto componente está marcado por la existencia de aspectos legales ambiguos y dispares. Si bien la Ley Nacional de Educación Sexual Integral prescribe la definición de los lineamientos curriculares por la agencia educativa estatal para todos los niveles y modalidades del sistema escolar; al mismo tiempo, avala la estructuración de contenidos propios por parte de las instituciones educativas, sin arrojar pistas sobre las instancias de conjugación de ambas propuestas en un mismo diseño pedagógico. Fundamentalmente en aquellas situaciones en que el proyecto pedagógico institucional se distancie, o incluso sea incompatible, respecto del marco conceptual sostenido por los lineamientos curriculares y por la propia normativa sancionada.

Cultura política con signos de confesionalidad, autonomía jurisdiccional, falta de presupuesto y de designación de funcionarios específicos, divergencias locales con las prescripciones jurídicas nacionales y resistencia de poderes religiosos, han confluido para configurar un escenario que refleja marcados desapegos a la implementación de las normativas que han promovido nuevos derechos.

Fundamentalmente en cuestiones de género, sexualidad y reproducción, el entramado jurídico y la orientación de los lineamientos estratégicos 
no se corresponden con las políticas públicas efectivamente ejecutadas, sea por el contraste con la direccionalidad de estas últimas, sea por la lisa y llana no aplicación de la norma aprobada.

En múltiples ocasiones, las discusiones parlamentarias fueron fruto de casos mediáticos que impulsaron los proyectos de ley, finalmente exitosos, de ampliación de derechos civiles. Pero al mismo tiempo, los decisores políticos piensan la implementación de las políticas públicas articuladas con las instituciones y agentes religiosos, en tanto entidades legitimadas de intermediación ante la sociedad civil.

El factor religioso, históricamente presente en el espacio público y dador de sentido en la construcción de la idea de nación, constituye un engranaje significativo en las percepciones dominantes que definen las formas de instrumentar los quehaceres políticos en la cotidianeidad. Más que una ética laica/secular diferenciadora de los campos de injerencia de lo político y lo religioso, y legitimadora de la autonomía estatal, prevalece una cosmovisión que integra y complementa ambas dimensiones, cimentada por una cultura cristiana tan arraigada como naturalizada. Vale aclarar que en esas representaciones los actores religiosos ocupan posiciones diferenciadas. El catolicismo es situado en un lugar privilegiado, el campo evangélico es decodificado de modo bifronte - respeto hacia las denominaciones del protestantismo histórico, recelo y lógica de intercambio hacia los líderes de las expresiones pentecostales - , sobrerrepresentación del poder institucional de las organizaciones judías, ajenidad con el mundo musulmán. El financiamiento, la colaboración, el reconocimiento y el registro son algunas de las herramientas de gestión estatal que, puestas en acción, reflejan los espacios diferenciados que ocupa cada una de las instituciones religiosas.

La elección de un papa argentino no ha hecho más que reforzar los procesos de yuxtaposición de las legitimidades político-religiosa. El propio dispositivo político ubica hoy a Francisco como un protagonista inexorable. Si históricamente la cercanía al obispo de la jurisdicción era anhelada como proyección - imaginada o real- para un mejor performance electoral o para fortalecer la gestión de gobierno, actualmente la foto junto a Francisco ya ha sido consumada por la gran mayoría de los actores relevantes de la política doméstica - partidarios, sindicales, económicos, judiciales-.24

24 La frase de José Ignacio de Mendiguren, diputado nacional y referente de la Unión Industrial Argentina, es representativa de todo el arco político y refleja fehacientemente la idiosincrasia de la clase dirigente en torno a la legitimidad que la religión - sus figuras, instituciones e íconos - proporciona en la arena electoral: "Todos piensan si un programa de espectáculos da vuelta una elección. Imagínense lo que puede hacer un Papa”, véase Diario 
Esta obra forma parte del acervo de la Biblioteca Jurídica Virtual del Instituto de Investigaciones Jurídicas de la UNAM

En simultáneo, se ven solapados los procesos de profundización de la democracia - con su dinámica receptiva de incorporación de demandas que instan a garantizar nuevos derechos ciudadanos-y de cogestión de las políticas públicas con entidades religiosas, en el marco de una cultura política tendiente a disociar los presupuestos de la laicidad con la imaginaria "idiosincrasia nacional". En la superposición de tales procesos, encontramos las claves analíticas para comprender la grieta que existe entre determinadas normativas vigentes y la no sustanciación de las mismas en políticas públicas.

Es esa convivencia dual la que permite catalogar a la laicidad argentina como subsidiaria. La laicidad subsidiaria corresponde a un tipo de Estado que presenta una fuerte matriz católica en su génesis e historia, pero que en los procesos de democratización y secularización han forjado novedosos reconocimientos respecto de los formatos plurales de las sociedades contemporáneas. ${ }^{25}$

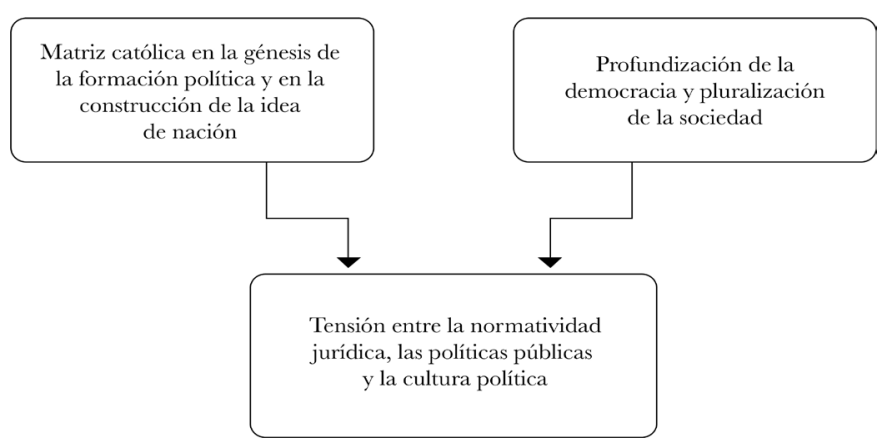

Se trata de un Estado que en paralelo a la conquista de espacios de autonomía y de mayor reconocimiento de derechos ciudadanos diversos sigue interpelando a las instituciones religiosas en la proyección de sus políticas públicas. Reproduce una lógica de subsidiariedad en la implementación de políticas públicas y en la interpelación al ciudadano, a través de la intermediación de actores colectivos, entre ellos, los religiosos. He aquí la singularidad de esta concepción de la laicidad.

Infobae, 12 de mayo de 2014, disponible en: http://wrwre.infobae.com/2014/05/12/1563670-todos-piensan-si-un-programa-espectaculos-da-vuelta-una-eleccion-imaginense-lo-que-puede-hacer-un-papa.

25 Esquivel, Juan Cruz, "Religión y política. La influencia religiosa sobre las definiciones parlamentarias en materia de derechos sexuales y reproductivos", en Esquivel, Juan Cruz y Vaggione, Juan Marco (comps.), Permeabilidades activas. Religión, politica y sexualidad en la Argentina democrática, Buenos Aires, Biblos, 2015. 
Esta obra forma parte del acervo de la Biblioteca Jurídica Virtual del Instituto de Investigaciones Jurídicas de la UNAM

Lejos de pensarse como contradicciones, interesa analizar las tensiones y distensiones que se generan en los procesos de negociación entre una normativa, su traducción en una política pública y el arraigo de una cultura política por parte de los cuadros gerenciales del Estado, encargados de ejecutar las políticas estatales.

La particularidad de este escenario, en tiempos de democracia, revitaliza la interrogante sobre el papel de lo religioso y sobre cómo se conjuga la participación pública de sus agentes e instituciones con los procesos de ampliación de derechos ciudadanos.

\section{BIBLIOGRAFÍA}

ASAD, Talal, The Formations of the Secular, Stanford, Stanford University Press, 2003.

BAubéROT, Jean, Les laicités dans le monde, París, PUF, 2007.

y MiLOT, Micheline, Laicités sans frontières, París, Seuil, 2011.

Berger, Peter, The Sacred Canopy: Elements of a Sociological Theory of Religion, Nueva York, Ancher Books, 1967.

, The Desecularization of the World, Washington, D. C., Ethics and Public Policy Center, 1999.

, "Further thoughts on Religion and Modernity", Society, Estados Unidos, vol. 49, issue 4, 2012.

BLANCARTE, Roberto, Los retos de la laicidady la secularización en el mundo contemporáneo, México, El Colegio de México, 2008.

, “CCómo podemos medir la laicidad?”, Estudios Sociológicos, México, vol. XXX, núm. 88, 2012.

Casanova, José, Public Religions in the Modern Word, Chicago, University of Chicago Press, 1994.

-, "Religions, Secularizations, Modernities", European fournal of Sociology, Gran Bretaña, vol. 52, 2011.

, "Religion, Politics and Gender Equity: Public Religion Revisited", en Casanova, José y Phillips, Anne, A Debate on the Public Role of Religion and its Social and Gender Implications, Ginebra, UNRISD-Heinrich Boll Stiftung, 2009, Gender and Development Paper, núm. 5.

EsQuivel, Juan Cruz, Detrás de los muros. La Iglesia católica en tiempos de Alfonsin y Menem (1983-1999), Bernal, Editorial de la Universidad de Quilmes, 2004. 
Esta obra forma parte del acervo de la Biblioteca Jurídica Virtual del Instituto de Investigaciones Jurídicas de la UNAM

, "Laicidad, secularización y cultura política: las encrucijadas de las políticas públicas en Argentina", Revista Laicidad y Libertades. Escritos jurídicos, Madrid, vol. I, núm. 8, 2008.

, "Religión y política. La influencia religiosa sobre las definiciones parlamentarias en materia de derechos sexuales y reproductivos", en EsQuivel, Juan Cruz y Vaggione, Juan Marco (comps.), Permeabilidades activas. Religión, politica y sexualidad en la Argentina democrática, Buenos Aires, Biblos, 2015.

MALLIMACI, Fortunato, "El catolicismo argentino de Bergoglio y el papado de Francisco. Una primera aproximación desde la Argentina", Revista Sociedady Religión, Buenos Aires, núm. 40, 2013.

Michel, Patrick y PACE, Enzo, "Religion and Politics", Annual Review of the Sociology of Religion, Inglaterra, núm. 2, VII-XIII, 2011.

Milot, Micheline, La laicidad, Madrid, CCS, 2009.

Montero, Paula, "Religião, laicidade e secularismo. Um debate contemporâneo à luz do caso brasileiro", Revista Cultura y Religión, Chile, vol. VII, núm. 2, 2013.

PeÑa-Ruiz, Henri, La emancipación laica. Filosofia de la laicidad, Madrid, Laberinto, 2001.

PORTIER, Phillipe, La régulation étatique du croire dans les pays de l'Europe de l'Ouest, Juiz de Fora, UFJF, 2012.

Poulat, Emile, Notre laicité publique, París, Berg International, 2003.

TAYLOR, Charles, A Secular Age, Cambridge, Harvard University, 2007. 
Esta obra forma parte del acervo de la Biblioteca Jurídica Virtual del Instituto de Investigaciones Jurídicas de la UNAM

\title{
LAICIDAD Y POLÍTICAS PÚBLICAS EN LA EUROPA ACTUAL: EL ROL ESTRATÉGICO DE LA ESFERA LOCAL
}

\section{Mar GRIERA*}

\begin{abstract}
SumARIO: I. Introducción. II. Antecedentes: los procesos históricos de separación Iglesia-Estado en Europa. III. Más allá de los modelos IglesiaEstado: la necesidad de otra mirada. IV. La adaptación de los modelos Iglesia-Estado: tiempos de transformación. V. La regulación religiosa desde la esfera local: un nuevo espacio estratégico. VI. La gestión de la diversidad religiosa a nivel local: principales desafíos. VII. Gobierno local y diversidad religiosa en Europa: ¿respuestas similares? VIII. ¿Qué quiere decir "acomodar" la diversidad religiosa? IX. Apuntes finales. X. Bibliografia.
\end{abstract}

\section{INTRODUCCIÓN}

La gestión de la diversidad cultural y religiosa ha emergido como un área clave para la gobernanza de las sociedades europeas en este inicio de siglo $\mathrm{XXI} .{ }^{1} \mathrm{El}$ incremento de las migraciones internacionales ha potenciado la diversificación religiosa del continente y ha provocado una mayor visibilización de las minorías religiosas en la esfera pública. ${ }^{2}$ En este contexto, el crecimiento del islam ha atraído una importante atención académica. ${ }^{3}$ Sin

* ISOR-Investigaciones en sociología de la religión, Universidad Autónoma de Barcelona.

1 Beckford, J. A., "The Management of Religious Diversity in England and Wales with Special Reference to Prison Chaplaincy. The Public Management of Religious Diversity", International Fournal on Multicultural Societies, vol. 1, núm. 2, 1999, pp. 55 y 66.

2 Bastian, J. P. y Messner, F., Minorités religieuses dans l'espace européen: Approches sociologiques et juridiques, París, Presses Universitaires de France, 2007; y Casanova, J., "Immigration and the New Religious Pluralism: A European Union/United States Comparison", en Banchoff, T. (ed.), Democracy and the New Religious Pluralism, Nueva York, Oxford University Press, 2007.

3 Maussen, M., The Governance of Islam in Western Europe: A state of the art report. IMES, Institute for Migration and Ethnic Studies, University of Amsterdam, 2006, disponible en: http:// imiscoe.socsci.uva.nl/publications/workingpapers/documents/GovernanceofIslam-stateoftheart_000.pdf; 
Esta obra forma parte del acervo de la Biblioteca Jurídica Virtual del Instituto de Investigaciones Jurídicas de la UNAM

embargo, los nuevos retos no se restringen sólo a la acomodación de las comunidades musulmanas. Iglesias pentecostales, grupos hinduistas, salones del reino de los testigos de Jehová o comunidades ortodoxas son algunas de las entidades religiosas, entre muchas otras, que en pocos años han adquirido una presencia significativa en las ciudades europeas y han otorgado un nuevo impulso a la necesidad de repensar el encaje de la religión en la sociedad contemporánea.

En la introducción de uno de los primeros libros dedicados específicamente a las políticas públicas en materia de diversidad religiosa, Pauline Côté y Jeremy Gunn afirman: "Desarrollo impensable hace unos años, la cuestión religiosa ha sido incorporada en la agenda pública de los gobiernos occidentales y se mantiene". ${ }^{4}$ La creciente movilización de las identidades religiosas en la esfera global ${ }^{5}$ contribuye aún más a afianzar la prominencia de las cuestiones religiosas en la agenda política de los gobiernos europeos. ${ }^{6}$

No obstante, y como el sociólogo británico James Beckford ha puesto de relieve, la gestión de la diversidad religiosa no es un ámbito exento de problemas ni de tensiones, sino, más bien, un campo de fuertes batallas políticas e ideológicas. ${ }^{7}$ Hoy en día no existe un consenso sobre cómo deben afrontarse los retos que genera la diversidad religiosa, qué mecanismos de gestión deben establecerse y desde qué perspectiva de gobierno se debe enmarcar. En cierto modo, esta doble propiedad de la gestión de la diversidad religiosa en las sociedades contemporáneas (ser percibido como un tema clave y, también, un espacio de polémica) favorece la irrupción de la cuestión religiosa en la agenda política. A estas dificultades se añade lo que al-

Laurence, J., "Managing Transnational Islam: Muslims and the State in Western Europe", en Parsons C. y Smeeding, T., Immigration and the Transformation of Europe, Cambridge, Cambridge University Press, 2006, pp. 251-273; Burchardt, M. y Michalowski, I., After Integration: Islam, Conviviality and Contentious Politics in Europe, Berlín, Springer, 2015, disponible en: http:// link.springer.com/chapter/10.1007/978-3-658-02594-6_1.

4 Côté, P. y Gunn, J., La nouvelle question religieuse: régulation ou ingérence de l'État?/The New Religious Question: State Regulation or State Interference, Bruselas, PIE, Peter Lang, 2006.

Berger, P., The Desecularization of the World. Resurgent Religion and World Politics, Washington, D. C., Ethics and Public Policy Center, William B. Eerdmans Publishing Company, 1999.

6 Hackett, R. I. J., "Rethinking the Role of Religion in the Public Sphere: Local and Global Perspectives", en Ostien P. y Nasir, J. (eds.), Comparative Perspectives on Shari'ah in Nigeria, Ibadan Spectrum, 2005, p. 79; Casanova, J., "The Problem of Religion and the Anxieties of European Secular Democracy”, en Motzkin, G. y Fischer, Y. (eds.), Religion and Democracy in Contemporary Europe, Londres, Alliance Publishing Trust, 2008.

7 Beckford, J. y Gilliat-Ray, S., Religion in Prison: Equal Rites in a Multi-Faith Society, Cambridge, Cambridge University Press, 1998. 
gunos han llamado el "analfabetismo religioso"8 de las autoridades políticas y los funcionarios de gobierno entorno a la diversidad religiosa.

El ámbito local es identificado en toda Europa como el contexto en el que la necesidad de definir nuevos modelos de acomodación de la diversidad religiosa es más visible y acuciante. Tres razones atribuyen al ámbito local esta prominencia estratégica: en primer lugar, las autoridades locales son los interlocutores políticos más próximos de las comunidades religiosas, y, por tanto, se convierten en los primeros receptores de las demandas y reivindicaciones de las minorías religiosas. En segundo lugar, es en el espacio local donde, en primera instancia, emergen y se producen las controversias y/o conflictos relacionados con la diversidad religiosa; algo que, por tanto, otorga un papel central a las autoridades locales en la construcción de la cohesión social y en el fomento de la buena convivencia. En tercer lugar, es en el nivel local donde los grandes principios sobre la "laicidad", la "aconfesionalidad" o la "libertad religiosa" deben traducirse en acciones políticas concretas, coherentes y útiles. De este modo, y si bien en la mayoría de países europeos las competencias principales en materia de diversidad religiosa radican en la esfera estatal y/o regional, los procesos de implementación y la gestión cotidiana recaen, en buena medida, en las autoridades locales. Es por este motivo que explorar cómo y de qué manera varios gobiernos locales europeos se enfrentan a los retos crecientes en esta área es relevante. Así, conocer los desafíos con los que se encuentran las administraciones locales y dirimir cuáles son las respuestas que ofrecen al nuevo escenario plural, puede ser un buen punto de partida para seguir pensando y reflexionando sobre esta área de interés.

Sin embargo, es pertinente tener en cuenta que la gestión política de la religión no es un área de gobierno nueva o de reciente creación. Es importante no olvidar que la negociación sobre el rol de las Iglesias tradicionales en los diferentes países europeos es central en la historia de los gobiernos occidentales a lo largo de los siglos XIX y XX. Además, la separación de la Iglesia y el Estado fue acompañada de la emergencia de una serie de leyes, políticas públicas y acciones políticas encaminadas a regular y normativizar la relación entre las organizaciones religiosas y el Estado. Todo este bagaje histórico constituye la matriz a partir de la que actualmente se produce la acomodación de las minorías religiosas en el

8 Bramadat, P., "Religious Diversity and International Migration: National and Global Dimension", en Koenig, M. y Bramadat, P. (eds.), International Migration and the Governance of Religious Diversity, Kingston, School of Policy Studies, Queen's University, 2008; Dinham, A. y Francis, M., Religious Literacy in Policy and Practice, Bristol, Policy Press, 2015. 
Esta obra forma parte del acervo de la Biblioteca Jurídica Virtual del Instituto de Investigaciones Jurídicas de la UNAM

continente europeo. ${ }^{9}$ Comprender cómo se producen los procesos de separación Iglesia-Estado y analizar la cristalización de estos procesos en los sistemas políticos occidentales es algo crucial para a posteriori poder comprender los desafíos y las formas de gestión de la diversidad religiosa a nivel local.

Es por este motivo que en el presente artículo empezaré mostrando los procesos históricos de separación Iglesia-Estado y analizaré las transformaciones y los cambios más relevantes que los modelos de regulación IglesiaEstado sufren en la actualidad. Es importante comprender cómo el modelo Iglesia-Estado se adapta a un proceso de pluralización religiosa creciente y a los desafíos emergentes en este ámbito. A posteriori, el artículo se focalizará propiamente en el ámbito local y desgranaré los retos principales que emergen en la gestión local de la diversidad religiosa, así como los dilemas asociados a esta cuestión.

La presentación se basa en una investigación que se realizó entre el 2008 y el 2012 sobre la gestión local de la diversidad religiosa en Europa financiada por el Centro por la Innovación Local de la Diputación de Barcelona y publicada en catalán en el libro Diversidad religiosa y ámbito local: una mirada a Europa (2011). ${ }^{10}$ En una primera fase se realizó trabajo de campo en cinco ciudades europeas: Marsella, Turín, Birmingham, Barcelona y Ámsterdam. ${ }^{11}$ En una segunda fase se realizó un estudio en profundidad de los municipios localizados en Cataluña a través de una encuesta cuantitativa y de un abordaje cualitativo en tres ciudades (Badalona, Vic, Manresa). ${ }^{12}$

9 Davie, G., Religion in Modern Europe: A Memory Mutate, Nueva York, Oxford University Press, 2000.

10 Griera, M., Diversitat Religiosa i Món Local: Una mirada a Europa, Barcelona, Diputació de Barcelona, 2011. El texto que aquí se presenta está extraído de una parte de este libro y se han adaptado algunas de las cuestiones que contiene.

11 En esta primera fase, el trabajo de campo fue realizado conjuntamente con Maria Forteza y Gemma Ponsa. Un resumen del proyecto fue publicado en Griera, M. y Forteza, M., "New Acts in the Governance of Religious Diversity in European Cities: the Role of Interfaith Platforms", en Haynes, J. y Henning A., Religious Actors in the Public Sphere: Means, Objectives \&' Effects, Oxon, Routledge, 2011 ; y Griera, M., "Public Policies, Interfaith Associations and Religious Minorities: a New Policy Paradigm?, Evidence from the case of Barcelona”, Social Compass, Países Bajos, vol. 59, núm. 4, 2012, pp. 570-587.

12 Esta segunda fase el trabajo fue realizada conjuntamente con Julia Martínez-Ariño y Gloria García-Romeral. Además, contó con la colaboración de la Fundación Pi i Suñer (Barcelona), y se publicó también en Sanchez Griñó J. M. y Serratussell Mirço, G., "La gestió del pluralisme religiós als municipis catalans", Revista Catalana de Sociologia, España, vol. 29, núm. 44, 2013. 
Esta obra forma parte del acervo de la Biblioteca Jurídica Virtual del Instituto de Investigaciones Jurídicas de la UNAM

\section{ANTECEDENTES: LOS PROCESOS HISTÓRICOS DE SEPARACIÓN IGLESIA-ESTADO EN EUROPA}

Las formas actuales de gestión de la diversidad religiosa son, en gran parte, deudoras del modelo Iglesia-Estado configurado históricamente en cada país; un modelo Iglesia-Estado que responde a una trayectoria histórica específica, constituida a partir de luchas particulares y elementos contextuales. Hoy en día, los modelos de relación Iglesia-Estado tienden hacia una cierta convergencia a nivel europeo, ${ }^{13}$ pero aún existen una gran variedad de modelos de regulación. Para entender cómo se ha producido el proceso de separación Iglesia-Estado a nivel europeo y detectar cuáles son los elementos más significativos que explican las diferencias principales entre los países, es útil tener en cuenta las investigaciones de la socióloga Françoise Champion en la materia. ${ }^{14}$

Esta socióloga pone de manifiesto que existe una diferencia clave en el proceso de separación Iglesia-Estado entre los países de tradición mayoritaria católica y los de tradición protestante. En términos generales, en los primeros, la separación fue el resultado de una lucha acérrima entre los partidarios de la Iglesia católica y sus detractores; esta separación se construyó a partir de un proceso violento, conflictivo y que se alarga mucho en el tiempo. Por el contrario, en los países de tradición protestante, la separación Iglesia-Estado no implicó ni la violencia ni las tensiones de los países de tradición católica. Ha sido un proceso más moderado, menos agresivo y más pausado. En cierto modo, como indica Champion, en los países de tradición protestante la Iglesia se secularizó paralelamente a la secularización de la sociedad y en ningún caso se ha producido una ruptura total entre las fuerzas secularizadoras y las religiosas. ${ }^{15}$

Esta diferencia es la que explica el hecho de que en los países de tradición protestante, aún hoy, la Iglesia cuenta con mayor reconocimiento y un estatus legal más ventajoso que en los países de mayoría católica. En este sentido, conviene recordar que en los países de tradición católica, como Irlanda o Francia, la separación entre las instituciones religiosas

13 Koenig, M., "Europeanising the Governance of Religious Diversity: An Institutionalist Account of Muslim Struggles for Public Recognition", Fournal of Ethnic and Migration Studies, Gran Bretaña, vol. 33, núm. 6, pp. 911 - 193, 2007.

14 Champion, F., "Laïcités européennes: de l'hétérogenéité à la convergence", Migrations Societé, París, núm. 16, vol. 96, 2004, pp. 43-60.

15 En este sentido, véase también Martin, D., On Secularization: Towards a Revised General theory, Londres, Ashgate Publishing, Ltd., 2005; Baubérot, J., Laïcité 1905-2005, entre passion et raison, París, Seuil, 2004. 
Esta obra forma parte del acervo de la Biblioteca Jurídica Virtual del Instituto de Investigaciones Jurídicas de la UNAM

y el poder político es más marcado. En cambio, en países de tradición protestante, como el Reino Unido, Dinamarca o Finlandia, las Iglesias tradicionales gozan de un estatus más privilegiado. ${ }^{16}$ Además, como expone la socióloga británica Grace Davie ${ }^{17}$ en países como Noruega o el Reino Unido la Iglesia oficial es percibida para la mayoría de la población como una institución pública más, es decir, una especie de anexo a la administración, ${ }^{18}$ que disfruta de altos niveles de reconocimiento y prestigio entre la sociedad.

En cierto modo, la mayor o menor virulencia del proceso de separación Iglesia-Estado ayuda a explicar la posición política y social actual de las instituciones religiosas en los diferentes países. Es también este bagaje lo que ayuda a comprender por qué, según Champion, la acomodación de las minorías religiosas ha sido más sencilla en aquellos países de tradición protestante. ${ }^{19}$ Estos son países donde no existía una gran desconfianza y recelo inicial hacia las minorías religiosas y donde los mecanismos de relación Iglesia-Estado otorgan mayores privilegios a las Iglesias - unos privilegios que, en determinadas ocasiones, se han hecho extensivos a las nuevas minorías religiosas-. Beckford pone de manifiesto que en Gran Bretaña el hecho de que la Iglesia (anglicana) cuente con una posición públicamente legitimada le ha permitido jugar un rol activo en la acomodación de las minorías religiosas. ${ }^{20}$ Es más, según este sociólogo británico, en numerosas ocasiones la Iglesia ha actuado como mediadora (bróker) entre las minorías religiosas y el gobierno británico, favoreciendo el reconocimiento de las minorías religiosas y su inclusión en las instituciones públicas y en la sociedad británica. ${ }^{21}$

16 En este contexto, el caso español es algo excepcional, ya que el hecho de que la separación se produzca mucho más tardíamente y con una Iglesia postconciliar (Vaticano II) hace que las características del acuerdo no sean tan radicales - y más positivas para la Iglesia católica - a diferencia de otros países católicos. Véase Llamazares Fernandez, D., "Poder político y poder religiosos: claves, cauces y modelos de relación. Acuerdos Iglesia-Estado", Laicidad y Libertades, España, núm. 3, 2003.

17 Davie, G., op. cit.

18 En este sentido, a propósito del caso danés, Champion expone que "La iglesia está realmente «dentro» del Estado, es como una especie de servicio administrativo: los pastores, y los obispos, son considerados funcionarios y las condiciones (laborales y de sueldo) están equiparadas con las del resto del funcionariado". Champion, F., op. cit.

19 Idem.

20 Beckford, J. A., op. cit.

21 Beckford, J. y Giliat-Ray, S., Religion in Prison: Equal Rites in a Multi-Faith Society, Cambridge, Cambridge University Press, 1998. 
Esta obra forma parte del acervo de la Biblioteca Jurídica Virtual del Instituto de Investigaciones Jurídicas de la UNAM

\section{MÁS ALLÁ DE LOS MODELOS IGLESIA-ESTADO:} LA NEGESIDAD DE OTRA MIRADA

Tradicionalmente los diferentes modelos de relación Iglesia-Estado se han clasificado en función del régimen constitucional que regula la relación entre la Iglesia y el Estado. Por ello, generalmente, se han clasificado los países en tres grandes modelos:

- Los que tienen un régimen de separación estricta entre la Iglesia y el Estado, como Francia, Irlanda o México.

- Los que tienen regímenes de cooperación selectiva con las organizaciones religiosas reconocidas como España, Italia o Bélgica.

- Los que tienen un modelo de Iglesia "nacional" o lo que se conoce como establishment (Inglaterra, Grecia y países Nórdicos). ${ }^{22}$

Ahora bien, según el italiano Silvio Ferrari, hoy esta clasificación está "cultural y legalmente obsoleta". ${ }^{23}$ Las limitaciones principales que tiene esta categorización son las que se mencionan a continuación. En primer lugar, es una clasificación poco útil porque se asimilan modelos que más allá del régimen constitucional tienen pocas cosas en común. Es decir, a pesar de que a partir de los arreglos constitucionales Inglaterra y Dinamarca sean clasificadas en la misma categoría, en la puesta en marcha de estos modelos existen numerosas diferencias que ponen de manifiesto la distancia existente entre ambos países. Además, la definición legal del modelo de relación Iglesia-Estado no siempre nos informa sobre cuál es el rol que se atribuye a la institución religiosa en el devenir de la sociedad y del país. Así, por ejemplo, es pertinente enfatizar el hecho de que no

22 Una clasificación similar pero ligeramente diferente es la que propone Bader a partir del análisis de los arreglos constitucionales. Según Bader, podemos distinguir entre los países que tienen una Iglesia constitucionalmente establecida (constitutional establishment) como Gran Bretaña o Grecia, y los países que no tienen ninguna Iglesia establecida como Francia, Irlanda o España. Ahora bien, entre los países con una Iglesia constitucionalmente establecida podemos distinguir entre un establishment fuerte o débil. Se reconocen como países con un fuerte establishment, a Grecia o Serbia, y países con un establishment más débil, a Gran Bretaña, Noruega, Dinamarca y Escocia. Es decir, estos últimos son aquellos que combinan la existencia de una Iglesia establecida constitucionalmente con cierta institucionalización del pluralismo religioso y mecanismos de cooperación selectiva con las minorías religiosas; véase Bader, V., Secularism or Democracy? Associational Governance of Religious Diversity, Amsterdam, Amsterdam University Press, 2007.

23 Ferrari, A., "France and Greece: Two Approaches to Religious Pluralism", Law and Fustice-The Christian Law Review, Londres, vol. 152, núm. 27, 2004, p. 6. 
Esta obra forma parte del acervo de la Biblioteca Jurídica Virtual del Instituto de Investigaciones Jurídicas de la UNAM

tiene por qué ser contradictoria la existencia de un régimen estricto de separación Iglesia-Estado o de un régimen de cooperación con el hecho de contar con una Iglesia mayoritaria con un rol simbólico fuerte a la hora de estructurar los debates de la nación, de proyectar su voz públicamente o de tener influencia más allá de los mecanismos legales establecidos. En este sentido, Grace Davie ${ }^{24}$ pone de manifiesto que, a pesar de que Irlanda es considerada como un país con un régimen estricto de separación entre la Iglesia y el Estado, la Iglesia católica continúa jugando un rol clave en el territorio. ${ }^{25}$

En segundo lugar, es también conflictivo ponerse de acuerdo sobre qué se entiende por cooperación selectiva. Así, a pesar de que teóricamente sólo unos pocos países cuentan con un régimen constitucional de cooperación selectiva, actualmente la mayoría de países europeos cuentan con mecanismos más o menos explícitos de cooperación con las Iglesias y las religiones reconocidas. Y es que, independientemente del modelo de Iglesia-Estado imperante en cada país, en todos los países europeos el Estado trata y toma en consideración las organizaciones religiosas de manera más favorable que a las organizaciones no religiosas. En esta línea, el filósofo Veit Bader afirma que "Todos los Estados occidentales... tratan las religiones favorablemente comparado a la mayoría de organizaciones no religiosas; las exime de tener una estructura democrática interna, de la aplicación de la legislación laboral y convenios colectivos, y de la igualdad de trato y no discriminación de las leyes". ${ }^{26}$ Por lo tanto, aunque sea implícitamente, en todos los Estados europeos existe una cierta cooperación con las organizaciones religiosas e "incluso los sistemas laicos (especialmente Francia y Estados Unidos) son menos laicistas de lo que sus ideólogos asumen". ${ }^{27}$ Es decir, que incluso en los países que afirman tener una separación estricta entre Estado y religión existe un cierto nivel de cooperación entre Estado e Iglesias. En este sentido, el caso francés resulta paradigmático en el análisis de las contradicciones existentes entre lo que dicta el régimen constitucional y lo que efectivamente se lleva a cabo desde las instituciones de gobierno. En esta línea, el sociólogo Raphaël Liogier en su libro France et ses religiones d'état afirma que si bien constitucionalmente existe una separación Iglesia-Estado y la laicidad es la ideología que reafirma y legitima esta separación, en la práctica el gobierno

24 Davie, G., op. cit.

25 En este sentido, “...La República de Irlanda es técnicamente un Estado laico, a pesar de ello el preámbulo de su Constitución es muy católico y... la práctica católica sigue siendo inusualmente alta en comparación con la media europea", ibidem, p. 18.

26 Bader, V., op. cit., p. 57.

27 Ibidem, p. 56. 
francés adopta una política altamente intervencionista en la gestión de la cuestión religiosa en Francia. ${ }^{28}$

En tercer lugar, se pone de manifiesto que más allá de los mecanismos constitucionales que regulan la relación Iglesia-Estado hay muchos otros elementos que entran en juego a la hora de gestionar la diversidad religiosa. Veit Bader afirma que los Estados disponen de muchas otras herramientas (más allá de las leyes) para poder intervenir en el campo religioso: pueden utilizar la financiación como una vía de control o regulación, pueden obligar a las minorías a crear estructuras de representación vertical, pueden legitimar unos grupos y desacreditar a otros, etcétera. ${ }^{29}$ De este modo, al analizar la gestión de la religión en un territorio y entender las complejidades imbricadas es importante ir más allá de las normas legales y constitucionales. Y es que, además, la mera descripción de los regímenes de regulación de las relaciones Iglesia-Estado no nos explica cómo se producen los procesos de implementación y de interpretación del marco legal.

\section{LA ADAPTACIÓN DE LOS MODELOS IGLESIA-ESTADO: TIEMPOS DE TRANSFORMACIÓN}

Actualmente los regímenes de relación Iglesia-Estado se encuentran en proceso de reconfiguración y readaptación en toda Europa. Por un lado, el hecho de que las Iglesias cristianas históricamente mayoritarias vayan perdiendo relevancia en el seno de las sociedades europeas obliga a reestructurar el peso que el Estado les otorga. Por otra parte, el crecimiento de la diversidad religiosa implica y fuerza a los Estados a buscar mecanismos para favorecer el reconocimiento y facilitar la gestión pública de estas otras religiones. Finalmente, la creciente relevancia de las instituciones europeas e internacionales en la gestión de la diversidad religiosa favorece un proceso de convergencia entre los diferentes sistemas europeos. Analizaremos brevemente estas tres cuestiones.

Por un lado, la secularización de las sociedades europeas ha conllevado a que la mayoría de Iglesias históricas pierdan fieles y se vean disminuidas en su relevancia social. Ante este hecho, han sido numerosos los partidos políticos y otras plataformas de la sociedad civil que han cuestionado públicamente la posición privilegiada que ostentan estas Iglesias en la mayoría de países europeos. Así, el estatus de las Iglesias mayoritarias (y, especial-

28 Liogier, R., Une lä̈cité “legitime”. La France et ses religions dÉtat, París, Médicis-Entrelacs, 2006 .

29 Bader, V., op. cit. 
Esta obra forma parte del acervo de la Biblioteca Jurídica Virtual del Instituto de Investigaciones Jurídicas de la UNAM

mente, la financiación que reciben por parte del Estado) ha sido objeto de polémicas en la esfera pública y, en algunos casos, se han creado comisiones de investigación, debates parlamentarios y, finalmente, modificación de los Acuerdos entre la Iglesia y el Estado. ${ }^{30}$ En cierto modo lo que en toda Europa se ponen en duda es la legitimidad de las Iglesias para seguir manteniendo unos privilegios que fueron acordados en un tiempo en que gozaban de un apoyo social mucho más amplio.

Por otro lado, debemos tener en cuenta que, tal y como pone de manifiesto Grace Davie, "las Iglesias históricas están perdiendo relevancia en el mismo momento en que están llegando numerosos grupos religiosos de otras regiones". ${ }^{31}$ Son varios los autores que argumentan y explican que los modelos de relación Iglesia-Estado se han (y están) acomodando para adaptarse a la nueva realidad plural de Europa. Un ejemplo paradigmático es el relato que hace Davie de la polémica en torno a la representación de las organizaciones religiosas en la segunda cámara del parlamento británico. La llamada House of Lords cuenta con una serie de miembros que son no electos; entre ellos, 26 obispos. A finales de la década de los noventa, en el proceso de reforma de la cámara, se abrió un fuerte debate sobre la continuidad de los obispos en la cámara. Los argumentos contrarios a la representación eran aquellos que alegaban que en una sociedad democrática y moderna este sistema de representación no tenía ninguna razón de ser. Sin embargo, la posición mayoritaria fue aquella que alegó que Gran Bretaña se había convertido en una sociedad plural y que, por tanto, la House of Lords también tenía que hacerse eco de esta nueva realidad. Es decir, no se ponía en cuestión el hecho de que los obispos formaran parte de la Cámara, sino que lo que se reclamaba era que no fueran los únicos representantes religiosos que participaban en ella. En cierto modo, si tradicionalmente las disputas públicas habían sido forjadas alrededor del eje religión versus laicidad, parece que en esta última discusión el eje se traslada hacia el binomio Iglesia mayoritaria versus pluralismo. Los obispos anglicanos, además, se mostraron partidarios de incluir otras organizaciones religiosas en el seno de la segunda cámara del parlamento. Episodios como el descrito por Davie se están produciendo en toda Europa y a raíz de estos acontecimientos los

30 En este sentido, por ejemplo, véase el caso de Dinamarca, que en 1994 creó una comisión parlamentaria encargada de examinar los vínculos de la Iglesia y el Estado (sobre todo en materia económica) y para incorporar las minorías religiosas en los Acuerdos. En 2000 entró en vigor la nueva ley que regula la situación de la Iglesia y de las minorías. Davie, op. cit., p. 40). En Suecia ha pasado algo parecido, y el 5 de marzo de 1998 se aprobó una nueva ley que regulaba el rol de la religión, la cual entró en vigor el lo. de enero de 2000.

31 Idem. 
Esta obra forma parte del acervo de la Biblioteca Jurídica Virtual del Instituto de Investigaciones Jurídicas de la UNAM

gobiernos se ven obligados a replantear los modelos de gestión de la diversidad religiosa y repensar cómo y de qué manera se otorgan nuevos derechos a las minorías.

Finalmente, son varios los autores que contribuyen a destacar la importancia creciente de la Unión Europea en la regulación de la religión a nivel estatal y el avance hacia una cierta convergencia. ${ }^{32}$ El jurista italiano Silvio Ferrari explica que el proceso de convergencia europeo se produce a partir de tres grandes características compartidas, con mayor o menor medida, por todos los países y afianzadas por la normativa de la Unión Europea y el derecho internacional: a) el derecho a la libertad religiosa, b) la incompetencia religiosa del Estado y la autonomía de los grupos religiosos y c) la cooperación selectiva de los Estados con los grupos religiosos. ${ }^{33}$

No obstante, y como pone de manifiesto Gérard González "En la legislación de la Unión Europea... la cuestión religiosa sigue siendo marginal". Es decir, la cuestión religiosa no se ha convertido en objeto de políticas activas ni de grandes declaraciones de principios. ${ }^{34}$ Sin embargo, los pocos espacios donde la cuestión religiosa es contemplada - y donde se ponen de manifiesto los derechos anteriormente mencionados- se han convertido en un recurso clave para las minorías religiosas a la hora de defender sus derechos. Nos referimos, sobre todo, a la existencia del Tribunal Europeo de los Derechos Humanos, que en los últimos tiempos ha ido creando una jurisprudencia que hoy configura el corpus normativo europeo en la materia. Un corpus normativo que, en general, protege a las minorías religiosas de los abusos y/o de la arbitrariedad de los Estados en la materia.

Según Koenig, la institucionalización de los derechos religiosos a través de organismos europeos es la que encamina los Estados hacia la convergencia en esta materia. Así, de acuerdo con el sociólogo alemán, se produce un "isomorfismo institucional" influenciado por la transnacionalización del

\section{Koenig, M. op. cit.}

33 Ferrari, S., op. cit., p. 7. Willaime añade un último inciso, que se refiere al derecho a disidencia y el pensamiento crítico. Willaime, J. P., "État, pluralisme et religion en France", en Baubérot, J., Pluralisme et minorités religieuses, Actas del coloquio CNRS-EPHE, LouvainParís, Peeters, 1991.

34 No obstante, la religión ha sido objeto de polémica en el seno de la Unión Europea, sobre todo para la discusión a raíz del preámbulo de la Constitución Europea. Asimismo, ha sido objeto de debate y se han creado grupos de reflexión sobre el tema, como el impulsado por Jaques Delors "Une âme pour l'Europe"; véase Schlesinger, P. y Foret, F., "Political Roof and Sacred Canopy?: Religion and the EU Constitution", European Fournal of Social Theory, Gran Bretaña, vol. 9, núm. 1, 2006. Sin embargo, no se ha desarrollado una política activa en la materia desde la Unión Europea. 
derecho que conduce a una disminución de las diferencias entre los modelos de gestión de cada país. En este sentido, Koenig, afirma que el hecho de que los grupos religiosos cuenten con la posibilidad de recurrir al Tribunal Europeo de los Derechos Humanos para reclamar sus derechos obliga a los Estados a adecuar sus órganos reguladores y armonizarlos a escala europea.

Sea como sea, lo que está claro es que en los últimos años la diversidad religiosa ha adquirido mayor visibilidad en la agenda política de los gobiernos europeos y que los antiguos mecanismos de gestión de las relaciones Iglesia-Estado están en proceso de redefinición. En esta línea Silvio Ferrari afirma que “...Los sistemas tradicionales de relaciones entre los Estados y las religiones ya no funcionan bien y, después de un periodo de relativa estabilidad, han entrado en una fase de transición. La fuerza de este cambio es bastante clara, pero es difícil ser preciso sobre los resultados concretos que conllevará". ${ }^{35}$

\section{LA REGULACIÓN RELIGIOSA DESDE LA ESFERA LOGAL: UN NUEVO ESPAGIO ESTRATÉGICO}

Frente a la pérdida de centralidad de los Estados en la regulación de la religión, son muchos los sociólogos y politólogos que otorgan un papel protagonista a las autoridades locales en la gestión de la diversidad religiosa en Europa en el siglo XXI. En cierto modo, tal y como la socióloga belga Corinne Torrekens afirma, "el mundo local es el gran protagonista en tiempos de globalización de los fenómenos sociales: para hacer frente a la pérdida de funcionalidad y eficiencia del Estado-nación, son las autoridades locales las primeras que han empujado una tarea pragmática de gestión del pluralismo religioso". ${ }^{36} \mathrm{Y}$ es que, como se ha mencionado anteriormente, son las autoridades locales las que en último término se encuentran confrontadas con la necesidad de dar respuesta a las demandas de las comunidades religiosas - las cuales dirigen sus reivindicaciones, inicialmente, en el espacio local- Asimismo, es en el ámbito municipal donde los "grandes principios" sobre el rol de la religión en la sociedad deben traducirse en acciones políticas concretas y exitosas.

A todo esto, además, hay que sumar el hecho de que la gestión de la diversidad religiosa es todavía un campo lleno de incertidumbres y con pocas "recetas de éxito" consolidadas; algo que mientras acentúa el rol clave del

35 Ferrari, S., op. cit., p. 103.

36 Torrekens, C., "Le pluralisme religieux en Belgique", Diversité Canadienne, Canadá, vol. 4, núm. 3, 2005. p. 12. 
Esta obra forma parte del acervo de la Biblioteca Jurídica Virtual del Instituto de Investigaciones Jurídicas de la UNAM

espacio local como laboratorio de experimentación e innovación, otorga mayor complejidad en la construcción de políticas públicas eficaces y consensuadas.

\section{LA GESTIÓN DE LA DIVERSIDAD RELIGIOSA A NIVEL LOCAL: PRINCIPALES DESAFÍOS}

El análisis de los retos que emergen a raíz del crecimiento de la diversidad religiosa nos muestra que existe una cierta homogeneidad en el tipo de problemáticas a las que los municipios europeos deben dar respuesta. La "diversificación" y la "intensificación" de la diversidad religiosa es un proceso paralelo en toda Europa; y pese a que podemos detectar diferencias considerables entre los municipios en función de la magnitud y la composición específica de tal diversidad, existe una cierta continuidad en relación al tipo de desafíos que este nuevo escenario genera en el mundo local europeo.

Unos retos que, en buena medida, se pueden agrupar en los siguientes tres grandes bloques: 1) la necesidad de hacer efectivos los derechos de las minorías religiosas; 2) la necesidad de construir un marco de convivencia inclusivo y laico, y 3) la cohesión social y la buena convivencia.

En primer lugar, se produce una multiplicación de las demandas de las minorías religiosas a las autoridades políticas. Unas demandas que, generalmente, se vinculan a la necesidad de hacer efectivos los derechos de libertad religiosa inscritos en el ordenamiento legal y jurídico. Nos referimos, entre otras, a cuestiones como el derecho a construir lugares de culto, la posibilidad de llevar a cabo los rituales funerarios según los preceptos religiosos o el derecho a disponer de alimentos kosher o halal en las escuelas y hospitales. Estas demandas no se formulan sólo en el ámbito local y las competencias para resolverlas no radican sólo en este nivel de gobierno, pero son las autoridades locales las que, en último término, deben diseñar políticas públicas específicas y/o implementar los programas políticos definidos en otras instancias gubernamentales.

Así, a pesar de que en casi todos los países son los Estados (o en determinados países los gobiernos regionales) quienes negocian con las minorías religiosas qué tipo de derechos les son atribuidos y cuáles son los grupos religiosos minoritarios que pueden acceder a estos, generalmente son los municipios los que tienen la última palabra en hacer verdaderamente efectivos estos derechos y en diseñar las formas de implementación. Es frecuente, además, que los Estados normativicen la definición de los derechos que les corresponden a las minorías - derecho a tener salas de velatorios pluriconfesionales, alimen- 
Esta obra forma parte del acervo de la Biblioteca Jurídica Virtual del Instituto de Investigaciones Jurídicas de la UNAM

tación kosher o halal en las escuelas, etcétera - pero que no estipulen concretamente cómo estos derechos deben ser llevados a la práctica.

En esta línea, por ejemplo, en 1992 el gobierno español firmó unos Acuerdos de cooperación, con rango de ley, con las comunidades judía, musulmana y protestante, donde se establecían y definían los derechos de estos grupos (festividades, cementerios, atención religiosa en hospitales y prisiones, etcétera). Sin embargo, paradójicamente, al aprobar los Acuerdos, no se elaboró un plan de implementación ni se dedicó una partida extraordinaria de financiación para llevarlos a la práctica. Incluso, a pesar de que muchas de las cuestiones estipuladas en los Acuerdos forman parte del ámbito competencial de las administraciones locales, numerosos ayuntamientos no tuvieron conocimiento de la existencia de dicho Acuerdos hasta bastante tiempo después de que fueron firmados. ${ }^{37}$

Han sido los ayuntamientos los que, cuando se han encontrado con demandas concretas de las comunidades, han tenido que buscar y pensar las estrategias para hacer efectivos estos derechos al tiempo que, en gran medida, han tenido que asumir el coste. Además, es necesario poner de manifiesto que, en la mayoría de ocasiones, estas demandas no tienen precedentes, ${ }^{38} \mathrm{y}$, por tanto, no existen referentes claros y explícitos a los que se pueda acudir. ${ }^{39}$

En segundo lugar, surge el reto de definir de qué manera se puede construir un marco de convivencia laico donde la existencia de una Iglesia históricamente dominante no implique un agravio comparativo y/o una ofensa para las minorías religiosas. La mayoría de países europeos históricamente han contado con una Iglesia mayoritaria que ha disfrutado de una posición de privilegio en la esfera pública en detrimento de las minorías religiosas. Sigue existiendo, además, lo que en otras ocasiones, utilizando la noción de Michael Billig de "nacionalismo banal", ${ }^{40}$ he definido como "cristianismo

37 Moreras, Jordi, "Limits and Contradictions in the Legal Recognition of Muslims in Spain”, en Shadid W. y Koningsveld, P. S. von (eds.), Religious Freedom and the Neutrality of the State: The Position of Islam in the European Union, Leiden, Peeters, 2002.

38 Esta cuestión, además, se acentúa por el hecho de que la mayoría de sistemas de gestión de la diversidad religiosa en los países europeos fueron diseñados mucho antes de la emergencia de estos nuevos grupos religiosos. En esta línea, el alcalde de la ciudad francesa de Mulhouse afirmó: "la mayoría de demandas religiosas eran inexistentes en Francia en 1905" (cuando se diseñó el sistema de laicidad francés); citado en Palard, J., "Introduction", en Skard, H. et al., Gods in the City. Intercultural and Inter-Religious Dialogue at Local Level, Estrasburgo, Local \& Regional, 2007. Lo que hace que, en muchas ocasiones, las autoridades locales cuenten con muy pocas guías de actuación frente esta nueva diversidad religiosa.

39 Ante la evidencia de las dificultades de la administración local respecto a estas cuestiones, España creó en 2011 el Observatorio del Pluralismo Religioso, que difunde buenas prácticas y se establece como órgano asesor de los ayuntamientos en esta materia.

40 Billig, M., Banal Nationalism, Londres, Sage Publications Ltd., 1995. 
banal". Billig sostiene que a pesar de que el nacionalismo suele estar vinculado públicamente a formas agresivas y ardientes de patriotismo, la forma más eficaz de reproducir la nación es aquella que se produce a través de gestos más sutiles y que generalmente pasan inadvertidos a la mayoría. En este sentido, nos dice: "La imagen metonímica del nacionalismo banal no es una bandera que se agita conscientemente con ferviente pasión; es la bandera que cuelga desapercibida en el edificio público". ${ }^{41}$

De forma similar, las Iglesias históricas en los países europeos reproducen su hegemonía integrados en la esfera de lo "normal" y de la reproducción de dinámicas cotidianas y gestos sutiles que son percibidos como banales o triviales para la población: la existencia de símbolos religiosos en el espacio público, la celebración de festividades religiosas, la invitación de actores religiosos a los actos públicos y otros muchos. Es por este motivo que definir concretamente qué rol debe tener la Iglesia mayoritaria y, también, las minorías religiosas en el espacio público e identificar qué significa y qué implica exactamente actuar desde la laicidad pero respetar la diversidad, es el tuétano de los debates actuales en torno a la diversidad religiosa.

Las autoridades locales se enfrentan hoy con la necesidad de construir un entorno inclusivo donde nadie se sienta excluido; al mismo tiempo, sin embargo, se encuentran con la dificultad de conjugar la tradición con los nuevos referentes y hacer compatible un pasado impregnado de tradiciones de raíz cristiana que hoy forman parte de la cultura popular común con un presente y un futuro que se define en plural.

Encontrar el equilibrio entre la discriminación y el absurdo de una neutralidad ficticia es el gran reto. Nos referimos a los debates sobre cuestiones tan dispares como la celebración de las festividades de origen religioso, la existencia de símbolos religiosos en el espacio público, el relato sobre la propia historia del municipio, la toma en consideración (o no) de los actores religiosos en la celebración de las efemérides y/o acontecimientos clave de la ciudad, la mayor/menor visibilización de las organizaciones religiosas en los medios de comunicación locales, etcétera.

Identificar qué prácticas pueden ser discriminatorias y evaluar qué cuestiones se deben replantear a la luz del nuevo escenario plural es una tarea acuciante y, a menudo compleja, que enfrentan las autoridades locales. Las respuestas de las autoridades locales europeas en la materia son muy diversas y no siguen un patrón común. En este sentido, mientras hay ayuntamientos como el de Berlín, que han prohibido la existencia de símbolos religiosos en los espacios públicos - especialmente en las escuelas-, hay

\footnotetext{
41 Ibidem, p. 8.
} 
Esta obra forma parte del acervo de la Biblioteca Jurídica Virtual del Instituto de Investigaciones Jurídicas de la UNAM

otros lugares como la región de Puglia, en Italia, donde han decidido considerar que los símbolos católicos son asumidos como parte de la tradición cultural de la zona y, por tanto, extraer las connotaciones religiosas y no identificarlos como discriminatorios con las minorías religiosas.

En algunas ciudades catalanas el tradicional pesebre navideño fue substituido por versiones laicas del mismo, mientras en otras la tradición continúa vigente y es impulsada desde los mismos ayuntamientos. Asimismo, se mezclan cuestiones relacionadas con la presencia y visibilidad de las nuevas confesiones religiosas en el espacio público y desde ahí emergen debates como los relacionados con el velo integral. ${ }^{42}$ Los retos son múltiples y el abanico de respuestas es muy amplio pero, en mayor o menor grado, todas las administraciones locales de Europa deben hacer frente a esta cuestión.

En tercer lugar, la necesidad de construir políticas públicas que logren asegurar la cohesión y la paz social es una cuestión urgente en todas partes. La emergencia de crisis de gobernabilidad vinculadas a cuestiones religiosas - como puede ser, por ejemplo, la crisis derivada de la publicación de las caricaturas de Mahoma - han puesto de relieve la importancia de tener en cuenta la variable religiosa como un factor clave en la construcción de la cohesión social.

También, por supuesto, las quejas vecinales por la construcción de lugares de culto ${ }^{43}$ otorgan un peso mayor a la necesidad de potenciar políticas públicas para fomentar la buena vecindad. En cierto modo, estas "crisis" han visibilizado la relevancia de contar con las herramientas adecuadas para prevenir y/o dar respuesta a los conflictos de esta índole. Cuestiones como la necesidad de construir una sociedad civil inclusiva, la necesidad de evitar la radicalización de las minorías religiosas o la importancia de fomentar una coexistencia respetuosa y tranquila forma parte de la agenda de los gobiernos locales.

Es relevante tener presente, además, que tal y como el sociólogo holandés Jan Rath pone de manifiesto, la incorporación en la agenda de estas cuestiones aparece inseparablemente vinculada a una creciente "sensación

42 Burchardt, op. cit; Moors, A. y Salih, R., "Muslim Women in Europe: Secular Normativities, Bodily Performances and Multiple Publics", Social Anthropology, Inglaterra, vol. 17, núm. 4, 2009, pp. 375-378, disponible en: http://doi.org/10.1111/j.1469-8676.2009.00090.x; Göle, N., "Islam in Public: New Visibilities and New Imaginaries", Public Culture, Estados Unidos, vol. 14, núm. 1, 2002, pp. 173-190.

43 Astor, A., "«Mezquita No!», The Origins of Mosque Oppositions in Spain”, GRITIM Working Paper Series, Barcelona, núm. 3, 2009; Maussen, M., "Mosques and Muslims in Marseilles", ISIM Review, Holanda, vol. 16, otoño, 2005. 
Esta obra forma parte del acervo de la Biblioteca Jurídica Virtual del Instituto de Investigaciones Jurídicas de la UNAM

de urgencia". ${ }^{44} \mathrm{El}$ miedo a que las cuestiones religiosas enciendan chispas de conflicto fomenta un sentimiento de angustia y urgencia entre las autoridades locales para poner en marcha estrategias que puedan evitar el estallido de crisis de gobernabilidad.

\section{GOBIERNO LOCAL Y DIVERSIDAD RELIGIOSA EN EUROPA: ¿RESPUESTAS SIMILARES?}

El análisis de las políticas locales con relación a la diversidad religiosa en Europa nos muestra que existen diferencias relevantes en la forma que las distintas administraciones locales abordan esta cuestión. Es decir, si los problemas a los que se enfrentan las autoridades locales tienen ciertas semejanzas, las respuestas específicas varían sustancialmente. Debemos tener en cuenta que, por un lado, hay diferencias notables en el nivel de competencias que tienen otorgados los municipios en esta área en los diferentes países europeos. ${ }^{45}$ Por otra parte, la distribución de la diversidad religiosa no es homogénea en todas las ciudades europeas ni en términos de cantidad ni en relación con el tipo de diversidad.

Ahora bien, no sólo es difícil hablar de convergencia a nivel europeo en materia de políticas locales sobre la diversidad religiosa, sino que, incluso, es complicado vislumbrar un patrón común entre los municipios de un mismo Estado. En este sentido, Bader pone de manifiesto que en relación con la gestión de la diversidad religiosa "realmente, hoy en día encontramos una amplia gama de políticas públicas y de acuerdos culturales, legales, administrativos diferentes e incluso, contradictorios dentro de un mismo Estado". ${ }^{46}$

Tanto los estudios de Rath et al., como los de Maussen en los Países Bajos en la comparación entre las políticas locales en materia de diversidad religiosa en Utrecht y Ámsterdam, como los estudios de Frégosi ${ }^{47}$ en la comparación entre dos ciudades de la región de Alsacia (Strasbourg y Mulhose)

44 Rath, J. et al., Western Europe and Its Islam, Leiden, Brill, 2001.

45 En este sentido, el Consejo Europeo mencionaba "Se observa que las autoridades locales europeas se encuentran cada vez más confrontadas al crecimiento de la diversidad cultural y religiosa, pero las competencias políticas en la materia varían considerablemente de un estado a otro". Resolution 202/2005, "Intercultural and Inter-faith dialog: initiatives and responsability of local authorities".

46 Bader, V., op. cit., p. 881.

47 Frégosi, F., "Droit de cité de l'islam et politiques municipales: analyse comparée entre Strasbourg et Mulhouse", en Frégosi, F. y Willaime, J. P., Le religieux dans la commune. Les régulations locales du pluralisme religieux en France, Genève, Labor et Fides, 2001, p. 92-137; Frégosi, F., "Les régulations locales du pluralisme religieux: éléments de problématique", en ibidem, pp. $11-26$. 
Esta obra forma parte del acervo de la Biblioteca Jurídica Virtual del Instituto de Investigaciones Jurídicas de la UNAM

indican que no puede extrapolarse la política local a partir del análisis de la política del Estado en la materia. Y, por tanto, menos aún se puede plantear la posibilidad de identificar una correspondencia clara de respuestas locales a la diversidad religiosa a nivel europeo.

En cierto modo, para comprender cuáles son los factores que influyen en definir el diseño específico de las políticas públicas de atención a la diversidad religiosa en cada ciudad, y que explican las diferencias entre ellas, es relevante fijarnos en los siguientes elementos: por un lado, obviamente, el modelo estatal de gobernanza de la religión - el cual, generalmente, viene definido a partir del marco de regulación Iglesia-Estado - influye en la configuración de un modelo específico de gestión de la diversidad religiosa a nivel local. ${ }^{48} \mathrm{Es}$ en el marco estatal donde, como ya hemos mencionado, se definen los grandes principios que orientan la gestión y se inscriben jurídicamente tanto los derechos como los deberes de las comunidades religiosas en el territorio. No obstante, a pesar de que el modelo estatal ofrece principios de acción, encontramos también muchas otras variables contextuales locales que reinterpretan, adaptan y dan lugar a una política específica en la materia.

Por otra parte, es importante tener presente que la trayectoria del municipio y las estrategias puestas en marcha en la gestión de la diversidad migratoria son, también, una variable clave que condicionará el establecimiento de unas políticas u otras. Así, por ejemplo, los sociólogos de los Países Bajos, Jan Rath y Marcel Maussen, explican cómo la experiencia acumulada en la gestión de la inmigración, y los modelos que se han creado en cada localidad, tienen un rol central, y gran influencia, en la forma en cómo se aborda hoy la diversidad religiosa en los municipios. Trayectoria y experiencia a la que se sumará la correlación de fuerzas políticas específicas que se produzca en cada municipio concreto.

Finalmente, la socióloga francesa Claire de Galembert, a partir del análisis que realiza de la construcción y apertura de la mezquita de Mantes-leJolie, demuestra cómo no se puede entender la política local sin comprender la microsociología de los actores. En este sentido, Galembert afirma: "En vez de interpretar las situaciones locales como el fruto de unos determinantes exteriores o como el producto de unas fuerzas colectivas anónimas, hay que hacerlo como la obra de unos destinos singulares y de unas incesantes experimentaciones de actores". ${ }^{49}$ Destaca, así, que es importante tener en

48 Fetzer, J. y Soper, C., Muslims and the State in Britain, France, and Germany, Cambridge, Cambridge University Press, 2005.

49 Galembert, C., "La ciudad de Mantes-la-Jolie y su mezquita: ¿un nuevo orden político-religioso en construcción?”, Revista CIDOB d’Afers Internacionals, Madrid, núm. 77, 2007. 
cuenta la acción y la actuación de personas individuales; ya que pueden influir enormemente en trazar el camino que emprenderá la regulación local de la diversidad religiosa. El peso excepcional que Galembert atribuye a los actores locales no es fortuito sino el resultado del hecho de que en la mayoría de los Estados europeos todavía no existe un modelo institucionalizado, explícito y bien delimitado sobre cómo las autoridades locales deben proceder en relación a las nuevas minorías religiosas. Y “...en ausencia de una relación institucionalizada entre el islam y el Estado o las colectividades tradicionales, la mediación de las personas tiende a volverse primordial". ${ }^{50}$ Una mediación que, además, toma mayor importancia cuando se producen conflictos relacionados con la diversidad religiosa que se convierten en elementos disruptivos que obligan a buscar respuestas rápidas a problemas urgentes, como pueden ser, por ejemplo, quejas por la construcción de oratorios islámicos u otros tipos de centros de culto o conflictos de convivencia interreligiosos.

En definitiva, la gestión de las minorías religiosas es un área relativamente reciente de la política pública tanto a nivel estatal como municipal y en función de la relación de fuerzas políticas y sociales existentes en cada municipio, del carácter de los agentes involucrados y de la propia historia del municipio en la gestión de la inmigración se definirán unas respuestas $\mathrm{u}$ otras para hacer frente a los retos que emergen de la diversidad religiosa.

\section{VIII. ¿QUÉ QUIERE DECIR “ACOMODAR” LA DIVERSIDAD RELIGIOSA?}

En cierto modo, la respuesta política al crecimiento de la diversidad religiosa depende de la concepción prevalente que tengan las autoridades sobre qué es la religión, cuál debe ser el rol de la religión en la sociedad y cuáles son las aportaciones (o la ausencia de ellas) de las confesiones religiosas en relación a la cohesión social y al bienestar de la ciudadanía entendida en sentido amplio. Son cuestiones que se vinculan con las diferentes concepciones de la laicidad y/o la secularización que se han construido históricamente. No repasaremos exhaustivamente cuáles son estas concepciones prevalentes sino que sólo enumeraré brevemente cuáles son los elementos más relevantes que se ponen en juego en relación a esta cuestión.

En primer lugar, surge la pregunta de hasta qué punto las autoridades públicas tienen la responsabilidad de "favorecer" la vida religiosa de sus

\footnotetext{
$50 \quad$ Ibidem, p. 115.
} 
ciudadanos; es decir, ¿es responsabilidad de los gobiernos asegurar la viabilidad y el mantenimiento de las instituciones religiosas en una sociedad moderna? En este sentido, a pesar de que la mayoría de los gobiernos se declaran seculares en materia religiosa, en determinados países prevalece la idea de que el Estado o los entes gubernamentales deben contribuir a facilitar el mantenimiento de las instituciones religiosas. Es por este motivo que, por ejemplo, en determinados países se financian las actividades religiosas y los gobiernos proveen fondos para que las organizaciones religiosas puedan llevar a cabo sus actividades regulares. Así, en Bélgica y en la región francesa de Alsacia determinados grupos religiosos reciben financiación per se (es decir, para llevar a cabo actividades religiosas) y las características de esta financiación las establecen los gobiernos nacionales. Son los gobiernos quienes pagan los salarios a los ministros de culto o quienes se encargan de financiar los nuevos centros de culto o la renovación de los antiguos. En Alemania, la decisión de financiar (o no) las comunidades religiosas recae en el nivel municipal y son los ayuntamientos los que, en función de determinados criterios, deben decidir si optan (o no) para financiar los grupos.

Ahora bien, la mayoría de gobiernos no otorgan financiación a las entidades religiosas per se, es decir, no pagan los salarios de los ministros de culto ni la construcción o mantenimiento de los centros de culto. Hay que tener presente, sin embargo, que en numerosos países todavía existe una desigualdad flagrante entre las Iglesias históricas y las minorías religiosas; es decir, mientras las primeras suelen recibir financiación por parte de los gobiernos, la financiación a las segundas es de carácter mucho más puntual — si es que existe- y, generalmente, va vinculado a la puesta en marcha de proyectos en pro del "bien común". En España, por ejemplo, la Fundación Pluralismo y Convivencia otorga subvenciones a las minorías en una convocatoria competitiva y con el objetivo de que realicen actividades en beneficio de la cohesión social, la buena vecindad y el bienestar general. En Inglaterra, como veremos, este tipo de financiación también ha tomado relevancia en los últimos años. Sin embargo, las diferencias entre la financiación que reciben las minorías y la que recibe la Iglesia tradicional es todavía abismal en la mayoría de lugares.

En segundo lugar, emerge el debate sobre hasta qué punto los órganos gubernamentales tienen la obligación de velar por "proteger" la ciudadanía de las actuaciones de los grupos religiosos. Es decir, ¿es responsabilidad del Estado evitar, por ejemplo, que los menores se hagan miembros de grupos religiosos o que se haga proselitismo en la vía pública? Esta cuestión ha ido generalmente ligada al polémico debate sobre las "sectas". Un debate que 
ha generado discusiones interminables y que tuvo un gran eco mediático en toda Europa durante la década de los noventa. En este sentido, han sido numerosos los países europeos - y también los municipios - que arrancaron o han puesto en marcha campañas contra los grupos religiosos considerados sectarios. No obstante, resulta importante poner de relieve que cuando se han intentado emprender medidas legales contra los grupos considerados sectarios, éstas han sido paradas a última hora, porque ha sido imposible hacerlas compatibles con el ordenamiento jurídico vigente y los derechos de reunión, libertad de expresión y asociación. ${ }^{51}$ Así, por ejemplo, en determinados países se quería proponer la prohibición de la incorporación de adolescentes a grupos religiosos, pero, entonces, surgía la pregunta: ¿qué es lo que justifica que los jóvenes no puedan hacerse miembros de un grupo religioso sin autorización de los padres/madres y, en cambio, se puedan hacer miembros de una asociación cultural? Asimismo, cuando se intentaba prohibir completamente estas asociaciones surgían contrapartidas como las siguientes: ¿cómo se justifica legalmente que haya conventos de clausura y, en cambio, se prohíba legalmente la existencia de determinados grupos religiosos que tienen formas de actuación semejantes? En cierto modo, la respuesta que los entes gubernamentales dan a estas cuestiones tiene toda una escala de gradaciones, y mientras en algunos lugares las autoridades son más estrictas, en otros tienen una actuación más tolerante.

Vinculado con este tema, y en tercer lugar, surge la pregunta sobre si el hecho de tratarse de grupos religiosos y no, por ejemplo, de asociaciones culturales, deportivas o políticas puede justificar que las autoridades lleven a cabo un mayor (o menor) control sobre su actividad. A nivel práctico, esta disyuntiva sobre si el hecho de que se trate de grupos religiosos requiere que se adopten medidas más "restrictivas" o no, se traduce en la pregunta: ¿es el carácter religioso de estos grupos algo que justifique un mayor/menor celo para facilitar las actividades de estas organizaciones dentro de la esfera pública?

Así, por ejemplo, hay muchas localidades que tienen prohibido el proselitismo religioso y por tanto, esto obliga a las autoridades locales a ser más cuidadosas al otorgar permisos a las organizaciones religiosas para realizar actividades en la vía pública o en los espacios públicos, a diferencia de los grupos de índole cultural o deportiva. Se considera que el proselitismo religioso es pernicioso para la convivencia y, por tanto, se controla las actividades en la esfera pública de las organizaciones religiosas. El problema, sin embargo, radica en delimitar exactamente qué significa "proselitismo

51 Richardson, J. T., Regulating Religion: Case Studies from Around the Globe, Nueva York, Kluwer Academic/Plenum Publishers, 2004. 
Esta obra forma parte del acervo de la Biblioteca Jurídica Virtual del Instituto de Investigaciones Jurídicas de la UNAM

religioso", así como en saber analizar y detectar qué podría constituir una discriminación de las autoridades hacia las minorías religiosas en relación al uso del espacio público.

Ahora bien, el dilema que se plantea es, ¿hasta qué punto pueden denegarse estos permisos y, en cambio, permitir las procesiones católicas? En Grecia, por ejemplo, el proselitismo está prohibido en la Constitución por lo que las autoridades (estatales y locales) restringen enormemente las actividades de las minorías religiosas en el espacio público. Un caso famoso en la jurisprudencia europea es lo que llevó un testigo de Jehová griego a denunciar al Estado griego ante el Tribunal Europeo de los Derechos Humanos por haberlo encarcelado (a él y su mujer durante una noche) debido a que llamó a la puerta de una mujer integrante de la Iglesia ortodoxa, para explicarle sus creencias. El juez europeo dio la razón al quejoso y afirmó que "el equilibrio de los derechos individuales obliga a tolerar que el pensamiento de otro soporte un minimum de influencias, sin que se llegue a una extraña sociedad de bestias silenciosas". ${ }^{52}$ Es también pertinente tener en cuenta lo que podría llamarse las paradojas de la visibilidad. En este sentido, mientras las autoridades acostumbran a ser muy cautelosas con la autorización de permisos para la realización del rezo de fin de ramadán en plazas públicas, suelen ser muy flexibles y permisivos frente a la organización de meditaciones colectivas y/o expresiones de la llamada "espiritualidad holística". ${ }^{53}$

En cuarto lugar, se pone de manifiesto que si bien hay cierto consenso ante la idea de que los Estados no tienen obligación de favorecer la vida religiosa de la ciudadanía, también hay un cierto acuerdo en que no la pueden entorpecer. El ejercicio de la libertad religiosa es un derecho, y, por tanto, los ciudadanos que profesen una determinada fe deben estar en posibilidades de ejercer este derecho con unas condiciones mínimas. Sin embargo, la pregunta clave es si no existen las "condiciones mínimas" para que la ciudadanía de un determinado país pueda ejercer este derecho, ¿quién las tiene que facilitar?, ¿las propias comunidades religiosas o los gobiernos? Es decir, en ocasiones las comunidades religiosas no tienen los medios necesarios para construir templos "dignos" o para llevar a cabo sus actividades adecuadamente o para garantizar que puedan vivir su cotidianidad según los requerimientos de su fe (por ejemplo, si enferman, en los rituales de muerte o en la educación de los hijos entre otras).

52 Seglers, A., "Llibertat religiosa i laïcitat: un estudi comparat", Idees. Revista de Temes Contemporanis, España, abril-septiembre, 2005, p. 175.

53 Heelas, P. et al., The Spiritual Revolution: Why Religion is Giving way to Spirituality, Londres, Blackwell Pub, 2005. 
¿Puede ser la precariedad de las comunidades algo que justifique la financiación y/o el apoyo de la administración a los grupos religiosos? En países como Francia se consideró durante muchos años que esto era responsabilidad exclusiva de las comunidades, pero en los últimos años esta respuesta ha comenzado a matizarse. Las religiones mayoritarias tienen unos derechos históricos asegurados que, en muchas ocasiones, han podido hacer efectivos debido al apoyo del Estado. Las minorías religiosas, por tanto, están en desigualdad de condiciones, y por este motivo se considera que en determinadas circunstancias, y hasta que los derechos de las minorías sean razonablemente comparables al de las mayorías, los entes gubernamentales deben poder intervenir para ayudar a las comunidades religiosas minoritarias con el objetivo de que ejerzan sus derechos (por ejemplo, apoyando las comunidades minoritarias en la construcción de lugares de culto "dignos", o bien facilitando que puedan disponer de un espacio religiosamente neutro en los hospitales para llevar a cabo sus rituales religiosos).

En quinto lugar, hay que tener en cuenta que los centros de culto no sólo son espacios donde se profesa una determinada fe, sino que en muchas ocasiones son también centros culturales y sociales. Además, las organizaciones religiosas juegan un rol clave entre las comunidades inmigrantes en tanto que sirven de espacios de encuentro, potencian la creación de redes de asistencia social, y pueden ser también lugares de producción/transmisión cultural. De este modo, si los gobiernos favorecen las asociaciones culturales y/o de inmigrantes, ¿por qué no deberían apoyar, escuchar y atender este tipo de asociaciones? Como ya he mencionado, en Gran Bretaña son muchas las comunidades religiosas que reciben financiación de las autoridades locales en tanto que desarrollan proyectos de implicación en la comunidad local (asistencia social, promoción del diálogo, implicación en programas de regeneración urbana). En Francia, a pesar de que la ley prohíbe la financiación a las comunidades religiosas, determinados ayuntamientos han optado por financiar los grupos religiosos por vía indirecta a través del sostenimiento económico de proyectos de interés social y/o cultural. En los últimos tiempos muchos gobiernos locales europeos han optado por considerar a las comunidades religiosas como entidades culturales en términos de financiación.

Hay muchas otras cuestiones que no tenemos espacio para abordar, pero que también resultan cruciales para comprender los dilemas que emergen en la gestión de la diversidad religiosa. Me refiero a cuestiones como la dificultad para establecer la frontera entre demandas de índole cultural y/o religiosa, las complejidades para dirimir quiénes son los representantes 
Esta obra forma parte del acervo de la Biblioteca Jurídica Virtual del Instituto de Investigaciones Jurídicas de la UNAM

legítimos de una religión o la misma definición de qué es una religión y qué grupos se pueden catalogar como tal. ${ }^{54}$

\section{APUNTES FINALES}

En los últimos tiempos, la gestión de la diversidad religiosa ha tomado creciente relevancia en toda Europa, y se ha hecho evidente el rol estratégico que tiene la administración local en esta materia. La recomposición del mapa religioso europeo ha hecho emerger nuevos desafíos, nuevos dilemas y nuevas respuestas a estas cuestiones. La pérdida de fieles de las Iglesias tradicionales ha ido acompañada de la creciente presencia de las minorías religiosas a la esfera pública y del surgimiento de nuevas formas de espiritualidad. Todos estos cambios han dibujado un escenario complejo que obliga a las autoridades públicas a tomar en consideración la cuestión religiosa y a establecer nuevas reglas de juego y formas de regulación. La gestión de la religión por la vía de la definición de un modelo constitucional de relación Iglesia-Estado deviene un sistema desfasado e insuficiente para la gobernanza contemporánea de la religión. En el nuevo contexto la religión entra a formar parte de la agenda política local y se requieren nuevas herramientas políticas para gestionar esta cuestión.

Ahora bien, el análisis sobre la gestión local de la diversidad religiosa nos muestra la existente heterogeneidad de los órdenes normativos, simbólicos y políticos sobre la religión y la laicidad en la Europa actual. Son muchas las variables que influyen en esta cuestión: por un lado, la trayectoria histórica y el marco legal del país en cuestión; por el otro, los factores contextuales domésticos e internacionales, y, finalmente, los aspectos relacionados con el municipio en cuestión (factores sociodemográficos, composición ideológica, trayectoria específica...). Además, el análisis empírico revela la extrema provisionalidad y fragilidad de los marcos locales de regulación que aún están en período embrionario y se encuentran sumidos a los vaivenes de las múltiples crisis internacionales y nacionales sobre el tema.

El análisis también pone de manifiesto la brecha relevante entre el marco legal y político, así como la situación cotidiana en los espacios locales. Es en los contextos locales particulares donde toma una relevancia crucial lo que Claire de Galembert llama la "microsociología de los actores". Las decisiones cotidianas, los acuerdos informales y las redes que se

54 Para profundizar más en estas cuestiones véase Griera, M., Diversitat Religiosa i Món Local: una mirada a Europa, Barcelona, Diputació de Barcelona, 2011. 
tejen entre actores religiosos, políticos y sociales son claves para comprender cómo se produce la gestión local de la diversidad religiosa. A veces, el impacto del marco legal y político se reduce sólo a nivel formal, y prima la importancia de las rutinas establecidas y los acuerdos que se desprenden de las microdinámicas informales producidas a nivel local. Por este motivo, resulta clave ir más allá del análisis jurídico y/o de la política formal para adoptar una mirada sociológica con tal de poder comprender las características actuales de la gestión de la diversidad religiosa y sus transformaciones en la sociedad contemporánea.

\section{Bibliografía}

Astor, A., "«Mezquita No!»: The Origins of Mosque Oppositions in Spain”, GRITIM Working Paper Series, Barcelona, núm. 3, 2009.

BADER, V., Secularism Or Democracy? Associational Governance of Religious Diversity, Amsterdam, Amsterdam University Press, 2007.

Bastian, J. P. y Messner, F., Minorités religieuses dans l'espace européen : Approches sociologiques et juridiques, París, Presses Universitaires de France, 2007.

Baubérot, J., Laïcité 1905-2005, entre passion et raison, París, Seuil, 2004.

Beckford, J. A. y Gilliat-Ray, S., Religion in Prison: Equal Rites in a MultiFaith Society, Cambridge, Cambridge University Press, 1998.

, "The Management of Religious Diversity in England and Wales with Special Reference to Prison Chaplaincy. The Public Management of Religious Diversity", International Journal on Multicultural Societies, vol. 1, núm. 2, 1999.

Berger, P., The Desecularization of the World. Resurgent Religion and World Politics. Washington, D. C., Ethics and Public Policy Center y William B. Eerdmans Publishing Company, 1999.

BilLig, M., Banal Nationalism, Londres, Sage Publications Ltd., 1995.

BRAmADAT, P., "Religious Diversity and International Migration: National and Global Dimensions", en Koenig, M. y BRAmadat, P. (eds.), International Migration and the Governance of Religious Diversity, Kingston, School of Policy Studies, Queen's University, 2008.

BURCHARDT, M. et al., "Narrating Liberal Rights and Culture: Muslim Face Veiling, Urban Coexistence and Contention in Spain", fournal of Ethnic and Migration Studies, Reino Unido, vol. 41, núm. 7, 2005. 
Esta obra forma parte del acervo de la Biblioteca Jurídica Virtual del Instituto de Investigaciones Jurídicas de la UNAM

y Michalowski, I., After Integration: Islam, Conviviality and Contentious Politics in Europe, Berlín, Springer, 2015, disponible en: http://linkspringer. com/chapter/10.1007/978-3-658-02594-6_1.

Casanova, J., "Immigration and the New Religious Pluralism: A European Union/United States Comparison", en BAnchoff, T. (ed.), Democracy and the New Religious Pluralism, Nueva York, Oxford University Press, 2007.

Democracy", en Motzkin, G. y Fischer, Y. (eds.), Religion and Democracy in Contemporary Europe, Londres, Alliance Publishing Trust, 2008.

CÔTÉ, P. y GunN, J., La nouvelle question religieuse: régulation ou ingérence de l'État? The New Religious Question: State Regulation or State Interference, Bruselas, PIEPeter Lang, 2006.

Champion, F., "Laïcités européennes: de l'hétérogenéité à la convergence", Migrations Societé, París, vol. 16, núm. 96, 2004.

DAvie, G., "Religious Representation in a Revised House of Lords. The Public Management of Religious Diversity", International fournal on Multicultural Societies, vol. 1, núm. 2, 1999.

, Religion in Modern Europe: A Memory Mutates, Nueva York, Oxford University Press, 2000.

Dinham, A. y Francis, M., Religious Literacy in Policy and Practice, Bristol, Policy Press, 2015.

Ferrari, A., "France and Greece: Two Approaches to Religious Pluralism", Law and Fustice-The Christian Law Review, Londres, núm. 152, vol. 27.

Fetzer, J. y Soper, C., Muslims and the State in Britain, France, and Germany, Cambridge, Cambridge University Press, 2005.

Foret, F. (ed.), Politique et religion en France et en Belgique, Bruselas, Éditions de l'Université de Bruxelles, 2009.

FRÉGOSI, F. y WiLLAIME J. P., Le religieux dans la commune. Les régulations locales du pluralisme religieux en France, 2001.

, "Droit de cité de l'islam et politiques municipales: analyse comparée entre Strasbourg et Mulhouse", en FrÉGOSI, F. y WiLlaime, J. P., Le religieux dans la commune. Les régulations locales du pluralisme religieux en France, Genève, Labor y Fides, 2001.

, "Les régulations locales du pluralisme religieux: éléments de problématique", en FrÉGOSI, F. y WiLlaime, J. P., Le religieux dans la commune. Les régulations locales du pluralisme religieux en France, Genève, Labor y Fides, 2001. 
Esta obra forma parte del acervo de la Biblioteca Jurídica Virtual del Instituto de Investigaciones Jurídicas de la UNAM

Galembert, G., "La ciudad de Mantes-la-Jolie y su mezquita: ¿un nuevo orden político-religioso en construcción?", Revista CIDOB d'Afers Internacionals, España, núm. 77, 2007.

Gole, N., "Islam in Public: New Visibilities and New Imaginaries", Public Culture, Estados Unidos, vol. 14, núm. 1, 2002.

Griera, M., Diversitat Religiosa i Món Local: Una mirada a Europa, Barcelona, Diputació de Barcelona, 2011.

-, "Public Policies, Interfaith Associations and Religious Minorities: a New Policy Paradigm?, Evidence from the Case of Barcelona", Social Compass, Países Bajos, vol. 59, núm. 4, 2012.

y Clot-Garrell, A., "Banal is not Trivial: Visibility, Recognition, and Inequalities between Religious Groups in Prison", fournal of Contemporary Religion, Londres, vol. 30, núm. 1, 2015.

Hackett, R. I. J., "Rethinking the Role of Religion in the Public Sphere: Local and Global Perspectives", en Ostien, P. y NAsiR, J. (eds.), Comparative Perspectives on Shari'ah in Nigeria, Ibadan, Spectrum, 2005.

HeELAS, P. et al., The Spiritual Revolution: Why Religion is Giving way to Spirituality, Londres, Blackwell Pub, 2005.

Koenig, M., "Europeanising the Governance of Religious Diversity: An Institutionalist Account of Muslim Struggles for Public Recognition", Journal of Ethnic and Migration Studies, Gran Bretaña, vol. 33, núm. 6, 2007.

LLAMAZARES FernáNDEZ, D., "Poder político y poder religiosos: claves, cauces y modelos de relación. Acuerdos Iglesia-Estado", Laicidad y Libertades, Madrid, núm. 3, 2003.

LaUrence, J., "Managing Transnational Islam: Muslims and the State in Western Europe", en PARsons, C., y Smeeding, T., Immigration and the Transformation of Europe, Cambridge, Cambridge University Press, 2006.

LAMINE, Anne-Sophie, "Mise en scène de la 'bonne entente' interreligieuse et reconnaissance", Archives de sciences sociales des religions, París, núm. 129, enero-marzo, 2005.

Liogier, R., Une laïcité "legitime". La France et ses religions d'État, París, Médicis-Entrelacs, 2006.

MARTin, D., On Secularization: Towards a Revised General Theory, Londres, Ashgate Publishing, Ltd., 2005.

MoOrS, A. y SALIH, R., "«Muslim women» in Europe: Secular Normativities, Bodily Performances and Multiple Publics", Social Anthropology, Londres, vol. 17, núm. 4, 2009, disponible en: http://doi.org/10.1111/j.14698676.2009.00090.x. 
Esta obra forma parte del acervo de la Biblioteca Jurídica Virtual del Instituto de Investigaciones Jurídicas de la UNAM

Maussen, M., "Mosques and Muslims in Marseilles", ISIM Review, Holanda, vol. 16, otoño, 2005.

, The Governance of Islam in Western Europe: A state of the art report, IMES, Institute for Migration and Ethnic Studies, University of Amsterdam, 2006, disponible en: http://imiscoe.socsci.uva.nl/publications/workingpapers/documents/GovernanceofIslam-stateoftheart_000.pdf.

Moreras, Jordi, "Limits and Contradictions in the Legal Recognition of Muslims in Spain", en SHADID, W. y Koningsveld, P. S. von (eds.), Religious Freedom and the Neutrality of the State: The Position of Islam in the European Union, Leiden, Peeters, 2002.

PALARD, J., "Introduction", en SKARD, H. et al., Gods in the City. Intercultural and Inter-Religious Dialogue at Local Level, Estrasburgo, Local \& Regional, 2007.

RATH, J. et al., Western Europe and Its Islam, Leiden, Brill, 2001.

Richardson, J. T., Regulating Religion. Case Studies from Around the Globe, Nueva York, Kluwer Academic-Plenum Publishers, 2004.

SÁnchez GriÑó, J. M. y Serratusell Miró, G., "La gestió del pluralisme religiós als municipis catalans", Revista Catalana de Sociologia, Barcelona, vol. 29, núm. 44, 2013.

Schlesinger, P. y Foret, F., "Political Roof and Sacred Canopy?: Religion and the EU Constitution", European Fournal of Social Theory, Gran Bretaña, vol. 9, núm. 1, 2006.

SEgLERS, A., "Llibertat religiosa i laïcitat: un estudi comparat", Idees. Revista de Temes Contemporanis, Madrid, abril-septiembre, 2005.

Torrekens, C., "Le pluralisme religieux en Belgique", Diversité Canadienne, Canadá, vol. 4, núm. 3, 2005.

Willaime, J. P., "État, pluralisme et religion en France", en BAUBEROT, J., Pluralisme et minorités religieuses, Actas del coloquio CNRS-EPHE, LouvainParís, Peeters, 1991.

Wydmusch, S., "Les maires du Bas-Rhin face au pluralisme religieux", en FRÉGOSI, F. y WILLAIME, J. P., Les régulations locales du pluralisme religieux, Genève, Labor et Fides, 2001. 


\title{
CONCLUSIONES \\ LAICIDAD Y CULTURA LAICA*
}

Jean BAUBÉROT ${ }^{* *}$

\begin{abstract}
SUMARIO: I. Introducción. II. Laicidady secularización. III. Los fundamentales de la laicidad. IV. El gran desafio cultural de la laicidad en el siglo XXI. V. Bibliografia.
\end{abstract}

\section{INTRODUGGIÓN}

Esta obra colectiva constituye una nueva prueba de la vitalidad científica de los estudios que en muchos países se refieren al concepto de "laicidad" y que lo ponen en relación con otros conceptos y nociones de las ciencias humanas, sociales y jurídicas. La riqueza de las diferentes aportaciones, la multiplicidad de las rutas exploradas hacen imposibles, y finalmente poco deseable, una improbable síntesis. Para no arriesgarme, voy a intentar retomar a mi manera algunos de los temas de esta obra, los cuales agruparé en tres puntos: en primer lugar, expondré algunos elementos sobre la autonomización del concepto de laicidad respecto del paradigma de la secularización; después indicaré lo que constituye, desde mi punto de vista, los fundamentos de la laicidad; finalmente, plantearé el gran desafío cultural de la laicidad hoy en día.

\section{LAICIDAD Y SECULARIZACIÓN}

Este libro es pluridisciplinario, algo fundamental para estudiar la laicidad. Por mi parte, soy historiador y sociólogo. Ambas disciplinas han jugado un papel central en los debates sobre la posibilidad de un acercamiento científico

* Traducción de Pauline Capdevielle.

** Grupo Sociedad, Religiones, Laicidades del CNRS-EPHE, París, Francia. 
sobre este objeto de estudio. La situación de partida es la existencia de un paradigma de la secularización, que ha sido elaborado paulatinamente a finales de los años 1950 y a principios de los años 1980. Este paradigma se presentaba como la herramienta conceptual que permitía pasar de una "historia religiosa" y de una "sociología religiosa" - consideradas como poco científicas - a un verdadero enfoque sociohistórico, científicamente fundado, de las religiones. A pesar de los matices introducidos por algunos sociólogos (por ejemplo, las reservas de David Martin - a partir de 1965- sobre el aspecto "de miscelánea" del paradigma, o las indicaciones de Bryan Wilson - en 1966 - sobre el posible florecimiento de pequeñas comunidades religiosas), la problemática de una "pérdida" de la importancia social de la religión y de su "privatización" en las sociedades modernas ha resultado dominante; iba unida con los cambios sociales vinculados con la dinámica de la economía capitalista o del socialismo de Estado.

En el corazón del paradigma de la secularización se encontraba un postulado: la sociedad industrial moderna generó progresivamente un sector que funciona con base en reglas independientes de la religión, y poco a poco, la pérdida de la influencia de la religión en este sector se fue extendiendo a los demás sectores de la sociedad. Este enunciado presenta todavía, según mi punto de vista, cierta validez para dar cuenta de algunos aspectos de la realidad empírica. En cambio, ya no es válido como teoría general. Pues ha ido de la mano con la óptica de una monocasualidad en última instancia (al contrario de la perspectiva de Max Weber, quien, sin embargo, era frecuentemente tomado como referencia), y en consecuencia, con la creencia en una suerte de sentido unívoco de la historia: los llamados países "en vía de desarrollo" iban a adoptar forzosamente el modelo de dichas sociedades "más modernas".

Peter Berger no duda en escribir que "la experiencia de las tradiciones religiosas occidentales" permite prejuzgar el "futuro de la religión en los países no occidentales, y con ello, cuál será su régimen político, socialista o no". ${ }^{1}$ Agregaba el sociólogo "sin gran riesgo a equivocarse" que este futuro "será marcado de manera decisiva por la secularización". Este paradigma de la secularización, en su pretensión abarcadora, aparece ahora muy revelador del clima intelectual y sociopolítico de una época que razonaba, por lo menos implícitamente, según el esquema infraestructura/ superestructura, y reducía el vínculo entre religión y política al estudio del

1 Berger, Peter, La religion dans la conscience moderne, París, Le Centurion, 197 1, p. 264. (The Sacred Canopy. Elements of a Sociological Theory of Religion, New York, Doublebay, 1967). Nota del traductor. Traducción libre. 
Esta obra forma parte del acervo de la Biblioteca Jurídica Virtual del Instituto de Investigaciones Jurídicas de la UNAM

comportamiento electoral de los grupos religiosos. Lo político, en el corazón de las relaciones humanas, como el acto de gobernar y de ser gobernado, como estructuración societal, era ampliamente disminuido, incluso ocultado. Era privilegiado lo económico como causa de la secularización y lo cultural como lugar de ésta.

Sin embargo, en las dos últimas décadas del siglo XX, el contexto cambió de manera estructural, haciendo recordar a los sociólogos que, si bien los diagnósticos pueden adquirir cierta cientificidad, ¡los pronósticos son más aventurados! Los vínculos entre religión y política se multiplicaron. En los Estados Unidos la aparición de la nueva derecha cristiana atestiguó el surgimiento de un despertar evangélico que entró en la política y contestó en un sentido dinámico (y conservador) a cierto desencanto respecto de la modernidad. Por otro lado, la hipótesis formulada por Wilson se concretó más allá de lo que había indicado su autor, con el desarrollo de Nuevos Movimientos Religiosos (NMR). Ellos provocaron controversias con fuerte dimensión política. La Revolución iraní (1979) y la irrupción de lo que se llamó "islam político" a escala internacional generaron múltiples estudios. Lo mismo ocurrió con el papel jugado por los actores "religiosos" en la caída de los regímenes comunistas de Europa del Este.

Asimismo, se produjo una nueva repartición político-religiosa en el mismo momento, ¡una paradoja!, en el que el paradigma de la secularización se había impuesto en la sociología de la religión como un factor importante de legitimidad profesional, de "distinción" (en sentido de Pierre Bourdieu). De esta manera, David Martin, después de muchas reticencias, publicó una teoría general de la secularización en 1978, al volverse presidente de la Sociedad Internacional de Sociología de las Religiones (SISR). La incorporación de lo político era presente en su obra, incluso, es lo que la hacía original en el marco del paradigma. Pero esta incorporación dio lugar a diversas expresiones que quedaban poco formalizadas (disestablishment, the disconnection of Church and State, the Church unhinged from the State, distinguishing Church from State, etcétera). Si la volvemos a leer hoy, nos percatamos de que Martin daba materiales para una problemática de la laicidad, pero sin lograr establecerla verdaderamente. Se da la impresión que las restricciones del paradigma empezaban a suplantar su interés heurístico.

El año de 1989 constituye un giro, al empezar con la fatwa del iman Khomeini en contra del escritor Salman Rushdie y al terminarse con la caída del Muro de Berlín. Es inútil recordar los atentados del 11 de septiembre de 2001. A finales del siglo XX y a principios del siglo XXI, el paradigma de la secularización, teóricamente construido en sus fundamentos, intenta adaptarse a los cambios societales que lo cuestionan, y a nuevas construcciones teóricas. Pero el carácter de vulgata cómoda sigue predominando sobre su elaboración 
Esta obra forma parte del acervo de la Biblioteca Jurídica Virtual del Instituto de Investigaciones Jurídicas de la UNAM

teórica, aunque ésta no es del todo ausente (véase los trabajos de Steve Bruce). De hecho, algunos estudios empiezan con un recordatorio sintético, que constituye una especie de homenaje al paradigma, del cual se libera después en gran medida.

Ahora bien, partir de 1994, José Casanova procedió a un análisis al cual me sumo de buena gana: la no pertinencia de la secularización como marco paradigmático y la validez de la secularización como concepto. El sociólogo desconstruye el paradigma, al mostrar que corresponde a tres "proposiciones" divergentes: declive religioso, privatización, diferenciación institucional. No existe, para Casanova, relación causal alguna entre las tres proposiciones. A la luz de las encuestas empíricas, el declive ("pérdida") y la privatización (ya) no corresponden a un conjunto significativo de situaciones empíricas. Cada una debe ser disociada de las otras. En cambio, la diferenciación entre instituciones se verifica en muchos casos, sin implicar necesariamente un declive irreversible de la religión, al mostrarse compatible incluso con formas de "religión pública moderna". Este enfoque conduce al sociólogo hispanoamericano a distinguir diversos tipos de religión pública a partir de sus relaciones con el Estado. Asimismo, integra el análisis de lo político y de lo jurídico, singularmente ausente en la elaboración del paradigma de la secularización.

El desarrollo de estudios sobre la laicidad (o, en inglés-americano, sobre el political secularism) resulta de un desplazamiento de este punto de vista, en el sentido casi geográfico de la expresión. Y si se trata de tomar en cuenta los acontecimientos contemporáneos más importantes, este desplazamiento no se reduce al estudio del presente. Por una parte, no podemos ignorar que las formas de religión han sido políticamente impuestas en el pasado, lo que el paradigma no tomaba en cuenta. Además, y en consecuencia, el proceso sociohistórico plural de la laicización como solución política de los conflictos político-religiosos ha sido analizado (véase, por ejemplo, Gill, 2008, o Cady y Sharkman-Hurd, 2010). ${ }^{2}$ Los trabajos recientes de la Colección Cultura Laica de la UNAM $^{3}$ y de El Colegio de México se inscriben en esta nueva perspectiva, la cual aporta nuevas ganancias de cientificidad. Significa, asimismo, que es imposible ahora adoptar un planteamiento que se limite a la sociología de las religiones (inclusive ampliada a los religious studies en general) como el paradigma de la secularización tendía a ser. La interdisciplinaridad se impone, lo hemos constatado a lo largo de esta obra. Esta interdisciplinaridad desborda las ciencias humanas

2 Gill, Antony, The Political Origins of Religious Liberty, Cambridge, Cambridge University Press, 2008; Cady, Liell E. y Shakman-Hurd, Elizabeth (eds.), Comparative Secularisms in a Global Age, Nueva York, Palgrave-MacMillan, 2010.

3 Colección Cultura Laica, México, UNAM, Instituto de Investigaciones Jurídicas, 2015 . 
y sociales, extendiéndose a los estudios jurídicos, como elemento clave de regulación sociopolítica en los Estados de derecho. Concluiré esta primera parte con tres indicaciones:

- La primera es que no se trata de substituir un paradigma por otro, o por lo menos, si se busca elaborar un paradigma de laicidad, es necesario - como bien se ha dicho - que este paradigma quede estrictamente heurístico y no pretenda ser epistemológico. Por lo mismo, me parece más pertinente un juego de tipos ideales que una pretensión abarcadora.

- La segunda indicación es que no se trata tampoco de sustituir una infraestructura política a una infraestructura económica, y quedarse con una explicación monocausal. Más bien, se trata de adoptar un enfoque pluriestructural. El enfoque socioeconómico - lo retomaré de forma breve en mi última parte- , no debe ser subestimado. Por otra parte, el título de la colección que publica esta obra es el de "cultura laica". La cultura laica es una cultura de referencia política, pero, a la inversa, todo actuar político se lleva a cabo en el marco de representaciones culturales.

- La última indicación busca señalar que hemos abordado en varias ocasiones las relaciones entre laicidad y democracia. Éstas constituyen un ejemplo clave de la imposibilidad de limitarse a los estudios sobre la religión: ciertamente, la problemática de la cultura laica se interesa en las diferentes religiones, en su lugar y papel sociales, pero también en las diferentes concepciones de Estado, en las libertades públicas, los derechos humanos, las tradiciones jurídicas, etcétera. Hemos abordado una gran diversidad de procesos y situaciones, de Canadá a Turquía, pasando por diferentes países latinoamericanos y europeos.

\section{LOS FUNDAMENTALES DE LA LAICIDAD}

¿Qué pertinencia científica puede tener el concepto de "laicidad"? Por supuesto, de la misma manera que se prueba el movimiento caminado, las diferentes contribuciones de este libro han mostrado la validez teórica de este enfoque. Sin embargo, con frecuencia, esta validez está hipotecada por la confusión entre la utilización analítica y el uso social del término de "laicidad”. Según los países que se abordan, este uso social puede ser importante (México, Francia, Turquía...) o débil, inclusive, casi inexistente. Sin embargo, desde mi perspectiva, la casi ausencia de un uso social de la palabra "lai- 
Esta obra forma parte del acervo de la Biblioteca Jurídica Virtual del Instituto de Investigaciones Jurídicas de la UNAM

cidad" no descalifica en absoluto la utilización analítica del concepto, especialmente si, como se hizo, está en relación con otros (por ejemplo el de "confesionalidad").

El uso social importante, incluso a veces avasallador (como en Francia o últimamente en Quebec) de la laicidad, no debe conducirnos a usarla, por poco que sea, como una referencia normativa. Uno de los autores ha insistido sobre la necesidad de deconstruir la noción de "laicidad". Me parece, en efecto, que una definición sustantiva o esencialista no es operadora. Es posible distinguir cuatro parámetros en interacción. ${ }^{4}$ Cada parámetro puede socialmente ser objeto de interpretaciones diferentes, que voy a desarrollar de forma breve, y los cuatro parámetros pueden también ser objeto de una jerarquización diferente (que no tendré tiempo de abordar).

El primer parámetro es la "libertad de conciencia". Esta libertad, como libertad pública, es invocada en diversas convenciones internacionales. Sin embargo, los usos sociales de esta expresión son diversos. Al analizarlos, es posible encontrar dos polaridades, según el uso social tienda a excluir o favorecer la libertad de religión. En la historia de la laicidad, tanto en Latinoamérica como en Europa o en Turquía, algunas concepciones de la laicidad han considerado que la religión es la "opresión de las conciencias" y que constituye un "obstáculo al progreso, a la ciencia". En esta óptica, la libertad de conciencia aparece casi como lo opuesto a la libertad de religión ya que es, principalmente, la libertad de liberarse de la religión. Este tipo de concepciones se ha desarrollado en periodos en los cuales la religión participaba (o por lo menos influenciaba fuertemente) la gobernanza estatal y se encontraba en posición dominante en relación con la sociedad. En este caso, lo que se vulneraba era la libertad de los heréticos, de los agnósticos, ateos y librepensadores. El combate para la libertad de conciencia se presentaba antes de todo y lógicamente como un combate para sustraerse de la influencia de la religión, para tener la libertad de vincularse con ella de diferentes maneras, a distancia de lo que imponían las autoridades religiosas, o incluso de no vincularse en absoluto. Se confundían casi totalmente combate anticlerical y combate por la libertad.

En algunas regiones del mundo (Arabia Saudita, pero no solamente), incluso en algunos ámbitos, como por ejemplo en materia de libertad sexual y reproductiva, dicho combate sigue vigente. Pero cuando se establece la laicidad (casi en el sentido inglés-americano de establishment), cuando

4 Véase Milot, Micheline, Laïcité dans le nouveau monde. Le cas du Québec, Turnhout, Brepols, 2002; Baubérot, Jean y Milot, Micheline, Laïcités sans frontières, París, Seuil, 2011; Baubérot, Jean, Les sept laïcités françaises, París, Editions maison des Sciences de l'Homme, 2015. 
la gobernanza política se vuelve laica, se plantea también la cuestión de la libertad de conciencia de los "creyentes", la libertad de practicar su religión y de vivir conforme con lo que uno cree ser la "verdad". A ello se suma - y aquí aparece el interés de vincular laicidad y secularización-, una dinámica social secularizadora, cuyo núcleo está constituido por las actividades vinculadas con la industria, y que tiende a garantizar que la vida en sociedad se desarrolle sin referencia a las normas religiosas. Es una ganancia de libertad para muchos, pero una sociedad no es una yuxtaposición de individuos aislados, lo que puede obstaculizar la vida religiosa.

Asimismo, existe el riesgo de que sigamos considerando la laicidad principalmente como la libertad de conciencia respecto de la religión, como en la antigua situación "clerical". Dado que las convenciones internacionales se refieren a la "libertad de religión y de convicción [no religiosa]", los que se sitúan en esta perspectiva tenderán a adoptar un doble discurso. Por un lado, afirmarán "el derecho igual a creer y a no creer", y por el otro, hablarán de la laicidad como emancipación respecto de la religión: habría que emanciparse (inclusive ser emancipado) de la religión para acceder a la libertad. Esta concepción autoritaria de la laicidad ${ }^{5}$ se vincula con la secularización, inclusive, se confunde con ella.

Diversas ponencias han tratado (implícita o explícitamente) del otro polo de la concepción de la libertad de conciencia. Se encuentra dominante, en efecto, en varios países, especialmente latinoamericanos. Se trata de una representación de la libertad de conciencia que aparece, sobretodo y antes de todo, como libertad de religión. Desde esta perspectiva, la religión, con sus creencias explícitas, sus rituales, sus ceremonias, sus diversas manifestaciones en el espacio público, debería estar más protegida por el Estado que la irreligión, la cual sería un simple fenómeno de la esfera privada. Y al manifestarse la irreligión en el espacio público mediante la crítica o incluso el ataque a la religión, se ofende, "se blasfema" contra lo "sagrado". No insistiré: conocemos las leyes antiblasfemia en varios países, las posiciones de muchas autoridades religiosas y sus tentativas de limitar la libertad de convicciones no religiosas, y los debates internacionales subsecuentes.

Habrá que evocar también, por supuesto, la horrible matanza operada en Francia, de la cual ha sido víctima la redacción de Charlie-Hebdo el 7 de enero de 2015. Muestra hasta dónde puede llegar una oposición violenta y fanática a la libertad de rechazo de la religión. La indispensable solidaridad de todos los demócratas con las víctimas, el aspecto inacep-

5 Baubérot, Jean y Milot, Micheline, Laïcités sans frontières, cit. 
table de esta matanza, no debe, sin embargo, coartar el espíritu crítico: sería paradójico. Al analizar los textos publicados por Charlie-Hebdo, esta publicación se ubica, de manera dominante, en la concepción de libertad de conciencia que tiende a confundir laicidad y secularización. ${ }^{6}$ Lo que naturalmente no justifica de ninguna manera la violencia que se desató en su contra.

El principio de "no discriminación" por motivo de religión y de convicción constituye el segundo parámetro de la laicidad. Sus diferentes representaciones son vinculadas a las representaciones divergentes de la libertad de conciencia. Aquí también el principio de no discriminación es parte de las normas internacionales. Pero el desafío consiste en determinar la frontera entre lo que es discriminatorio y lo que no lo es. El ejemplo del "acomodo razonable" canadiense bien ha mostrado la complejidad de dicho problema: por una parte, las discriminaciones pueden ser "indirectas" y la ley en su generalidad puede resultar, de hecho, discriminatoria; por otra parte, el escrupuloso respeto del principio de no discriminación no solamente entra en tensión con el respeto de los derechos de los demás, sino también con las necesidades propias de las instituciones o de las políticas públicas (véase las políticas urbanas, especialmente) y con el costo del acomodo razonable, lo cual no debe ser excesivo. Aquí también hay que recordar que lo social no se reduce a una yuxtaposición de los individuos. Y no en vano la expresión "acomodo razonable" comporta dos términos; el primero induce a la no discriminación, el segundo puede limitar sus efectos. ¿Cuáles son las limitaciones que no son discriminatorias? He aquí un desafio interpretativo esencial.

La decisión caso por caso se impone, y las normas interpretativas, así como sus aplicaciones, son dadas por el derecho. Existe después una tecnicidad jurídica, que ha sido puesta de relieve en la contribución de la jueza de la Suprema Corte mexicana, Olga Sánchez Cordero. Esta tecnicidad induce una importancia social de los jueces, la cual puede ser vivida como una forma de despojo por parte de los ciudadanos ordinarios. Este sentimiento de despojo es instrumentalizado mediáticamente y políticamente. Es lo que pasó en Quebec, entre 2006 y 2008, con la "crisis de los acomodos razonables", en una situación compleja en la cual la avería del proyecto soberanista agravaba el antagonismo histórico entre la Bella Provincia y la Federación canadiense. Ciertamente, el principio del derecho, inherente a la democracia, implica que cada uno se distancie de sus afectos, de sus emociones, acepte reglas no disponibles según sus humores. Sin embargo, el análisis debe tomar en cuenta esta sensación victimaria, aunque sea para descífrala,

6 Baubérot, Jean, Historia de la laicidad francesa, Estado de México, El Colegio Mexiquense, 2005. 
Esta obra forma parte del acervo de la Biblioteca Jurídica Virtual del Instituto de Investigaciones Jurídicas de la UNAM

pues no podemos escapar del problema de la tensión que puede existir entre el proceso de decisión político y el derecho.

Libertad de conciencia y no discriminación constituyen dos finalidades fundamentales de la laicidad. De forma complementaria, los dos medios principales para alcanzar estas finalidades son la separación y la neutralidad, parámetros igualmente susceptibles de diferentes interpretaciones. Como lo ha mencionado Roberto Blancarte, la "separación" no se reduce a la existencia de una ley formal que establezca explícitamente la separación de la religión y del Estado. Cuando existe dicha ley, sus modalidades pueden inducir modelos de separación diferentes. Así, y al contrario de una percepción común, la separación es, en varios aspectos, más estricta en Estados Unidos que en Francia. ${ }^{7}$

La noción de separación puede acercarse a la de "diferenciación" desde la óptica utilizada por Casanova (1994). De acuerdo con él, hay que distinguir las "religiones establecidas por el Estado" (established State Churches), en las cuales existe un vínculo orgánico entre el Estado y la religión, como la España franquista, u hoy en día, la República islámica de Irán, y por otra parte, las diversas situaciones en las cuales la religión ya no es parte de las instituciones obligatorias del Estado (state compulsory institutions), sino que constituyen instituciones religiosas libres, que son partes de la sociedad civil (free religious institutions of civil society). En esta hipótesis, pueden existir situaciones en las cuales la religión sigue siendo oficialmente "establecida" (Inglaterra, Dinamarca, etcétera) pero cuyo vínculo con el Estado se ha vuelto "residual" en menor o mayor medida: el funcionamiento de la democracia, el respecto de los derechos fundamentales, inscriben, de manera dominante, la religión en las instituciones "libres", disociada del Estado (los "bienes de salvación" no son de su incumbencia).

Podemos plantear la hipótesis según la cual cuanto más poderosos son los vínculos orgánicos entre el Estado y la religión — y hacen que ella pueda imponer, gracias a él, ciertas normas incluyendo a los que no quieren seguirlas_-, más débil o incluso inexistente será la separación. A la inversa, cuanto más constituye la religión una de las instituciones libres de la sociedad civil, cuyas normas son únicamente objeto de una adhesión o rechazo voluntario, más consistente resultará la separación. En este caso, la religión puede disfrutar de su "libertad", de su desplazamiento del lado de la sociedad civil, para hallar nuevos papeles. Sin contribuir a la gobernanza política desde arriba, puede, sin embargo, influenciarla como una institución libre que

7 Zoller, Elisabeth, La conception américaine de la laïcité, París, Dalloz, 2005, p. 3-32; Berlinerblau, Jacques, How to be Secular, Boston, Houghton Mifflin Harcourt, 2012. 
tiene cierta fuerza de atracción para algunos ciudadanos. Aquellos pueden, en especial, tomar en cuenta criterios religiosos en su voto. La separación se vuelve más una separación entre el poder político (lo cual puede usar de la coacción legítima, como lo indica Max Weber) y las autoridades religiosas, que entre la política y lo religioso de manera global. Por otro lado, pueden producirse transferencias de sacralidad cuando las instituciones seculares toman el relevo, en mayor o menor grado, de la institución religiosa e imponen nuevas normas al laos (pueblo). Aquí también, la problemática de la laicidad se aleja de los estudios que se centran solamente en lo religioso.

Varias aportaciones abordan el tema de los derechos sexuales y reproductivos. He aquí una pista de que la noción de separación desborda de una concepción que la vincula exclusivamente con una ley que separa formalmente el Estado y las religiones, y que existen desafíos interpretativos fuertes sobre lo que implica la separación. A pesar de las "religiones establecidas" en Inglaterra o en Escocia, el Reino Unido ha laicizado el divorcio e instaurado la libertad de aborto (1867 y 1967) antes que Francia (1884 y 1975). España y Canadá, donde la separación es menos formal que en Francia, han legalizado antes que ella el matrimonio entre personas del mismo sexo (2005 por una parte, y 2013 por la otra). En Argentina, dicho matrimonio es legal desde 2010, pero el aborto sigue siendo prohibido. Por lo que es indispensable precisar la noción de separación y el ámbito en el cual se analiza. Aquí también, existen muchos conflictos interpretativos.

La "neutralidad" y sus diversas interpretaciones constituye el cuarto parámetro que permite desubstancializar el concepto de laicidad. Desde hace mucho tiempo, estos debates sobre lo que implica la neutralidad son intensos en diferentes países, especialmente respecto de la escuela. ¿La transmisión del saber ha de distinguir entre conocimiento y creencia? De Brasil a Turquía, hemos visto el desafío que representa una enseñanza de la religión. En Quebec, un acercamiento cultural de la religión se imparte en la escuela pública, en Francia, la cuestión de una "enseñanza laica de la religión” genera un fuerte debate.

Sabemos que la neutralidad de la escuela pública constituye una característica fuerte de la laicidad francesa. Durante mucho tiempo, la Iglesia católica ha acusado a esta escuela de no ser verdaderamente "neutra". Jean Jaurès le contestó: "si la neutralidad consiste en no tener ni doctrina, ni pensamiento, ni eficacia intelectual y moral”, entonces, "isólo la nada será neutral!” Precisaba, sin embargo, que la escuela laica debiera ser imparcial: "Sería un crimen para el maestro violentar la mente de los niños en el sentido de su propio pensamiento. Al proceder por afirmaciones sin 
contrapeso, haría uso de autoridad y faltaría a su función que es despertar y educar la libertad. Al esconder a los niños parte de los hechos y al presentarles solamente los que apoyan determinada tesis, no tendría ni la probidad ni el alcance de mente sin los cuales no hay buenos maestros". ${ }^{8}$ Ferdinand Buisson, adjunto de Jules Ferry, ya había mencionado, cinco años antes, la necesidad de poner al alumno "frente a afirmaciones diversas, opiniones contrarias, ante los pros y los contras, diciéndole compara y decide tú mismo".

Sin embargo, esta concepción de la neutralidad-imparcialidad no es compartida para todos. De la misma manera, respecto del Estado, Aristide Briand, el expositor de la ley francesa de 1905 sobre la separación de las Iglesias y del Estado, afirmaba que las Iglesias "tienen constituciones" y el "espíritu de neutralidad en el cual concebimos la reforma consiste en no hacer nada que fuese una violación a la libre constitución de estas Iglesias". ${ }^{9}$ ¡Estamos lejos de la reputación de la laicidad francesa! Sin embargo, esta reputación no es completamente falsa, ya que hoy, la representación dominante de la neutralidad, en Francia, dista de ser tan filosóficamente liberal. $\mathrm{Al}$ contrario, prima una concepción soberana (galicana) y extensiva que busca imponer una neutralidad religiosa a los ciudadanos (y no solamente a la potencia pública, como arbitrio imparcial) en algunos sectores del espacio público. ${ }^{10}$ Habremos entendido que en este conflicto interpretativo, están en juego concepciones divergentes de la relación entre el Estado, los ciudadanos y los grupos intermedios. Los desafíos de la cultura laica son efectivamente desafíos de cultura política. Tres comentarios permiten cerrar esta segunda parte:

- En primer lugar, los conflictos y las negociaciones, las relaciones de fuerza entre las diferentes interpretaciones de estos cuatro parámetros de la laicidad hacen que la laicidad presente siempre concretizaciones muy diversas. La laicidad como instrumento de análisis se declina en "laicidades" como realidades empíricas. Estas laicidades siempre están en movimiento y constituyen un reto sociopolítico entre los diferentes actores. Existe una producción social de la definición legítima de la palabra "laicidad", cuyo propósito es dar un sentido unívoco

8 Revue de l'Education Primaire et Primaire Supérieur, núm.1, 1908. Nota de la traductora, traducción libre.

9 Citado en Baubérot, Jean, Les sept läicités françaises, cit., p. 66.

10 Baubérot, Jean, "Laïcité and freedom of Conscience in Pluricultural France", en Berlinerbau, J. (ed.), Secularism on the Edge, Nueva York, Palgrave MacMillan, 2014. 
a este término, un sentido evidente. Así pasa en Francia, en donde pude encontrar siete representaciones divergentes de la laicidad. ${ }^{11}$

- Después, las interpretaciones diferentes de los cuatro parámetros no resultan equivalentes en la perspectiva de las relaciones entre laicidad y democracia. Hacer de la separación o de la neutralidad un fin en sí mismo y no un medio orientado a las finalidades de la libertad de conciencia y de la no discriminación, no es indiferente en el marco de dicha relación. La neutralidad axiológica no impide establecer que tal forma de laicidad sea más congruente con un nivel más elevado de democracia que otra. Ello, si no se pierde de vista que la noción de "democracia" constituye en sí un desafío entre representaciones divergentes, y si se analiza estas representaciones, especialmente, las diversas formas del Estado (federal, centralizado...), el sistema judicial (common law, derecho romano...) y las relaciones entre lo jurídico y lo político.

- Finalmente, la desconstrucción de la laicidad en cuatro parámetros permite rebasar la oposición entre su uso analítico y su empleo social. Algunos pretenden que el término de "laicidad" es intraducible en algunos idiomas como el inglés-americano o el alemán. Pero anglófonos y germanófonos, aun sin ser especialistas del tema, saben que existe, en su país y en otros lados, desafíos de libertad de conciencia, de no discriminación, de separación entre el poder estatal y las autoridades religiosas, de neutralidad arbitral.

\section{EL GRAN DESAFÍO GULTURAL DE LA LAICIDAD EN EL SIGLO XXI}

En 2005, hemos impulsado Roberto Blancarte, Micheline Milot y yo la publicación de una Declaración Universal de la Laicidad en el siglo XXI, la cual ha sido co-firmada por 250 universitarios de treinta países. No voy a retomar en esta ocasión el contenido de esta Declaración, pero quisiera terminar mi argumento articulando el análisis de un sociólogo-historiador y el cuestionamiento de un ciudadano laico. En particular, voy a privilegiar un desafío cultural que me parece esencial. Se trata de la relación entre la laicidad y lo que los historiadores llaman, en general, "la creencia en el progreso".

Evento estructurador del siglo XVIII, el terremoto de Lisboa, ocurrido el día emblemático de Todos los Santos (1775) provocó la muerte de miles de personas en un Portugal muy católico, y tuvo un papel relevante en la

11 Baubérot, Jean, Les sept laïcités françaises, cit. 
perdida de la teodicea como creencia social. Voltaire y muchos otros subrayaron el aspecto arbitrario de la selección entre víctimas y sobrevivientes. Un docto debate pretendió explicar el seísmo por causas naturales con el propósito de prevenir otras catástrofes gracias al desarrollo del saber. Condorcet, y luego Kant, participaron en esta empresa. Se pasó de la inquietud ante algo que parecía imprevisible, a la confianza, creciente en el siglo XIX, en la capacidad de los seres humanos en dominar la "naturaleza" por el conocimiento científico.

De ahí, un doble discurso en torno al "progreso": primero, la representación del progreso como la conjunción de diversos progresos: el progreso científico genera progreso técnico, lo cual se transforma, por medio del progreso de la acción pública y política, en progreso social, progreso de bienestar. Un progreso, asimismo, eminentemente "moral", que legitimaba algunos daños colaterales. Luego, la idea según la cual Europa, que se extiende en Occidente en el sentido geográfico de esta noción, constituía el motor del progreso. Los tratados desiguales, el colonialismo, el imperialismo van a encontrar aquí una justificación civilizacional. Xavier Martin insiste en el "nacimiento del hombre inferior en el corazón de la Ilustración". ${ }^{12}$ Ello parece pertinente, a condición de dialectizarlo con el recordatorio de su "cosmopolitismo", de su apertura sobre otras civilizaciones.

Los procesos de laicización del siglo XIX y de parte del siglo XX son vinculados con esta utopía del progreso. En Francia, fuente inagotable de discursos de autoridades republicanas, el Gran Diccionario Universal de Pierre Larousse (1864-1876) afirma: "esta idea que la humanidad se vuelve cada día mejor y más feliz es muy entrañable a nuestro siglo. La fe en la ley del progreso es la verdadera fe de nuestra edad. Es una creencia que encuentra pocos incrédulos". ${ }^{13}$

El declive progresivo de la creencia en el progreso constituye un cambio estructural en relación con la época histórica inaugurada por la Ilustración. Eso me parece, entre otros, un factor explicativo de la constatación que se hace a lo largo de las páginas de esta obra colectiva: la dinámica de la laicización fue más fuerte, en Latinoamérica, en el siglo XIX que en la segunda mitad del siglo XX. Además de la hipótesis de Gauchet (1985) de una reciente "salida de la religión", ${ }^{14}$ se suma la de una actual salida societal de la

12 Martin, Xavier, Naissance du sous-homme au cœur des Lumières. Les races, les femmes, le peuple. París, Editions Dominique Martin Morin, 2014.

13 Tomo 13, p. 926.

14 Gauchet, Marcel, Le désenchantement du monde, París, Gallimard, 1985. 
Ilustración. Este proceso no deriva del hecho de que la Ilustración hubiera originado los regímenes totalitarios, como lo pretende cierto discurso conservador. Se trata de una crisis del éxito. Además de que la parte obscura de la Ilustración es manifiesta (dinámica imperialista del Occidente como entidad geopolítica), el éxito mismo del proyecto generó nuevos problemas para las sociedades globalizadas. Sólo un ejemplo: la aparición de estados intermedios entre la vida y la muerte (sobrevivencia artificial, vida vegetativa...) generados por los progresos de la medicina moderna.

Los años 1930 constituyen, en Europa por lo menos, el inicio de un desencantamiento, suscitado por una reflexión a posteriori sobre un elemento estructurador - ya no un cataclismo "natural" como el terremoto de Lisboa-, sino una catástrofe, consecuencia del progreso científico-técnico humano: la gran masacre (y fenómenos novedosos como los gases asfixiantes) de la Gran Guerra (1914-1918). Más tarde, la reflexión sobre Auschwitz e Hiroshima los definen también como eventos estructuradores, que no solamente pusieron en juego la "barbarie totalitaria" sino también la política extranjera de un país democrático (e... imperialista). El titular del periódico francés Le Monde, del 8 de agosto de 1945 anunciaba Hiroshima como una ¡Revolución científica!

Sin embargo, más que una crítica frontal de la narrativa del progreso, estos eventos pusieron de relieve la oposición entre el "mal" progreso bélico y un "buen" progreso pacífico, siendo símbolo de ello el contraste subrayado entre la energía nuclear militar nefasta y la fasta energía nuclear civil. Sin embargo, dos elementos estructurales más hacen imposible hoy esta distinción. Con el primero, Chernóbil (1986), la demostración queda incompleta, pues esta catástrofe manifiesta también la quiebra del modelo soviético. El segundo es aún más significativo, y sus consecuencias se extenderán a largo plazo. Se trata de Fukushima (2011), ocurrido en un país que parecía ser un lugar seguro para las plantas termonucleares, donde las precauciones tecnológicas más avanzadas habían sido tomadas.

$\mathrm{Al}$ anunciar catástrofes ecológicas, Fukushima aporta leña al fuego de esta narrativa, la cual, de manera tan unilateral como la vieja fascinación en el progreso, se desarrolló en las últimas décadas. El cuestionamiento de la ciencia sobre sus propias aplicaciones técnicas constituye un vuelco respecto de la Ilustración y sus deslumbramientos ante los efectos técnicos de las ciencias incipientes. Progreso en cuanto a la reflexividad, este vuelco genera incertidumbre colmado prontamente por un discurso social repleto de certidumbres negativas que voltean el progreso en su contra, al anunciar una apocalipsis secularizada y técnica, un tiempo de catástrofes (no solamente 
nucleares, sino también sanitarias, climáticas, etcétera), en breve, un nuevo fin del mundo producido por el ser humano.

El apocalipsis religioso confiaba en otro mundo, era promesa de consuelo. La modernidad nos lo dijo: sólo existe un mundo, pero el de mañana será mejor que el de hoy.

[El] tema moderno del progreso comparte con el tema religioso del fin del mundo la creencia según la cual el tiempo... es la dimensión que acerca a los hombres de un término deseable: ya sea por la voluntad divina, ya sea por la alianza entre la temporalidad y la libertad humana... El nuevo retrato de la catástrofe transforma profundamente la experiencia del tiempo... Ya no debemos consolarnos de la permanencia en el mundo (con sus injusticias), sino del riesgo de su desaparición definitiva y sin futuro. ${ }^{15}$

Los que piensan que sólo existe un mundo están en la situación donde se desarrolla la creencia fuerte de que no hay mucho más que "salvar" en el futuro. Asimismo, lo político tiene mucha dificultad en pedir esfuerzos para construir el futuro. La progresión de los discursos milenaristas, como los discursos salafistas en el islam y pentecostales en el protestantismo, se explica en buena parte por dicho contexto sociocultural. Estos discursos reconstruyen de manera mítica e idílica el pasado fundador de su religión. Pero este universo apocalíptico no se limita a lo religioso: muchos jóvenes están familiarizados con él mediante los videojuegos y las películas del cine contemporáneo. El "humo que mata": podemos verlo en la propaganda de Daech, como en la serie televisada Lost.

Debemos cuidar de no desarrollar, por nuestra parte, un discurso nostálgico, una invocación del conjuro de la Ilustración que nos cegaría a su complejidad, o al contrario, una suerte de negación del acervo de la historia de Occidente. No es en vano que utilicé la expresión de "crisis del éxito". Me encuentro por mi parte, y no sorprenderá a las y los que nos conocen, en una perspectiva muy análoga a la que desarrolló Roberto Blancarte y que consiste en pensar a la vez en la "crítica (la autocrítica) y el elogio" de Occidente, dando a esta noción un sentido axiológico e institucional, despojado de cualquier carácter geográfico, ya que diferentes civilizaciones incorporaron y se apropiaron algunos valores e instituciones históricamente nacidas en occidente y los adaptaron a su propia cultura.

En este punto - me parece - podemos definir nuevos proyectos para la laicidad. Evocaré rápidamente algunos.

15 Foessel, Michaël, “Apocalypse et Consolation”, Esprit, París, núm. 6, 2014, pp. 64-74. 
- La tecnociencia, a la luz de lo que acabo de indicar, ya no puede constituir el fundamento de una adhesión a la laicidad, sino devenir en un elemento de cuestionamiento: ¿acaso no existen nuevos clérigos que intentan imponer su visión propia como si sólo existiera una sola posibilidad de concretización del conocimiento científico? Por mucho tiempo, el combate laico trató esencialmente del acceso al saber. A escala mundial, este combate es vigente más que nunca. Sin embargo, se desdobla, pues no podemos más, hoy en día, evitar la pregunta: ¿qué hacemos de lo que sabemos?, ¿en qué deviene el conocimiento científico en el espacio social?

- De manera conjunta al desarrollo del conocimiento, la constitución, la afirmación de los Estados-nación ha sido un factor esencial del proceso de laicización. En el siglo XX, Latinoamérica ha sido claro ejemplo de ello. Un dispositivo jurídico laico en mayor o menor medida se vinculó con este marco estatal nacional. Desde la segunda parte del siglo XX, un orden jurídico supranacional intenta, sin embargo, constituirse. ¿Cómo repensar la laicidad en esta situación? ¿Cómo lograr una laicidad más o menos desterritorializada?

- El poder de los medios de comunicación masiva a nivel mundial constituye un elemento importante de la globalización. Ello induce una extensión del espacio y un aplanamiento del tiempo. Como lo indica el historiador François Hartog, el vuelco de la representación del progreso genera un "vuelco del régimen moderno de historicidad". ${ }^{16}$ Ya no se vive en el tiempo y el ritmo de su cultura, sino en un universo mundializado que privilegia la instantaneidad sobre la temporalidad. Los acontecimientos relativos a las caricaturas son vinculados con esta nueva situación y la matanza de CharlieHebdo muestra que cada país forma ahora un espacio globalizado. Aquí también se ve afectada en primer plano la laicidad.

- Los vínculos que históricamente existieron entre los procesos distintos de la secularización y de laicización se ven también afectados. La laicidad es, cada vez más, la regulación político-social de individuos y de grupos, los cuales tienen religiones y convicciones distintas, pero también relaciones diferentes con la secularización. Menos que una pérdida de la religión, se ha producido una individualización acentuada de lo religioso. Se puede hablar de pluralismo extensivo. ¿Cuáles límites no discriminatorios podemos poner a la

16 Hartog, François, Régimes d'historicité. Présentisme et expériences du temps, París, Seuil, 2003. 
libertad de conciencia, al pluralismo cultural? Propongo distinguir lo irreversible (mutilación genital femenina, matrimonios forzados, etcétera) y lo reversible (uso de vestimenta, etcétera). Lo primero induce a una laicidad firme, para no aceptar destinos sociales, el segundo puede ir de la mano con una laicidad liberal.

Para terminar, dos comentarios. Primero, no debemos olvidar las luchas sociales. Jean Jaurès insistió sobre el vínculo entre laicidad y justicia socioeconómica. Debemos lograr articular lo sociocultural y lo socioeconómico. La crisis de la laicidad kemalista turca vino en parte por el desarrollo de las redes de solidaridad alrededor de las mezquitas, mientras que la burguesía, que vivía en los barrios acomodados del Bósforo, no vinculó la laicidad con los problemas sociales. Entre diferentes factores de expansión del pentecostalismo, en Latinoamérica y en otras partes, está la esperanza de ascenso social vinculada con la conversión, con la función de pastor y con la creación de subsociedades, incluso de contrasociedades, es decir, lo que la filósofa Cécile Laborde llama "clases de vulnerabilidad".

Mis palabras finales quieren ser optimistas. Se ha abordado en varias contribuciones la cuestión de los derechos de las mujeres y de las minorías sexuales, al insistir, con razón, en las vulneraciones que conocen. Pero una comunicación ha mostrado que en Francia, por ejemplo, la laicidad se preocupó muy recientemente de la igualdad de género (ciertamente, Uruguay ha sido más favorable a las mujeres); incluso, la manera de cómo aborda esta igualdad sigue impregnada, de manera dominante, por el tema de la "mujer sumisa" (al clericalismo) que ha marcado su historia. Por otra parte, hasta finales del siglo XX, la idea de que el matrimonio pudiese vincular a dos personas del mismo sexo no era ni siquiera pensable. A pesar de las vulneraciones a los derechos, el hecho de que estas cuestiones sean públicamente planteadas, probablemente de manera irreversible, constituye la pista de un progreso. En nuestro tiempo de crisis de representación del progreso, no es inútil recordarlo.

\section{BibliografíA}

Baubérot, Jean, Historia de la laicidad francesa, Estado de México, El Colegio Mexiquense, 2005.

, "Laïcité and Freedom of Conscience in Pluricultural France", en Berlinerbau, J. (ed.), Secularism on the Edge, Nueva York, Palgrave MacMillan, 2014. 
Esta obra forma parte del acervo de la Biblioteca Jurídica Virtual del Instituto de Investigaciones Jurídicas de la UNAM

— Les sept laïcités françaises, París, Éditions Maison des Sciences de l'Homme, 2015. - y Milot, Micheline, Laïcités sans frontières, París, Seuil, 2011.

Berger, Peter, La religion dans la conscience moderne, París, Le Centurion, 1971. , The Sacred Canopy. Elements of a Sociological Theory of Religion, Nueva York, Doublebay, 1967.

Berlinerblau, Jacques, How to be Secular, Boston, Houghton Mifflin Harcourt, 2012.

CAdy, Liell E. y SHAKMAn-Hurd, Elizabeth (eds.), Comparative Secularisms in a Global Age, Nueva York, Palgrave-Macmillan, 2010.

Casanova, José, Public Religions in the Modern World, Chicago, University of Chicago Press, 1994.

Foessel, Michaël, “Apocalypse et consolation”, Esprit, París, núm. 6, 2014.

Gauchet, Marcel, Le désenchantement du monde, París, Gallimard, 1985.

GILL, Antony, The Political Origins of Religious Liberty, Cambridge, Cambridge University Press, 2008.

Hartog, François, Régimes d'historicité. Présentisme et expériences du temps, París, Seuil, 2003.

MARTIN, David, "Towards eliminating the concept of secularization", en GOULD, J. (ed.), Penguin Survey of the Social Sciences, Baltimore, Penguin, 1965.

—, A General Theory of Secularization, Oxford, Basil Blackwell, 1978.

MARTIN, Xavier, Naissance du sous-homme au cœur des Lumières. Les races, les fermmes, le peuple, París, Éditions Dominique Martin Morin, 2014.

Milot, Micheline, Laïcité dans le nouveau monde. Le cas du Québec, Turnhout, Brepols, 2002.

Wilson, Bryan, Religion in a Secular Society, Londres, Watts \& Co., 1966.

ZOLLER, Elisabeth, La conception américaine de la laïcité, París, Dalloz, 2005. 
Nuevos retos y perspectivas de la laicidad, editado por el Instituto de Investigaciones Jurídicas de la UNAM, se terminó de imprimir el 5 de diciembre de 2017 en los talleres Cromo Editores, S. A. de C. V., Miravalle 703, colonia Portales, delegación Benito Juárez, 03570 Ciudad de México, tel. 5674 2137. Se utilizó tipo Baskerville en 9, 10 y 11 puntos. En esta edición se empleó papel book cream de 60 gramos para los interiores y cartulina couché de 250 gramos para los forros. Consta de 300 ejemplares (impresión offset). 
ace algunas décadas el estudio de las relaciones entre lo político y lo religioso, lo público y lo privado, podría haber parecido obsoleto frente a la convicción generalizada que apunta hacia una aparente pérdida de la religiosidad en las sociedades contemporáneas. Sin embargo, la reflexión aquí plasmada resulta fructífera dado el acercamiento interdisciplinario a la complejidad derivada de la convivencia en el Estado laico. Las temáticas abordadas van desde la libertad de las personas y la igualdad de las minorías religiosas, hasta la gestión de la pluralidad y el papel de la neutralidad en la construcción de ambientes para la conformación de identidades.

Agrupados en tres secciones: "Reflexiones en torno a la secularización y pluralismo", “Laicidad y libertades laicas", y “Laicidad y políticas públicas", los trabajos que integran la presente obra hacen hincapié en la necesidad de revisar de manera crítica el paradigma de la secularización y la modernidad. El lector encontrará aquí un esfuerzo de interpretación que hace patente las inercias en torno a la laicidad y las relaciones emergentes entre las personas, el Estado y las instituciones religiosas. 